\title{
Synthesis of N-Glycans Implicated in Asthma and Allergy
}

By

Gregory William Haslett

2010

$\underset{\text { UNverstry of welluscron }}{\text { Victoria }}$

Te Whare Wānanga

o te Ūpoko o te Ika a Māui

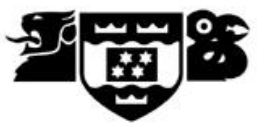

A thesis submitted to Victoria University of Wellington

In fulfilment of the requirements for the degree of

Master of Science in Chemistry 


\begin{abstract}
Asthma and allergies affect a large number of people, with over 300 million people worldwide suffering from asthma alone. Although, on the 'macroscopic' level, it is known how allergens trigger allergic reactions, it is not known how an allergen's 'micro' structure causes such a profound allergic response in sensitised individuals. A review of inter-species carbohydrate motifs revealed a striking similarity between carbohydrate moieties (N-glycans) present on antigens derived from species known to give an allergic T helper (Th) 2 response in humans (such as pollen, schistosomes, and food allergens). Preliminary studies on mixtures of allergen extracts have suggested that these carbohydrate motifs (glycoproteins) bias the immune response to an allergic (Th2) response.
\end{abstract}

This project presents work conducted towards the synthesis of three fragments of a larger $\mathrm{N}$-glycan found on allergens. The synthesis of these $\mathrm{N}$-glycans will allow the first detailed study regarding the relationship between $\mathrm{N}$-glycan structure and $\mathrm{Th} 2$ bias to be performed and thereby aid in our understanding of the molecular triggers of asthma. Ultimately, this could lead to the elucidation of the mechanisms of the allergic Th2 immune response. 


\section{ACKNOWLEDGEMENTS}

Firstly I would like to thank both of my supervisors Bridget and Mattie for the help and guidance they have given me, not only during my MSc but also throughout my BSc (Hons) and time as a research assistant. You have definitely helped to instil a work ethic in me that will serve me well for the future.

I would also like to thank the rest of the Immunoglycomics research group for their help and advice and also for making the lab a more exciting and enjoyable place. In particular I would like to thank Gert-Jan for helping to re-introduce dance music back into the lab as well as for keeping his half of the fume hood tidy, Emma and Anna for all their tips with working with water soluble compounds, Ashna, Janice and Stephanie for always being cheerful and making sure that I was on track to finish on time, and last but not least Hilary for her help with freeze drying samples.

I would like to thank my Mum, Dad and Step mum for their support and continual encouragement throughout the year. I would also like to thank my flat mates and good friends Seth, Chelsea, Kate, and Mark whose understanding and perspective helped me get through this year.

Lastly, I would like to thank the Tertiary Education Commission (Bright Futures Top Achiever Doctoral Scholarship) for the funding they have given me in order to complete my Masters year. 


\title{
GLOSSARY
}

\author{
$\underline{\text { Abbreviations used }}$ \\ Ac Acetyl \\ APC Antigen presenting cell \\ AR Analytical reagent \\ Arom. Aromatic \\ ATR Attenuated total reflection \\ Bn Benzyl \\ $\mathrm{Bu} \quad$ Butyl \\ COSY Correlation spectroscopy \\ CSA Camphorsulfonic acid \\ DALYs Disability adjusted life years \\ DBU 1,8-Diazabicyclo[5.4.0]undec-7-ene \\ DC Dendritic cell \\ DCM Dichloromethane \\ dfBz 2,6-Difluorobenzoyl \\ DME 1,2-Dimethoxyethane \\ DMF Dimethylformamide \\ ELISA Enzyme-linked immunosorbent assays \\ ESI Electrospray ionisation \\ Fuc Fucose \\ GATA GATA-binding protein \\ GFP Green fluorescent protein \\ Glc Glucose \\ GlcNAc $\quad N$-Acetyl glucosamine \\ HBTU $O$-(Benzotriazol-1-yl)- $N, N, N^{\prime}, N^{\prime}$-tetramethyluronium hexafluorophosphate \\ HMBC Heteronuclear multiple bond coherence \\ HMDS Hexamethyldisilazide \\ HOBt Hydroxylbenzotriazole \\ HRMS High resolution mass spectrometry \\ HSQC Heteronuclear single quantum coherence \\ $\mathrm{Hz} \quad \mathrm{Hertz}$ \\ IFN Interferon \\ IgE Immunoglobulin E \\ IL Interleukin \\ IR Infrared \\ KLH Keyhole limpet hemocyanin \\ LPS Lipopolysaccharide \\ Man Mannose \\ MeOTf Methyl trifluoromethanesulfonate \\ MHC Major histocompatibility complex \\ Mp Melting point \\ MP $\quad p$-Methoxyphenyl
}




$\begin{array}{ll}\text { MS } & \text { Molecular sieves } \\ \text { NIS } & \text {--Iodosuccinimide } \\ \text { NKT } & \text { Natural killer T } \\ \text { OVA } & \text { Ovalbumin } \\ \text { PA } & \text { Pro analysis } \\ \text { PCR } & \text { Polymerase chain reaction } \\ \text { Ph } & \text { Phenyl } \\ \text { Phth } & \text { Phthaloyl } \\ R_{f} & \text { Retardation factor } \\ \text { RT } & \text { Room temperature } \\ \text { SPPS } & \text { Solid-phase peptide synthesis } \\ \text { STAT } & \text { Signal transducer and activator of transcription } \\ \text { TBAI } & \text { Tetrabutylammonium iodide } \\ \text { TBDMS } & \text { tert-Butyldimethylsilyl } \\ \text { TBDMSCl } & \text { tert-Butyldimethylsilyl chloride } \\ \text { TCR } & \text { T cell receptor } \\ \text { TDS } & \text { Thexyldimethylsilyl } \\ \text { TES-H } & \text { Triethylsilane } \\ \text { TfN } & \text { Trifluoromethanesulfonic azide } \\ \text { TFA } & \text { Trifluoroacetic acid } \\ \text { TFAA } & \text { Trifluoroacetic anhydride } \\ \text { TfO } & \text { Trifluoromethanesulfonic anhydride } \\ \text { TfOH } & \text { Trifluoromethanesulfonic acid } \\ \text { Th } & \text { T helper } \\ \text { THF } & \text { Tetrahydrofuran } \\ \text { TLC } & \text { Thin-layer chromatography } \\ \text { TLR } & \text { Toll-like receptor } \\ \text { TMS } & \text { Trimethylsilyl } \\ \text { TMSOTf } & \text { Trimethylsilyl trifluoromethanesulfonate } \\ \text { Tol } & \text { Toluene } \\ \text { Troc } & 2,2,2-\text { Trichloroethoxycarbonyl } \\ \text { TSLP } & \text { Thymic stromal lymphopoietin } \\ p \text {-TsOH } & \text { para-Toluenesulfonic acid } \\ \text { WHO } & \text { World Health Organisation } \\ & \end{array}$




\section{$\underline{\text { Terms used }}$}

Allergen An antigen that causes a Th2 immune response resulting in IgE production.

Antigen A molecule recognized by the immune system.

B cell A type of lymphocyte - their principal function is to make antibodies against antigens.

Basophil A type of granulocyte - recruited to the site of allergic inflammation.

C-type lectin A calcium dependant carbohydrate binding receptor.

Chemokine A type of cytokine that guides the migration of cells.

Cytokine Proteins responsible for cellular signalling.

DALYs Disability adjusted life years: The sum of years of potential life lost due to premature mortality and the years of productive life lost due to disability.

Dendritic cell An immune cell that takes up and processes antigens for presentation to other cells.

Epithelial cell Cells that line the cavities and surfaces of structures throughout the body.

Eosinophil A type of granulocyte - responsible for killing antibody-coated parasites.

Eosinophilia The state of high levels of eosinophils in the target location.

GATA3 A human protein - it is a transcriptional activator which binds to the enhancer of the T-cell receptor genes.

Glycoproteins A protein with oligosaccharides covalently bound to the peptide side chains.

Granulocyte A class of white blood cell characterised by the presence of granules in their cytoplasm.

Lymphocyte A class of white blood cell in the vertebrate immune system.

Mast cell A type of granulocyte - releases granules containing histamine, heparin and other active agents.

Macrophage A type of white blood cell - their main role is to phagocytose (engulf and digest) cellular debris and pathogens. 
STAT5 and 6 Human genes - The STAT family members are phosphorylated by the receptor associated kinases in response to cytokines and growth factors. 


\section{CONTENTS}

$\begin{array}{ll}\text { ABSTRACT } & \text { ii }\end{array}$

ACKNOWLEDGEMENTS

GLOSSARY iv

CONTENTS viii

INTRODUCTION 1

1.1 Asthma Overview 1

1.2 Types of Asthma 2

1.3 Generation of the Allergic T Helper 2 Immune Response 5

1.3.1 Initiation of the Th2 Immune Response $\quad 5$

1.3.2 Perpetuation of the Th2 Immune Response in Allergic Asthma 8

1.3.3 Current Treatments for Asthma 10

$1.4 \mathrm{~N}$-Glycans as Allergens 11

$\begin{array}{ll}1.5 \text { Project Aims } & 13\end{array}$

1.6 N-Glycan Synthesis $\quad 14$

1.6.1 Overview of Syntheses of Similar N-Glycans 14

1.6.2 Synthetic Targets for this Masters Project 20

1.7 Biological Testing $\quad 25$

RESULTS AND DISCUSSION 27

2.1 Synthesis of the Mannose Trisaccharide $\quad 27$

2.1.1 Synthesis of the Mannose Imidate Donor Building Block 27

2.1.2 Synthesis of the Mannose Acceptor $\quad 29$

2.1.3 Synthesis of the Mannose Trisaccharide $\quad 30$

2.1.4 Deprotection of the Mannose Trisaccharide 36

2.2 Synthesis of the FucGlcNAc Disaccharide 38

2.2.1 Synthesis of the Thiofucose Building Block 38

2.2.2 Synthesis of the FucGlcNAc Disaccharide 39

2.2.3 Synthesis of the FucGlcNAc Acceptor 46

2.3 Synthesis of the GlcNAc(Fuc)GlcNAc Trisaccharide 47

2.3.1 Synthesis of the Glucose Azide Donor 47

2.3.2 Synthesis of the Glc $\left(\mathrm{N}_{3}\right)(\mathrm{Fuc}) \operatorname{Glc}\left(\mathrm{N}_{3}\right)$ Trisaccharide $\quad 48$

2.3.3 Glc $\left(\mathrm{N}_{3}\right) \operatorname{Glc}\left(\mathrm{N}_{3}\right)$ Disaccharide Model Glycosidation 49

2.3.4 Synthesis of the Troc Protected Donor 55

2.3.5 Glc(NHTroc)Glc $\left(\mathrm{N}_{3}\right)$ Disaccharide Model Glycosidation 56

2.3.6 Glc(NHTroc)(Fuc)Glc $\left(\mathrm{N}_{3}\right)$ Trisaccharide Glycosidation 56

2.4 Feasibility of $N$-Troc Protected Acceptor $\quad 58$

2.4.1 Synthesis of the Glc(NHTroc) Acceptor 58

2.4.2 Formation of the FucGlc(NHTroc) Disaccharide Acceptor 59

2.4.3 Synthesis of the Disaccharide $N$-Troc Donor 59

2.4.4 Comparison of the $N$-Troc and Azide Disaccharide Acceptors 61 
2.5 Deprotection of the FucGlc $\left(\mathrm{N}_{3}\right)$ Disaccharide $\quad 64$

2.5.1 Initial Deprotection Strategy 64

2.5.2 Revised Deprotection Strategy 66

2.6 Deprotection of the Glc(Troc)(Fuc)Glc $\left(\mathrm{N}_{3}\right)$ Trisaccharide $\quad 71$

2.6.1 Achieved Deprotection Reactions $\quad 71$

2.6.2 Future Work - Proposed Deprotection Strategy 71

2.7 Anomeric Amine Formation 72

2.7.1 N-Acetylglucosamine $\quad 72$

2.7.2 FucGlcNAc and $\mathrm{Man}_{3}$ Anomeric Amine Formation 76

$\begin{array}{ll}2.8 \text { Future Work } & 77\end{array}$

2.8.1 Proposed Strategy for the Coupling to Latex Beads and/or Proteins 77

$\begin{array}{ll}\text { CONCLUSION } & 79\end{array}$

$\begin{array}{ll}\text { EXPERIMENTAL } & 81\end{array}$

$\begin{array}{ll}\text { REFERENCES } & 111\end{array}$

$\begin{array}{ll}\text { APPENDIX } & 122\end{array}$ 


\section{INTRODUCTION}

\subsection{Asthma Overview}

Asthma and allergies are important worldwide health issues and have been for some time.

The Austrian scientist and paediatrician Clemens von Pirquet first defined the term "allergy" in 1906 to describe the "hypersensitive reactions" that were triggered and observed in particular individuals when exposed to certain substances. ${ }^{1}$ The term allergy is now more specifically defined as "disease following a response by the immune system to an otherwise innocuous antigen". ${ }^{2}$ Today, more than $25 \%$ of the Western population is affected by allergies and The World Health Organisation (WHO) estimates that there are 300 million asthma sufferers worldwide. ${ }^{3-5}$ Asthma is also the most common chronic disease among children.

Asthma is a chronic respiratory disease which results in a local immune response within the lung that is characterised by airway inflammation and airway hyperresponsiveness (increased narrowing of the airways), with the individual affected suffering from recurrent attacks of wheezing, coughing, breathlessness and tightness in the chest. ${ }^{6}$ Though the symptoms and severity differ between individuals, asthma prevents many sufferers from being able to live a normal life. In 2001, the disability adjusted life years (DALYs) lost worldwide due to asthma was estimated at 15 million years each year. ${ }^{7}$ The DALY ranking for asthma is similar to that for diabetes, cirrhosis of the liver, and schizophrenia.

Asthma is most prevalent in Western countries such as the United Kingdom, the United States of America, Australia, and New Zealand (Figure 1), however, $80 \%$ of deaths $(255,000 \text { deaths worldwide in } 2005)^{4}$ occur in low to low-middle income countries. ${ }^{4}$ Asthma is of particular significance to New Zealand, as New Zealand has the second highest rate of asthma worldwide with over 600,000 people suffering from asthmatic symptoms (approximately $16 \%$ of adults and $25 \%$ of children). ${ }^{8}$ In addition, hospitalisation rates for asthma have more than doubled in the last 30 years and asthma is 
now the most common cause of admission to hospital for New Zealand children. ${ }^{8}$ The annual cost to New Zealand due to asthma is estimated to be greater than $\$ 825$ million, with medical costs accounting for $\$ 125$ million, while the other $\$ 700$ million is associated with days absent from work, loss of healthy life due to disability, and premature death. ${ }^{8}$ In the United States medical costs associated with asthma are estimated to be $\$ 8.1$ billion annually. ${ }^{9}$
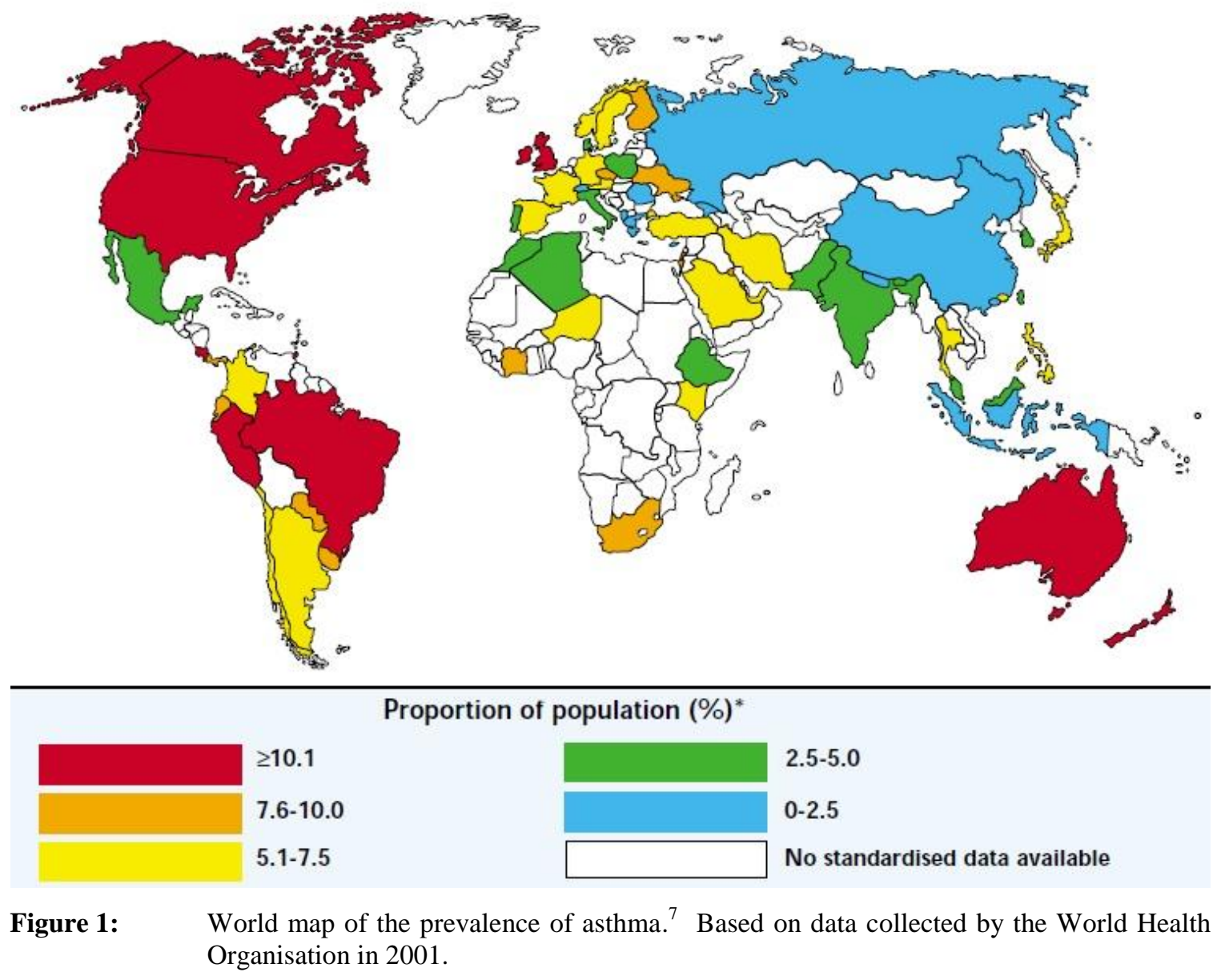

\subsection{Types of Asthma}

Asthma is an extremely complex disease with several different forms or phenotypes involving multiple cell types and several molecular and cellular pathways. ${ }^{6}$ These phenotypes include allergic asthma, severe steroid-resistant asthma, and asthma that is 
induced by exposure to air pollution, cigarette smoke, diesel exhaust particles, obesity, aspirin, exercise, and even cold temperatures. ${ }^{6}$ An individual's asthmatic response need not be limited to one particular phenotype and is often the result of several different triggers and asthmatic pathways acting in synergy. That said, 70-80\% of asthma, including the reported incidences in New Zealand, is related to allergic asthma which is typically caused by allergens that are inhaled. ${ }^{8,10}$ The source of allergens is broad and can include dust mites, pollen and plant material, food, and animal material (e.g. hair, saliva, urine, and dander-dead skin flakes). ${ }^{4,8}$ Although asthmatic allergens are defined on a macroscopic level, little is known about what it is that is responsible for inducing their sensitivity on a microscopic or "molecular" level. Most of the asthma research and treatment focus over the past 25 years has concerned allergic asthma.

Allergic asthma gives rise to an immune response called the $\mathrm{T}$ helper (Th) 2 immune response, which is associated with the adaptive immune system. This is in contrast to the non-allergen induced immune response (i.e. asthma caused by air pollution, obesity, aspirin, exercise etc). Non-allergen induced asthma does not require a Th2 immune response to induce airway inflammation and airway hyper-reactivity, and is instead induced by various alternative cellular pathways including natural killer T (NKT) cells and Th17 cells. ${ }^{6}$ The remainder of this introduction will focus on and explain what is understood about allergic (or Th2 “driven”) asthma.

Parasitic helminths (worms) are known to cause a Th2 immune response in humans, ${ }^{11-13}$ and accordingly, are often used for in vivo mouse assays to study and model the Th2 immune response. ${ }^{14-16}$ One such "Th2-model" uses the infective third stage (L3) larvae of the nematode (roundworm) Nippostrongylus brasiliensis, which are non-pathogenic to humans. ${ }^{14,15}$ The similarities between helminth-induced and allergic asthmatic Th2 immune responses has led to the hypothesis that for individuals who are genetically predisposed to developing asthma, the immune system is tricked into sensitization by exposure to otherwise innocuous environmental allergens, which in turn results in an asthma attack. In contrast, in the case of parasitic infection, a Th2 immune response is desirable as it results in clearance of the parasite. 
The prevalence of asthma and allergy has significantly increased in western countries since 1960. ${ }^{6,17,18}$ This rate of increase is too fast to be attributed to genetic changes alone, although it is agreed that the propensity to develop asthma and allergies is related to genetics. Similarly, this increase is unlikely to be due to better diagnosis as the symptoms of asthma and allergy are easily identified and have been recognised since the early 1900 's. ${ }^{17}$ Although the exact causes still remain unclear, broadly speaking, it has been suggested that the increase in the prevalence of asthma and allergy is due to the increased hygiene standards, increased use of antibiotics, and environmental changes associated with a "western lifestyle". ${ }^{17,19}$ This belief is known as the "hygiene hypothesis".

According to the hygiene hypothesis, a lack of exposure to infectious agents, endotoxins, parasites, and other pathogenic and non-pathogenic microorganisms during early childhood leads to an increased susceptibility to allergies and asthma. ${ }^{2,20}$ There are two thoughts as to why this is. Initially it was believed that the underdevelopment of the Th1 immune response, which is associated with bacterial and viral infections, promotes an immune system with an overactive Th2 immune response bias. ${ }^{2}$ However, this does not explain the inverse correlation seen between parasitic helminth infection and the development of allergy, as helminth infection results in a Th2 immune response and would therefore not aid in the development of the Th1 response. In view of this, the latest hypothesis is that exposure to infection early in life aids in the development of regulatory $\mathrm{T}$ cells, which in turn downregulate both Th1 and Th2 immune responses via the production of cytokine interleukin 10 (IL10). ${ }^{2}$ This latest proposition also helps to explain the increase of Th1-derived autoimmune diseases in Western countries. ${ }^{2}$ Parasites have developed mechanisms to induce IL10 production which enables them to remain in the host by downregulating the Th2 immune response ${ }^{20,21}$ and this may explain why individuals with parasite infections are less susceptible to developing allergies and asthma. In allergic and asthmatic immune responses such downregulatory mechanisms are not triggered or are overwhelmed by inflammatory factors thus leading to airway inflammation that is characteristic of an asthma attack. ${ }^{20}$ 


\subsection{Generation of the Allergic T Helper 2 Immune Response}

Humans are exposed to allergens on a regular basis. Such environmental allergens are inhaled and come into contact with the mucosal surfaces and epithelial cells in the lungs. The mucosal layer and intercellular tight junctions between epithelial cells present in the respiratory tract provide a defence by limiting the access of allergens to the immune system. ${ }^{10}$ However, these barriers are not entirely impenetrable. In non-asthmatics, inhaled allergens that come in contact with the immune system induce tolerance and do not result in an inflammatory immune response. For people who suffer from allergic asthma, however, allergens interact with the immune system resulting in the Th2 immune response. The Th2 immune response leads to the secretion of a variety of cytokines, chemokines, and the recruitment of multiple cell types, which results in the airway remodelling (structural changes of the airway wall) and airway hyperresponsiveness (narrowing of the airways due to inflammation) associated with an asthma attack. ${ }^{10}$ Asthma is a chronic disease resulting in "chronic inflammation" and it is this repetitive exposure to allergens that results in the continual presence of higher than normal levels of innate and adaptive immune cells. ${ }^{20}$ This alteration in cell number and type results in structural changes to the airways (airway remodelling) ${ }^{20}$ and also mean that the epithelial barrier is no longer as effective at preventing allergens from reaching the immune system, which in turn increases the individual's chance of an asthma attack. ${ }^{10}$

\subsubsection{Initiation of the Th2 Immune Response}

On a cellular level, the Th2 immune response is associated with the differentiation of naive $\mathrm{CD}^{+} \mathrm{T}$ cells (a type of lymphocyte) into Th2 cells via the action of several simultaneous cellular and signalling processes (Figure 2). Briefly, a $\mathrm{T}$ helper cell is a subgroup of lymphocytes that plays an important role in establishing and maximising the capabilities of the immune system. ${ }^{2}$ Mature T cells express the surface protein CD4 and are referred to as (naive) $\mathrm{CD}^{+} \mathrm{T}$ cells. In the generation of the Th2 immune response, it is generally understood that dendritic cells (DCs) take up antigens that have passed through the epithelial barrier then migrate to the lymph node where they act as antigen presenting cells (APCs) by presenting the antigen to naive $\mathrm{CD}^{+} \mathrm{T}$ cells. ${ }^{2,22}$ The antigen 
is presented by the major histocompatibility complex (MHC) class II receptor of the DC and recognised by the $\mathrm{T}$ cell receptor (TCR) of the $\mathrm{CD} 4^{+} \mathrm{T}$ cell. For $\mathrm{Th} 2$ differentiation antigen presentation must occur in the presence of the cytokine IL4 and other costimulatory factors. ${ }^{2,23}$ Although IL4 is required for Th2 differentiation, ${ }^{23}$ the cellular and signalling pathways responsible for the production of this initial IL4 are, surprisingly, still not well understood. ${ }^{24}$

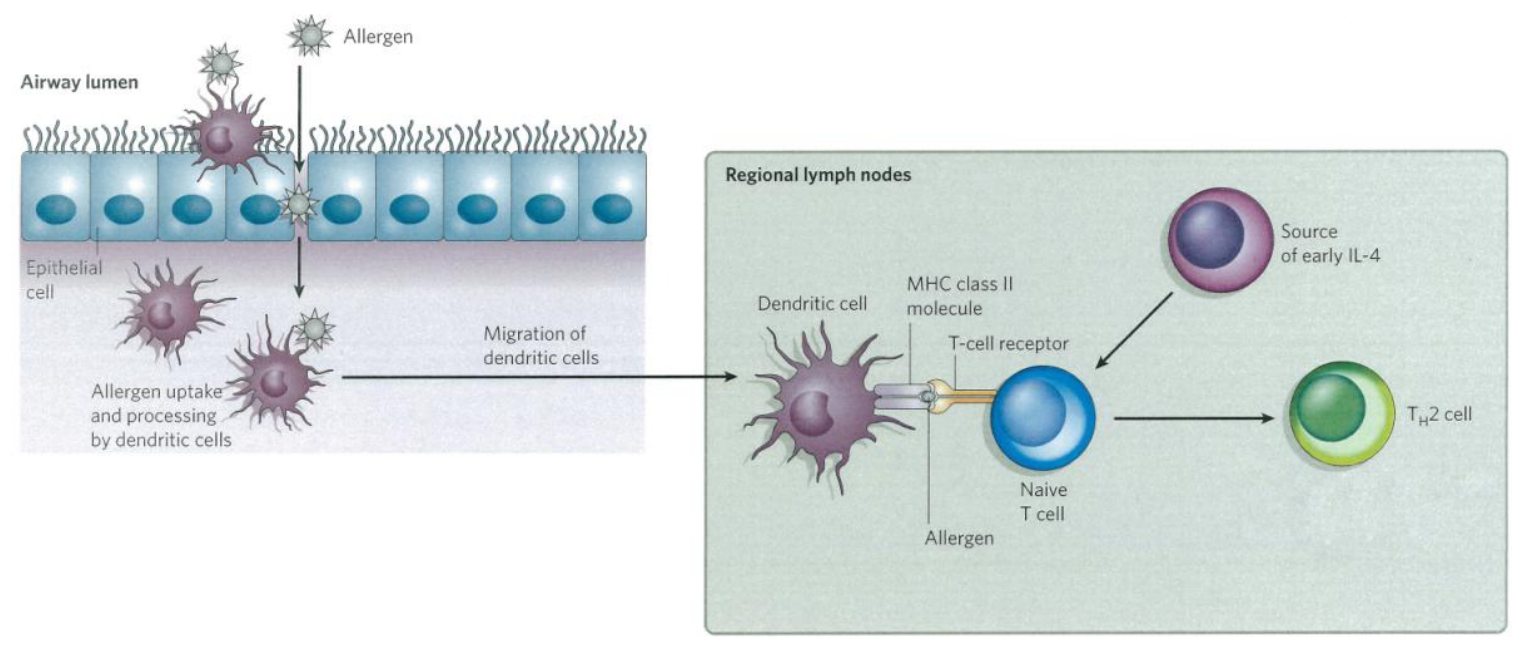

Figure 2: $\quad$ Allergens that pass though the epithelial cells are taken up and processed by DCs. The DCs then migrate to the lymph node where they present the allergen to naive $\mathrm{CD} 4^{+} \mathrm{T}$ cells. If this presentation occurs in the presence of IL4 and other co-stimulatory factors the naive $\mathrm{CD}^{+}{ }^{+} \mathrm{T}$ cells differentiate to $\mathrm{Th} 2$ cells resulting in the allergic $\mathrm{Th} 2$ immune response. Adapted from Galli et al..$^{20}$

When considering the Th2 immune response in more detail, it is known that for Th2 differentiation to occur in naive $\mathrm{CD}^{+} \mathrm{T}$ cells, allergen presentation must occur simultaneously with the expression of GATA-binding protein 3 (GATA3) and the activation of signal transducer and activator of transcription 5 (STAT5), both of which bind to important parts of the Th2 cytokine locus within the $\mathrm{CD} 4^{+} \mathrm{T}$ cell (Figure 3). ${ }^{20,25}$ GATA3 is expressed upon the activation of STAT6, which is induced via IL4 binding to the IL4 receptor (IL4R) on naive $\mathrm{CD} 4{ }^{+} \mathrm{T}$ cells. ${ }^{25}$ It has long been thought that the binding of IL4 resulting in STAT6 activation was the only way in which GATA3 expression could occur. However, recent work has illustrated that IL4 is not necessary to induce a Th2 immune response, although it is necessary for the resulting Th2 immune response once naive $\mathrm{CD} 4{ }^{+} \mathrm{T}$ cells have been differentiated to the Th2 phenotype. ${ }^{26}$ In this study, in 
vivo GATA3 expression was IL4 independent. It has also been shown that GATA3 expression can be induced in an IL4 independent manner by low signal strength TCR activation (i.e. allergen presentation by MHC class II complexes to the TCRs of $\mathrm{CD} 4^{+} \mathrm{T}$ cells). However, if high levels of allergen were used, GATA3 expression was not observed resulting in failure of Th2 differentiaiton. ${ }^{27}$ STAT5 activation occurs via IL2, IL7, and/or thymic stromal lymphopoietin (TSLP) binding to naive $\mathrm{CD}^{+}{ }^{+} \mathrm{T}$ cells through their associated receptors. ${ }^{25}$ The sources of IL4, IL2, IL7, and TSLP are not well understood, however adaptive immune responses are often caused as a result of recognition of infectious agents by the innate immune system. ${ }^{24}$

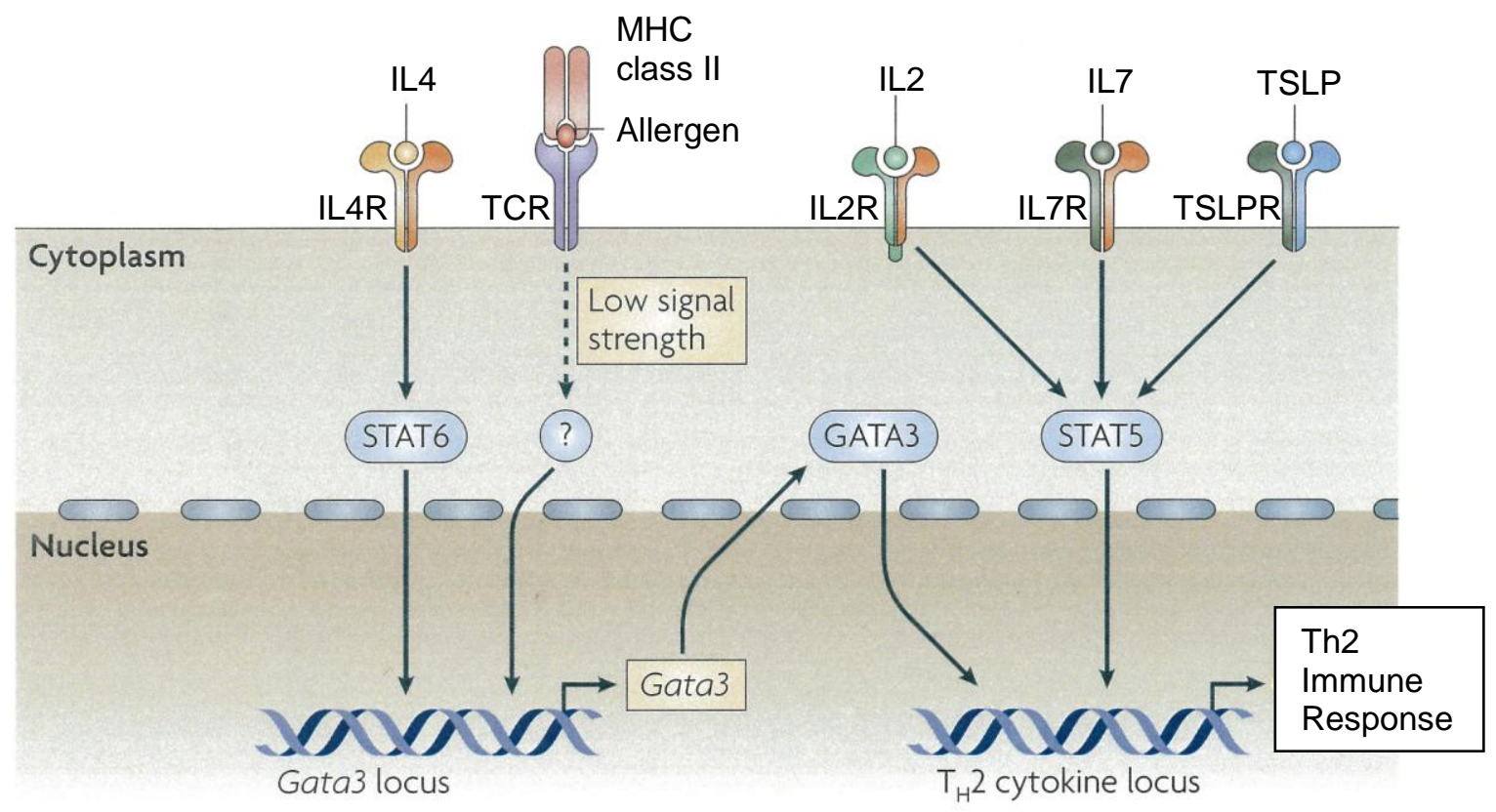

Figure 3: $\quad$ Th2 differentiation of naive $\mathrm{CD}^{+} \mathrm{T}$ cells requires binding of both GATA-binding protein 3 (GATA3) and signal transducer and activator of transcription 5 (STAT5) to the Th2 cytokine locus in the nucleus of the naive $\mathrm{CD}^{+} \mathrm{T}$ cell. GATA3 expression can occur via either IL4 induced STAT6 production or via low signal strength T cell receptor (TCR) activation. STAT5 can be activated by IL2, IL7, or thymic stromal lymphopoietin (TSLP). Adapted from Paul and $\mathrm{Zhu} .^{25}$

Allergen presentation was long believed to occur via MHC class II presentation on DCs; however, recently, there has been strong evidence to suggest that MHC class II allergen presentation by basophils can induce a Th2 response. ${ }^{28-30}$ The idea of basophil allergen presentation also supports the theory that the expression of GATA3 occurs as the result of 
low strength TCR signalling for basophils express lower levels of MHC class II than DCs. ${ }^{25}$ These and other studies have also shown that upon allergen challenge, basophils can produce the IL4 and TSLP required for Th2 differentiation. ${ }^{24}$ It is quite possible that DCs and basophils both play a role in antigen presentation and that both mechanisms act in parallel. For example it has been proposed that TSLP produced by basophils could suppress IL12 production from DCs (a Th1 associated cytokine required for Th1 differentiation), thus biasing antigen presentation by DCs away from Th1 and towards Th2. ${ }^{25}$ That said, there is still much to be understood about how the immune system activates naive $\mathrm{CD} 4^{+} \mathrm{T}$ cells in order to generate a Th2 immune response.

\subsubsection{Perpetuation of the Th2 Immune Response in Allergic Asthma}

Once Th2 cell activation has been initiated, a number of cellular and signalling processes occur, many of which act in a self-perpetuating manner to amplify and maintain the Th2 immune response and thus give rise to the symptoms of asthma. ${ }^{2} \mathrm{Th} 2$ cells induce their characteristic immune response via the production of various cytokines, including IL4, IL5, IL9, IL13, IL21, and IL25, and through their migration to specific tissue sites resulting in the recruitment and activation of cell types responsible for inflammation and airway hyperresponsiveness (Figure 4). Through the release of IL4 and IL13, Th2 cells promote $\mathrm{B}$ cell class switching to immunoglobulin $\mathrm{E}$ ( $\mathrm{IgE}$ ) resulting in the production of IgE. ${ }^{6,25} \mathrm{IgE}$ was the fifth and final class of human antibody discovered and is responsible for transferring sensitivity to allergens. ${ }^{5}$ The IgE produced by B cells binds to the high affinity IgE receptor, Fc\&RI, on the surface of basophils and mast cells. Cross-linking of these IgE-FceRI complexes by allergens triggers a complex process resulting in mastcell/basophil degranulation and the release of cytokines (IL4, IL5, and IL13), chemokines, histamine, heparin, serotonin, and proteases causing smooth muscle constriction (narrowing of the airways), vascular permeability, recruitment of inflammatory cells, and increased mucous secretion (further obstructing airways)., ${ }^{520,25}$ Cross-linking of the IgE-FceRI complex also results in the increased expression of Fc\&RI leading to a powerful amplification mechanism. ${ }^{25}$ Asthmatic individuals have higher levels of IgE expression than non-asthmatics. As both IgE and mast cells are found in the 
mucosal tissue, they are often one of the first defence mechanisms against allergens and accordingly lead to the recurrent Th2 responses observed in asthmatic individuals. ${ }^{5}$

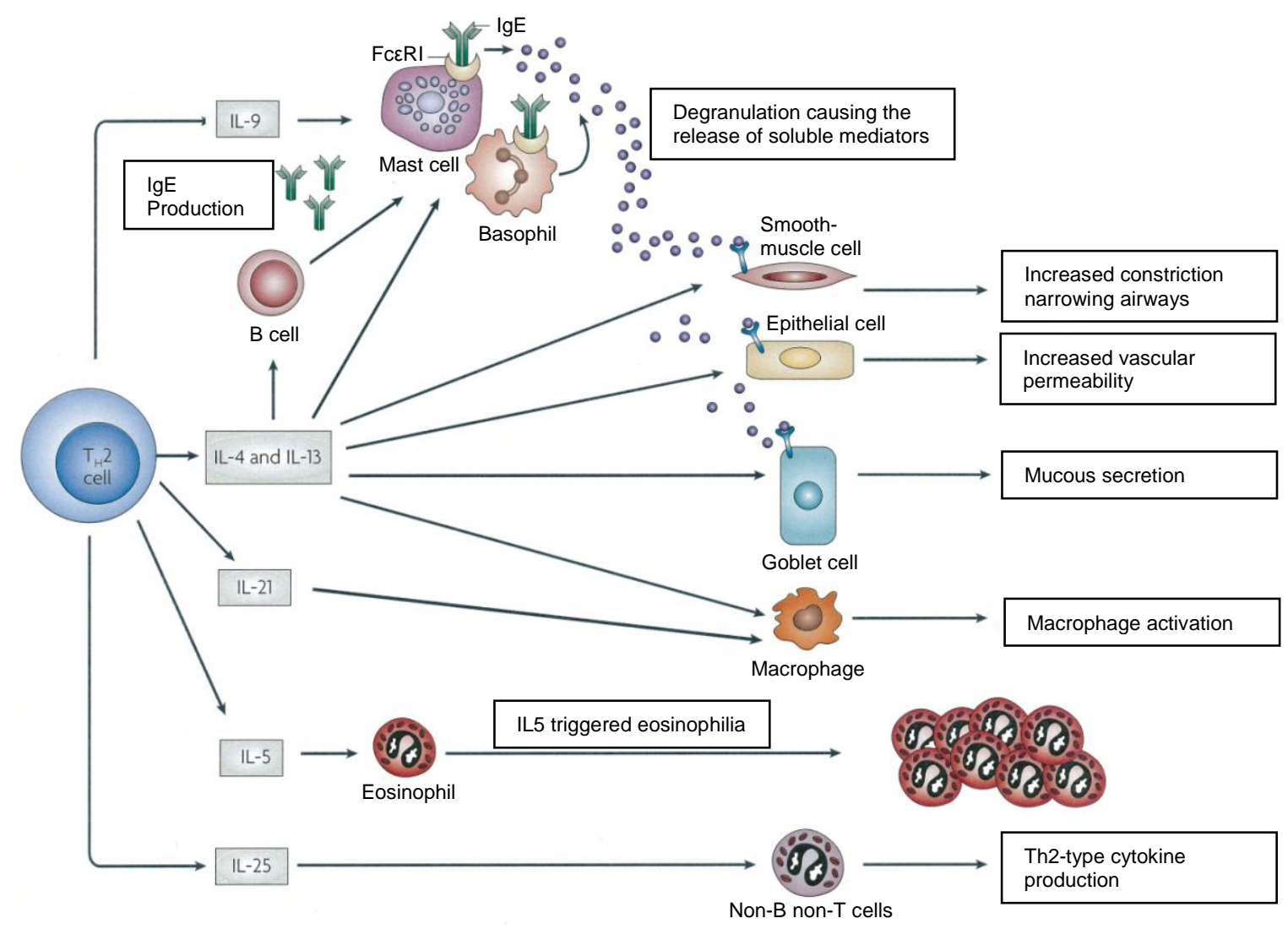

Figure 4: $\quad$ Th2 cells control the allergic Th2 immune response via the production of cytokines in the lymph nodes and periphery. IL4 and IL13 promote B cell class switching resulting in the production of IgE. The produced IgE binds to the high affinity IgE receptor FceRI on both mast cells and basophils which are recruited via IL9, IL4 and IL13. Cross-linking of IgE bound to either mast cells or basophils by an allergen causes degranulation resulting in the release of histamine, heparin and other soluble mediators, which act on smooth muscle cells, epithelial cells, and goblet cells. IL4 and IL13 also act on smooth muscle cells, epithelial cells, and goblet cells causing constriction and narrowing of the airways, mucous secretion and increased permeability of the epithelial barrier. IL4 and IL13 in combination with IL21 result in macrophage activation. IL5 triggers eosinophilia and IL25 results in increased production of Th2-type cytokines by non-B non-T cells. Adapted from Anthony et al. ${ }^{31}$

Th2 cells also migrate to the lung tissue (from the lymph node where they are activated) and release IL5 resulting in the recruitment of eosinophils into the airways causing eosinophilia, one of the major characteristics of an asthma attack. ${ }^{10,25}$ Eosinophilia results in damage to airway epithelial cells (via the release of highly inflammatory granules), 
stimulates mucous secretion, and induces airway hyperresponsiveness. ${ }^{10}$ Th2 cells in the

lung also recruit and promote the growth of mast cells via IL9 production, ${ }^{6,25,32}$ and can also act directly on epithelial cells and smooth muscle cells (both via the generation of IL4 and IL13) which leads to mucous production, goblet cell metaplasia, and airway hyperresponsiveness. ${ }^{25}$ The Th2 cytokines IL4, IL13, and IL21 also activate macrophages, while IL25 acts on IL5 and IL13 producing non-B non-T cells further enhancing the generation of Th2-type cytokines. ${ }^{25}$

\subsubsection{Current Treatments for Asthma}

As the underlying cellular pathways involved in initiating the asthmatic Th2 immune response remain largely unknown, most of the available asthmatic medications are nonspecific and generally only control the symptoms of the Th2 response. ${ }^{33}$ These asthmatic medications are either anti-inflammatory or bronchodilator drugs, and help by relaxing the constricted muscle bands around the airways. Inhaled corticosteroids are a very effective anti-inflammatory drug and can be used for patients of all ages and disease severity. ${ }^{4,33}$ They can be used daily on a long term basis as the human body will not build up immunity towards the drugs, and when used in standard doses, show minor side effects. ${ }^{33}$ However, corticosteroids do not reduce or reverse airway remodelling and must be taken on a regular basis as inflammation recurs upon withdrawal of the treatment. ${ }^{10}$ In fact, it has been shown that lung function reduces more rapidly over time in asthmatic individuals than non-asthmatic individuals, illustrating the progressive nature of asthma. ${ }^{10}$ Bronchodilators can help relieve wheezing, coughing and tightness in the chest and, as they function instantaneously, they are taken when needed. However, like corticosteroids they do not treat the underlying cause of asthma. With the right treatment, most (but not all) patients can control their asthma using a combination of these two medications. ${ }^{20}$ The downside however, is that medication is needed on a daily basis and in individuals with more severe symptoms, it may be required multiple times a day.

Other asthma treatments that have been developed recently include the IgE-specific antibody drug omalizumab. Omalizumab acts as a receptor antagonist to $\operatorname{IgE}$ and 
functions by binding to a site on $\operatorname{IgE}$ required for the binding of the high affinity $\operatorname{IgE}$ receptor, FceRI, thus resulting in reduced mast cell and basophil degranulation. ${ }^{34}$ Omalizumab is expensive and has only been approved for patients with moderate to severe persistent allergic asthma who do not respond to conventional treatment. Even then, the drug is not effective in all patients and if treatment is stopped, relapse is possible. $^{5,20}$ It is, however, a step in the right direction for the treatment of asthma as it works by preventing part of the immune response rather than dampening the symptoms of the immune response. Recent results from trials of IL5 blocking antibodies have not been as promising as omalizumab. This suggests that blocking pathways earlier on in the immune response (e.g. IgE) may provide better therapies. ${ }^{35}$

\section{4 $\underline{\text { N-Glycans as Allergens }}$}

To better understand the cause of allergic asthma and thus provide better, more specific therapies, the specific molecular triggers that cause the asthmatic (Th2) response need to be determined. In studies of allergens known to cause a Th2 response in humans, it was noticed that many of the glycoproteins isolated from these known allergens contained similar oligosaccharides. These conserved oligosaccharides were found on a wide range of allergens such as pollen, ${ }^{36-39}$ schistosomes, ${ }^{40,41}$ and food allergens, ${ }^{42-44}$ and contain a common pentasaccharide core $\left[\mathrm{Man}_{3}(\mathrm{GlcNAc})_{2}\right]$ with $\alpha-1,3-\mathrm{L}-$ fucose and/or $\beta-1,2-\mathrm{D}-$ xylose residues attached to the proximal GlcNAc and to the $\beta$-linked mannose, respectively (Figure 5). ${ }^{36-40,43-45}$ The oligosaccharide in turn, is $N$-linked to the protein via an amide linkage with the carboxamide side chains of asparagine residues. The asparagine residue is present in the tripeptide sequence, asparagine- $\mathrm{X}$-serine/threonine, where $\mathrm{X}$ is any amino acid except proline. ${ }^{36-40,43-45}$ 


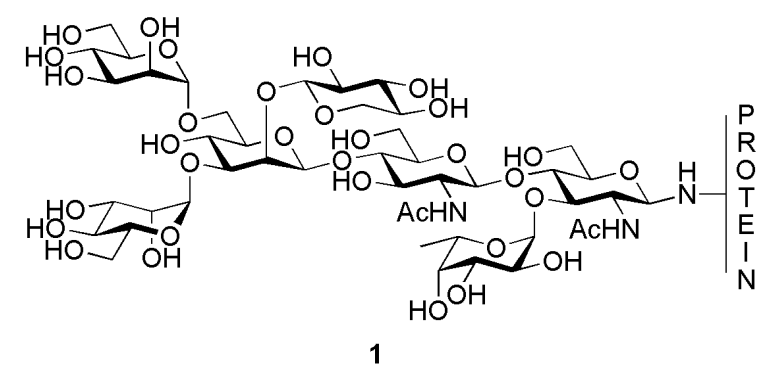

Figure 5: $\quad$ Common $\mathrm{N}$-glycan structure, showing both the $\alpha-1,3-\mathrm{L}$-fucose and the $\beta$-1,2-D-xylose residues, found on allergens known to induce a Th2 immune response.

The common pentasaccharide core of the oligosaccharide $\left[\operatorname{Man}_{3}(\mathrm{GlcNAc})_{2}\right]$ is present in $\mathrm{N}$-glycans in humans and is capped with a combination of high mannose, lactosamine, and/or sialic acid residues attached to the two terminal mannose residues. ${ }^{46-48}$ The $\alpha-1,3-$ L-fucose sugar, however, is not found on proximal GlcNAc residues in mammalian Nglycans, though $\alpha-1,6-\mathrm{L}-$ fucose proximal-linked residues are. ${ }^{40}$ Xylose residues are not present in mammalian $\mathrm{N}$-glycans either, although both are common features of plant and invertebrate $\mathrm{N}$-glycans. ${ }^{36,38,42}$ It is also interesting to note that viruses and bacteria, which elicit a Th1 rather than Th2 immune response, have different $\mathrm{N}$-glycans and that these do contain $\alpha$-1,3-L-fucose or $\beta-1,2$-D-xylose residues. ${ }^{49-51}$

To illustrate that specific xylose- and/or fucose-containing glycoproteins elicit an allergic immune response, studies have been performed using glycoprotein allergens containing $\mathrm{N}$-glycans with $\alpha$-1,3-L-fucose and/or $\beta$-1,2-D-xylose residues isolated from natural sources. These studies illustrate that these glycoproteins cause an increase in the production of Th2 specific cytokines (such as IL4, IL5, IL10 and IL13). ${ }^{37,40-42,52,53}$ One study of $\mathrm{N}$-glycan-containing peanut allergen extracts also postulated that the $\mathrm{N}$-glycan caused Th2 cytokine production via its interaction with C-type lectins on DCs. ${ }^{42}$ However, if true, it still remains to be understood how the allergen was processed and presented in order to induce the Th2 response. C-type lectins are most commonly associated with pathogen endocytosis and are not involved in antigen presentation. ${ }^{41,54}$ Production of $\operatorname{IgE}^{44,53,55}$ and IgE binding ${ }^{44,56-58}$ in response to a number of glycoproteins from different classes of allergen (i.e. cross-reactivity between allergens) has also been observed with a variety of unrelated allergens containing $\alpha-1,3$-L-fucose and/or $\beta-1,2-D-$ xylose residues on the core $\operatorname{Man}_{3}(\mathrm{GlcNAc})_{2}$ motif. The cross-reactivity of unrelated 
allergens, such as pollen (plant derived) and seafood or insect venom (invertebrate derived) can be explained by the conserved $\mathrm{N}$-glycan structure. ${ }^{36,59}$ For example, when the carbohydrate residues of the glycoprotein allergens have been cleaved, IgE antibody binding is inhibited ${ }^{60,61}$ and there is a significant decrease in the production of Th2 specific cytokines. ${ }^{52}$ These results suggest that the carbohydrate moiety of the glycoprotein allergen plays a vital role in producing the Th2 immune response. One study has also illustrated the possibility that the free carbohydrate moiety itself (i.e. not attached to a protein) may bind to the receptor(s) responsible for inducing the Th2 response yet does not induce a Th2 response and rather, acts as a Th2 antagonist. ${ }^{37}$

\subsection{Project Aims}

This masters project focuses on synthesising truncations of the heptasaccharide Nglycoprotein 1, in order to determine the specific molecular triggers that are responsible for causing the asthmatic (Th2) immune response.

Although several studies suggest the importance of $\alpha-1,3-\mathrm{L}$-fucose and/or $\beta-1,2-\mathrm{D}-\mathrm{xylose}$ residues on the conserved $\operatorname{Man}_{3}(\mathrm{GlcNAc})_{2}$ core, due to the heterogeneity of the isolated glycoproteins tested thus far, it is difficult to assign, with certainty, a specific carbohydrate moiety as the cause of the Th2 response. In addition, a need for $\mathrm{N}$-glycan allergens containing two or more glycosylated sites (multivalent) that bear the same carbohydrate moiety (homogeneous) has been expressed. It has been proposed that the specific sugar recognition patterns of anti-carbohydrate antibodies could have a significant impact on whether a specific carbohydrate moiety is able to result in IgE recognition and cross-linking. ${ }^{44,59,62}$ Multivalent $\mathrm{N}$-glycans are needed because monovalent $\mathrm{N}$-glycans (such as the previously tested pineapple bromelain antigen, which carries only one carbohydrate) are unable to cross-link $\operatorname{IgE}$ receptors and are therefore unable to result in mast cell and basophil degranulation. ${ }^{44,62}$ Chemical synthesis, however, enables the desired glycoprotein to be synthesised in sufficient quantity and purity to precisely determine the portion of the carbohydrate moiety responsible for 
inducing the Th2 immune response. The carbohydrate portion of the glycoprotein can be synthesised and coupled to a protein or a fluorescent latex bead, or can be conjugated to a proteinaceous allergen, such as worm extract that has been stripped of its native carbohydrates. The use of the different protein or protein mimics, will establish whether the carbohydrate is, on its own, sufficient to cause a Th2 response and whether a specific carrier protein is needed. Furthermore, through synthesis, a library of homogeneous glycoproteins (truncated structures of the common heptasaccharide 1) can be assembled to determine the minimum structure required to induce a Th2 immune response. Understanding the structure-activity profile of $\mathrm{N}$-glycans will provide insight into potential targets for receptor blocking drugs, and may lead to smaller, more easily synthesised structures for studying the Th2 immune response.

\subsection{N-Glycan Synthesis}

\subsubsection{Overview of Syntheses of Similar N-Glycans}

To date, there has been no reported synthesis of the conserved heptasaccharide or any similar heptasaccharide glycoconjugate (e.g. 1). There are, however, a number of published syntheses of $\mathrm{N}$-glycans that contain the $\mathrm{Man}_{3}(\mathrm{GlcNAc})_{2}$ pentasaccharide core. As mentioned previously, this core pentasaccharide is present in $N$-linked glycoproteins that are biosynthesised by humans. ${ }^{46-48}$ Interest in the role that mammalian N-glycans play in biological systems ${ }^{63-69}$ has, in turn, resulted in the synthetic preparation of this $\operatorname{Man}_{3}(\text { GlcNAc })_{2}$ glycan.

Both Ogawa and co-workers ${ }^{70,71}$ and Unverzagt and co-workers ${ }^{72-74}$ have published several syntheses of carbohydrates containing the pentasaccharide core. Both groups used similar protecting group strategies, with the $N$-acetate groups of the GlcNAc residues being protected as their $N$-phthalimido ( $N$-Phth) derivatives and the reducing anomeric centre being protected as a $\beta$-azide, which can be reduced to give the desired $\beta$-amine required to form the $N$-linked glycopeptide (Scheme 1). That said, the disconnection 
strategies employed by each group were slightly different. Both groups formed the core pentasaccharide 2 by bis-glycosylation of a suitably protected $\mathrm{Man}(\mathrm{GlcNAc})_{2}$ trisaccharide (Scheme 1). Ogawa and co-workers used a mannose donor 3 with acetate protecting groups on the $\mathrm{C}-2$ hydroxyl to install the two capping mannose residues. This gave the desired $\alpha$-anomer selectively due to neighbouring group participation. Unverzagt and co-workers, en route to a larger carbohydrate motif, used a mannose donor 9 that was already glycosylated at the C-2 hydroxyl, meaning selectivity could not be controlled by neighbouring group participation. Here the $\alpha: \beta$ ratio of the coupling was not reported. The order of assembly of the Man(GlcNAc) $)_{2}$ trisaccharide 4 was different for each group. Ogawa and co-workers first formed the ManGlcNAc disaccharide 5, whereas Unverzagt and co-workers first coupled the two GlcNAc residues to give the (GlcNAc) 2 disaccharide 11. The other main difference was that Ogawa and co-workers chose to use mannose donor 7 to install the $\beta$-1,4-mannose linkage. The disadvantage of this strategy is that it resulted in the production of both $\alpha$ - and $\beta$-1,4-linked mannose in an almost 1:1 ratio. Unverzagt and co-workers, however, chose to install the $\beta$-1,4-linked mannose using a glucose donor containing a 2 - $O$-acetyl group to control $\beta$-selectivity via neighbouring group participation. This resulted in the $\beta$-anomer of 4 exclusively. Following this selective glycosylation, the stereochemistry of the C-2 hydroxyl was then inverted to give the desired mannose stereochemistry. This was achieved via the conversion of the C-2 hydroxyl, after acetate deprotection, to the corresponding triflate that was then heated, resulting in a manno-configurated imidocarbonate, hydrolysed to the carbonate, then subjected to methanolysis to give the C-2 hydroxyl with the desired mannose configuration. 


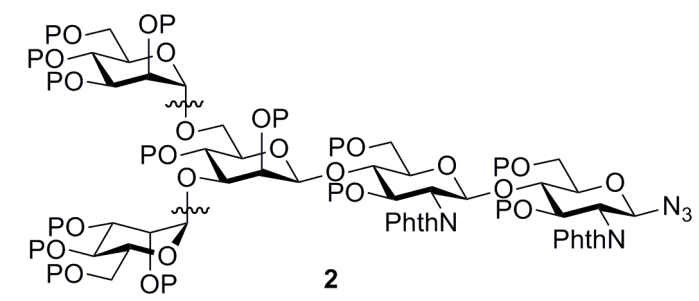

A: Ogawa and Co-workers

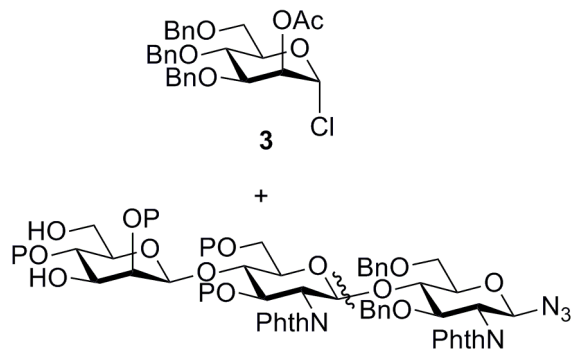

4
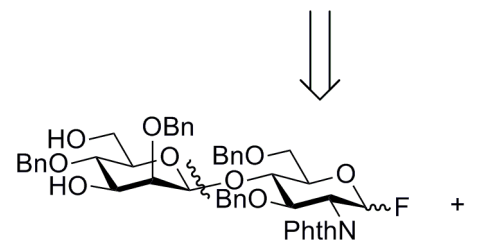

5
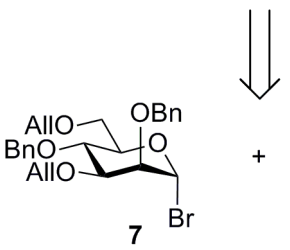

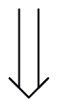

B: Unverzagt and Co-workers

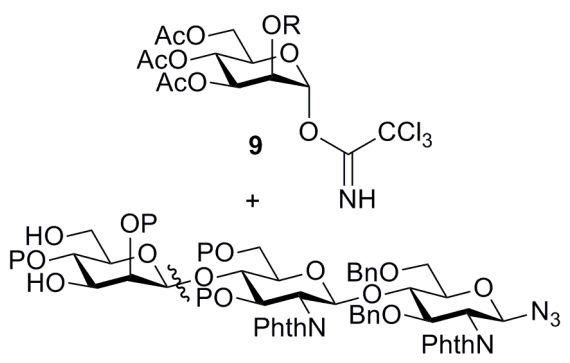

4

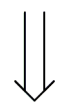

Scheme 1: $\quad$ Strategies employed by Ogawa and co-workers (retrosynthesis A) and Unverzagt and coworkers (retrosynthesis B) to synthesis carbohydrates containing the core $\operatorname{Man}_{3}(\mathrm{GlcNAc})_{2}$ pentasaccharide. $\mathrm{P}=$ protecting group, $\mathrm{R}=$ another sugar residue $\mathrm{MP}=p$-methoxyphenyl.

Danishefsky and co-workers have also produced a number of fully synthetic $N$-linked glycopeptides containing the core $\operatorname{Man}_{3}(\mathrm{GlcNAc})_{2}$ pentasaccharide and have utilised several different assembly strategies to do so. ${ }^{75-79}$ For the installation of the $\beta-1,4-$ linked mannose residue they have used mannose donors ${ }^{77}(\alpha: \beta=1: 6)$, as well as glucose donors with neighbouring group participation ${ }^{75,76}$ (complete $\beta$-selectivity) and subsequent inversion of the C-2 hydroxyl (oxidation, reduction) to give the desired mannose stereochemistry. Danishefsky and co-workers also used two different protecting group strategies for the protection of the $N$-acetamide of the GlcNAc residues. Like Ogawa and Unverzagt, Danishefsky used $N$-phthalimido protected GlcNAc residues, which resulted 
in the selective formation of the desired $\beta$-1,4-linkage due to neighbouring group participation. However, they have also used sulfonamide protected GlcNAc residues. Unlike the use of the $N$-phthalimido protected GlcNAc donor, the use of the sulfonamide protected GlcNAc donor did not result in completely stereoselective glycosylation and instead gave a 1:6 $\alpha: \beta$ ratio when the two GlcNAc residues were coupled. ${ }^{75}$ Danishefsky and co-workers have most commonly employed 2-O-benzoate protection on the mannose donors to gain the desired $\alpha$-linkage for the capping mannose residues via neighbouring group participation. ${ }^{76,77}$ They reported the formation of undesired orthoester in approximately $50 \%$ yield when $2-O$-acetate protection was used. ${ }^{75}$

Once the carbohydrate has been fully assembled the anomeric centre of the reducing end of the sugar must be converted to a $\beta$-amine, which is required for formation of the $\beta-N$ linkage to the peptide (Scheme 2). There are two commonly employed routes for the formation of the required anomeric $\beta$-amine. The first employs $\beta$-azide protection of the anomeric centre whereby the azide can be subsequently reduced to the required $\beta$-amine. Danishefsky and co-workers used this method during their initial synthesis of the core $\mathrm{Man}_{3}(\mathrm{GlcNAc})_{2}$ pentasaccharide. However, they reported that following reduction of the $\beta$-azide and subsequent acylation to the peptide they obtained the $N$-linked glycopeptide in approximately a 1:1 ratio of $\alpha: \beta$ anomers, indicating that the C-1 stereocentre had epimerised en route to the $N$-linked glycopeptide (Scheme 2) ${ }^{75}$ An alternative to azide reduction is the conversion of the anomeric hydroxyl of the reducing end GlcNAc residue to the corresponding $\beta$-amine (Scheme 2). This methodology has been used very successfully by Danishefsky and co-workers to selectively create $\beta$ - $N$-linked glycopeptides of very complex oligosaccharides. ${ }^{76,77}$ For the conversion of the hydroxyl to the $\beta$-amine, Danishefsky and co-workers employed Kochetkov amination conditions. ${ }^{80}$ 


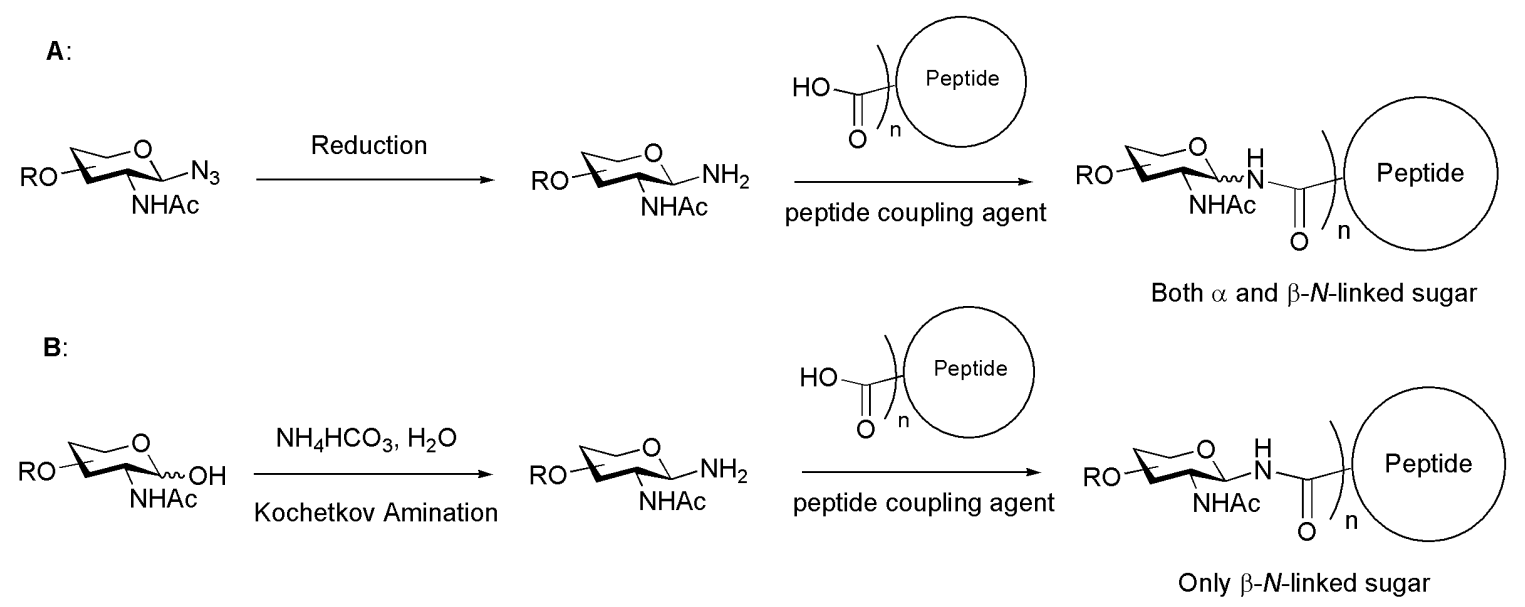

Scheme 2: $\quad$ Formation of the anomeric $\beta$-amine via either A: reduction of an azide or $\mathbf{B}$ : Kochetkov amination of a free sugar and subsequent acylation to form an $N$-linked glycopeptide.

The carbohydrate moiety can be conjugated to the peptide in either a stepwise or convergent manner (Scheme 3). Stepwise synthesis involves coupling of the carbohydrate moiety to an individual amino acid residue to give a glycosylated amino acid building block that can then be used in stepwise solid-phase peptide synthesis (SPPS) ${ }^{81}$ SPPS is limited to producing peptides of $<50$ amino acid residues; however, the production of larger glycopeptides and glycoproteins has been achieved using native chemical ligation of glycopeptides. ${ }^{82}$ Stepwise synthesis has two main drawbacks. Firstly, some of the $O$ glycosidic bonds present in complex oligosaccharides are not stable under the acidic conditions normally used in SPPS for resin cleavage or side-chain deprotection. ${ }^{81,83}$ Secondly, introducing the sugar to the peptide via a glycosylated amino acid building block means that the sugar is incorporated as part of a linear synthetic strategy, thus reducing the efficiency of the synthesis with respect to the carbohydrate moiety. This is undesirable given the amount of effort required to synthesise complex oligosaccharides. ${ }^{83}$ As we are planning to couple our carbohydrates directly to proteins, stepwise synthesis will not be further discussed. The other method, which we plan to use, is convergent synthesis in which the carbohydrate moiety is coupled to an already formed peptide. Here it needs to be noted that when a peptide is used instead of an amino acid, there is the possibility of a competing intramolecular side reaction to form the aspartimide (Scheme 4). Cohen-Anisfeld and Lansbury, ${ }^{83}$ however, discovered that minimising the amount of base used in the reaction reduces the amount of aspartimide formation. It could also be 
expected that coupling to a peptide would result in lower yields than coupling to a single amino acid residue. To circumvent this potential problem, it was found that using $O$ (Benzotriazol-1-yl)- $N, N, N^{\prime}, N^{\prime}$-tetramethyluronium hexafluorophosphate (HBTU) resulted in high yields and that using fully deprotected sugars instead of their $O$-acetate derivatives also increased yields. The procedure developed by Cohen-Anisfeld and Lansbury $^{83}$ has been successfully used by several groups to produce complex glycopeptides. ${ }^{76,77,84}$

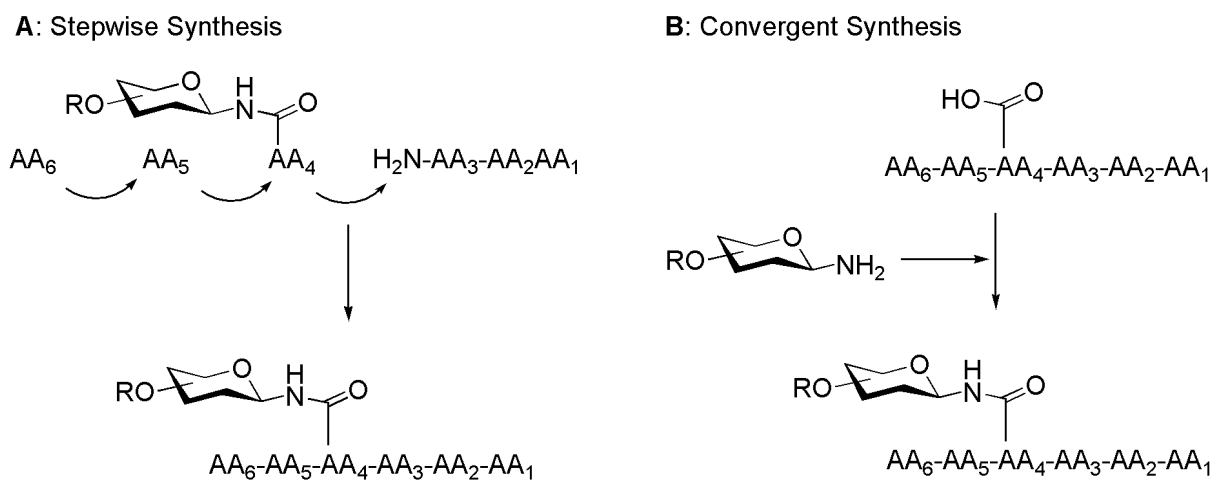

Scheme 3: $\quad$ Different strategies for glycopeptide synthesis. Amino acid (AA).

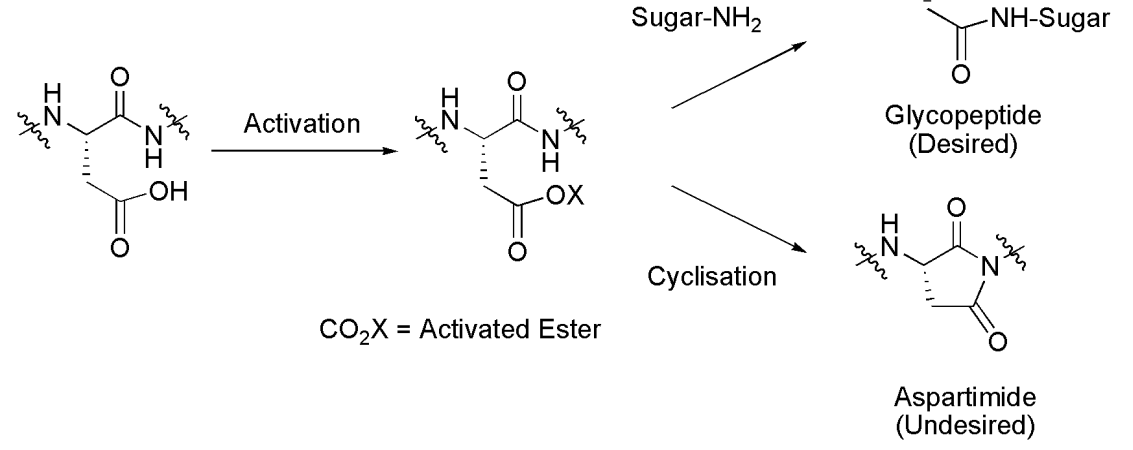

Scheme 4: Aspartimide formation from an activated aspartic acid residue during a convergent synthetic approach to glycopeptides. 


\subsubsection{Synthetic Targets for this Masters Project}

This masters project focuses on synthesising three glycoconjugates, that of the GlcNAc monosaccharide 14, the FucGlcNAc disaccharide 15, and the $\mathrm{Man}_{3}$ trisaccharide 16 (Figure 6). All three structures are truncations of the heptasaccharide N-glycan 1.

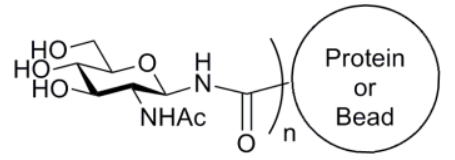

14

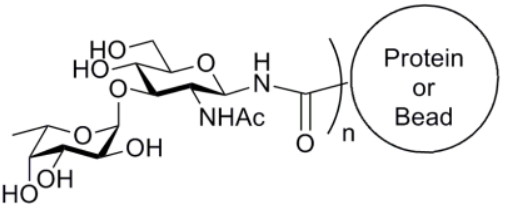

15

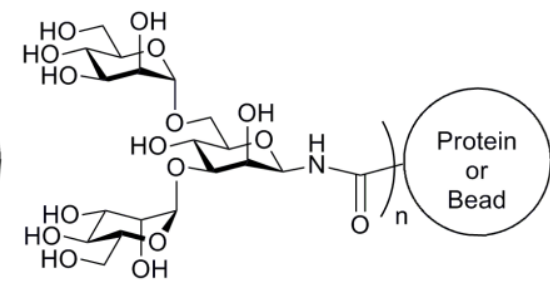

16

Figure 6: $\quad$ Synthetic targets for this masters project.

The synthesis of monosaccharide glycoconjugate $\mathbf{1 4}$ involves conversion of the commercially available $\mathrm{N}$-acetylglucosamine (GlcNAc) to the corresponding glycosylamine using Kochetkov amination ${ }^{80}$ and subsequent conjugation to either a protein or a fluorescent latex bead using Cohen-Anisfeld and Lansbury's coupling methodology. ${ }^{76,83}$ Two different proteins, keyhole limpet hemocyanin (KLH) or ovalbumin (OVA), will be used in order to assess the effect that the protein has on the Th2 bias. KLH has been chosen as it is a highly antigenic protein and it stimulates a strong $\mathrm{CD}^{+} \mathrm{T}$ cell response including detectable Th2 activity. OVA, on the other hand, has been chosen as it also stimulates a good $\mathrm{CD}^{+} \mathrm{T}$ cell response but does not bias towards a Th2 immune response. By comparing the Th2 activity of the KLH and OVA glycoconjugates, insight will be gained into the importance of the protein in the asthmatic Th2 response. The fluorescent latex bead conjugates can also be synthesised and tested in order to deduce whether a protein component is necessary for a Th2 response.

Retrosynthetic analyses for the glycoconjugates $\mathbf{1 5}$ and $\mathbf{1 6}$ are shown in Scheme 5. Here, it should be noted that the syntheses of the glycoconjugates $\mathbf{1 5}$ and $\mathbf{1 6}$ were designed with the synthesis of the heptasaccharide $\mathbf{1}$ in mind. 


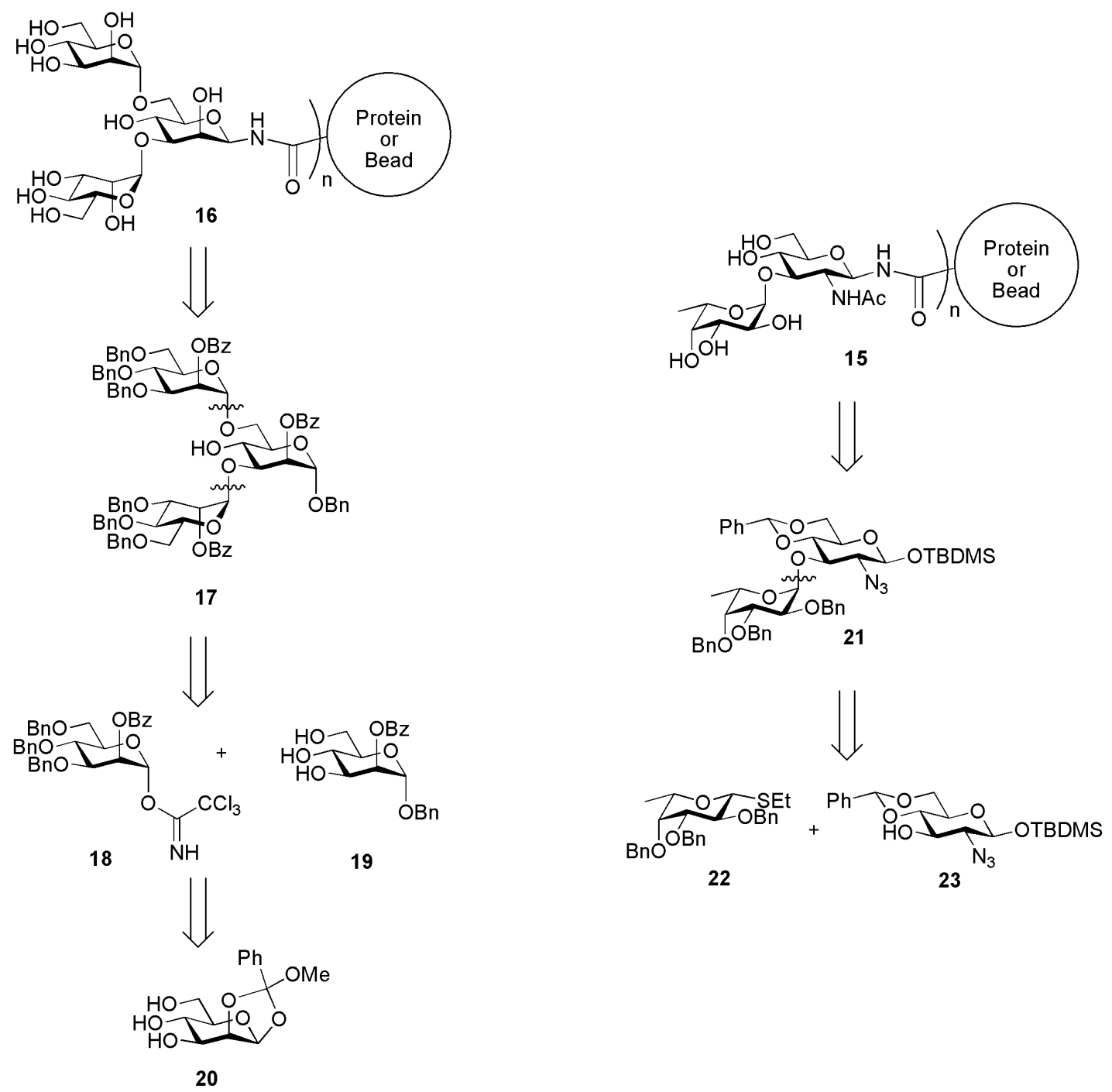

Scheme 5: $\quad$ Retrosyntheses for the target glycoconjugates $\mathbf{1 5}$ and $\mathbf{1 6}$

The $\mathrm{Man}_{3}$ glycoconjugate 16 can be synthesised from the protected trisaccharide $\mathbf{1 7}$. This requires complete deprotection of the trisaccharide 17 , followed by conversion of the resulting free glycan to the corresponding glycosylamine using Kochetkov amination ${ }^{80}$ and subsequent conjugation to either a protein or a fluorescent latex bead using CohenAnisfeld or Lansbury acylation. ${ }^{76,83}$ The protected trisaccharide $\mathbf{1 7}$ can itself be constructed via a trimethylsilyl trifluoromethanesulfonate (TMSOTf) mediated glycosylation reaction ${ }^{85}$ between mannose trichloroacetimidate donor $\mathbf{1 8}$ and the triol mannose acceptor 19. There is literature precedent for selective 3,6-bis-glycosylaion of mannose acceptors that are only protected at the anomeric centre, ${ }^{86-90}$ and the success of this reaction is probably based on steric factors. Both donor $\mathbf{1 8}$ and acceptor $\mathbf{1 9}$ are 
readily prepared from the mannose orthoester 20, itself synthesised from D-mannose in four steps following literature procedures. ${ }^{91,92}$ The $O$-2-benzoyl protection of mannose donor 18 was chosen to give $\alpha$-selectivity via neighbouring group participation, with benzoyl protection being chosen over acetate protection because 2-O-acetate protected mannose donors can lead to the formation of undesired orthoester. ${ }^{86}$ The mannose donor 18 will also be used for installing the two mannose capping residues in the larger heptasaccharide glycoconjugate and accordingly, will be synthesised on a large scale.

The disaccharide glycoconjugate $\mathbf{1 5}$ can be synthesised from the protected disaccharide 21, using methodology similar to that mentioned above along with azide reduction and acetylation to give the required $N$-acetyl group. The protected disaccharide $\mathbf{2 1}$ can in turn be constructed from the two selectively protected building blocks 22 and 23 via Ogawa glycosylation with $\mathrm{CuBr}_{2} / \mathrm{Bu}_{4} \mathrm{NBr}^{.93-95}$ The desired $\alpha$ stereochemistry of the 1,3-linkage can be obtained via the anomeric effect. Benzyl protected thiofucose donors are commonly used for installation of $\alpha$-fucose residues, with both thiophenyl ${ }^{96-98}$ and thioethyl $^{94-96,99}$ donors having been used for this purpose. We chose to use a thioethyl group as glycosylation can be achieved using Ogawa conditions, ${ }^{93}$ which are milder than the triflic acid (TfOH) and $N$-iodosuccinimide (NIS) ${ }^{96,98}$ conditions used for thiophenyl activation. The ability to achieve coupling under milder conditions was desired as difficulties in installing the $\alpha$-fucose residue have been reported in literature. ${ }^{72,100,101}$ This is often attributed to the increased acid lability of the resulting $\alpha$-fucosyl linkage. The chosen thiofucose building block 22 can in turn be prepared from L-fucose in five steps following modified literature procedures. ${ }^{102,103}$ Glucosazide building block 23 can be prepared from D-glucosamine in six steps following modified literature procedures. ${ }^{104-106}$ Here, the protecting group pattern and functionality of $\mathbf{2 3}$ was chosen such that $\mathbf{2 3}$ can be used for both GlcNAc residues in the core pentasaccharide $\left[\mathrm{Man}_{3}(\mathrm{GlcNAc})_{2}\right]$, creating a more convergent synthesis if one considers the preparation of the larger $\mathrm{N}$-glycan. The $\mathrm{N}$ acetyl groups present in the glycoconjugate targets were masked as azides due to the Lewis basicity of $\mathrm{N}$-acetyl groups which makes them incompatible with Lewis acid mediated glycosylation reactions required for imidate and thiol donors. Although the azido group is not able to induce the desired $\beta$-1,4-linkage between the two GlcNAc 
residues via neighbouring group participation, the desired $\beta$-selectivity can be achieved via the use of acetonitrile as a participating solvent. ${ }^{107,108}$ The azide can be reduced and acetylated in the final stages of the synthesis to give the desired $\mathrm{N}$-acetyl group. To illustrate the need for the orthogonality of the protecting group pattern on $\mathbf{2 3}$, one needs to first realise that coupling at either the $3-\mathrm{OH}$ or $4-\mathrm{OH}$ position of the glucosazide is required. Coupling at the 4 position is required for construction of the heptasaccharide and other structures containing the $(\mathrm{GlcNAc})_{2}$ disaccharide, while selective $3-\mathrm{OH}$ coupling is required for the construction of the introduction of the fucose residue.

The formation of the $\beta$-1,4-linkage joining the two GlcNAc residues will also be investigated during this Masters project via the synthesis of the GlcNAc(Fuc)GlcNAc trisaccharide 24 (Scheme 6). Formation of this $\beta$-linkage is vital to the successful synthesis of the larger glycoconjugates and accordingly, needs to be thoroughly investigated. The trisaccharide $\mathbf{2 4}$ can be synthesised via the TMSOTf mediated coupling of the glucose azide donor $\mathbf{2 5}$ with FucGlc disaccharide acceptor $\mathbf{2 6}$ using acetonitrile to induce the desired $\beta$-selectivity. ${ }^{107,108}$ The FucGlc disaccharide acceptor $\mathbf{2 6}$ is also a key intermediate in the synthesis of the heptasaccharide 27 (Scheme 6) required for the synthesis of glyconconjugate $\mathbf{1}$. FucGlc disaccharide acceptor $\mathbf{2 6}$ can be synthesised via selective opening of the 4,6-benzylidene of the FucGlc disaccharide 21. The imidate donor 25, required for this model glycosylation, can be synthesised from the glucose azide building block $\mathbf{2 3}$, further illustrating the orthogonality of the protection strategy of 23. 


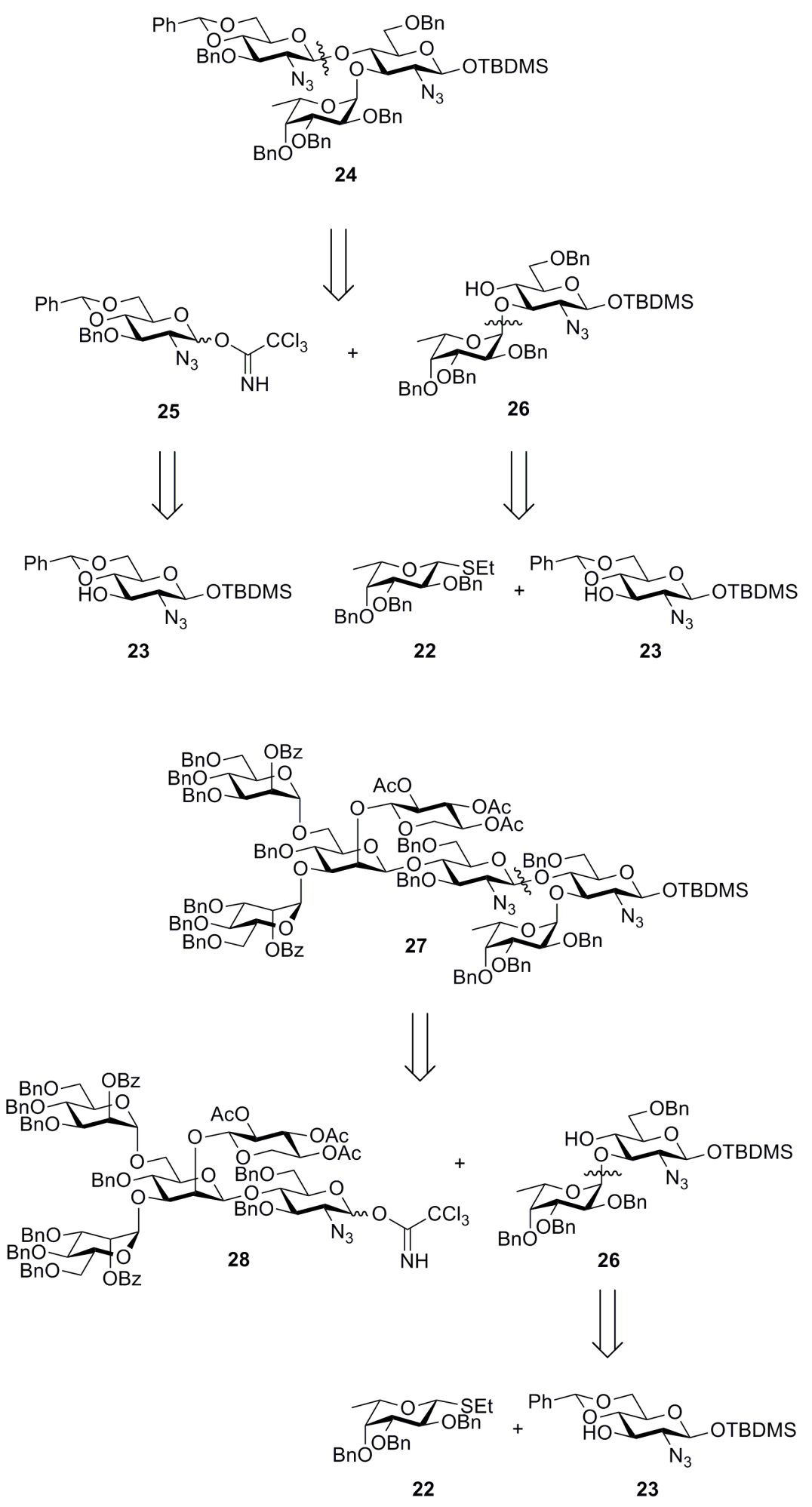

Scheme 6: $\quad$ Retrosynthesis of the Glc(Fuc)Glc trisaccharide 24. The synthetic methodology required for the formation of the $\beta$-1,4-linkage between the two GlcNAc residues can be established via the synthesis of trisaccharide $\mathbf{2 4}$ before it is required for the formation of the heptasaccharide 27. 


\subsection{Biological Testing}

Biological testing of the conjugated $\mathrm{N}$-glycans will be conducted at the Malaghan Institute of Medical Research, Wellington, New Zealand. Though the testing itself is outside the scope of this project, brief mention of the assays that will be used is given below.

Glycoconjugates $\mathbf{1 4}, \mathbf{1 5}$, and $\mathbf{1 6}$ will be tested for their ability to bias the Th response to a Th2 immune response using the recently developed IL4/green fluorescent protein (GFP) reporter mice. ${ }^{15}$ IL4/GFP reporter mice have a fluorescent reporter gene construct stably inserted into the IL4 gene locus and when a T cell differentiates to the Th2 phenotype, the IL4 gene locus becomes active and transcribes the fluorescent reporter construct. The advantage of using the IL4/GFP reporter system is that GFP is not secreted making it possible to detect the in vivo development of Th2 cells using flow cytometry without requiring in vitro restimulation. GFP also has a relatively long half life. These characteristics make GFP a sensitive reporter for the in vivo production of IL4.

Testing of the synthesised N-glycan's ability to induce a Th2 immune response using the IL4/GFP reporter mice will involve the injection of solutions of the N-glycan into the dermal layer of a mouse ear and then collecting the ear draining lymph node after seven days. The absolute number of $\mathrm{CD}^{+} \mathrm{GFP}^{+} \mathrm{T}$ cells in the ear draining lymph node is calculated using flow cytometry and expressed as the number of $\mathrm{CD}^{+} \mathrm{GFP}^{+}$cells per ear draining lymph node.

If the $\mathrm{N}$-glycans stimulate the production of IL4 in the IL4/GFP assay, other assays will be conducted to determine whether the glycoproteins stimulate all aspects of a Th2 immune response. Enzyme-Linked ImmunoSorbent Assays (ELISA) of mouse blood will be used for determination of $\operatorname{IgE}$ antibody production, quantitative polymerase chain reaction (PCR) analysis of lymph nodes will be used for the determination of other Th2 cytokines (IL5 and IL13), and cytospin assays will be used for the determination of eosinophil and basophil infiltration of tissue sites injected with the glycoprotein. The fluorescent latex bead glycoconjugates, 14, 15, and 16, can be visually tracked by 
fluorescent microscopy and will provide information on the types of antigen presenting cells (DCs, basophils, B cells, macrophages) involved with the initial recognition and cellular uptake of the N-glycans. 


\section{RESULTS AND DISCUSSION}

\subsection{Synthesis of the Mannose Trisaccharide}

\subsubsection{Synthesis of the Mannose Imidate Donor Building Block}

Mannose imidate $\mathbf{1 8}$ is the building block responsible for installing the terminal mannose capping residues of the $\operatorname{Man}_{3}(\mathrm{GlcNAc})_{2}$ pentasaccharide core (Scheme 7). Synthesis of the mannose imidate is possible in seven steps from D-mannose following literature procedures. $^{91,92}$ The synthesis was conducted on a large scale so that additional imidate 18, not required for the production of the target mannose trisaccharide conjugate 16, can be used in the synthesis of the heptasaccharide conjugate 1 and other derivatives (Scheme 7).

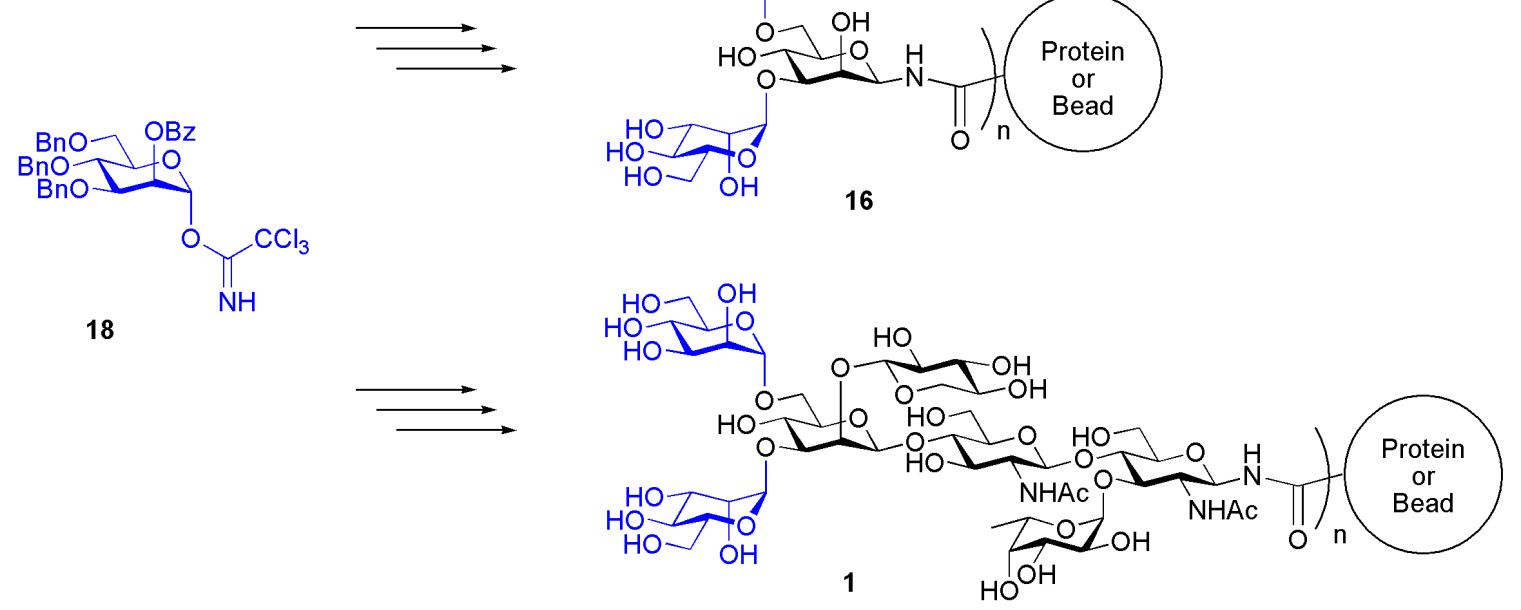

Scheme 7: $\quad$ Uses for the mannose imidate building block 18.

The first step in the synthesis of the mannose imidate 18 (Scheme 8) was the benzoylation of D-mannose which proceeded in $96 \%$ yield to give per-benzoylated mannose 29. . Treatment of benzoylated mannose $\mathbf{2 9}$ with $\mathrm{HBr}$ and acetic acid resulted in the glycosyl bromide 30. The crude bromide 30 was then converted to the corresponding orthoester 31 by reaction with $\mathrm{MeOH}$ and 2,6-lutidine before removal of the benzoyl groups using standard Zemplén conditions ${ }^{109}(\mathrm{NaOMe}, \mathrm{MeOH}, \mathrm{pH} \approx 9)$ to give the triol * Previously synthesised in the group (Dr Stocker) 
orthoester 20 in $68 \%$ yield over 3 steps. ${ }^{*}$ Benzylation of triol 20 resulted in benzyl protected orthoester 32 in an $81 \%$ yield. Successful introduction of the three benzyl groups was confirmed by the appearance of three characteristic $\mathrm{AB}$ systems in the ${ }^{1} \mathrm{H}$ NMR spectrum of 32 (3-O-Bn 4.88 and 4.83 ppm, 4- $O-\mathrm{Bn} 4.91$ and $4.65 \mathrm{ppm}$, and 6- $O$ Bn 4.44 and $4.41 \mathrm{ppm})$. Opening of the 1,2-orthoester using acetic acid and water gave the 2-O-benzoyl protected lactol 33 in $82 \%$ yield. Successful opening of the 1,2orthoester was seen in the ${ }^{1} \mathrm{H}$ NMR of $\mathbf{3 3}$ by the disappearance of the methoxyl protons and the downfield shift of $\mathrm{H}-2$, resulting from newly formed electron withdrawing 2-Obenzoate (from $\delta_{\mathrm{H} 2}=4.70$, to $\delta_{\mathrm{H} 2}=5.63$ ). The appearance of a broad $\mathrm{OH}$ stretch (3343 $\mathrm{cm}^{-1}$ ) in the IR spectrum was also observed. A small amount (8\%) of the anomeric $\alpha-O$ acetate $\mathbf{3 4}$ was also formed during the opening of the 1,2-orthoester. Anomeric acetate protection was confirmed by the HMBC between the $O$-Ac carbonyl carbon (168.6 ppm) and both the anomeric proton $\left(6.26 \mathrm{ppm}, J_{1,2}=2.2 \mathrm{~Hz}\right)$ and the $O$-Ac methyl protons (2.11 ppm) as well as electrospray ionisation high resolution mass spectrometry (HRMS(ESI)) analysis ( $\mathrm{m} / \mathrm{z}$ calcd. for $\left[\mathrm{C}_{36} \mathrm{H}_{36} \mathrm{O}_{8}+\mathrm{Na}\right]^{+}: 619.2308$, obsd.: 619.2324). The synthesis of mannose imidate $\mathbf{1 8}$ was completed by treatment of lactol $\mathbf{3 3}$ with trichloroacetonitrile and 1,8-diazabicyclo[5.4.0]undec-7-ene (DBU) which resulted in the thermodynamic $\alpha$-imidate product $18\left(\delta_{\mathrm{H} 1 \alpha}=6.43, J_{1,2}=2.1 \mathrm{~Hz}\right)$ in $89 \%$ yield. Conversion to the acetimidate was confirmed by the presence of the diagnostic $\mathrm{CCl}_{3}$ carbon peak in the ${ }^{13} \mathrm{C}$ NMR spectrum at $90.1 \mathrm{ppm}$ and the introduction of the singlet $\mathrm{NH}$ peak at $8.70 \mathrm{ppm}$ in the ${ }^{1} \mathrm{H}$ NMR spectrum. The imidate was obtained as a colourless oil that crystallised overnight upon storage in the freezer. In total $5.76 \mathrm{~g}$ of the imidate donor 18 was synthesised, which was stored in the freezer until required.

\footnotetext{
* The mannose orthoester 20 was synthesised from per-benzoylated mannose 29 in conjunction with a summer research student.
} 

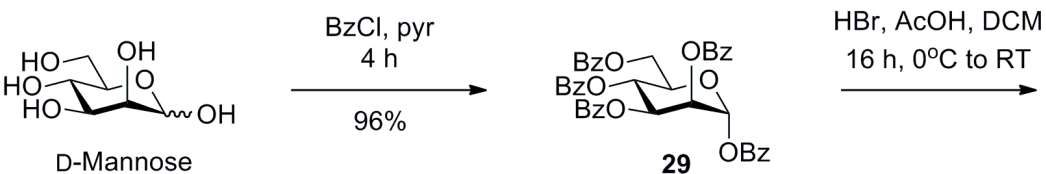

D-Mannose

$29 \mathrm{OBz}$
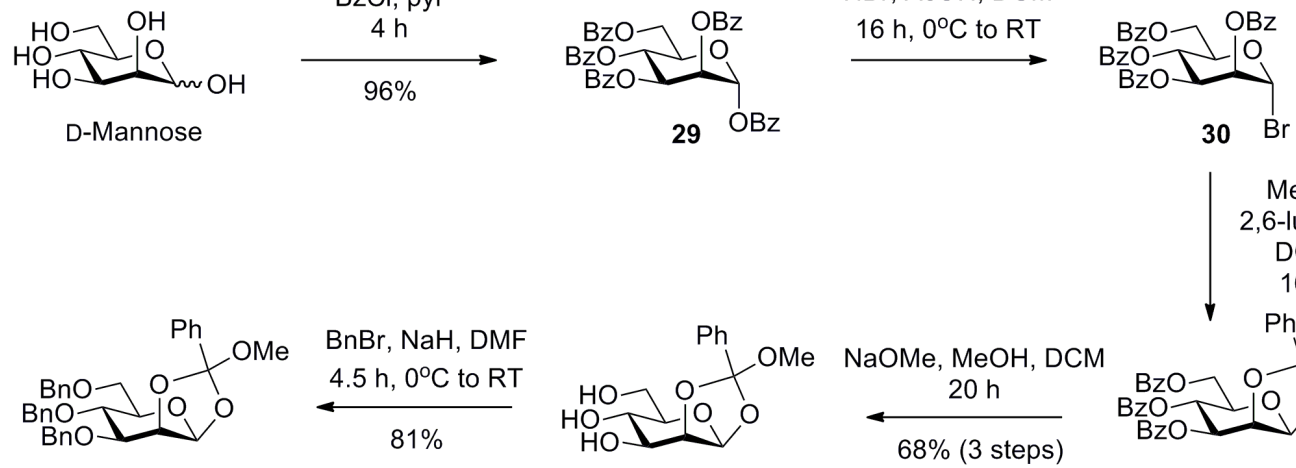

20

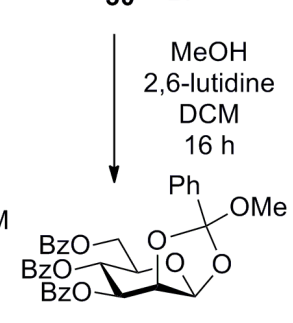

32

31
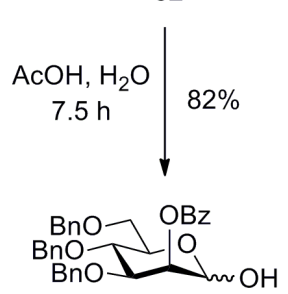

$\mathrm{CNCCl}_{3}, \mathrm{DBU}, \mathrm{DCM}$

33
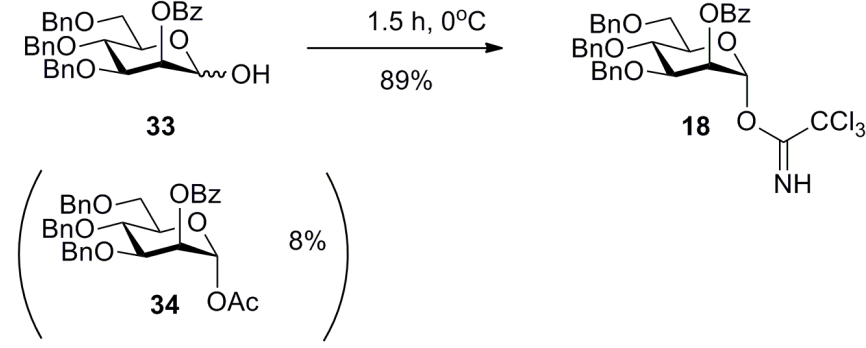

Scheme 8: $\quad$ Seven step synthesis of the mannose imidate building block 18.

\subsubsection{Synthesis of the Mannose Acceptor}

The mannose acceptor 19, required to form the mannose trisaccharide $\mathbf{1 7}$, is accessible in one step from the triol orthoester $\mathbf{2 0}$, an intermediate in the mannose imidate synthesis. It has been shown by members of our group that direct glycosylation of triol orthoester $\mathbf{2 0}$ does not result in the desired trisaccharide. ${ }^{110}$ Instead it results in the formation of the $O$ methyl glycoside of the mannose imidate donor due to the instability of the orthoester in the presence of TMSOTf, which is used as the activator in the bis-glycosylation reaction.

Opening of the 1,2-orthoester of $\mathbf{2 0}$ using camphorsulfonic acid (CSA) in the presence of excess benzyl alcohol resulted in the formation of the $\alpha$-anomeric benzyl protected acceptor $19\left(\delta_{\mathrm{H} 1 \alpha}=5.05, J_{1,2}=1.4 \mathrm{~Hz}\right)$ in $46 \%$ yield (Scheme 9$){ }^{*}$ Successful opening to produce the benzyl glycoside $\mathbf{1 9}$ resulted in the introduction of a characteristic $\mathrm{AB}$ system in the ${ }^{1} \mathrm{H}$ NMR spectrum (1-O-Bn 4.74 and $\left.4.56 \mathrm{ppm}\right)$ as well as the downfield

\footnotetext{
* The mannose acceptor 19 was synthesised from orthoester $\mathbf{2 0}$ in conjunction with a summer research
} student. 
shift of $\mathrm{H}-2$ (from $\delta_{\mathrm{H} 2}=4.74$, to $\delta_{\mathrm{H} 2}=5.40$ ) due to the 2-O-benzoate. The low yield obtained for the opening of the orthoester was surprising as no by-products were observed after aqueous workup, suggesting any by-product formed was water soluble. The low yield is most likely due to presence of water in the reaction resulting in hydrolysis to form lactol 35 (Scheme 9), which with four hydroxyls is likely to be removed during the aqueous workup. The reaction was not repeated as enough of the mannose acceptor 19 was produced. However, if the reaction were to be repeated more care needs to be taken to ensure the reaction is free from water. Although the 1,2orthoester was co-evaporated prior to the reaction, which was done under a nitrogen atmosphere, no precautions were taken to remove water from the benzyl alcohol. The benzyl alcohol should have been either co-evaporated with the 1,2-orthoester (b.p. $(\mathrm{BnOH})=$ $205^{\circ} \mathrm{C}$ ) or distilled prior to use. The addition of molecular sieves would also have been beneficial, as would the use of freshly distilled dichloromethane (DCM) instead of DCM dried over molecular sieves.

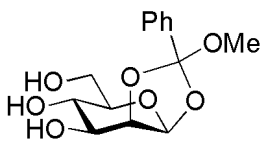

20

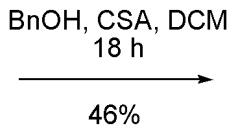

$46 \%$

Scheme 9: $\quad$ Synthesis of the mannose acceptor 19.

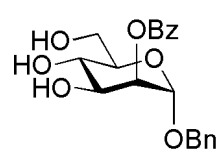

19

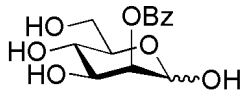

35

\subsubsection{Synthesis of the Mannose Trisaccharide}

With both the mannose imidate donor 18 and the mannose triol acceptor 19 in hand synthesis of the mannose trisaccharide $\left(\mathrm{Man}_{3}\right) 17$ was attempted (Scheme 10). Although the acceptor has three free hydroxyls and only bis-glycosylation is desired it was expected that glycosylation would occur selectively at the C-3 and C-6 hydroxyls. ${ }^{86-90,111}$ The thought was that the more reactive and accessible primary C-6 hydroxyl would react first followed by glycosylation at the more reactive C-3 hydroxyl, in preference of the C4 hydroxyl, as the C-4 hydroxyl is now more sterically hindered and has been shown to be to be inherently unreactive. ${ }^{86,112}$ There is literature precedent for selective $[1 \rightarrow 3]$, $[1 \rightarrow 6]$ bis-glycosylations of mannose acceptors that are only protected at the anomeric 
position with both mannose and other donors. ${ }^{86-90,111}$ Selective glycosylation at O-3 and O-6 is achievable as the C-4 hydroxyl of mannose is inherently unreactive as previously mentioned. ${ }^{86}$ There is also literature precedent that selective $[1 \rightarrow 6]$ mono-glycosylation can be achieved on mannose acceptors that are again only protected at the anomeric position. ${ }^{113}$ In these studies, imidate and bromide donors are the most commonly used and all of the donors have been either acetate or benzoate protected.

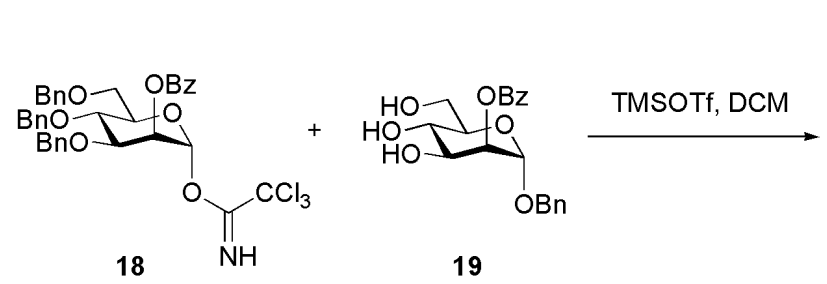

Scheme 10: $\quad$ Synthesis of the mannose trisaccharide 17.

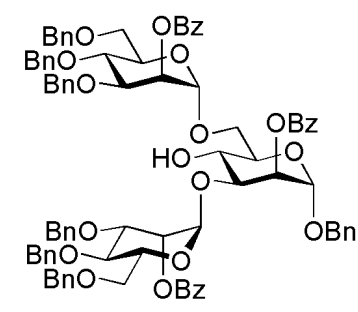

17

The initial attempt at forming trisaccharide $\mathbf{1 7}$ involved the coupling of triol acceptor $\mathbf{1 9}$ with three equivalents of donor 18 using TMSOTf (0.1 equiv.) as the activating agent at $-40^{\circ} \mathrm{C}$. The complete consumption of the triol acceptor was seen after 2 hours by TLC analysis (ethyl acetate/light petroleum ether, 1/1, v/v) so the reaction was quenched with triethylamine. Gradient column chromatography of the crude reaction mixture using both ethyl acetate/light petroleum ether $(1 / 20 \rightarrow 1 / 2, \mathrm{v} / \mathrm{v})$ and $\mathrm{DCM} /$ light petroleum ether $(1 / 3 \rightarrow 1 / 0, v / v)$ columns on silica gel was unsuccessful in purifying the mixture of products produced. It was impossible to determine if any trisaccharide had been produced via interpretation of the ${ }^{1} \mathrm{H}$ NMR spectrum of the inseparable mixture, therefore HRMS(ESI) analysis was obtained, which confirmed the presence of trisaccharide $(\mathrm{m} / \mathrm{z}$ calcld. for $\left[\mathrm{C}_{88} \mathrm{H}_{86} \mathrm{O}_{19}+\mathrm{Na}\right]^{+}:$1469.5661, obsd.: 1469.5651). Although HRMS(ESI) confirmed the presence of trisaccharide it does not provide information on the glycosylation pattern and indeed there may be a mixture of trisaccharides.

As the product mixture of the first reaction was seemingly inseparable it was decided to repeat the glycosylation reaction. This time fewer equivalents of donor (2.7 equiv.) were used but activation conditions were kept the same (0.1 equiv. TMSOTf). The thought was 
that with fewer equivalents of donor the glycosylation would be more regioselective due to the lower concentration of donor present and may result in a more easily separable mixture of products. The second reaction was followed more closely via TLC. This time DCM was used to develop the TLC instead of ethyl acetate/lightpetroleum ether, 1/1, v/v, as it produced better separation of the acceptor and donor as well as the products. After two hours at $-40^{\circ} \mathrm{C}$, TLC analysis (DCM) showed the complete consumption of acceptor and the formation of 2 higher running product spots. TLC analysis after 4 hours at $-40^{\circ} \mathrm{C}$ still showed the presence of two potential product spots. It was assumed that the lower $R_{f}$ product was mono-glycosylated product (most likely glycosylated on the more reactive primary C-6 hydroxyl) and that the higher $R_{f}$ product was bis-glycosylated product. The reaction was therefore allowed to warm to $0^{\circ} \mathrm{C}$ and stirred for a further 3 hours until complete disappearance of the lower $R_{f}$ product was observed. Purification of the reaction mixture was attempted using gradient column chromatography (DCM/light petroleum ether, $1 / 3 \rightarrow 1 / 0, v / v)$. However, this again did not lead to the separation of the mixture of products formed.

As normal phase gradient column chromatography had so far been unsuccessful in the separation of the reaction mixtures, separation using Sephadex ${ }^{\circledR}$ LH-20 size-exclusion chromatography (bead size $25-100 \mu$ ) was attempted. At this stage it was not known which products were present in the inseparable reaction mixture; it was assumed there would be a mixture of mono-, di-, tri-, and potentially tetrasaccharides. Both inseparable reaction mixtures were combined and loaded onto the Sephadex size-exclusion column which was eluted with DCM/methanol, 1/1, v/v. Size-exclusion chromatography did not produce purified trisaccharide; however, hydrolysed donor $\mathbf{3 3}$ was successfully separated from the reaction mixture, which was the last eluted compound from the column. Again all fractions that contained mixtures of products were combined. TLC analysis of this mixture was conducted in order to find a solvent system that gave the best separation. It was found that when the TLC was developed in ethyl acetate/toluene, 1/6, v/v the mixture contained at least four different products. Gradient column chromatography was attempted once again, this time using ethyl acetate/toluene, $1 / 30 \rightarrow 1 / 10$, v/v. The products were again eluted as mixtures and even fractions that appeared to contain one product via 
TLC analysis (ethyl acetate/toluene, 1/6, v/v) were seen to be mixtures via interpretation of their ${ }^{1} \mathrm{H}$ NMR spectra. However to our surprise and relief, the last compound eluted in the 1/10 ethyl acetate/toluene fractions $\left(R_{f} 0.47\right.$ (ethyl acetate/toluene, $\left.\left.1 / 6, \mathrm{v} / \mathrm{v}\right)\right)$ was pure by ${ }^{1} \mathrm{H}$ NMR analysis and appeared to contain three $\alpha$-anomeric protons $\left(\delta_{\mathrm{H} 1 \alpha}=5.37, J_{1,2}=\right.$ $\left.1.7 \mathrm{~Hz}, \delta_{\mathrm{H} 1 \alpha}=5.08, J_{1,2}=1.7 \mathrm{~Hz}, \delta_{\mathrm{H} 1 \alpha}=5.06, J_{1,2}=1.7 \mathrm{~Hz}\right)$. HRMS(ESI) analysis confirmed that it was a trisaccharide produced by the bis-glycosylation of acceptor 19 by donor $18\left(\mathrm{~m} / z\right.$ calcld. for $\left[\mathrm{C}_{88} \mathrm{H}_{86} \mathrm{O}_{19}+\mathrm{Na}\right]^{+}: 1469.5661$, obsd.: 1469.5668$)$ and analysis of the HMBC spectrum confirmed that the pure product was in fact the desired $[1 \rightarrow 3]$, $[1 \rightarrow 6]$ linked mannose trisaccharide 17 (Figure 7). The first fractions eluted from the ethyl acetate/toluene column $\left(R_{f} 0.71\right.$ (ethyl acetate/toluene, 1/6, v/v)) also appeared to be a single compound by TLC analysis, however, the ${ }^{1} \mathrm{H}$ NMR spectrum clearly showed it was a mixture of products. The HRMS(ESI) of this mixture showed it contained both $[1 \rightarrow 1]$ donor-donor coupled by-product $36\left(\mathrm{~m} / z\right.$ calcld. for $\left[\mathrm{C}_{68} \mathrm{H}_{66} \mathrm{O}_{13}+\mathrm{Na}\right]^{+}:$1113.4401, obsd.: 1113.4390) and tetrasaccharide 37 (resulting from tri-glycosylation) $(\mathrm{m} / \mathrm{z}$ calcld. for $\left[\mathrm{C}_{122} \mathrm{H}_{118} \mathrm{O}_{25}+\mathrm{Na}\right]^{+}:$2005.7860, obsd.: 2005.7854) (Scheme 11). The other fractions were not analysed by HRMS(ESI) but did not contain the desired product according to TLC analysis. 


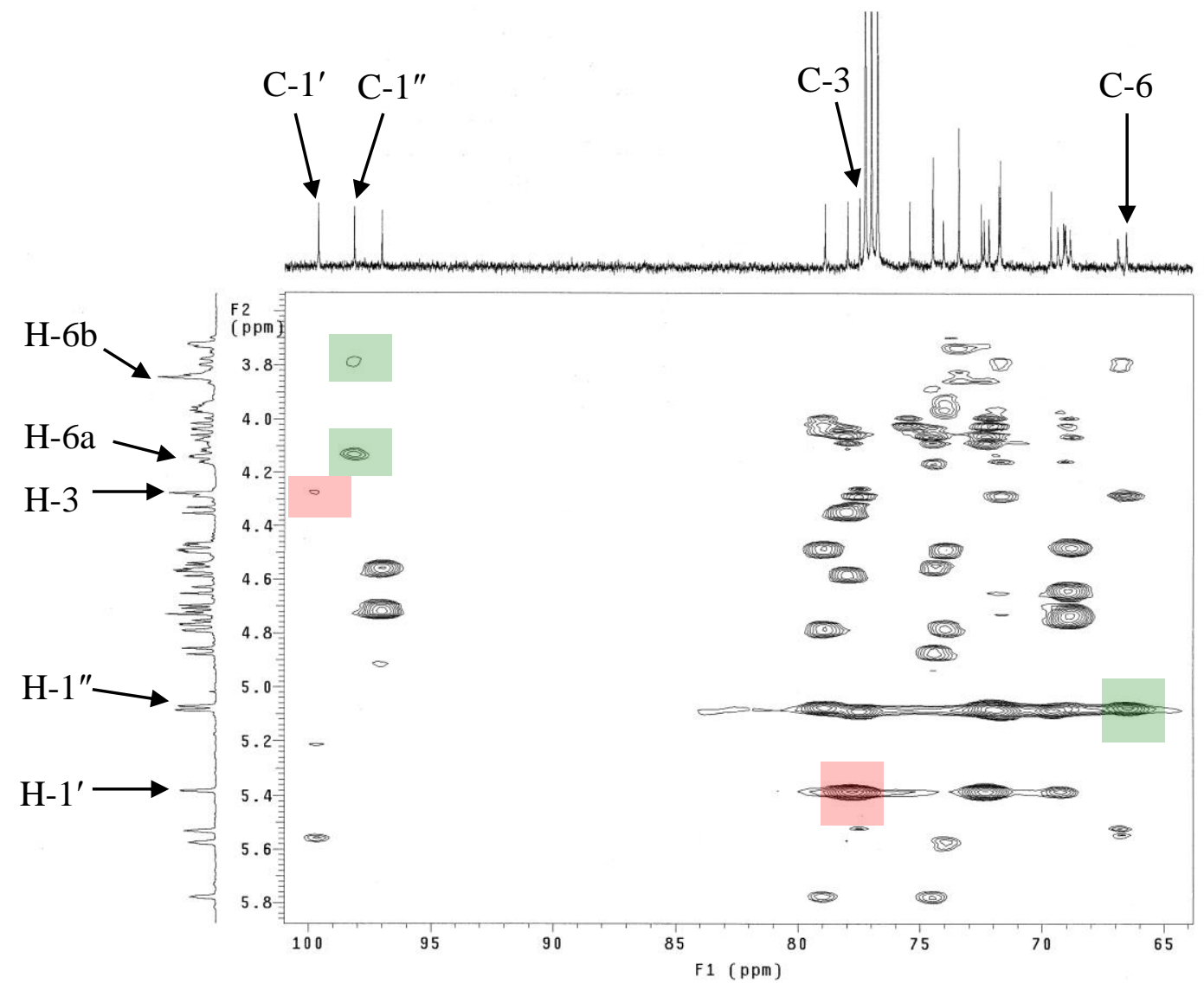

Figure 7: $\quad$ HMBC of the mannose trisaccharide 17 confirming the $[1 \rightarrow 3],[1 \rightarrow 6]$ glycosylation pattern.

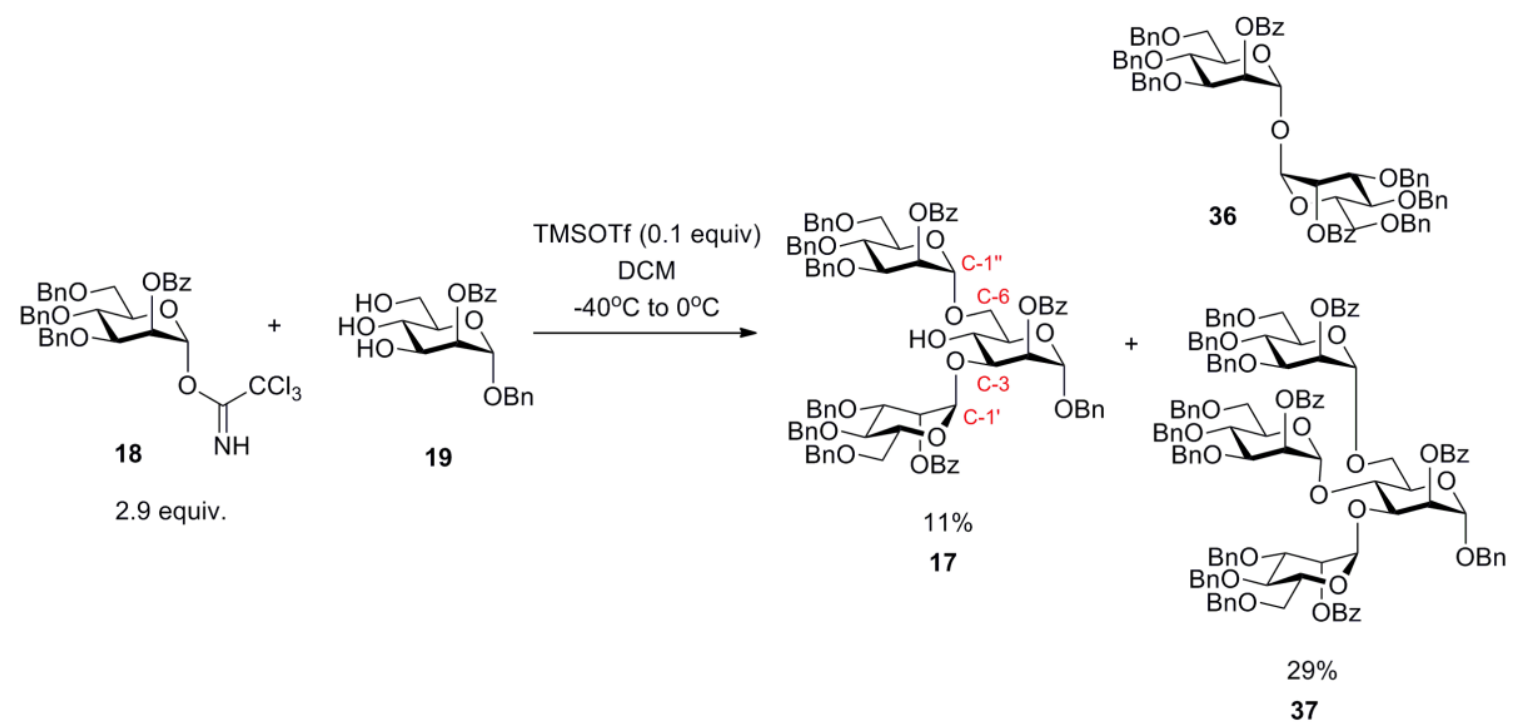

Scheme 11: $\quad$ Products resulting from the mannose trisaccharide coupling reaction. 
The desired product 17 was obtained in a very low yield $(0.097 \mathrm{~g}, 11 \%)$, along with a significant amount of tetrasaccharide $(0.340 \mathrm{~g}, 29 \%)$. However, the selective $[1 \rightarrow 3]$, $[1 \rightarrow 6]$ bis-glycosylations reported in literature also do not have excellent yields and are typically around $30 \%$ with some reported yields as low as $17 \% .^{86-90,111}$ As the amount of trisaccharide 17 that was produced was sufficient for deprotection and subsequent coupling to bead/protein, the selective $[1 \rightarrow 3],[1 \rightarrow 6]$ bis-glycosylation was not attempted again. Selective $[1 \rightarrow 3],[1 \rightarrow 6]$ bis-glycosylation is also not required in the synthesis of the larger heptasaccharide, and other derivatives containing the $\operatorname{Man}_{3}(\mathrm{GlcNAc})_{2}$ pentasaccharide core, as the C-4 hydroxyl of the mannose acceptor (38 or 39) is benzyl protected in the proposed strategy (Scheme 12). 4-O-Benzyl protection is required because once bis-glycosylation has been achieved, the fully protected oligosaccharide (40 or 41) is converted into the corresponding imidate, which requires that the only free hydroxyl be the anomeric hydroxyl at the reducing end of the sugar.

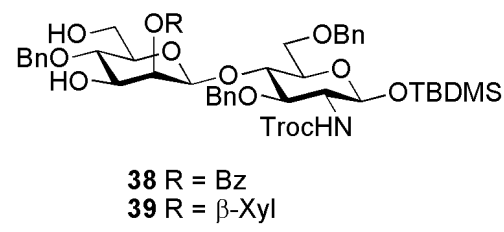
$39 R=\beta-X y l$
TMSOTf, DCM

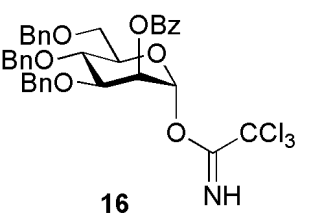

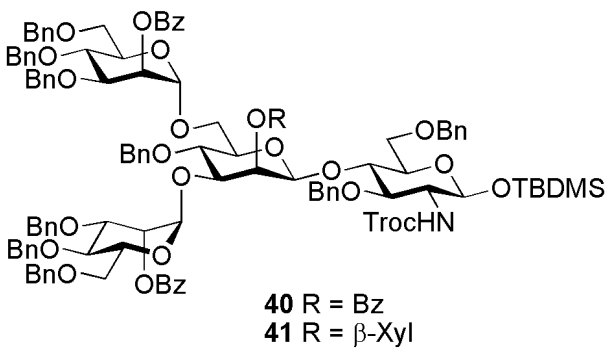

$40 \mathrm{R}=\mathrm{Bz}$
$41 \mathrm{R}=\beta-X y \mid$

Scheme 12: Mannose bis-glycosylation strategy for producing the heptasaccharide and $\mathrm{Man}_{3}(\mathrm{GlcNAc})_{2}$ pentasaccharide core containing derivatives.

However, if the reaction were to be conducted again the amount of donor used would be decreased to two equivalents, to reduce and hopefully prevent the formation of tetrasaccharide. On closer examination of the literature it was discovered that overglycosylation has been observed when more than two equivalents of donor are used. ${ }^{86}$ In the attempted $[1 \rightarrow 3],[1 \rightarrow 6]$ bis-glycosylation it was initially thought that triglycosylation would not occur as once bis-glycosylation had occurred, presumably at the C-3 and C-6 hydroxyls due to literature precedent, the C-4 hydroxyl was deemed to be too sterically crowded to react, as well as the fact that the C-4 hydroxyl in mannose has 
been shown to be inherently unreactive. ${ }^{112}$ This unfortunately was not the case as the yield of tetrasaccharide was nearly three times that of the desired trisaccharide. The highreactivity of the donor used in our attempted bis-glycosylation may also have played a part in the over glycosylation that was observed. The donor we used contained three benzyl groups, as well as the $O$-2-benzoyl group required for neighbouring group participation to give the desired $\alpha$-glycosylation. All of the donors reported in literature used for selective $[1 \rightarrow 3],[1 \rightarrow 6]$ bis-glycosylation of mannose have been either acetate or benzoate protected. Acetates and benzoates are "disarming" protecting groups due to their electron withdrawing nature whereas benzyl protecting groups are "arming" due to their electron donating properties. ${ }^{114}$ Therefore acetate and benzoate protected donors are less reactive than their benzyl protected counterparts as the ring oxygen (O-5) is less able to stabilise the oxacarbenium ion via resonance due to the electron withdrawing groups at C-4 and C-6. ${ }^{114}$ The more reactive benzyl protected donor was designed with production of the heptasaccharide in mind as regio-selectivity is not an issue in the bis-glycosylation and therefore the most reactive donor possible is desired in order to achieve the highest possible yield.

\subsubsection{Deprotection of the Mannose Trisaccharide}

Before the mannose trisaccharide $\mathbf{1 7}$ could be coupled to a bead or a protein it first had to be fully deprotected and then converted into the corresponding anomeric amine. Removal of the three $O$-benzoyl groups was achieved using Zemplén conditions ${ }^{109}$ to give 41 in a 74\% yield (Scheme 13). Removal of the benzoyl groups was seen in the ${ }^{1} \mathrm{H}$ NMR spectrum of 41 by the upfield shift of the three H-2 resonances from $\delta 5.77,5.57$, and 5.52 in the benzoylated starting material to $\delta 4.19-4.18(\mathrm{~m}), 4.19-4.18(\mathrm{~m})$, and 4.07$4.04(\mathrm{~m})$ in the deprotected product. Although the removal of all 3 benzoyl groups was slow and required three days to go to completion, the reaction was easily monitored with the di- and mono- benzoylated intermediates distinguishable via TLC analysis $\left(R_{f} 0.34\right.$ and 0.13 respectively (ethyl acetate/light petroleum ether, 1/2, v/v) ). It should be noted that extra care should be taken to ensure that the reaction does not become too basic when debenzoylation is attempted on the larger structures which contain the $\mathrm{Man}_{3}(\mathrm{GlcNAc})_{2}$ 
pentasaccharide core. Alkali degradation of polysaccharides is a well known process and although it is rarely seen in fully protected structures, ${ }^{115}$ Nagorny et al. $^{77}$ have recently reported that degradation was observed during de-acetylation of their dodecasaccharide 43 which contains the $\operatorname{Man}_{3}\left(\mathrm{GlcNHPhSO}_{2}\right)_{2}$ pentasaccharide core (Scheme 14). When using $\mathrm{NaOH}$ for de-acetylation they observed a significant amount of cleavage of either the Man $[1 \rightarrow 4] \mathrm{Glc}\left(\mathrm{NHPhSO}_{2}\right)$ (to give 44) or the $\mathrm{GlcNHPhSO}_{2}[1 \rightarrow 4] \mathrm{GlcNHPhSO}_{2}$ (to give 45) linkages present in the core pentasaccharide. They reported that formation of these "peeling reaction" by-products was "drastically reduced" when NaOMe was used instead of $\mathrm{NaOH}$ in the de-acetylation.

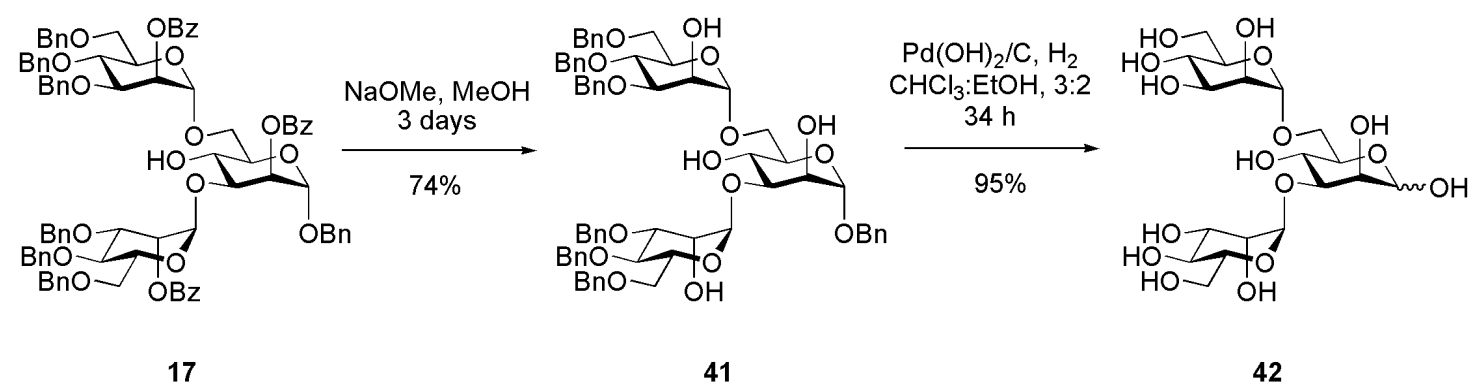

Scheme 13: Deprotection of the mannose trisaccharide 17, resulting in the fully deprotected mannose trisaccharide $\mathbf{4 2}$.
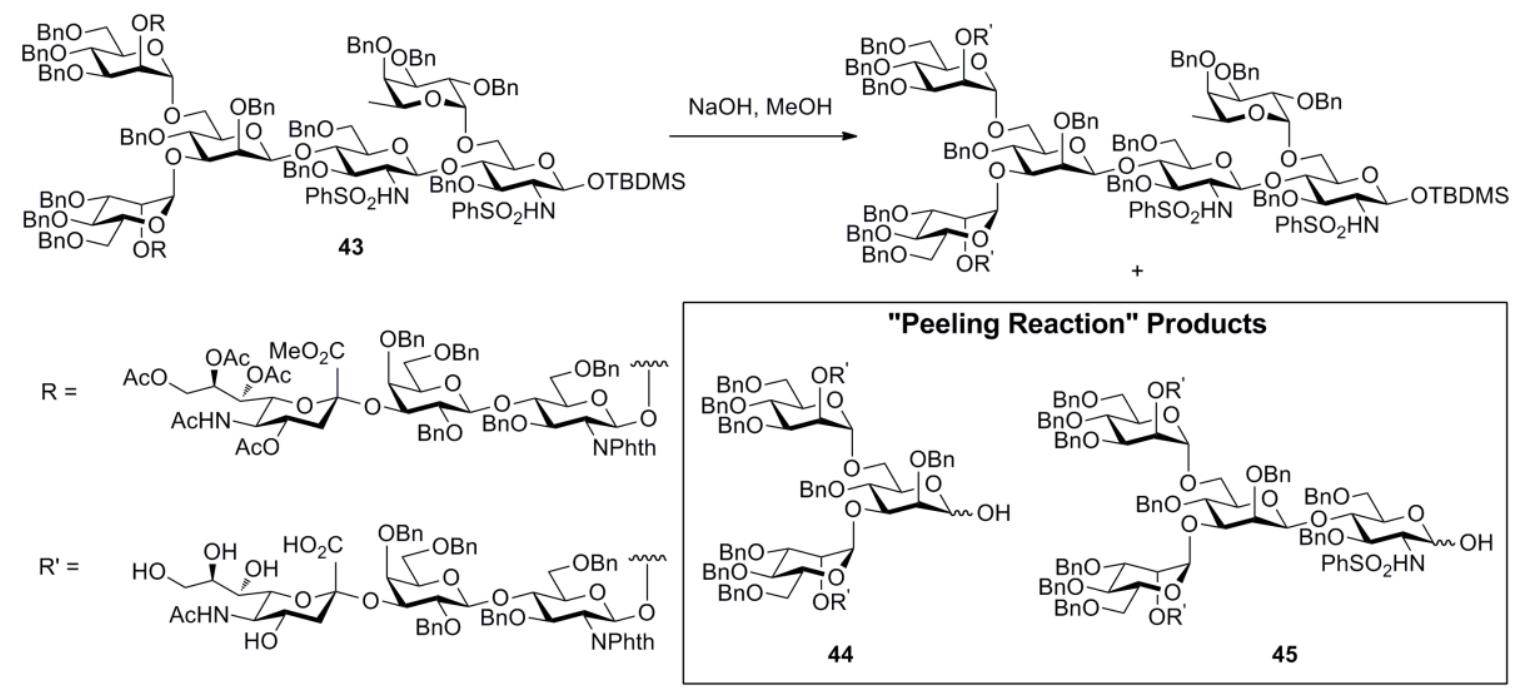

Scheme 14: Reported de-acetylation of dodecasaccharide $\mathbf{4 3}$ using $\mathrm{NaOH}$ by Nagorny et al. ${ }^{77}$, which resulted in the formation of the peeling reaction by-products 44 and 45 formed by cleavage of the Man $[1 \rightarrow 4]$ Glc $\left(\mathrm{NHPhSO}_{2}\right)$ or the $\mathrm{GlcNHPhSO}_{2}[1 \rightarrow 4] \mathrm{GlcNHPhSO}_{2}$ linkage respectively. 
The $O$-benzyl groups of $\mathbf{4 1}$ were then successfully removed via hydrogenation using $\mathrm{Pd}(\mathrm{OH})_{2} / \mathrm{C}$ in $\mathrm{CHCl}_{3}$ : EtOH, 3:2 to give fully deprotected mannose trisaccharide 42, which was purified using $\mathrm{C}_{18}$ reverse phase chromatography resulting in a $95 \%$ yield (Scheme 13). The fully deprotected product was confirmed by the absence of all aromatic and benzyl $\mathrm{AB}$ system protons in the ${ }^{1} \mathrm{H}$ NMR spectrum of $\mathbf{4 2}$ as well as HRMS(ESI) confirming the product was the correct molecular weight $(\mathrm{m} / \mathrm{z}$ calcld. for $\left[\mathrm{C}_{18} \mathrm{H}_{32} \mathrm{O}_{16}+\mathrm{Na}\right]^{+}:$527.1588, obsd.: 527.1594). The deprotected trisaccharide 42 was freeze dried from water in order to remove any excess traces of solvent in preparation of anomeric amine formation, resulting in $\mathbf{4 2}$ as a white amorphous powder.

\subsection{Synthesis of the FucGlcNAc Disaccharide}

\subsubsection{Synthesis of the Thiofucose Building Block}

Synthesis of the thiofucose building block 22 was achieved in five steps from L-fucose following modified literature procedures (Scheme 15). ${ }^{102,103}$ Firstly, L-fucose was peracetylated using acetic anhydride-pyridine in accordance with Ruttens et al.'s procedure. $^{103}$ Acetic anhydride-pyridine was used for acetylation as Ruttens et al. reported excessive furanose formation ( $c a .30 \%$ based on TLC observations) when they used Ichikawa et al.'s ${ }^{116}$ method involving acetic anhydride-NaOAc. Acetylation proceeded smoothly resulting in the formation of both $\alpha$ and $\beta$ per-acetylated fucopyranoses 46 in a 1:2 ratio respectively, based on integration of ${ }^{1} \mathrm{H}$ NMR signals $\left(\delta_{\mathrm{H} 1 \alpha}=6.34, J_{1,2}=2.7 \mathrm{~Hz}\right.$ and $\left.\delta_{\mathrm{H} 1 \beta}=5.68, J_{1,2}=8.3 \mathrm{~Hz}\right)$. The formation of minor amounts of $\alpha$ and $\beta$ per-acetylated fucofuranoses (total $c a$. $12 \%$, based on integration in ${ }^{1} \mathrm{H}$ NMR spectrum, $\delta_{\mathrm{H} 1 \beta}=6.31, J_{1,2}=4.6 \mathrm{~Hz}$ and $\delta_{\mathrm{H} 1 \alpha}=6.19, J_{1,2}=0 \mathrm{~Hz}$ ) was also observed via ${ }^{1} \mathrm{H}$ NMR. The percentage of furanose products formed is in accordance with that obtained by Ruttens et al. (ca. 7\%, based on ${ }^{1} \mathrm{H}$ NMR) when using acetic anhydride-pyridine. The crude acetylated product was treated with $\mathrm{HBr}$ in acetic acid, resulting in the formation of the $\alpha$-bromide $47\left(\delta_{\mathrm{H} 1 \alpha}=6.69, J_{1,2}=3.9 \mathrm{~Hz}\right)$. The bromide was used without purification in a two step one pot procedure to convert the anomeric bromide into the corresponding 
ethyl thiofucoside followed by de-acetylation to afford $\beta$-thiofucoside $\mathbf{4 8}$. Triol $\mathbf{4 8}$ was purified by column chromatography, which removed any furanose by-products, and recrystallised from diethyl ether resulting in a 68\% yield over the 4 steps (Scheme 15). Benzylation of triol $\mathbf{4 8}$ produced the $\beta$-thiofucose building block 22 as a colourless oil, which was crystallised from light petroleum ether to give white needle-like crystals (82\% yield) $\left(\delta_{\mathrm{H} 1 \beta}=4.40, J_{1,2}=9.8 \mathrm{~Hz}\right)$. The synthesis of the fucose building block 22 was completed in $56 \%$ yield over five steps from L-fucose. The spectral data for the thiofucoside 22 is in accordance with literature. ${ }^{117}$

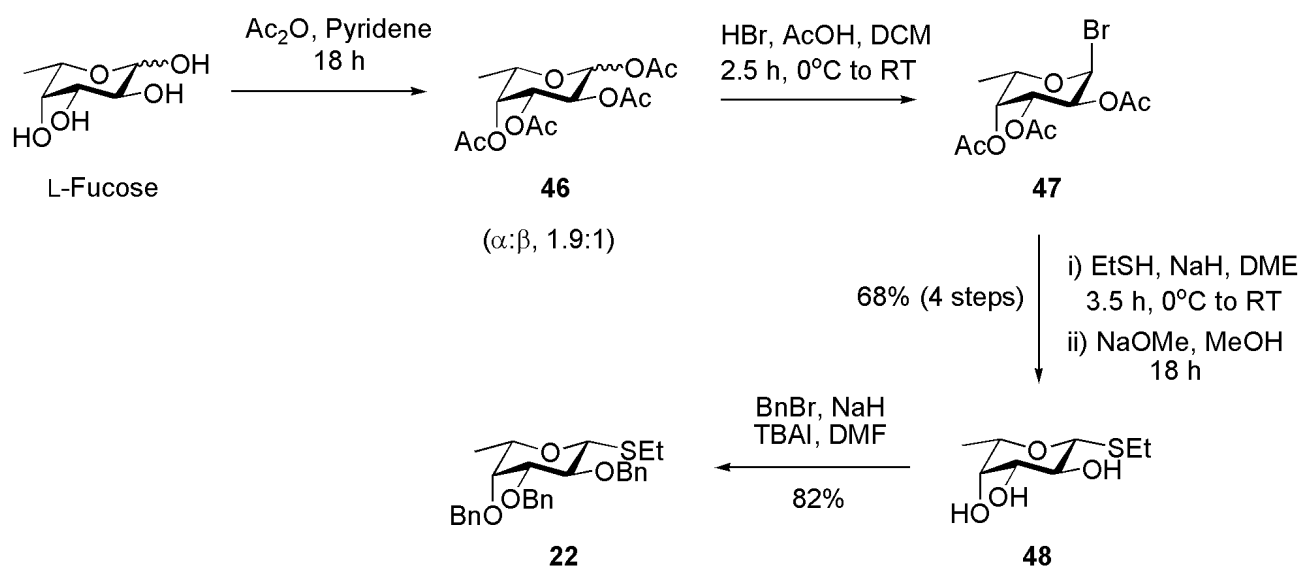

Scheme 15: $\quad$ Synthesis of thiofucose building block 22 .

\subsubsection{Synthesis of the FucGlcNAc Disaccharide}

With the thiofucose building block $\mathbf{2 2}$ and the previously prepared glucosazide building block 23 (synthesised in 6 steps from D-glucose, 39\%) ${ }^{118}$ in hand, formation of the $\alpha-1,3-$ linked FucGlcNAc disaccharide 21 was attempted (Scheme 16). The $\alpha$-1,3-linked FucGlcNAc disaccharide $\mathbf{2 1}$ had been previously synthesised by the candidate during his Honours research project. However, the reaction had not been optimised and a large excess of donor was required in order to achieve an adequate yield and selectivity (2.6 equiv. donor, $74 \%, \alpha: \beta=20.5: 1$ ). The use of a large excess of donor in glycosidation reactions, although not uncommon, is not desirable in this particular coupling reaction given the high cost of L-fucose in combination with the amount of disaccharide $\mathbf{2 1}$ needed for the production of the heptasaccharide and all its truncated analogues. 


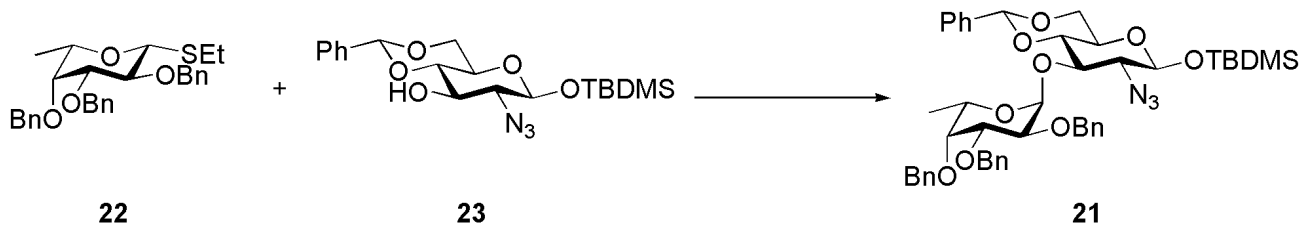

Scheme 16: Reaction of thiofucose donor 22 with glucosazide acceptor 23 to form the FucGlcNAc disaccharide 21. Reaction conditions are given in Table 1.

Though several conditions have been reported in the literature for the formation of $\alpha$ linked FucGlcNAc substrates, via the glycosylation between a suitably protected glucose acceptor and a thiofucose donor, the formation of an $\alpha$-fucosyl linkage is not always straightforward, with literature yields varying from $26 \%$ to $99 \% .{ }^{98,119}$ The difficulties encountered are often attributed to the increased acid lability of the $\alpha$-fucosyl linkage. ${ }^{72,100,101}$ It has been found that ether-type (e.g. benzyl) protected fucose residues show an increased acid lability over unprotected or acetate protected fucose residues $;{ }^{72}$ however for the formation of an $\alpha$-linkage a non-participatory (e.g. ether) group at the C2 position of the fucose donor is mandatory. The enhanced lability of ether protected fucose residues is due to the ability of the ether groups to stabilise the positive charge of the glycosyl cation through inductive effects. The alpha selectivity of the glycosidation reaction is due to the anomeric effect which is especially strong for fucosides due to the absence of the 6-hydroxyl.

The initial attempts at forming the $\alpha-1,3$-linked FucGlcNAc disaccharide 21 during the candidate's Honours project involved activation of the thiol donor using triflic acid (TfOH) and $N$-iodosuccinimide (NIS) (Table 1, Entries 1-2). ${ }^{96,98}$ Although these activation conditions resulted in product formation, the yield and selectivity were rather disappointing ( $33 \%, \alpha: \beta=1.3: 1)$. The $\alpha$-1,3-linkage was confirmed via the HMBC spectrum which showed coupling between $\mathrm{C}-1^{\prime}$ of the fucose (97.6 ppm) and $\mathrm{H}-3$ of the glucose $(3.73 \mathrm{ppm})$ and also between the $\mathrm{H}-1^{\prime}$ of the fucose $\left(5.39 \mathrm{ppm}, \mathrm{d}, J_{1,2}=3.9 \mathrm{~Hz}\right.$,) and C-3 of the glucose (74.2 ppm); the molecular mass was confirmed by HRMS(ESI) $\left(\mathrm{m} / z\right.$ calcld. for $\left[\mathrm{C}_{46} \mathrm{H}_{57} \mathrm{O}_{9} \mathrm{~N}_{3} \mathrm{Si}+\mathrm{Na}\right]^{+}:$846.3762, obsd.: 846.3765). Unreacted acceptor was also recovered from these reactions (31\%), however, no unreacted donor was recovered and there was a large amount of degradation observed via TLC analysis. The 
low yield and decomposition were thought to be due to the acidic reaction conditions given the lability of the $\alpha$-fucosyl linkage in acidic conditions. Therefore of the two other possible activation conditions the milder $\mathrm{CuBr}_{2}, \mathrm{Bu}_{4} \mathrm{NBr}$ activation (Ogawa conditions) ${ }^{93}$ were chosen to be investigated over methyl trifluoromethanesulfonate activation. ${ }^{99}$ The use of Ogawa activation conditions resulted in an increase in both the yield and selectivity of the reaction. The best yield $(74 \%)$ and selectivity $(\alpha: \beta=20.5: 1)$ were obtained during a small scale reaction (53 mg acceptor, $161 \mathrm{mg}$ donor) (1\% acceptor recovered) (Entry 4). However, the high yield and selectivity were achieved via the use of a large excess of donor (2.6 equiv.), and when the reaction was done with only 1.1 equivalents of donor (104 mg acceptor, $129 \mathrm{mg}$ donor) the yield was only 50\% and selectivity was reduced ( $\alpha: \beta=13.1: 1)$ (44\% acceptor recovered) (Entry 3 ). The yield and selectivity $(59 \%, \alpha: \beta=7.6: 1)$ were also significantly compromised when the reaction was conducted on a large scale ( $0.651 \mathrm{~g}$ acceptor, $1.235 \mathrm{~g}$ donor), using a moderate and acceptable excess of donor (1.6 equiv.) (34\% acceptor recovered) (Entry 5). Therefore, during this Masters project a way of producing gram quantities of the $\alpha-1,3$-linked FucGlcNAc disaccharide 21 in good yields and selectivity, whilst using a moderate excess of donor, was required. 
Table 1: Initial attempts at forming the FucGlcNAc disaccharide 21. All reactions in this table were conducted during the candidate's Honours project.

\begin{tabular}{|c|c|c|c|c|c|c|}
\hline \multirow[t]{2}{*}{ Entry } & \multirow{2}{*}{$\begin{array}{c}\text { Reaction } \\
\text { Conditions }\end{array}$} & \multirow{2}{*}{$\begin{array}{c}\text { Time of } \\
\text { Reaction }\end{array}$} & \multicolumn{2}{|c|}{ Equivalents } & \multirow[t]{2}{*}{ Yield $^{2}$} & \multirow{2}{*}{$\begin{array}{c}\text { Ratio }^{3} \\
\alpha: \beta\end{array}$} \\
\hline & & & Acceptor & Donor & & \\
\hline 1. & $\begin{array}{c}\text { NIS, TfOH }(0.1 \\
\text { equiv. }), \mathrm{DCM}, \\
0^{\circ} \mathrm{C}\end{array}$ & 2 hours & $\begin{array}{c}1 \\
0.1009 \mathrm{~g}\end{array}$ & $\begin{array}{c}1.1 \\
0.1245 \mathrm{~g}\end{array}$ & $\begin{aligned} \text { product: } & 0.0581 \mathrm{~g} \\
& (28 \%) \\
\text { acceptor: } & 0.0289 \mathrm{~g} \\
& (29 \%)\end{aligned}$ & $1.5: 1$ \\
\hline 2. & $\begin{array}{c}\text { NIS, TfOH }(0.1 \\
\text { equiv. }), \mathrm{DCM}, \\
0^{\circ} \mathrm{C},\end{array}$ & $20 \mathrm{~min}$ & $\begin{array}{c}1 \\
0.0859 \mathrm{~g}\end{array}$ & $\begin{array}{c}1.1 \\
0.1060 \mathrm{~g}\end{array}$ & $\begin{aligned} \text { product: } & 0.0568 \mathrm{~g} \\
& (33 \%) \\
\text { acceptor: } & 0.0267 \mathrm{~g} \\
& (31 \%)\end{aligned}$ & $1.3: 1$ \\
\hline 3. & $\begin{array}{c}\mathrm{Et}_{4} \mathrm{NBr}, \mathrm{CuBr}_{2}, \\
\mathrm{DMF}: \mathrm{DCM} \\
(1: 1), \mathrm{RT}\end{array}$ & 48 hours & $\begin{array}{c}1 \\
0.1044 \mathrm{~g}\end{array}$ & $\begin{array}{c}1.1 \\
0.1287 \mathrm{~g}\end{array}$ & $\begin{aligned} \text { product: } & 0.1054 \mathrm{~g} \\
& (50 \%) \\
\text { acceptor: } & 0.0460 \mathrm{~g} \\
& (44 \%)\end{aligned}$ & $13.1: 1$ \\
\hline 4. & $\begin{array}{c}\mathrm{Et}_{4} \mathrm{NBr}, \mathrm{CuBr}_{2}, \\
\mathrm{DMF}: \mathrm{DCM} \\
(1: 1), \mathrm{RT}\end{array}$ & 48 hours & $\begin{array}{c}1 \\
0.0529 \mathrm{~g}\end{array}$ & $\begin{array}{c}2.6 \\
0.1605 \mathrm{~g}\end{array}$ & $\begin{aligned} \text { product: } & 0.0795 \mathrm{~g} \\
& (74 \%) \\
\text { acceptor: } & 0.0006 \mathrm{~g} \\
& (1 \%)\end{aligned}$ & $20.5: 1$ \\
\hline 5. & $\begin{array}{c}\mathrm{Et}_{4} \mathrm{NBr}, \mathrm{CuBr}_{2}, \\
\mathrm{DMF}: \mathrm{DCM} \\
(1: 1), \mathrm{RT}\end{array}$ & 72 hours & $\begin{array}{c}1 \\
0.6507 \mathrm{~g}\end{array}$ & $\begin{array}{c}1.6 \\
1.2350 \mathrm{~g}\end{array}$ & $\begin{aligned} \text { product: } & 0.7813 \mathrm{~g} \\
& (59 \%) \\
\text { acceptor: } & 0.2180 \mathrm{~g} \\
& (34 \%)\end{aligned}$ & $7.6: 1$ \\
\hline
\end{tabular}

All reactions used type 4A molecular sieves (MS) that were only activated by heating. Room temperature (RT), dichloromethane (DCM), dimethylformamide (DMF).

${ }^{2}$ Product yields combined $\alpha$ and $\beta$.

${ }^{3} \alpha: \beta$ ratio based on the integration values for ${ }^{1} \mathrm{H}$ NMR signals.

With the isolation of hydrolysed donor and the recovery of unreacted acceptor from the glycosylation reactions it was thought that the variable yields and selectivities were due to the presence of water in the reaction mixture. Complete consumption of the donor was always observed via TLC analysis and no unreacted donor was ever recovered from the previous reactions (Table 1). With this in mind the reaction was repeated changing various factors with an effort to reduce the amount of water present. The amount of donor added was always kept between 1.6 and 1.8 equivalents.

Previously the molecular sieves, which were added to the reaction in order to absorb any water present, had only been activated (removal of absorbed water) by heating. It was thought that heating alone may not have been sufficient to properly activate the molecular sieves, therefore resulting in the introduction of water to the reaction. The reaction was therefore attempted using molecular sieves that had been activated by heating under 
vacuum. This unfortunately did not result in an increased yield (42\%, $\alpha: \beta=17: 1)$ and unreacted acceptor was again isolated (29\%) along with the observation of hydrolysed donor via TLC analysis (Table 2, Entry 1). The coupling reaction was repeated without molecular sieves in order to determine whether they were a source of water. The reaction with no molecular sieves did not result in product formation and a lot of degradation was observed via TLC analysis (Table 2, Entry 2). From this it was obvious that the molecular sieves were vital in decreasing the amount of water in the reaction solution, present from other sources, to a level where product formation was possible.

Table 2: $\quad$ Attempts at forming the FucGlcNAc disaccharide 21. All reactions in this table were conducted during the candidate's Masters project.

\begin{tabular}{|c|c|c|c|c|c|c|}
\hline \multirow[t]{2}{*}{ Entry } & \multirow{2}{*}{$\begin{array}{c}\text { Reaction } \\
\text { Conditions }\end{array}$} & \multirow{2}{*}{$\begin{array}{l}\text { Time of } \\
\text { Reaction }\end{array}$} & \multicolumn{2}{|c|}{ Equivalents } & \multirow[t]{2}{*}{ Yield $^{2}$} & \multirow{2}{*}{$\begin{array}{c}\text { Ratio }^{3} \\
\alpha: \beta\end{array}$} \\
\hline & & & Acceptor & Donor & & \\
\hline 1. & $\begin{array}{c}\mathrm{Et}_{4} \mathrm{NBr}, \mathrm{CuBr}_{2}, \\
\mathrm{MS}\end{array}$ & 50 hours & $\begin{array}{c}1 \\
0.2463 \mathrm{~g}\end{array}$ & $\begin{array}{c}1.7 \\
0.4822 \mathrm{~g}\end{array}$ & $\begin{aligned} \text { product: } & 0.2076 \mathrm{~g} \\
& (28 \%) \\
\text { acceptor: } & 0.0705 \mathrm{~g} \\
& (29 \%)\end{aligned}$ & $17.0: 1$ \\
\hline 2. & $\mathrm{Et}_{4} \mathrm{NBr}, \mathrm{CuBr}_{2}$ & 48 hours & $\begin{array}{c}1 \\
0.0200 \mathrm{~g}\end{array}$ & $\begin{array}{c}1.8 \\
0.0423 \mathrm{~g}\end{array}$ & $\begin{array}{c}\text { product: } 0 \mathrm{~g} \\
(0 \%) \\
\text { acceptor: } \operatorname{not} \\
\text { calculated }\end{array}$ & N/A \\
\hline 3. & $\begin{array}{c}\mathrm{Pr}_{4} \mathrm{NBr}, \mathrm{CuBr}_{2}, \\
\text { (added in } \\
\text { solution), } \\
\text { Crushed MS }\end{array}$ & 72 hours & $\begin{array}{c}1 \\
0.4557 \mathrm{~g}\end{array}$ & $\begin{array}{c}1.8 \\
0.9625 \mathrm{~g}\end{array}$ & $\begin{array}{c}\text { product: } 0.3879 \mathrm{~g} \\
(42 \%) \\
\text { acceptor: } 0.1940 \mathrm{~g} \\
(43 \%) \\
\text { donor: } 0.3861 \mathrm{~g} \\
(40 \%)\end{array}$ & $19.5: 1$ \\
\hline 4. & $\begin{array}{c}\mathrm{Pr}_{4} \mathrm{NBr}, \mathrm{CuBr}_{2}, \\
\text { (added in } \\
\text { solution), } \\
\text { MS }\end{array}$ & 60 hours & $\begin{array}{c}1 \\
0.5193 \mathrm{~g}\end{array}$ & $\begin{array}{c}1.8 \\
1.0897 \mathrm{~g}\end{array}$ & $\begin{array}{c}\text { product: } 0.7213 \mathrm{~g} \\
(69 \%) \\
\text { acceptor: not } \\
\text { calculated }\end{array}$ & $16.7: 1$ \\
\hline 5. & $\begin{array}{c}\mathrm{Pr}_{4} \mathrm{NBr}, \mathrm{CuBr}_{2}, \\
\mathrm{MS}\end{array}$ & 60 hours & $\begin{array}{c}1 \\
0.1405 \mathrm{~g}\end{array}$ & $\begin{array}{c}1.8 \\
0.2970 \mathrm{~g}\end{array}$ & $\begin{array}{c}\text { product: } 0.2295 \mathrm{~g} \\
(81 \%) \\
\text { acceptor: non } \\
\text { isolated }\end{array}$ & $19.2: 1$ \\
\hline 6. & $\begin{array}{c}\mathrm{Pr}_{4} \mathrm{NBr}, \mathrm{CuBr}_{2}, \\
\mathrm{MS}\end{array}$ & 50 hours & $\begin{array}{c}1 \\
0.4726 \mathrm{~g}\end{array}$ & $\begin{array}{c}1.6 \\
0.8664 \mathrm{~g}\end{array}$ & 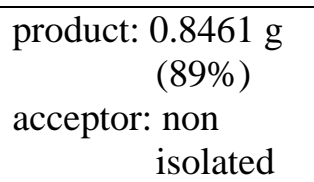 & $22.3: 1$ \\
\hline
\end{tabular}

\footnotetext{
All reactions were conducted at room temperature in DCM/DMF, 1/1, v/v. If molecular sieves (MS) were used in the reaction they were type $4 \mathrm{~A}$ and were activated by heating under vacuum.

${ }^{2}$ Product yields combined $\alpha$ and $\beta$.

${ }^{3} \alpha: \beta$ ratio based on the integration values for ${ }^{1} \mathrm{H}$ NMR signals.
} 
The reaction solvent is a potential source of water contamination. Ogawa conditions employ a mixture of dichloromethane (DCM) and dimethylformamide (DMF) as the reaction solvent. It was thought that the DMF was not a source of water as the donor and acceptor were co-evaporated together with DMF and on the final co-evaporation only half of the DMF is evaporated leaving the DMF used for the reaction. Any water present in the DMF should be removed in this half co-evaporation as DMF has a significantly higher boiling point than water (b.p. of $\mathrm{DMF}=153^{\circ} \mathrm{C}$ ). The $\mathrm{DCM}$ used thus far in the coupling reactions had been dried by storage over molecular sieves. As this drying method is potentially inadequate for glycosylation reactions the DCM used in subsequent reactions (Table 2, Entries 3-6) was instead freshly distilled over phosphorus pentoxide before use.

The activators are also another possible source of water introduction, both via their absorption of water and also when they are added to the reaction flask as they are both solids and are added sequentially $\left(\mathrm{Et}_{4} \mathrm{NBr}\right.$ followed by $\mathrm{CuBr}_{2}$ an hour later) after the donor and acceptor have been pre-stirred with molecular sieves for an hour. In all the previously conducted reactions $\mathrm{Et}_{4} \mathrm{NBr}$ had been used instead of the more commonly used $\mathrm{Bu}_{4} \mathrm{NBr}$ due to availability. The $\mathrm{Et}_{4} \mathrm{NBr}$ used was not fine white crystals as expected and instead it had agglomerated, indicating the potential absorption of water. Therefore the potentially wet $\mathrm{Et}_{4} \mathrm{NBr}$ was replaced with $\mathrm{Pr}_{4} \mathrm{NBr}$ from a freshly opened bottle. The $\mathrm{CuBr}_{2}$ was not thought to be a potential source of water as it was fine greyish black crystals as expected and it was observed that when $\mathrm{CuBr}_{2}$ absorbed atmospheric water it dissolved resulting in a green solution.

The reaction was once again repeated, this time using freshly distilled DCM and the newly opened $\mathrm{Pr}_{4} \mathrm{NBr}$. The molecular sieves were crushed prior to activation by heating under vacuum to give them a greater surface area and enable them to absorb more water. The $\mathrm{Pr}_{4} \mathrm{NBr}$ and $\mathrm{CuBr}_{2}$ were added in solution via a needle in an effort to reduce water as the septum had to be removed to add them as solids. They were co-evaporated together with DMF, dissolved in DCM, and stirred with crushed activated molecular sieves prior to addition. With the measures taken to ensure the reaction was as dry as possible the 
yield was expected to be significantly higher. Surprisingly, the yield was still only $42 \%$ $(\alpha: \beta=19.5: 1)$, however, unreacted donor (40\%) was recovered for the first time, as well as unreacted acceptor (43\%) (Table 2, Entry 3), indicating that the amount of water present in the reaction had been significantly reduced and the low yield was due to incomplete reaction rather than hydrolysis of the donor. The incomplete activation of donor was thought to be due to insufficient activator being added. Although 3.2 equivalents of both $\operatorname{Pr}_{4} \mathrm{NBr}$ and $\mathrm{CuBr}_{2}$ were used, as in all previous reactions, not all of the activator was transferred to the reaction flask due to the crushed molecular sieves. Some of the activator adhered to the crushed molecular sieves, which could not be transferred via syringe. During the reaction it was also observed that the usual deep purple black colour of the reaction solution faded, potentially indicating that the crushed molecular sieves were detrimental to activation. The reaction was repeated with the use of non-crushed molecular sieves, both in the reaction flask and pre-drying of the activators, whilst keeping the other reaction conditions constant. This resulted in the expected increase in yield $(69 \%)$ whilst selectivity was relatively unchanged $(\alpha: \beta=$ 16.7:1) (Table 2, Entry 4).

The use of both freshly distilled DCM and dry $\mathrm{Pr}_{4} \mathrm{NBr}$, instead of potentially wet $\mathrm{Et}_{4} \mathrm{NBr}$, were thought to be the main contributing factors for the increase in yield rather than the addition of the reagents in solution via a needle. To prove this the reaction was repeated with activated molecular sieves but this time both $\mathrm{Pr}_{4} \mathrm{NBr}$ and $\mathrm{CuBr}_{2}$ were added as solids, maintaining a flow of nitrogen over the flask while the septum was lifted for addition. Our hypothesis was confirmed and the yield increased to $81 \%$ whilst maintaining good selectivity $(\alpha: \beta=19.2: 1)$ (Table 2, Entry 5). The increase in yield suggests that the co-evaporation and drying with molecular sieves actually increased the amount of water added to the reaction rather than reducing it. The reaction was repeated on a larger scale ( $0.47 \mathrm{~g}$ acceptor, $0.89 \mathrm{~g}$ donor, 1:1.6) using these reaction conditions which again resulted in an increase in yield (89\%) and also gave slightly greater selectivity ( $\alpha: \beta=22.3: 1)$ (Table 2, Entry 6). 
The reaction conditions were successfully optimised to enable synthesis of the $\alpha-1,3$ linked FucGlcNAc disaccharide in an excellent yield and selectivity on both small and large scale.

The $\alpha$ and $\beta$ anomers were separated by column chromatography (ethyl acetate/light petroleum ether, 1/17, v/v). Although they are indistinguishable via TLC, as they have the same $R_{f}\left(R_{f}=0.52\right.$, ethyl acetate/light petroleum ether, $1 / 5$, v/v), the $\beta$ anomer is eluted before the $\alpha$ anomer. Fractions must be individually analysed by ${ }^{1} \mathrm{H}$ NMR in order to determine the $\alpha: \beta$ ratio and therefore which fractions should be combined. Unfortunately unreacted acceptor $\left(R_{f}=0.36\right.$, ethyl acetate/light petroleum ether, $\left.1 / 5, \mathrm{v} / \mathrm{v}\right)$ was also co-eluted with the $\alpha$ and $\beta$ anomers in the ethyl acetate/light petroleum ether, $1 / 17, \mathrm{v} / \mathrm{v}$ fractions which is surprising given their difference in $R_{f}$ values. If there was unreacted acceptor present in the crude reaction mixture Sephadex ${ }^{\circledR}$ LH-20 size exclusion chromatography (eluted with DCM/methanol, 1/1, v/v) was first used to separate the product and unreacted acceptor. Purification by size exclusion chromatography was also able to successfully separated unreacted donor, and hydrolysed donor from the product.

\subsubsection{Synthesis of the FucGlcNAc Acceptor}

At this stage the $\alpha-1,3$-linked FucGlcNAc disaccharide 21 could either be deprotected and coupled to a bead or protein, or the benzylidene protecting group could be selectively opened to give the acceptor required for the creation of the heptasaccharide 27.

Selective opening of the 4,6-benzylidene to give the C-4 hydroxyl was achieved using Ratner et al.'s ${ }^{120}$ procedure of triethylsilane (TES-H), trifluoroacetic acid (TFA), and trifluoroacetic anhydride (TFAA) to give disaccharide acceptor $\mathbf{2 6}$ as a colourless oil in $78 \%$ yield (Scheme 17). We were very pleased that this reaction proceeded so smoothly given the lability of the $\alpha$-fucose residue under acidic conditions. The reaction was extremely selective as none of the possible C-6 hydroxyl by-product was observed. Selective opening to give the free hydroxyl at C-4, and C-6 $O$-benzyl protection was confirmed by the HMBC correlation between C-6 (69.7 ppm) and the methylene protons 
of the benzyl protecting group (4.61 and $4.57 \mathrm{ppm}$ ) and also between the benzyl methylene carbon (73.6 ppm) and both C-6 methylene hydrogens (3.77 and $3.66 \mathrm{ppm}$ ) (see Appendix, pg XV). The molecular weight was confirmed via HRMS(ESI) which confirmed that the C-4 hydroxyl was now unprotected $(\mathrm{m} / \mathrm{z}$ calcld. For $\left[\mathrm{C}_{46} \mathrm{H}_{59} \mathrm{O}_{9} \mathrm{~N}_{3} \mathrm{Si}+\mathrm{Na}\right]^{+}:$848.3918, obsd.: 848.3919). Though the selective opening of the 4,6-benzylidene to afford the C-4 free hydroxyl with a Brønsted acid is largely empirical, it is thought that the 4-O-benzylidene oxygen is more basic than the oxygen at the 6position and is therefore preferentially protonated. The use of a sterically bulky Lewis acid however, instead of a Brønsted acid, results in co-ordination to the less sterically hindered 6-O position leading to selective benzylidene opening to give a free hydroxyl at the 6 position. $^{121}$
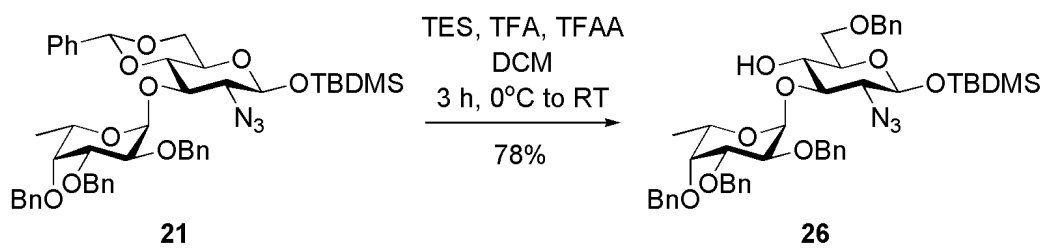

Scheme 17: $\quad$ Selective opening of the FucGlcNAc disaccharide to give the disaccharide acceptor 26.

\subsection{Synthesis of the GlcNAc(Fuc)GlcNAc Trisaccharide}

\subsubsection{Synthesis of the Glucose Azide Donor}

The glucose azide donor $\mathbf{2 5}$ was successfully synthesised from the previously prepared glucose azide acceptor $\mathbf{2 3}^{118}$ in three steps. The first step was benzylation of the C-3 hydroxyl (Scheme 18). Benzylation of 23 using $\mathrm{NaH}, \mathrm{BnBr}$, and TBAI resulted in fully protected glucose building block 49 as a colourless oil, which subsequently crystallised upon refrigeration ( $86 \%$ yield). 


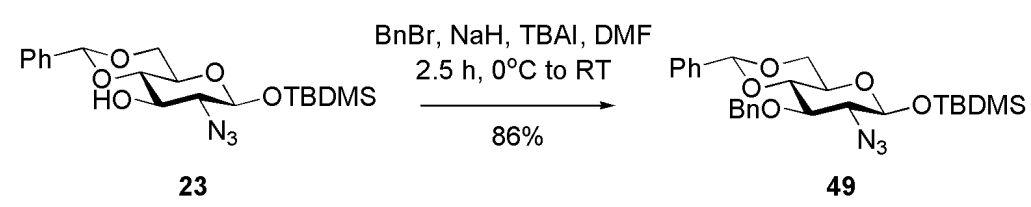

Scheme 18: $\quad$ Synthesis of the fully protected glucosazide 49.

Next the anomeric TBDMS ether was selectively deprotected using HF.pyridine to quantitatively give lactol $\mathbf{5 0}$ as a white amorphous powder following purification by column chromatography (Scheme 19). The removal of the silyl protecting group was seen in the ${ }^{1} \mathrm{H}$ NMR spectra by the disappearance of the silyl methyl protons. The appearance of an $\mathrm{OH}$ stretch $\left(3403 \mathrm{~cm}^{-1}\right)$ in the IR spectrum was also observed.

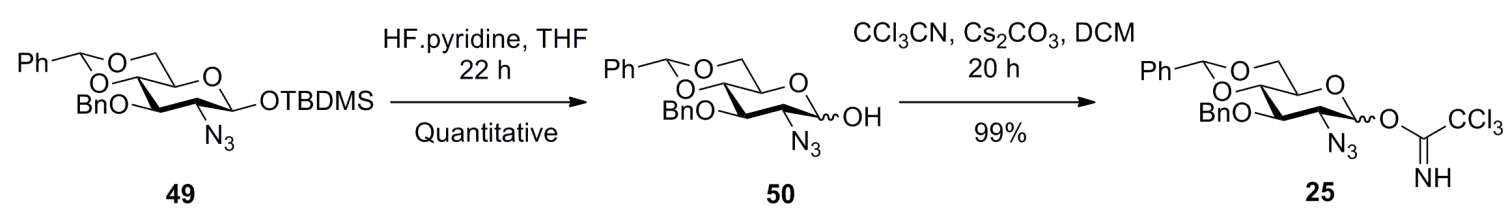

Scheme 19: $\quad$ Synthesis of the acetimidate donor $\mathbf{2 5}$ from the fully protected glucosazide $\mathbf{4 9}$.

Conversion of lactol $\mathbf{5 0}$ to the trichloroacetimidate donor 25, was achieved in a 99\% yield using trichloroacetonitrile $\left(\mathrm{Cl}_{3} \mathrm{CCN}\right)$ in the presence of a catalytic amount of caesium carbonate. The $\alpha$-anomer was a colourless oil, while the $\beta$-anomer was a white powder. Conversion to the acetimidate was confirmed by the presence of the diagnostic peak of the $\mathrm{CCl}_{3}$ carbon in the ${ }^{13} \mathrm{C}$ NMR spectrum at $90.8(\alpha)$ and $90.5(\beta)$ ppm and the introduction of the singlet $\mathrm{NH}$ peak at $8.75(\alpha)$ and $8.77(\beta)$ ppm in the ${ }^{1} \mathrm{H}$ NMR spectrum.

\subsubsection{Attempted Synthesis of the $\operatorname{Glc}\left(\mathrm{N}_{3}\right)(\mathrm{Fuc}) \operatorname{Glc}\left(\mathrm{N}_{3}\right)$ Trisaccharide}

With the successful synthesis of both the acetimidate donor 25 and the disaccharide acceptor 26, synthesis of the GlcNAc(Fuc)GlcNAc trisaccharide 24 was attempted. A $\beta$ 1,4-linkage was required. However, as the acetimidate donor 25 does not possess a participating group at $\mathrm{C}-2$, which would result in the formation of the $\beta$-linkage due to neighbouring group participation, participating solvent effects were employed in an attempt to favour $\beta$-selectivity. ${ }^{107}$ The use of acetonitrile at low temperatures in the 
presence of a suitable activator results in the fast formation of the $\alpha$-nitrilium-nitrile conjugate 51 (irrespective of the anomeric stereochemistry of the donor) due to the anomeric effect (Figure 8). ${ }^{107}$ This $\alpha$-nitrilium-nitrile conjugate in turn blocks the $\alpha$-face leading to more selective formation of a $\beta$-glycoside. ${ }^{107}$

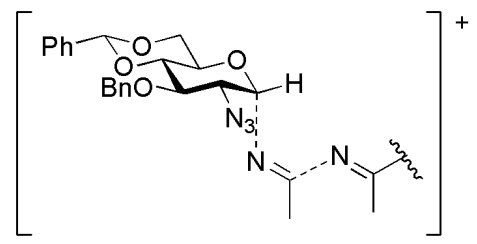

51

Figure 8: $\quad$ The $\alpha$-nitrilium-nitrile conjugate which leads to higher selectivity in the formation of $\beta$ glycosides by blocking the $\alpha$-face.

Coupling of acetimidate donor $\mathbf{2 5}$ and disaccharide acceptor $\mathbf{2 6}$ (3:1 equiv. respectively) was attempted using TMSOTf (0.1 equiv.) as the activator and acetonitrile as a participatory solvent, at $-40^{\circ} \mathrm{C}$ (Scheme 20 ). Unfortunately no product was formed and unreacted acceptor (43\%) and hydrolysed donor were recovered from the reaction mixture.

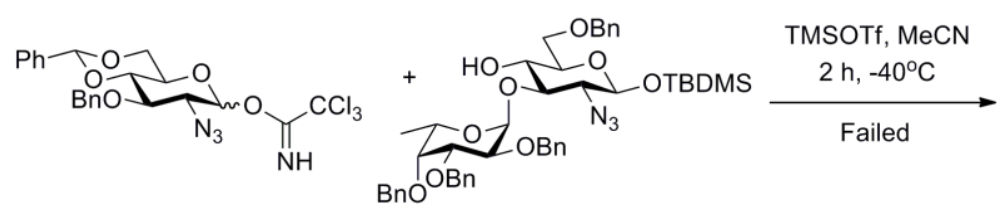

25

26

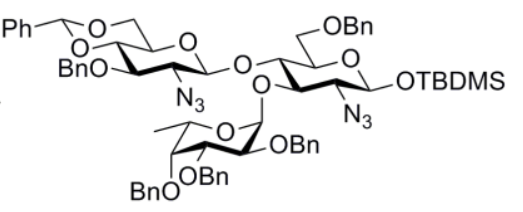

24

Scheme 20: $\quad$ Attempted reaction of the acetimidate donor $\mathbf{2 5}$ with disaccharide acceptor $\mathbf{2 6}$ to form the GlcNAc(Fuc)GlcNAc trisaccharide 24.

\subsection{3 $\mathrm{Glc}\left(\mathrm{N}_{3}\right) \operatorname{Glc}\left(\mathrm{N}_{3}\right)$ Disaccharide Model Glycosidation}

Due to the value of the disaccharide acceptor $\mathbf{2 6}$, the conditions for the formation of the $\beta$-1,4-linkage were further investigated using the less valuable glucose azide acceptor $\mathbf{5 2}$. The glucose azide acceptor was previously synthesised by the candidate ${ }^{118}$ and was accessible in one step from the fully protected building block 49 via selective opening of the 4,6-benzylidene using TES, TFA, and TFAA to give a free hydroxyl at C-4 (Scheme 21). 


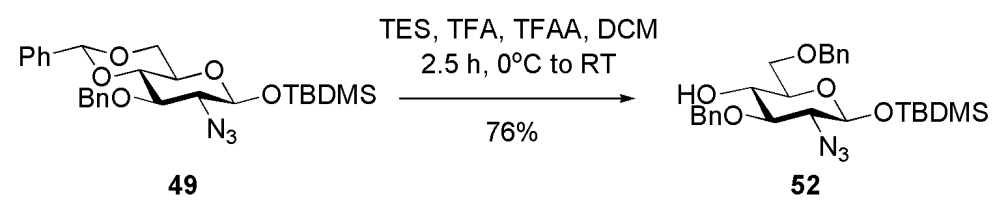

Scheme 21: Previously conducted synthesis of the glucosazide acceptor $\mathbf{5 2}$ from fully protected glucosazide 49.

Coupling of acetimidate donor $\mathbf{2 5}$ and glucosyl acceptor $\mathbf{5 2}$ to form disaccharide $\mathbf{5 3}$ (Scheme 22) was initially attempted using the same conditions as were used for the attempted formation of trisaccharide $\mathbf{2 4}$ in order to determine whether the disaccharide acceptor was solely responsible for the failed reaction. Activation with TMSOTf $(0.1$ equiv.) using 1.6 equivalents of donor and freshly distilled acetonitrile as the participating solvent, at $-40^{\circ} \mathrm{C}$ (Table 3, Entry 1) did not result in product formation. This was fortunate as it meant that the disaccharide acceptor was not solely responsible for the lack of product formation. Although no product was formed, unreacted acceptor (98\%) and unreacted donor $(31 \%)$ were isolated along with hydrolysed donor. The recovery of unreacted donor indicated that the donor was not properly activated. The coupling was repeated this time using 0.3 equivalents of TMSOTf in order to achieve more complete activation of the donor (Table 3, Entry 2). Unfortunately this resulted in degradation of the donor rather than product formation.

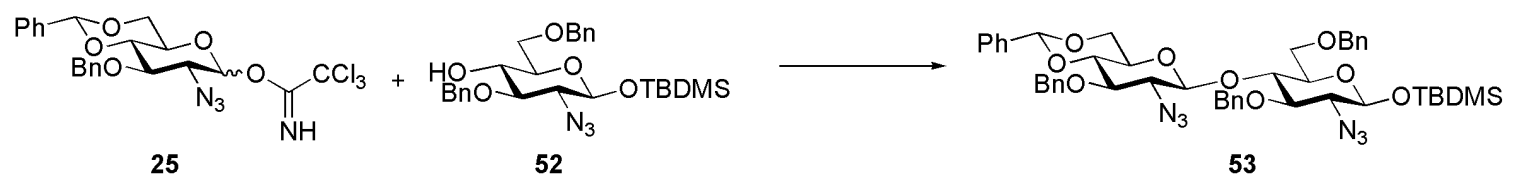

Scheme 22: Reaction of the acetimidate donor $\mathbf{2 5}$ with glucosyl acceptor $\mathbf{5 2}$ to form the GlcNAcGlcNAc disaccharide 53. Reaction conditions are given in Table 3 below. 
Table 3: $\quad$ Attempts at forming the $\operatorname{Glc}\left(\mathrm{N}_{3}\right) \operatorname{Glc}\left(\mathrm{N}_{3}\right)$ disaccharide 53.

\begin{tabular}{|c|c|c|c|c|c|c|}
\hline \multirow[t]{2}{*}{ Entry } & \multirow{2}{*}{$\begin{array}{c}\text { Reaction } \\
\text { Conditions }\end{array}$} & \multirow{2}{*}{$\begin{array}{l}\text { Time \& } \\
\text { Temp. }\end{array}$} & \multicolumn{2}{|c|}{ Equivalents } & \multirow[t]{2}{*}{ Yield $^{2}$} & \multirow{2}{*}{$\begin{array}{c}\text { Ratio }^{3} \\
\alpha: \beta\end{array}$} \\
\hline & & & Acceptor & Donor & & \\
\hline 1. & $\begin{array}{c}\text { TMSOTf } \\
(0.1 \text { equiv), } \\
\text { MeCN }\end{array}$ & $\begin{array}{l}45 \mathrm{mins} \\
-40^{\circ} \mathrm{C}\end{array}$ & $\begin{array}{c}1 \\
0.1000 \mathrm{~g}\end{array}$ & $\begin{array}{c}1.6 \\
0.1714 \mathrm{~g}\end{array}$ & $\begin{array}{c}\text { product: } 0 \mathrm{~g} \\
(0 \%) \\
\text { acceptor: } 0.0980 \mathrm{~g} \\
(98 \%) \\
\text { donor: } 0.0531 \mathrm{~g} \\
(31 \%)\end{array}$ & N/A \\
\hline 2. & $\begin{array}{c}\text { TMSOTf } \\
\text { (0.3 equiv), } \\
\text { MeCN }\end{array}$ & $\begin{array}{l}90 \text { mins } \\
-40^{\circ} \mathrm{C}\end{array}$ & $\begin{array}{c}1 \\
0.0966 \mathrm{~g}\end{array}$ & $\begin{array}{c}1.5 \\
0.1522 \mathrm{~g}\end{array}$ & $\begin{aligned} & \text { product: } 0 \mathrm{~g} \\
&(0 \%) \\
& \text { acceptor: not } \\
& \text { calculated }\end{aligned}$ & N/A \\
\hline 3. & $\begin{array}{c}\text { TMSOTf } \\
\text { (0.4 equiv), } \\
\text { EtCN/DCM, } \\
1 / 1\end{array}$ & $\begin{array}{l}90 \text { mins } \\
-78^{\circ} \mathrm{C}\end{array}$ & $\begin{array}{c}1 \\
0.0800 \mathrm{~g}\end{array}$ & $\begin{array}{c}1.5 \\
0.1267 \mathrm{~g}\end{array}$ & $\begin{array}{c}\text { product: } 0 \mathrm{~g} \\
(0 \%) \\
\text { acceptor: } 0.0290 \mathrm{~g} \\
(36 \%) \\
\text { TMS-acc }^{4}: 0.0345 \mathrm{~g} \\
(38 \%) \\
\text { donor: } 0.0465 \mathrm{~g} \\
(37 \%)\end{array}$ & N/A \\
\hline 4. & $\begin{array}{c}\text { TMSOTf } \\
\text { (0.1 equiv), } \\
\text { MeCN }\end{array}$ & $\begin{array}{c}30 \text { mins } \\
-40^{\circ} \mathrm{C} \\
2.5 \text { hours } \\
0^{\circ} \mathrm{C} \\
2 \text { hours } \\
\text { RT }\end{array}$ & $\begin{array}{c}1 \\
0.0657 \mathrm{~g}\end{array}$ & $\begin{array}{c}2.0 \\
0.1388 \mathrm{~g}\end{array}$ & $\begin{aligned} \text { product: } & 0.0134 \mathrm{~g} \\
& (12 \%) \\
\text { acceptor: } & 0.0506 \mathrm{~g} \\
& (77 \%)\end{aligned}$ & $1: 3.3$ \\
\hline 5. & $\begin{array}{c}\text { TMSOTf } \\
(0.1 \text { equiv), } \\
\text { MeCN }\end{array}$ & $\begin{array}{l}30 \text { mins } \\
0^{\circ} \mathrm{C} \\
6 \text { hours } \\
\text { RT }\end{array}$ & $\begin{array}{c}1 \\
0.0500 \mathrm{~g}\end{array}$ & $\begin{array}{c}2.0 \\
0.1093 \mathrm{~g}\end{array}$ & $\begin{aligned} \text { product: } & 0.0190 \mathrm{~g} \\
& (23 \%) \\
\text { acceptor: } & 0.0350 \mathrm{~g} \\
& (70 \%)\end{aligned}$ & $1: 2.8$ \\
\hline
\end{tabular}

\footnotetext{
${ }^{\mathrm{I}}$ Type 4A molecular sieves were used in all reactions and were activated by heating under vacuum.

${ }^{2}$ Product yields combined $\alpha$ and $\beta$. Hydrolysed donor was observed for all reactions.

${ }^{3} \alpha: \beta$ ratio based on the integration values for ${ }^{1} \mathrm{H}$ NMR signals.

${ }^{4}$ Trimethylsilyl protected acceptor.
}

It was thought that if the temperature of the reaction was lower upon the addition of TMSOTf the donor would be less likely to degrade. As acetonitrile has a freezing point of $-45^{\circ} \mathrm{C}$ a different participating solvent was required if the reaction was to be attempted at lower temperatures. Propionitrile was chosen as it has a freezing point of $-92^{\circ} \mathrm{C}$ and also has the ability to form the $\alpha$-nitrilium-nitrile conjugate as acetonitrile does. Unfortunately the donor and acceptor did not dissolve in propionitrile so a 1:1 mixture of propionitrile and DCM was used. The reaction was done at $-78^{\circ} \mathrm{C}$ with 0.4 equivalents of TMSOTf (initially 0.2 equiv. were added with another 0.2 equiv added after an hour) (Table 3, 
Entry 3). TLC analysis was promising with the formation of a higher $R_{f}$ product $\left(R_{f}=\right.$ 0.76 , ethyl acetate/light petroleum ether, $1 / 5, \mathrm{v} / \mathrm{v})$. Unfortunately this higher $R_{f}$ product was not the desired disaccharide $\mathbf{5 3}$ and was instead trimethylsilyl (TMS) protected acceptor $(0.08 \mathrm{ppm}, \mathrm{s}, 9 \mathrm{H}, 3 \mathrm{x}$ Me TMS). Unreacted donor and acceptor were also isolated along with hydrolysed donor, indicating that the reaction temperature was too low for complete donor activation.

As activation below $-45^{\circ} \mathrm{C}$ did not result in product formation the solvent was switched back to acetonitrile because propionitrile required the use of DCM which does not act as a participatory solvent. The next reaction (Table 3, Entry 4) was activated with 0.1 equivalents of TMSOTf at $-40^{\circ} \mathrm{C}$. The reaction was kept at $-40^{\circ} \mathrm{C}$ for 30 minutes at which time TLC analysis showed formation of the TMS protected acceptor as well as a potential product spot $\left(R_{f}=0.56\right.$, ethyl acetate/light petroleum ether, $\left.1 / 5, \mathrm{v} / \mathrm{v}\right)$. The reaction was then warmed to $0^{\circ} \mathrm{C}$ and stirred for a further 2.5 hours, after which the TMS protected acceptor was no longer present by TLC analysis and the intensity of the potential product spot had increased. The reaction was then allowed to stir for a further 2 hours at room temperature. Fortunately the potential product spot was in fact product, which was confirmed by HRMS(ESI) ( $\mathrm{m} / z$ calcld. for $\left[\mathrm{C}_{46} \mathrm{H}_{56} \mathrm{O}_{9} \mathrm{~N}_{6} \mathrm{Si}+\mathrm{Na}\right]^{+}$: 887.3776 , obsd.: 887.3767 ) but unfortunately the yield was only $12 \%$ and the selectivity only slightly favoured the desired $\beta$-anomer $\left(\alpha: \beta=1: 3.3\right.$, based on integration of ${ }^{1} \mathrm{H}$ NMR signals, $\mathrm{H}$ $1^{\prime}-\alpha 5.65 \mathrm{ppm}, J_{1-2}=4.2 \mathrm{~Hz}, \mathrm{H}-1^{\prime}-\beta 4.41 \mathrm{ppm}, J_{1-2}=8.1 \mathrm{~Hz}$ ). Unreacted acceptor (77\%) and hydrolysed donor were also isolated. As warming the reaction to $0^{\circ} \mathrm{C}$ resulted in the disappearance of TMS protected acceptor, it was thought that activation at $0^{\circ} \mathrm{C}$ would result in an increased yield as the TMS protected acceptor would be unstable at this temperature and therefore give the acceptor more chance to react with the donor before donor hydrolysis occurred. Activation at $0^{\circ} \mathrm{C}$ with 0.1 equivalents of TMSOTf followed by warming to room temperature after 30 minutes (Table 3, Entry 5) resulted in an increase in yield to $23 \%$, which is still well below acceptable especially given the low selectivity $(\alpha: \beta=1: 2.8)$. Unreacted acceptor $(70 \%)$ and hydrolysed donor were again isolated. 
The limited success with $\beta$-1,4-glycosidation involving the glucose azide donor was thought to be due to the poor reactivity of the acceptor combined with the instability of the activated donor thus resulting in donor hydrolysis before glycosylation could occur. Being able to achieve high yields with significant $\beta$-selectivity is extremely important for this glycosidation as it is the final glycosylation in the proposed synthesis of the heptasaccharide 27 and any other $\operatorname{Man}_{3}(\mathrm{GlcNAc})_{2}$ containing truncations (Scheme 23). An alternative strategy was therefore needed to increase either the reactivity of the acceptor or the stability of the activated donor. Of the two possible options it was easiest to increase the stability of the activated donor through the use of a participating protecting group on the amino function at $\mathrm{C}-2$. This would enable neighbouring group participation, which should result in the increased stability of the activated donor and also greater $\beta$-selectivity compared to solvent stabilisation with acetonitrile.

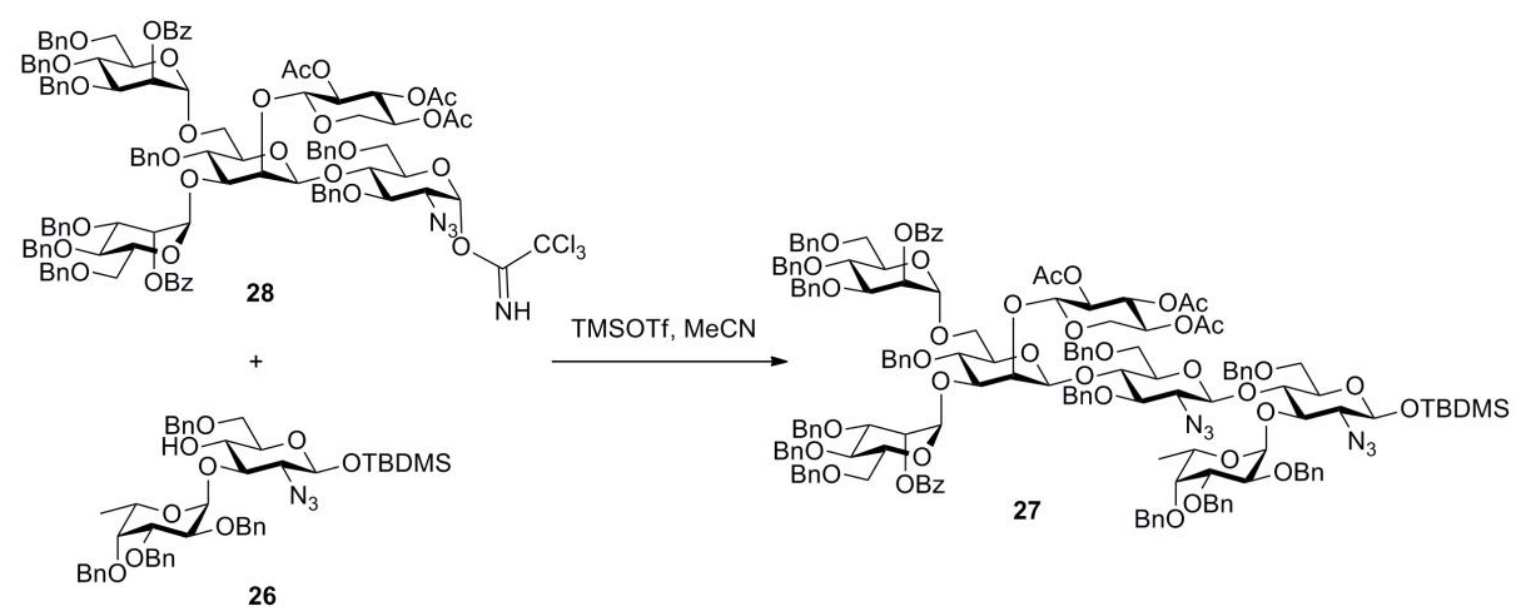

Scheme 23: $\quad$ Proposed final $\beta-1,4$-glycosidation in the formation of the heptasaccharide 27.

Choosing a suitable participating protecting group required careful consideration. Although it would appear desirable to use $N$-acetyl protection, as both the target glycoconjugates contain $\mathrm{N}$-acetyl groups, there are several reasons why this is problematic. First, the presence of a Lewis basic acetamide group during glycosylations can be problematic as it can interact with the Lewis acid used for thioglycoside and imidate donor activation. In addition, the presence of a 2-acetamido group in glycosyl donors is problematic as it may result in the formation of a stable oxazoline (A, Figure 9) instead of the desired glycoside. ${ }^{122}$ The oxazoline can be reactivated using strong acid 
and high temperatures, but this often results in degradation and lower glycosylation yields. ${ }^{122}$ Lastly, it has been shown that the reactivity of the C-4 hydroxyl in $N$ acetylglucosamine derivatives is reduced due to the presence of the electron withdrawing acetate group. ${ }^{123,124}$ This is an issue as coupling to the C-4 hydroxyl is required in forming the donor for the heptasaccharide and other $\operatorname{Man}_{3}(\mathrm{GlcNAc})_{2}$ containing truncations. The other two main participating amine protecting groups used in carbohydrate chemistry are the phthalimido ( $N$-Phth) group (B, Figure 9$)$ and the 2,2,2trichloroethoxycarbonylamino ( $N$-Troc) group (C, Figure 9). There are several disadvantages with using the phthalimido group. Though the phthalimido group does not form an oxazoline during glycosylation reactions, protection of the amine with this group requires two steps and its deprotection is sometimes problematic as it requires harsh conditions (strongly basic conditions and elevated temperatures), which can result in low yields of the deprotected product. ${ }^{122}$ The phthalimido group is also sterically bulky which can cause glycosylation problems at C-3 of phthalimido protected glucosamines, which was taken into consideration when the initial protecting group strategy was devised. Instead the Troc group was chosen as it can be installed in one step from the unprotected amine and can be removed at room temperature in a high yield with zinc powder under acidic conditions. ${ }^{125}$ It also does not form an oxazoline during glycosylation reactions and Koizumi et al. have reported significantly improved glycosylation yields using Troc protected donors as compared to phthalimido protected donors, which they reasoned was due to steric hindrance from the phthalimido group. ${ }^{126}$ Azide protection had been initially chosen over Troc protection because a conserved amine protection strategy was desired as it requires fewer deprotection steps and it was thought that azide protection would be compatible with both donor and acceptor GlcNAc units. It was thought that the Troc protecting group, being a carbamate which is electron withdrawing, would result in a less reactive acceptor, than the corresponding azide, as it has been shown that the C-4 hydroxyl of 2-azido-2-deoxy-glucopyranosides is more reactive than the electron withdrawing $N$-phthalimido ( $N$-Phth) and $N$-acetyl ( $N$-Ac) glucosaminopyranoside derivatives. ${ }^{124}$ Azides can also be easily converted to an amine by a number of different reductive conditions (e.g. hydrogenation, or Staudinger reduction) $)^{127,128}$ and it was thought the $\beta$-glycosidic bond could be successfully installed using acetonitrile as a 
participating solvent. ${ }^{107}$ However, the work described above indicated this strategy was unfruitful.

A

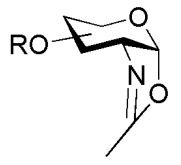

B:

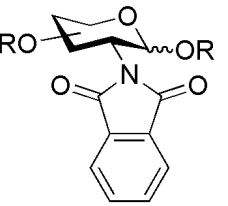

C:

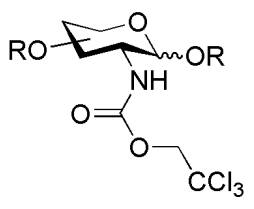

Figure 9: A: Stable oxazoline formed during glycosylation when using a glycosyl donor with a 2acetamido group. B: Phthalimido (Phth) protected glucosamine. C: 2,2,2-trichloroethyl chloroformate (Troc) protected glucosamine.

\subsubsection{Synthesis of the Troc Protected Donor}

Synthesis of the Troc protected donor started with conversion of the fully protected glucose azide 49 into the corresponding Troc protected glucosamine 54 in a two step one pot reaction (Scheme 24). The azide was first reduced to an amine via Staudinger reduction with $\mathrm{PMe}_{3}$. When complete reduction of the azide was observed via TLC analysis 2,2,2-trichloroethyl chloroformate (Troc $\mathrm{Cl})$ was added, resulting in the $\mathrm{N}$-Troc protected compound 54 (79\% yield). The methylene protons of the Troc group were observed as a multiplet at 4.71-4.63 ppm along with the introduction of the NH resonance at $5.03 \mathrm{ppm}\left(\mathrm{d}, 1 \mathrm{H}, J_{2, \mathrm{NH}}=6.9 \mathrm{~Hz}, \mathrm{NH}\right)$ in the ${ }^{1} \mathrm{H}$ NMR spectrum.

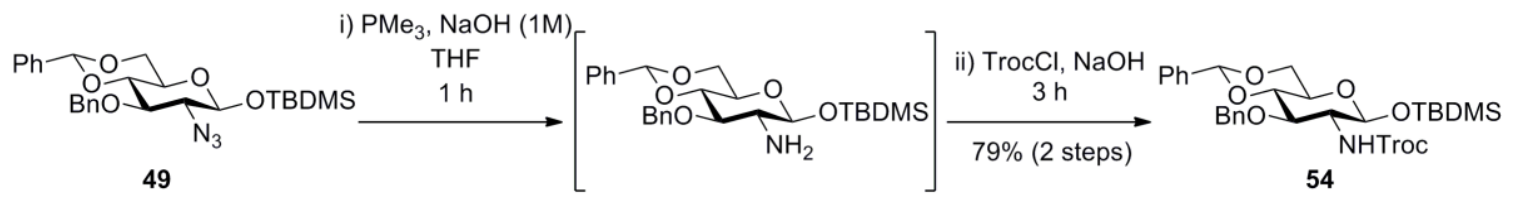

Scheme 24: $\quad$ Formation of the fully protected $N$-Troc building block 54.

With $N$-Troc conversion complete the $N$-Troc imidate donor was synthesised using the methodology that was used to create the azide donor (Scheme 25). Conversion to the lactol 55 using HF.pyridine proceeded in 90\% yield, and the subsequent treatment with trichloroacetonitrile and caesium carbonate (cat.) resulted in the $N$-Troc imidate $\mathbf{5 6}$ in a $99 \%$ yield. 


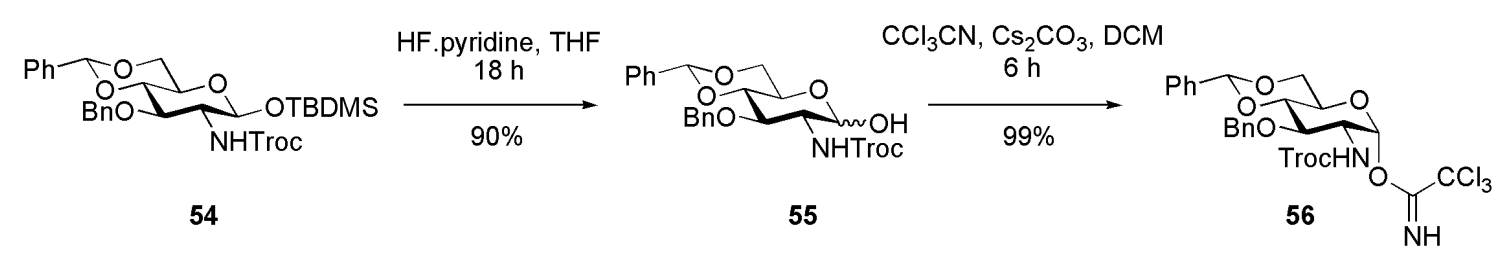

Scheme 25: $\quad$ Synthesis of the $N$-Troc imidate 56 from the $N$-Troc building block 54 .

\subsubsection{Glc(NHTroc)Glc $\left(\mathrm{N}_{3}\right)$ Disaccharide Model Glycosidation}

The $\beta$-1,4-glycosidation reaction was re-attempted, this time with the hopefully more robust $N$-Troc imidate donor (Scheme 26). DCM was used as the reaction solvent as the Troc group controls $\beta$-selectivity through neighbouring group participation. The reaction with 1.8 equivalents of donor was activated at $-40^{\circ} \mathrm{C}$ using 0.1 equivalents of TMSOTf and was allowed to warm up to $-10^{\circ} \mathrm{C}$ before it was quenched after an hour and 15 minutes. The use of the $N$-Troc instead of the azide donor resulted in a significant increase in yield (74\%) and only the $\beta$-anomer was formed. This suggests that participation from the $N$-Troc group resulted in a more stable donor allowing it to react with the acceptor before being hydrolysed. The $\beta$-linkage was confirmed by the $J_{1^{\prime}, 2^{\prime}}$ coupling constant of $8.5 \mathrm{~Hz}$ and the molecular weight of the product was confirmed by HRMS(ESI) ( $/ \mathrm{m} / z$ calcld. for $\left[\mathrm{C}_{49} \mathrm{H}_{59} \mathrm{O}_{11} \mathrm{~N}_{4} \mathrm{Cl}_{3} \mathrm{Si}+\mathrm{Na}\right]^{+}:$1035.2913, obsd.: 1035.2908).

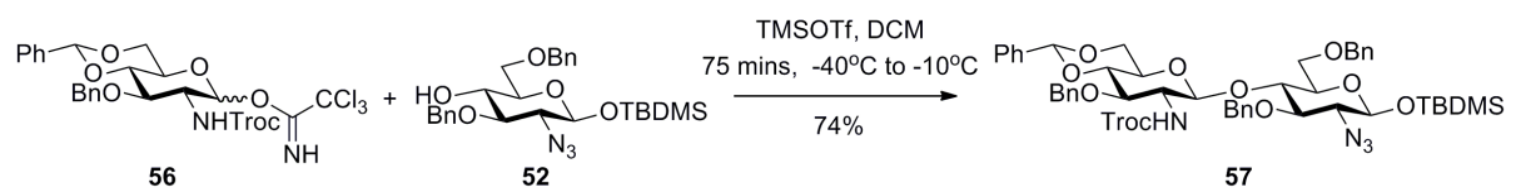

Scheme 26: $\quad$ Successful coupling between the $N$-Troc imidate donor $\mathbf{5 6}$ and the glucose azide acceptor 52.

\subsubsection{Glc(NHTroc)(Fuc)Glc( $\left.\mathrm{N}_{3}\right)$ Trisaccharide Glycosidation}

After the success of forming the $\beta$-1,4-linkage with the glucose azide monosaccharide acceptor 52 in good yield and selectivity, attention was once again turned to the formation of the $\beta-1,4-$ linked trisaccharide (Scheme 27). The reaction was again activated at $-40^{\circ} \mathrm{C}$ with 0.1 equivalents of TMSOTf. The reaction temperature was maintained at $-40^{\circ} \mathrm{C}$ as the partial consumption of acceptor was observed via TLC analysis after 20 
minutes, with the complete consumption of acceptor seen after an hour and 10 minutes. To our delight only pure $\beta$-product was formed in a good yield of $72 \%$, with the use of only 1.5 equivalents of donor. The observation of the anomeric proton of the newly installed Glc(NHTroc) residue at $4.41 \mathrm{ppm}\left(\mathrm{d}, 1 \mathrm{H}, J_{1^{\prime \prime}, 2^{\prime \prime}}=7.9 \mathrm{~Hz}\right)$ in the ${ }^{1} \mathrm{H} \mathrm{NMR}$ spectrum along with confirmation of the product's mass by HRMS(ESI) $(\mathrm{m} / \mathrm{z}$ calcld. for $\left[\mathrm{C}_{69} \mathrm{H}_{81} \mathrm{O}_{15} \mathrm{~N}_{4} \mathrm{Cl}_{3} \mathrm{Si}+\mathrm{Na}\right]^{+}: 1361.4431$ obsd.: 1361.4424) confirmed successful formation of trisaccharide 58.
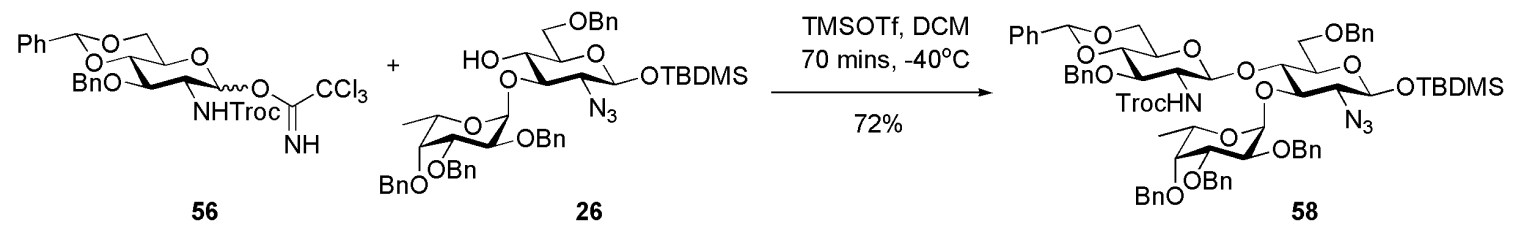

Scheme 27: $\quad$ Successful coupling between the $N$-Troc imidate donor $\mathbf{5 6}$ and the disaccharide acceptor 26.

The successful formation of the $\beta$-1,4-linkage present in both disaccharide $\mathbf{5 7}$ and trisaccharide 58 in good yields with complete $\beta$-selectivity was an important milestone in the consideration of forming the larger structures containing the $\operatorname{Man}_{3}(\mathrm{GlcNAc})_{2}$ pentasaccharide core. Our studies have shown that the C-2 amine of the donor must have a protecting group that is capable of neighbouring group participation in order to prevent hydrolysis before glycosidation can occur. The use of $N$-Troc protection also resulted in the completely stereoselective formation of the $\beta$-product. This is extremely useful as mixtures of $\alpha$ and $\beta$ anomers can be difficult to separate, $c f$. the FucGlc $\left(\mathrm{N}_{3}\right)$ disaccharide 21, not to mention the increase in yield associated with selective formation of the desired anomer. 


\subsection{Feasibility of $N$-Troc Protected Acceptor}

\subsubsection{Synthesis of the Glc(NHTroc) Acceptor}

Due to the requirement for $N$-Troc protection of the donor in the formation of the $\beta-1,4-$ linkage between the two GlcNAc residues the feasibility of using an $N$-Troc protected acceptor was also investigated as a conserved protection group strategy is favoured as less deprotection steps are required. The feasibility of an $N$-Troc protected acceptor was explored for both the formation of the $\alpha-1,3$-fucosyl linkage and the $\beta-1,4$-glucosylamine linkage.

The first step was formation of the $N$-Troc protected acceptor required for the $\alpha-1,3-$ fucose coupling. The previously used azide acceptor $\mathbf{2 3}$ was converted into the $N$-Troc acceptor 59 via Staudinger reduction and subsequent Troc protection of the resulting amine (Scheme 28). The two step one pot methodology that was used for Troc conversion of the fully protected building block was used for formation of $N$-Troc acceptor 59. Troc conversion was achieved in $61 \%$ yield. In an attempt to increase this yield two other methodologies were attempted. Both still involved Staudinger reduction of the azide, however, the reaction was subjected to aqueous work up before the crude amine $\mathbf{6 0}$ was Troc protected. Treatment of the crude amine with $\mathrm{TrocCl}$ in pyridine afforded $N$-Troc acceptor $\mathbf{5 9}$ in $46 \%$ yield along with formation of the di-Troc side product $\mathbf{6 1}$ in 25\% (Troc protection of the C-3 hydroxyl and the C-2 amine). Reaction of the crude amine with $\mathrm{TrocCl}$ and $N, N$-diisopropylethylamine (DIPEA) achieved $N$-Troc protection with the highest yield in $73 \%$ with no di-Troc side product observed.

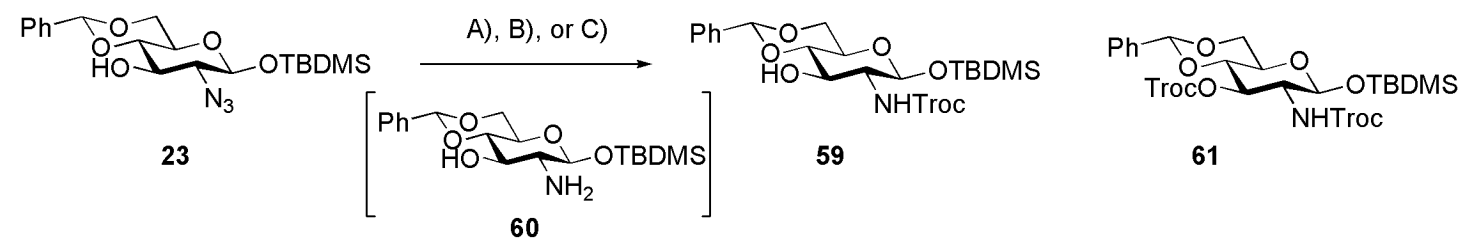

A) i) $\mathrm{PMe}_{3}, \mathrm{NaOH}(1 \mathrm{M})$, THF

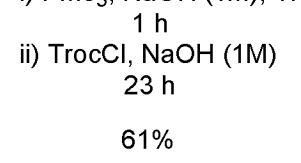

B) i) $\mathrm{PMe}_{3}, \mathrm{NaOH}(1 \mathrm{M}), \mathrm{THF}$
ii) TrocCl, Pyridine
$1 \mathrm{~h} 40 \mathrm{~min}$
$46 \%$ and $25 \% 61$

C) i) $\mathrm{PMe}_{3}, \mathrm{NaOH}(1 \mathrm{M})$, THF

ii) TrocCl, DIPEA, DCM

$1 \mathrm{~h} 40 \mathrm{~min}$

$73 \%$

Scheme 28: $\quad$ The three methodologies attempted for formation of $N$-Troc acceptor 59. 


\subsubsection{Formation of the FucGlc(NHTroc) Disaccharide Acceptor}

With the $N$-Troc protected acceptor in hand, formation of the $\alpha-1,3$-fucosyl linkage was attempted (Scheme 29). The reaction was conducted using the optimised reaction conditions that were used in forming the $\alpha-1,3$-fucosyl linkage with the azide acceptor. Our theory that the electron withdrawing nature of the $N$-Troc group would result in a poorer acceptor and thus reduce the success of the glycosylation was correct. The glycosidation was attempted twice and both times resulted in significantly reduced yields (58\% and $42 \%$ ) compared to glycosidation with the azide acceptor (89\%). The selectivity was however comparable $(\alpha: \beta=16.8: 1)$ and the anomers were separated via column chromatography using DCM as the eluent.

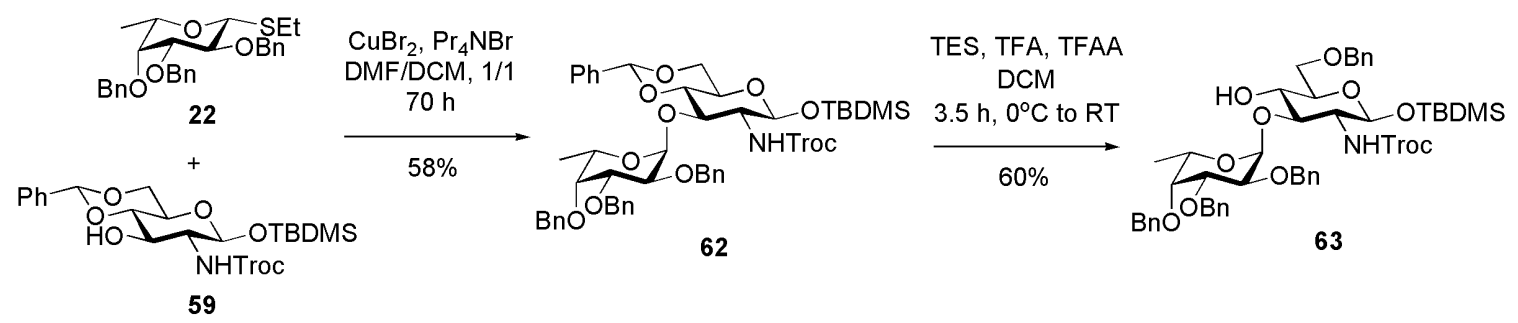

Scheme 29: $\quad$ Synthesis of the $N$-Troc protected disaccharide acceptor 63 .

The 4,6-benzylidene of $N$-Troc disaccharide $\mathbf{6 2}$ was then selectively opened with TES, TFA, and TFAA to give the $N$-Troc disaccharide acceptor $\mathbf{6 3}$ in 60\% yield (Scheme 29). Again the opening was $100 \%$ regioselective with none of the C-6 hydroxyl product observed.

\subsubsection{Synthesis of the Disaccharide $N$-Troc Donor}

The fully protected $N$-Troc disaccharide $\mathbf{6 4}$ had been synthesised by another member of the research group as an intermediate in the production of the $\mathrm{Man}_{3} \mathrm{Glc}$ (NTroc) pentasaccharide donor 65 and the $\operatorname{Man}_{3}(\mathrm{Xyl}) \mathrm{Glc}(\mathrm{NTroc})$ pentasaccharide donor 66 (Scheme 30). Comparison of the $N$-Troc and azide disaccharide acceptors was conducted using the disaccharide donor $\mathbf{6 7}$ instead of the previously used $N$-Troc monosaccharide donor 56 because it provides a better comparison to glycosidation with the larger tetra- 
and pentasaccharide donors. Conversion of the disaccharide 64 into the corresponding imidate donor 67 was achieved via HF.pyridine mediated TBDMS ether deprotection to give lactol 68 (92\% yield), followed by imidate formation with trichloroacetonitrile and caesium carbonate (50\% yield) (Scheme 30 ). Several attempts were made at forming the imidate, however, the yields obtained were much lower than when forming either the Glc $\left(\mathrm{N}_{3}\right)$ or Glc(Troc) imidate donors (both 99\% yields). Although TLC analysis showed complete conversion to the disaccharide imidate, impure starting material was isolated after column chromatography, indicating that hydrolysis occurred during purification. No hydrolysis was observed when purifying either of the monosaccharide donors suggesting that the disaccharide donor is less stable. It has since been shown by members within our research group that using a silica column that is pre-neutralised with $1 \%$ triethylamine in DCM reduces the acid catalysed hydrolysis of imidates during purification.

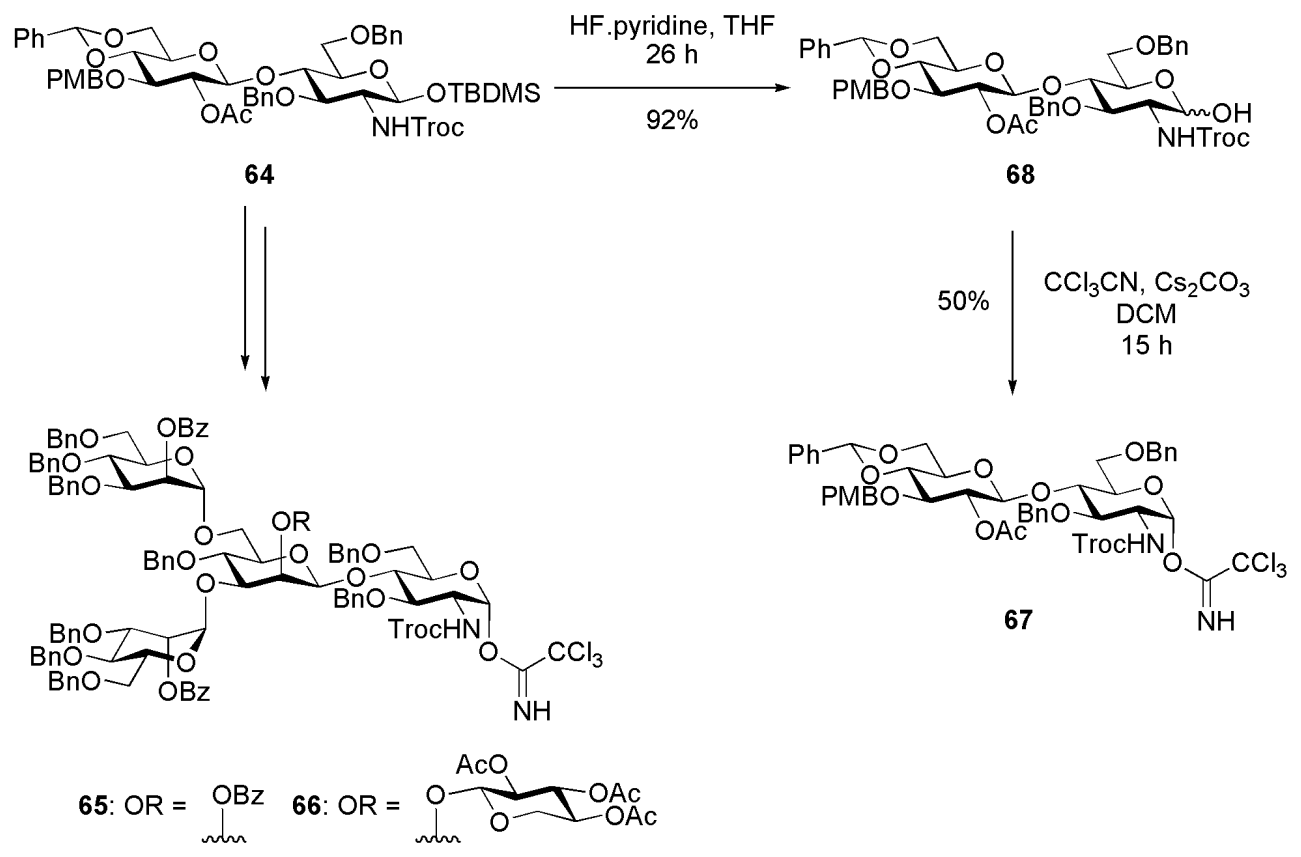

Scheme 30: $\quad$ Synthesis of the disaccharide imidate donor 67 from disaccharide 64, which can also be used for the synthesis of tetrasaccharide donor $\mathbf{6 5}$ and the pentasaccharide donor $\mathbf{6 6}$. 


\subsubsection{Comparison of the $N$-Troc and Azide Disaccharide Acceptors}

Coupling of the disaccharide imidate donor $\mathbf{6 7}$ was attempted with both the azide and the Troc protected acceptors (Scheme 31). Both couplings were activated at $-40^{\circ} \mathrm{C}$ with 0.1 equivalents of TMSOTf in freshly distilled DCM with activated molecular sieves. The reactions were then allowed to warm to room temperature before being quenched when TLC analysis showed complete consumption of donor. TLC analysis of the Troc acceptor reaction showed a large amount of donor hydrolysis and it appeared that formation of product had been unsuccessful. In order to determine if any product had been formed the crude reaction mixture was analysed using HRMS(ESI), which unfortunately did not detect the presence of any product. On the other hand TLC analysis of the azide acceptor reaction, despite also showing a large amount of donor hydrolysis, showed the formation of a higher $R_{f}$ compound ( $R_{f}=0.71$ ethyl acetate/toluene, $1 / 6, \mathrm{v} / \mathrm{v}$ ) which was thought to be product. Unfortunately after purification by column chromatography this higher $R_{f}$ compound was not isolated, suggesting that it was most likely TMS protected acceptor which was hydrolysed during purification. Thus both reactions using the disaccharide donor were unsuccessful. The couplings were not reattempted due to the limited availability of the disaccharide imidate donor. 


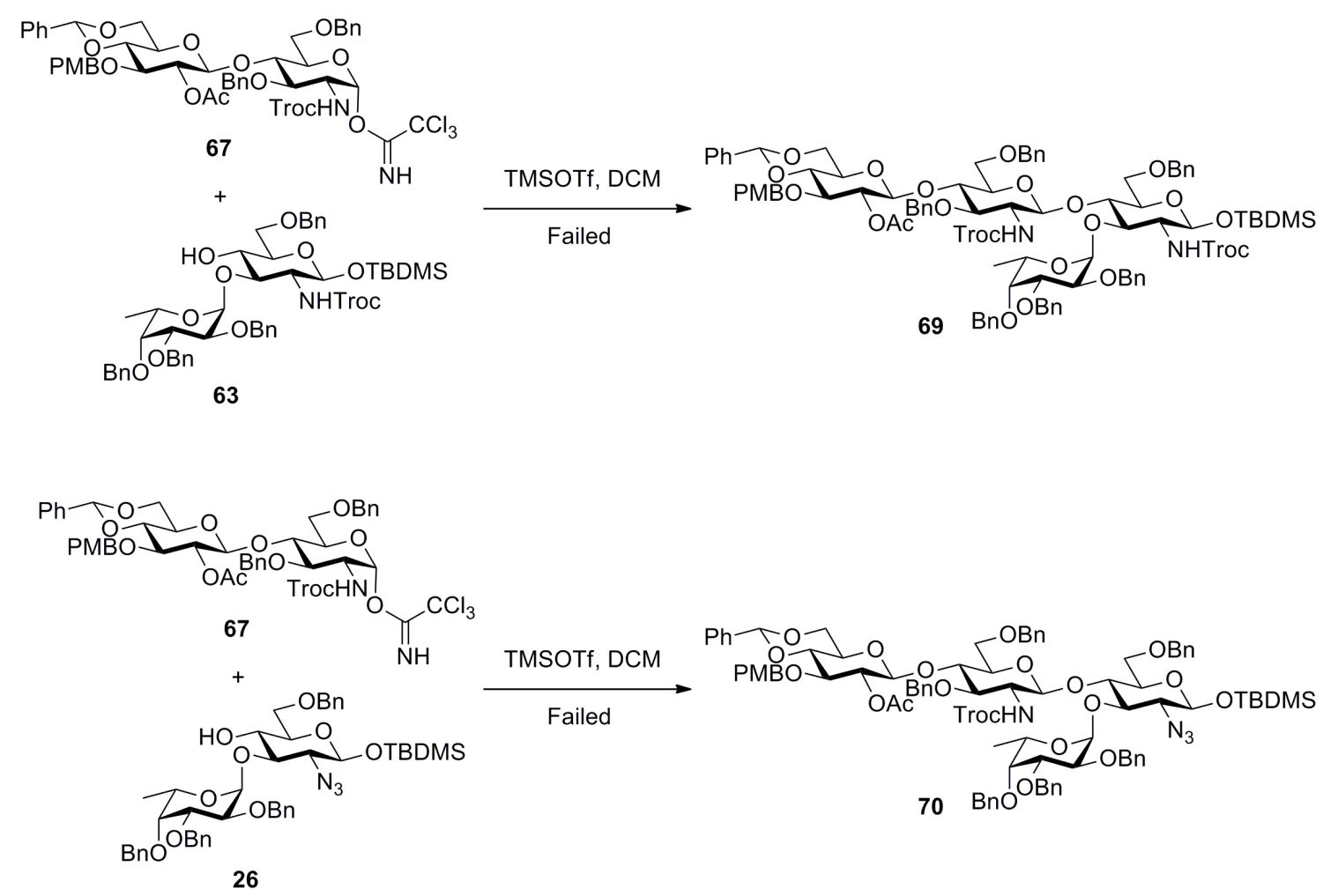

Scheme 31: Attempted coupling of the disaccharide imidate donor 67 with both the azide and the Troc protected acceptors ( $\mathbf{2 6}$ and $\mathbf{6 3}$ respectively).

It was thought that both couplings failed due to the quality of the TMSOTf used. The successful synthesis of the fully protected hexasaccharide 71, using the azide protected disaccharide acceptor 26, has since been conducted in our research group using freshly distilled TMSOTf (Scheme 32). The exact conditions for this reaction are yet to be optimised. 


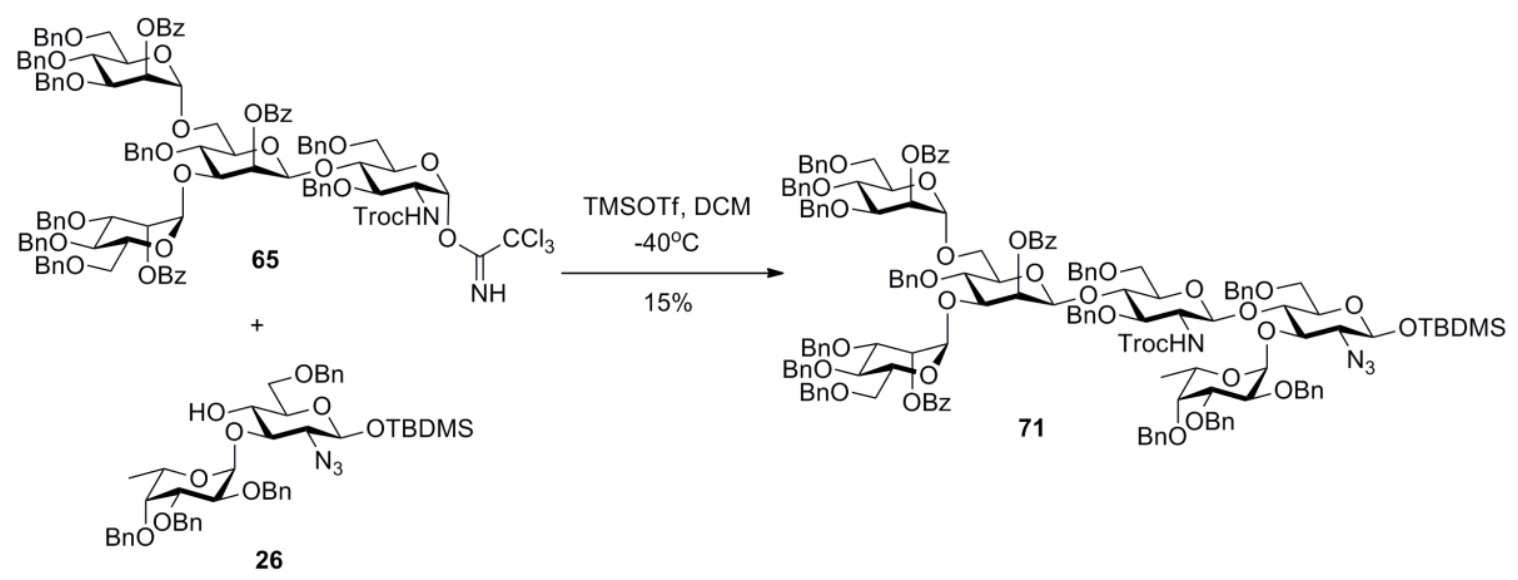

Scheme 32: Successful formation of the fully protected hexasaccharide $\mathbf{7 0}$ using the disaccharide azide acceptor 26. Reaction not yet optimised. (Conducted by another member of our group).

Another comparison of Troc and azide acceptors was conducted by another member of our group. The Troc protected disaccharide 64 required for the synthesis of the tetra- and pentasaccharide donors, 65 and $\mathbf{6 6}$ respectively, was initially synthesised via glycosidation of thiol donor $\mathbf{7 2}$ with azide acceptor $\mathbf{5 2}$ (99\% yield), followed by subsequent Troc conversion of the resulting azide disaccharide 73 (Scheme 33). As it is desirable to minimise the number of protecting group manipulations required after coupling, glycosidation was attempted using the Troc protected acceptor 74 (Scheme 33). Coupling to the Troc protected acceptor was considerably less successful than to the azide acceptor with yields of less than $10 \%$ obtained. Given this knowledge combined with the reduced yields obtained in forming the $\alpha-1,3$-fucosyl linkage with a Troc protected acceptor (Section 2.4.2), azide protection of the proximal GlcNAc residue was chosen, even despite the associated increase in deprotection steps required due to the presence of both azide and Troc protected amines. 


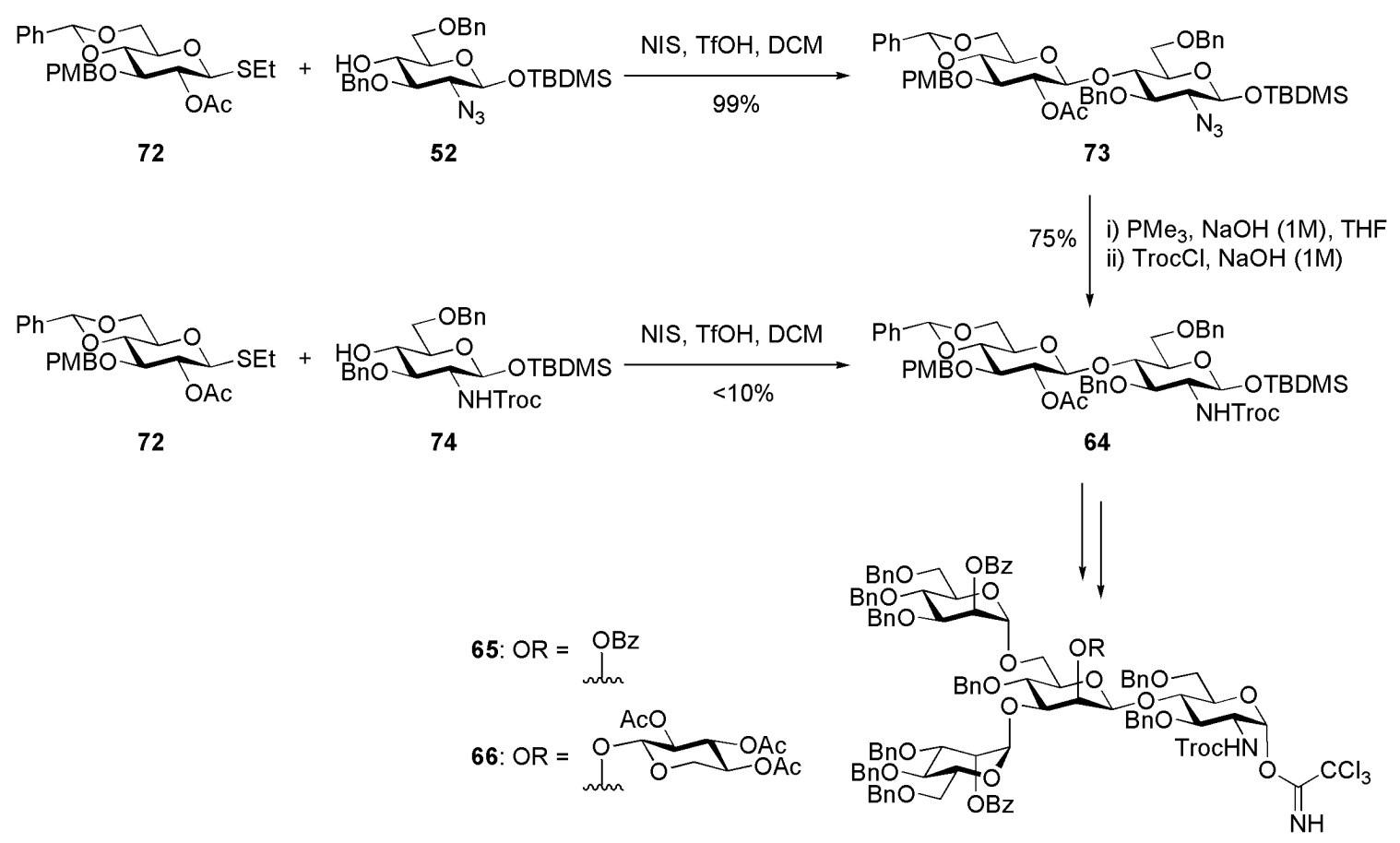

Scheme 33: $\quad$ Comparison of the azide 52 and Troc $\mathbf{7 4}$ acceptors in the formation of the $\beta$-1,4-linkage. (Conducted by another member of our group).

\subsection{Deprotection of the FucGlc $\left(\mathrm{N}_{3}\right)$ Disaccharide}

\subsubsection{Initial Deprotection Strategy}

With the decision that azide protection was favoured over Troc protection for the proximal GlcNAc residue, deprotection and acetamide formation of the fully protected FucGlc $\left(\mathrm{N}_{3}\right)$ disaccharide 21 was attempted. As complete deprotection was desired, the removal of several different protecting groups with one reaction was favoured. With this in mind the first step in the deprotection strategy was removal of the benzyl and benzylidene protecting groups as well as reduction of the azide to an amine by hydrogenation using $\mathrm{Pd}(\mathrm{OH})_{2}$ (Scheme 34). It was also hoped that conversion of the azide to the desired acetamide could be achieved during hydrogenation as there is literature precedent for in situ acetylation of amines during hydrogenation by the addition of acetic anhydride. ${ }^{129-132}$ Hydrogenation of disaccharide $\mathbf{2 1}$ was conducted in a FisherPorter bottle with 4 bars of hydrogen pressure and $\mathrm{Pd}(\mathrm{OH})_{2}$ in chloroform/ethanol/acetic 
anhydride, 1/1/0.1, v/v/v. From the ${ }^{1} \mathrm{H}$ NMR spectrum of the crude reaction mixture it appeared that removal of the benzyl and benzylidene protecting groups was successful. However, it was difficult to tell if acetylation of the amine was complete so the crude reaction mixture was re-subjected to acetic anhydride to ensure complete acetylation. $\mathrm{K}_{2} \mathrm{CO}_{3}$ was used as the added base instead of pyridine to prevent acetylation of the hydroxyl groups. This resulted in the acetamide $\mathbf{7 5}$ in $61 \%$ yield over the two steps. The appearance of the characteristic acetamide methyl group singlet at $1.99 \mathrm{ppm}$ in the ${ }^{1} \mathrm{H}$ NMR spectrum of $\mathbf{7 5}$ showed acetylation of the amine had occurred and HRMS(ESI) confirmed the product was of the correct molecular weight $(\mathrm{m} / \mathrm{z}$ calcld. for $\left[\mathrm{C}_{20} \mathrm{H}_{39} \mathrm{O}_{10} \mathrm{NSi}+\mathrm{Na}\right]^{+}: 504.2235$ obsd.: 504.2244$)$. Unfortunately, when the reaction was reattempted on a larger scale $(93 \mathrm{mg}$ instead of $21 \mathrm{mg}$ ) using the same conditions, the desired product was not formed. The presence of $\alpha$ and $\beta$-L-fucose was observed in the ${ }^{1} \mathrm{H}$ NMR spectrum $\left(\delta_{\mathrm{H} 1 \alpha}=5.17, J_{1,2}=3.9 \mathrm{~Hz}\right.$ and $\left.\delta_{\mathrm{H} 1 \beta}=4.52, J_{1,2}=7.8 \mathrm{~Hz}\right)$ of the crude hydrogenation reaction mixture along with other unidentifiable by-products. The addition of acetic anhydride could have resulted in the production of acetic acid due to water present in the $\mathrm{Pd}(\mathrm{OH})_{2} / \mathrm{C}$ catalyst, leading to the cleavage of the acid labile fucose residue. However, the reduction of azides by hydrogenation requires the presence of some acid to protonate the resulting amine in order to prevent it from co-ordinating to and poisoning the palladium catalyst. ${ }^{133}$ Although the larger scale reaction was unsuccessful the material from the first reaction was continued with. The last step in the full deprotection was removal of the TBDMS ether. Previously when TBDMS removal had been required for conversion to the corresponding imidate donor it was achieved using HF.pyridine. However, an alternative strategy was needed as the use of HF.pyridine requires an aqueous workup, from which recovery of the fully deprotected product would be impossible. Corey and Venkateswarlu have reported the removal of a TBDMS ether using acetic acid/water/THF, 3/1/1, v/v/v at room temperature. ${ }^{134}$ These reaction conditions were used as they do not require an aqueous workup and instead the reaction mixture can be concentrated in vacuo (Scheme 34). No reaction was observed according to TLC analysis at room temperature so the solution was heated to $65^{\circ} \mathrm{C}$ for six hours. This resulted in the formation of base-line material according to TLC analysis (DCM/methanol/ethanol/ $\mathrm{NH}_{3}$ (30\% aq.), 15/2/2/1, v/v/v/v). Although from the ${ }^{1} \mathrm{H} \mathrm{NMR}$ 
spectrum of the crude reaction mixture it seemed as though some of the fully deprotected product 76 had been formed, it also contained $\beta$-L-fucose $\left(\delta_{\mathrm{H} 1 \beta}=4.52, J_{1,2}=7.8 \mathrm{~Hz}\right)$ and unreacted starting material. HRMS(ESI) confirmed that there was product present in the crude reaction mixture $\left(\mathrm{m} / \mathrm{z}\right.$ calcld. for $\left[\mathrm{C}_{14} \mathrm{H}_{25} \mathrm{O}_{10} \mathrm{~N}+\mathrm{Na}\right]^{+}: 390.1376$ obsd.: 390.1378$)$. Unfortunately the presence of $\beta$-L-fucose indicated hydrolysis of the $\alpha$-1,3-linkage. Although the glycosidic bond of deprotected $\alpha$-fucose residues is known to be more stable under acidic conditions than that of the corresponding benzyl protected residue, it appeared that it was not stable enough to withstand the conditions required for TBDMS removal. Due to the difficulties encountered with cleavage of the acid labile $\alpha$-fucose residue during the deprotection, an alternative strategy was required which did not use acid at elevated temperatures.

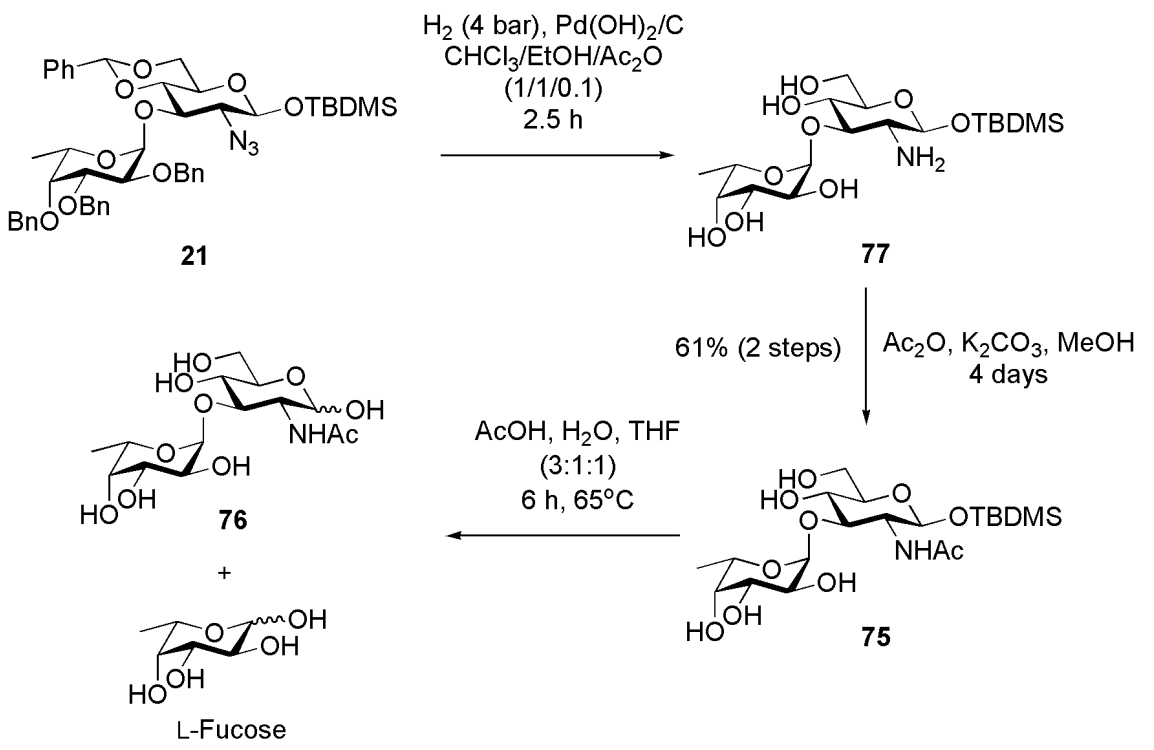

Scheme 34: $\quad$ Initial deprotection strategy for the FucGlc $\left(\mathrm{N}_{3}\right)$ disaccharide 21.

\subsubsection{Revised Deprotection Strategy}

Nagorny et al. also used TBDMS ether protection for the reducing anomeric centre of their dodecasaccharide. ${ }^{77}$ Their deprotection strategy involved conversion of the protected C-2 amine groups into the corresponding acetamides, followed by removal of the anomeric TBDMS, then cleavage of the acetate groups before removal of the benzyl protecting groups, resulting in the fully deprotected sugar. The adaption of Nagorny et 
al.'s strategy to our disaccharide has two advantages over our initial strategy. Firstly, although they used phthalimide protecting groups instead of an azide, the selective conversion of the azide to the desired acetamide would reduce the problems associated with hydrogenation as acid would not be required to protonate the resulting amine, thus reducing the chance of $\alpha$-fucose hydrolysis. Secondly, by removing the TBDMS protecting group earlier in the deprotection strategy HF.pyridine can be used as the resulting lactol can be isolated from an aqueous workup.

The first step in the revised deprotection strategy was conversion of the azide to an acetamide. As Staudinger reduction of the azide was previously successful during the synthesis of the Troc imidate donor it was attempted on the fully protected FucGlc $\left(\mathrm{N}_{3}\right)$ disaccharide. Conversion of the azide $\mathbf{2 1}$ to the acetamide $\mathbf{7 8}$ was successfully achieved in $79 \%$ yield over two steps via Staudinger reduction $\left(\mathrm{PMe}_{3}, \mathrm{NaOH}\right)$ followed by acetylation of the crude amine with acetic anhydride and pyridine (Scheme 35). However, when the reaction was scaled up ( $240 \mathrm{mg}$ instead of $33 \mathrm{mg}$ ) the yield decreased to $42 \%$ and the urea 79 was also isolated in $25 \%$ yield. The formation of urea by-product, although surprising, can be rationalised by amine $\mathbf{8 0}$ reacting with either carbonate or bicarbonate anions during the reduction $\left(\mathrm{CO}_{2}\right.$ is absorbed by $\mathrm{NaOH}$ resulting in $\left.\mathrm{Na}_{2} \mathrm{CO}_{3}\right)$ or during the aqueous workup (saturated aqueous $\mathrm{NaHCO}_{3}$ ), resulting in carbamate $\mathbf{8 1}$. This carbamate can then react with acetic anhydride to produce anhydride $\mathbf{8 2}$ which can undergo nucleophilic attack by amine 80 to give the observed urea byproduct 79 (Scheme 35 ). Conversion to the acetamide was repeated (120 mg scale) whilst trying to minimise carbamate formation. A freshly made solution of $\mathrm{KOH}$ was used instead of $\mathrm{NaOH}(\mathrm{KOH}$ absorbs less $\mathrm{CO}_{2}$ than $\mathrm{NaOH}$ ) and saturated aqueous $\mathrm{NaHCO}_{3}$ was not used during the work up. Disappointingly this resulted in only a $38 \%$ yield of the desired acetamide $\mathbf{7 8}$ and the formation of several unidentifiable by-products. 

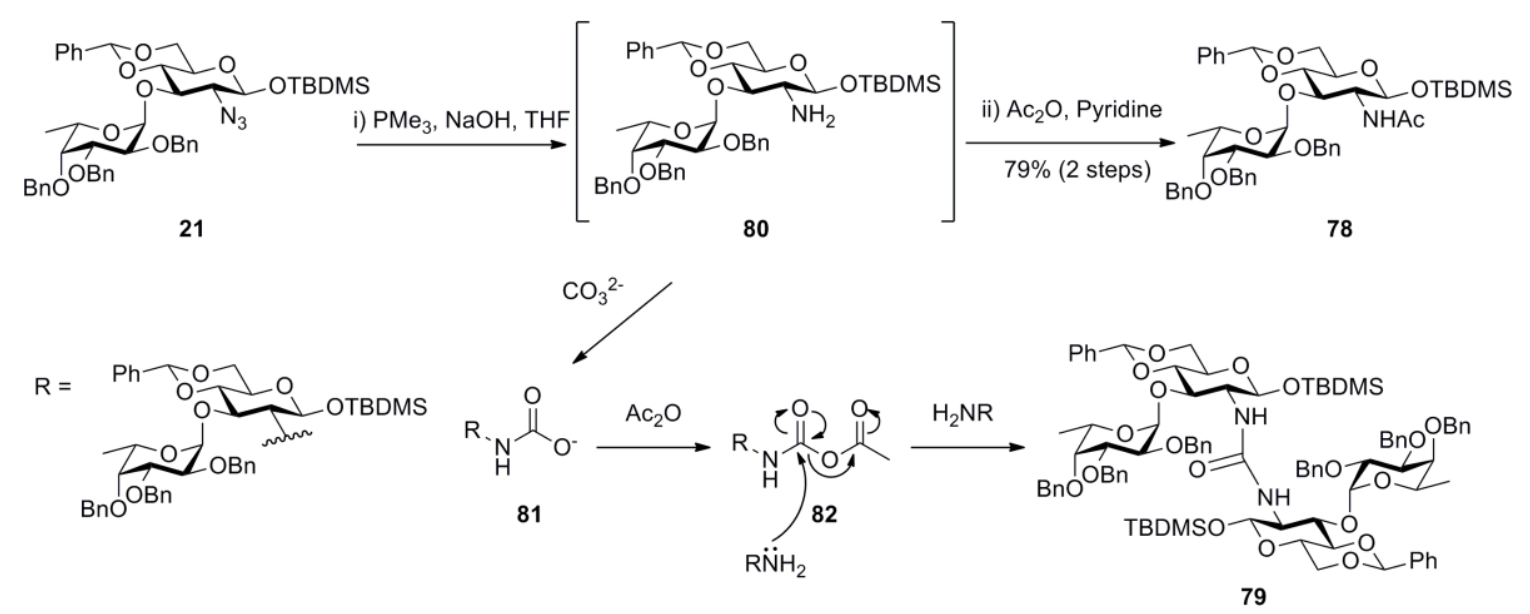

Scheme 35: Synthesis of acetamide 78 using Staudinger reduction and the proposed mechanism for the formation of the urea by-product 79 .

As the Staudinger reduction method was too unreliable, an alternative strategy for converting the azide to the acetamide was required. Koizumi et al. have recently reported the conversion of both an azido group and a Troc group, in the same step, to their corresponding acetamido moieties using zinc, acetic acid and acetic anhydride at room temperature. ${ }^{126}$ As this methodology would be very useful in the deprotection of our larger carbohydrates, bearing both a Troc and an azido group, the reaction was attempted on the azide containing disaccharide 21 (Scheme 36). Unfortunately the reaction was unsuccessful both times it was attempted. Although some product was isolated (26\%), neither reaction went to completion, despite stirring for 24 hours (Koizumi et al. reported completion of the reaction after 1 hour), and the formation of several by-products was also observed. The by-products were not fully characterised due to purification difficulties. Although the reaction mixture was purified via column chromatography (ethyl acetate/light petroleum ether, $1 / 10 \rightarrow 1 / 3, v / v$ ), one of the by-products was inseparable from unreacted starting material $\left(R_{f}=0.61\right.$ ethyl acetate/light petroleum ether, $1 / 5, \mathrm{v} / \mathrm{v})$ and the other two were co-eluted $\left(R_{f}=0.18\right.$ ethyl acetate/light petroleum ether, $1 / 5, \mathrm{v} / \mathrm{v}$ ). The by-products were tentatively assigned using HRMS(ESI) analysis as: the 2-O-acetate 83 (eluted with starting material) $\left(\mathrm{m} / z\right.$ calcld. for $\left[\mathrm{C}_{48} \mathrm{H}_{60} \mathrm{O}_{11} \mathrm{Si}+\mathrm{Na}\right]^{+}$: 863.3803 obsd.: 863.3806), the 2,6-di- $O$-acetate $84\left(\mathrm{~m} / z\right.$ calcld. for $\left[\mathrm{C}_{43} \mathrm{H}_{58} \mathrm{O}_{12} \mathrm{Si}+\mathrm{Na}\right]^{+}$: 817.3595 obsd.: 817.3604), and the elimination product $85(\mathrm{~m} / z$ calcld. for 
$\left[\mathrm{C}_{41} \mathrm{H}_{54} \mathrm{O}_{10} \mathrm{Si}+\mathrm{Na}\right]^{+}: 757.3384$ obsd.: 757.3395 ) (acetylation of $O-6$, instead of $O-4$ was assumed due to the greater reactivity of primary hydroxyls) (Scheme 36).
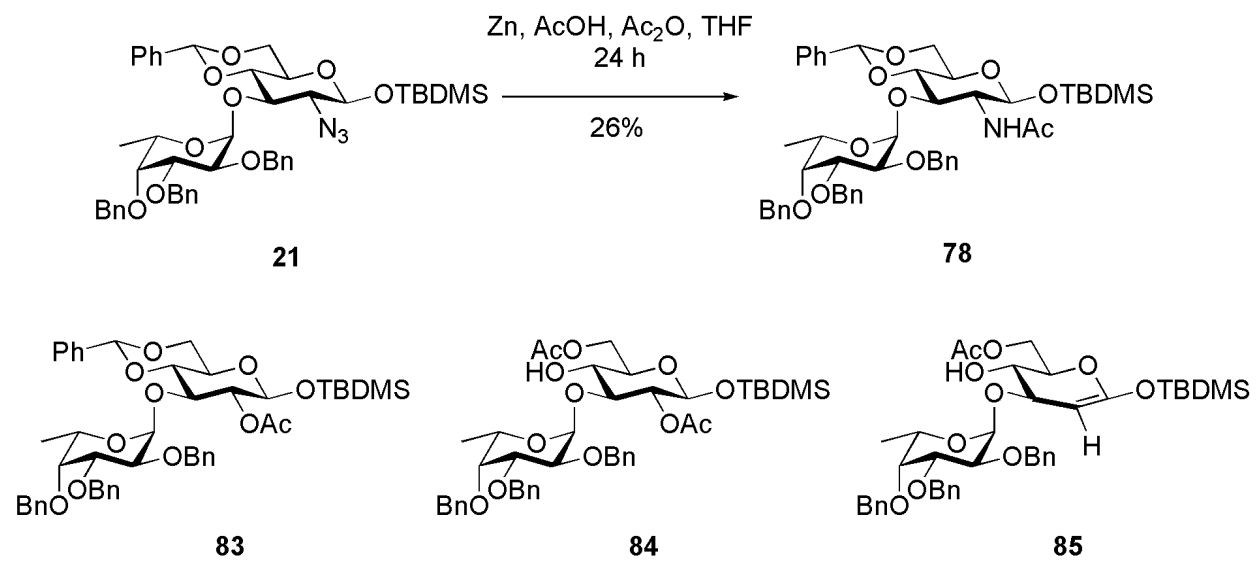

Scheme 36: Attempted synthesis of acetamide $\mathbf{7 8}$ using $\mathrm{Zn}, \mathrm{AcOH}$ and $\mathrm{Ac}_{2} \mathrm{O}$ with the tentatively assigned by-products 83,84 and 85 .

Due to difficulties with the zinc reaction it was clear another method was required. On further investigation it was discovered that thioacetic acid has been successfully used in the deprotection of carbohydrates to convert azides directly to the corresponding acetamide. $^{135-138}$ Thioacetic acid conversion has been shown to be compatible with both benzylidene protection and benzyl protected $\alpha-1,3$-linked fucose residues. ${ }^{136}$ It has also been used on carbohydrates bearing both azide and $N$-Troc groups to selectively convert the azide to an acetamide before zinc mediated cleavage of the Troc group was conducted. ${ }^{137,138}$ The FucGlc $\left(\mathrm{N}_{3}\right)$ disaccharide 21 was treated with thioacetic acid and pyridine $(1 / 1, \mathrm{v} / \mathrm{v})$ to afford the acetamide 78 in an acceptable yield of $62 \%$ (Scheme 37). Conversion of the azide to the acetamide was seen in the IR spectrum of $\mathbf{7 8}$ by the disappearance of the strong absorption at $2111 \mathrm{~cm}^{-1}$, associated with the asymmetric stretching vibration of the azide, and the introduction of a strong absorption at $1660 \mathrm{~cm}^{-1}$ associated with the $\mathrm{C}=\mathrm{O}$ stretch of the newly formed amide.

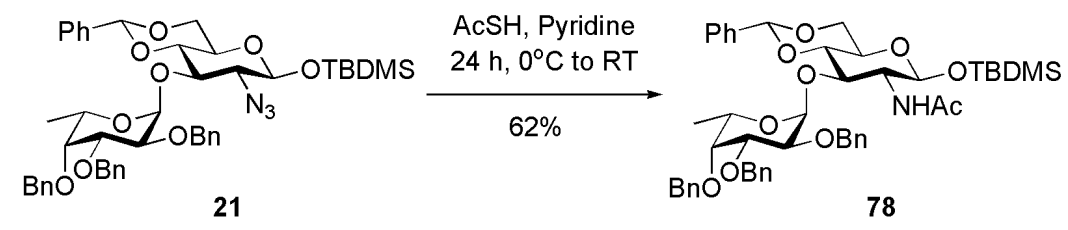

Scheme 37: $\quad$ Successful synthesis of acetamide $\mathbf{7 8}$ using AcSH and pyridine. 
With a reliable way of converting the azide to an acetamide, attention was then turned towards removal of the TBDMS ether. To our relief the previously used HF.pyridine method was compatible with the benzyl protected $\alpha-1,3$-fucose residue and resulted in lactol 86 in an excellent yield of $98 \%$ (Scheme 38). The final deprotection step was removal of the benzylidene and benzyl groups. It was hoped that hydrogenation would now be successful as the azide has already been converted to an acetamide. Hydrogenation of lactol $\mathbf{8 6}$ was attempted using $\mathrm{Pd}(\mathrm{OH})_{2}$ as the catalyst and chloroform/ethanol, 3/2, v/v as the solvent. Unfortunately, although the removal of the benzylidene and benzyl groups was successful to give fully deprotected disaccharide 76, the ${ }^{1} \mathrm{H}$ NMR spectrum of the crude reaction mixture also showed the presence of $\beta$-Lfucose $\left(\delta_{\mathrm{H} 1 \beta}=4.52, J_{1,2}=7.8 \mathrm{~Hz}\right)$ and $\alpha / \beta-N$-acetylglucosamine $\left(\delta_{\mathrm{H} 1 \alpha}=5.16, J_{1,2}=3.4 \mathrm{~Hz}\right.$ and $\delta_{\mathrm{H} 1 \beta}=4.67, J_{1,2}=8.3 \mathrm{~Hz}$ ) indicating that hydrolysis had once again occurred during hydrogenation. It was thought that the use of chloroform resulted in the acidic conditions responsible for cleaving the $\alpha$-fucose residue. Purification of disaccharide $\mathbf{7 6}$ was attempted using $\mathrm{C}_{18}$ and $\mathrm{C}_{8}$ reverse phase chromatography but it was not possible to remove the $\alpha / \beta$-L-fucose and $\alpha / \beta-N$-acetylglucosamine. Therefore the hydrogenation was reattempted using ethanol/ethyl acetate, 1/1, v/v. Ethyl acetate was used because the starting material was insoluble in straight ethanol and Matsuoka et al. successfully used ethyl acetate in the hydrogenation of a trisaccharide which also contained a benzyl protected $\alpha$-fucose residue. ${ }^{138}$ To our relief hydrogenation using ethanol/ethyl acetate was successful with no hydrolysis by-products observed, resulting in disaccharide $\mathbf{7 6}$ in $92 \%$ yield (Scheme 38).

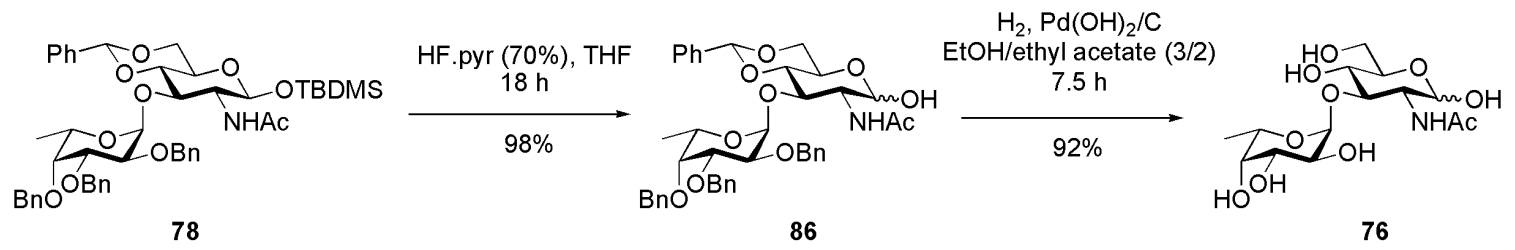

Scheme 38: Successful deprotection of the fully protected acetamide $\mathbf{7 8}$ resulting in the fully deprotected FucGlcNAc disaccharide $\mathbf{7 6}$. 


\subsection{Deprotection of the Gle(Troc)(Fuc)Glc( $\left.\mathbf{N}_{3}\right)$ Trisaccharide}

\subsubsection{Achieved Deprotection Reactions}

With the successful deprotection of the FucGlcNAc disaccharide achieved, attention was given to deprotecting the $\mathrm{Glc}(\mathrm{Troc})(\mathrm{Fuc}) \mathrm{Glc}\left(\mathrm{N}_{3}\right)$ trisaccharide 58. The first step in the deprotection was conversion of the azide to the corresponding acetamide. The azide must be converted before the Troc group as during the FucGlcNAc deprotection it was shown that the azide was incompatible with the Troc deprotection conditions ( $\mathrm{Zn}$, acetic acid). Treatment of azide $\mathbf{5 8}$ with thioacetic acid in pyridine resulted in the successful conversion to acetamide 87 in $71 \%$ yield (Scheme 39). The molecular weight of the acetamide 87 was confirmed by $\operatorname{HRMS}(\mathrm{ESI})\left(\mathrm{m} / \mathrm{z}\right.$ calcld. for $\left[\mathrm{C}_{71} \mathrm{H}_{85} \mathrm{O}_{16} \mathrm{~N}_{2} \mathrm{Cl}_{3} \mathrm{Si}+\mathrm{Na}\right]^{+}$: 1377.4632 obsd.: 1377.4646). The $N$-acetyl methyl protons were observed in the ${ }^{1} \mathrm{H}$ NMR spectrum of $\mathbf{8 7}$ as a singlet at 1.72 ppm as well as the disappearance of the azide absorption $\left(2111 \mathrm{~cm}^{-1}\right)$ from the IR spectrum, confirming conversion of the azide to the acetamide.

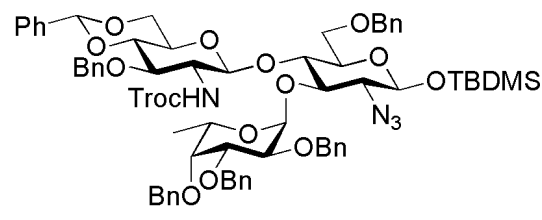

58

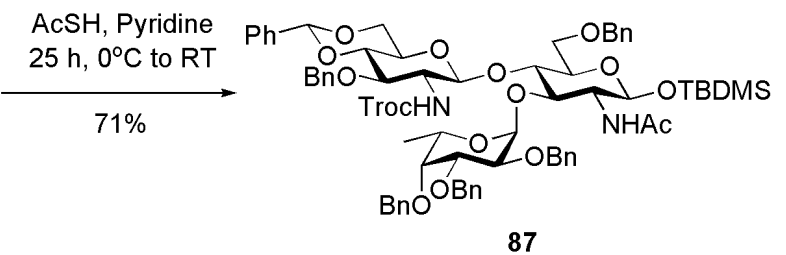

87

Scheme 39: $\quad$ Successful synthesis of acetamide 87 using AcSH and pyridine.

\subsubsection{Future Work - Proposed Deprotection Strategy}

The full deprotection of the GlcNAc(Fuc)GlcNAc trisaccharide $\mathbf{8 7}$ requires three more steps. The next step in the deprotection sequence is the conversion of the $N$-Troc group of $\mathbf{8 7}$ to the corresponding $N$-acetate $\mathbf{8 8}$ (Scheme 40). The $N$-Troc group can be removed via treatment with zinc and acetic acid and the resulting amine can be acetylated in situ by the addition of acetic anhydride. ${ }^{137}$ The two remaining deprotection steps have already been conducted and optimised on the FucGlcNAc dimer. They are removal of the anomeric silyl protecting group using HF.pyridine resulting in lactol 89, followed by 
hydrogenation using $\mathrm{Pd}(\mathrm{OH})_{2} / \mathrm{C}$ as the catalyst and ethanol/ethyl acetate as the solvent to give the fully deprotected trisaccharide $\mathbf{9 0 .}$

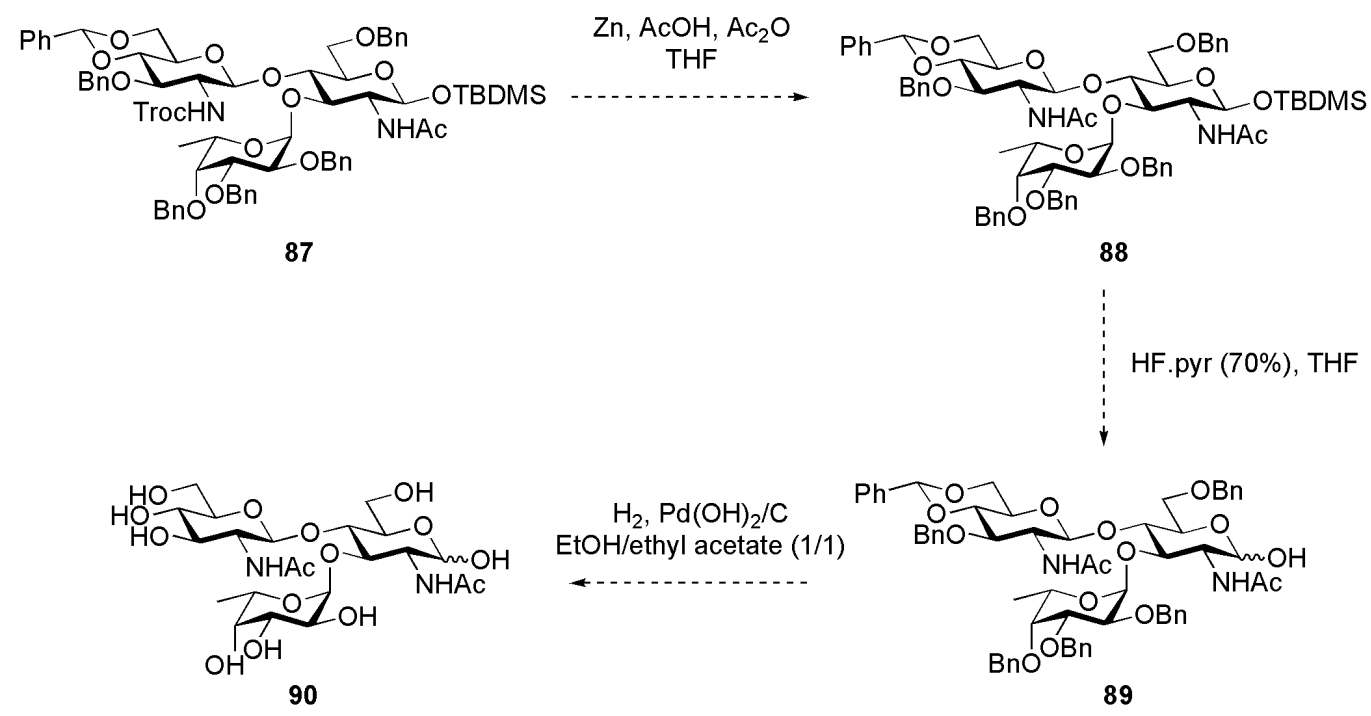

Scheme 40: Proposed deprotection strategy for the GlcNAcFucGlcNAc trisaccharide.

\subsection{Anomeric Amine Formation}

\subsection{1 $\mathrm{N}$-Acetylglucosamine}

The formation of the $\beta$-anomeric amine is a key component in the synthesis of any $N$ linked glycoprotein or glycoconjugate. The most commonly used procedure for converting anomeric hydroxyls into $\beta$-glycosylamines (Scheme 41), especially in the synthesis of glycosylamines of complex synthetic oligosaccharides, is the Kochetkov amination reaction. ${ }^{80}$ This involves treating the fully deprotected sugar with a large excess of ammonium bicarbonate in water. As the reaction occurs in aqueous media, the $\beta$-amino product is favoured due to the extended hydrogen bonding network. The excess ammonium bicarbonate is removed via repeated lyophilisation to give the $\beta$-anomeric glycosylamine. Another method recently developed by Likhosherstov uses ammonium carbonate in methanol and involves precipitation of the product as the carbamic acid salt. ${ }^{139}$ This salt is then converted to the desired free amine by base treatment or high 
vacuum. Kochetkov's method was chosen for anomeric amine conversion as Likhosherstov's method required precipitation and filtration of the carbamic acid salt which is impractical given the small scale we will be conducting the amination reactions on $(<20 \mathrm{mg})$.

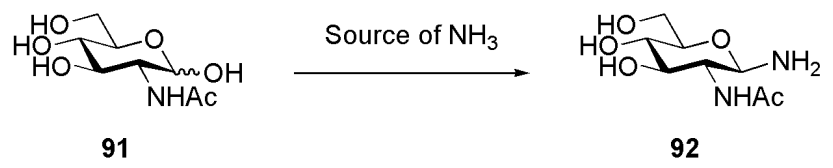

Scheme 41: $\quad$ Anomeric conversion of $N$-acetylglucosamine (91) to form the anomeric amine 92.

Although the Kochetkov method is widely used, numerous variations of this method have been reported which involve changes to the temperature and duration of the reaction, the ammonium bicarbonate concentration, the sugar concentration, and the use or absence of aqueous ammonia. ${ }^{76,77,80,140-142}$ The incomplete conversion of starting material and formation of by-products are known to be potential problems during this reaction. ${ }^{80,140}$ The main by-products for this conversion of 91 into 92 are the diglycosylamine 93 and the glycosylcarbamate 94 (Figure 10). The formation of the diglycosylamine 93 is more prevalent at high temperatures, especially above $50^{\circ} \mathrm{C}$ and when the concentration of the reactant sugar is above $0.5 \mathrm{molL}^{-1} \cdot{ }^{140}$ Fortunately, although the formation of diglycosylamine is undesirable, the presence of dimer does not interfere with subsequent acylations. ${ }^{143}$ The formation of the carbamate 94 is a consequence of the ammonium bicarbonate and increases at higher concentrations of ammonium bicarbonate although it is not considered problematic as it is in equilibrium with the desired amine product and the equilibrium is shifted by evaporation, lyophilisation, and dilution. ${ }^{140}$ Another problem with the formation of anomeric glycosylamines is their instability. They have been known to dimerise upon storage (especially at room temperature) and are prone to hydrolysis in acidic or neutral aqueous solution, which makes purification and characterisation extremely difficult. ${ }^{80,140,144}$ Therefore, complex glycosylamines are often used without purification and are only characterised via mass spectrometry after removal of ammonium bicarbonate via lyophilisation. ${ }^{77,142}$ It should also be noted that the reaction vessel should be opened periodically during the reaction to allow the liberated $\mathrm{CO}_{2}$ to 
escape, as Kochetkov and co-workers reported yields of $<30 \%$ when the vessel was sealed throughout the reaction. ${ }^{80}$
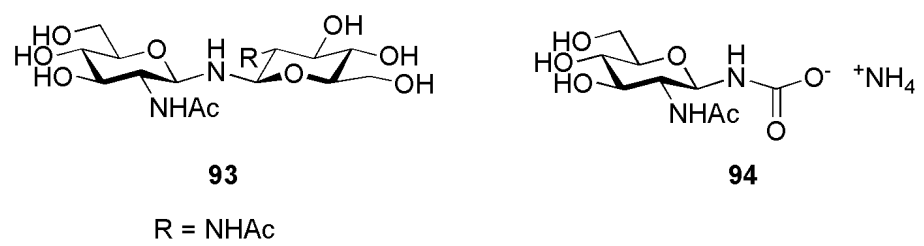

Figure 10: Possible by-products from the anomeric amine conversion reaction.

In order to determine the optimum conditions for the anomeric conversion, six different variations of the Kochetkov reaction were conducted on $\mathrm{N}$-acetylglucosamine (91), while thought was given to the fact that the synthesis of the larger glycosylamines would be conducted using $<20 \mathrm{mg}$ of starting material. A summary of the six conditions used to form $\mathrm{N}$-acetyl glucosamine is shown in Table 4. Entries 1, 2, and 3 were based on Nagorny et al.'s conversion of a dodecasaccharide to the corresponding anomeric amine. $^{77}$ Their reaction used only $11 \mathrm{mg}(4.23 \mu \mathrm{mol})$ of starting material with $6 \mathrm{~g}$ of ammonium bicarbonate in $5 \mathrm{~mL}$ of water and was stirred for three days at $40^{\circ} \mathrm{C}$. Entry 4 was based on both Wang et al. ${ }^{76}$ and Miller et al.'s ${ }^{142}$ synthesis, which were both conducted at room temperature for 3 and 6 days respectively, using quantities of oligosaccharide, ammonium bicarbonate, and water comparable to that of Nagorny et al. Entry 5 was based on Shin et al. ${ }^{141}$ and Vetter and Gallop's ${ }^{143}$ procedure which used saturated aqueous ammonium bicarbonate with addition of a small amount of ammonium bicarbonate to maintain saturation. Lastly entry 6 was based on Lubineau et al.'s 140 procedure in which the sugar $(0.2 \mathrm{M})$ and ammonium bicarbonate $(0.2 \mathrm{M})$ were dissolved in $16 \mathrm{M}$ aqueous ammonia and left for 36 hours at $42^{\circ} \mathrm{C}$. 
Table 4: $\quad$ Different reaction conditions attempted for the anomeric amine conversion reaction.

\begin{tabular}{|c|c|c|c|c|}
\hline Entry & $\begin{array}{l}\text { Reaction } \\
\text { Conditions }\end{array}$ & $\begin{array}{l}\text { Time of } \\
\text { Reaction }\end{array}$ & Temperature & $\begin{array}{c}\text { Ratio }^{1} \\
\text { Product:Starting Material }\end{array}$ \\
\hline 1. & $\begin{array}{c}91(0.0047 \mathrm{~g}) \\
\mathrm{NH}_{4} \mathrm{HCO}_{3}(6 \mathrm{~g}) \\
\mathrm{H}_{2} \mathrm{O}(5 \mathrm{~mL})\end{array}$ & 6 days & $40^{\circ} \mathrm{C}$ & $3.5: 1$ \\
\hline 2. & $\begin{array}{c}91(0.1090 \mathrm{~g}) \\
\mathrm{NH}_{4} \mathrm{HCO}_{3}(6 \mathrm{~g}) \\
\mathrm{H}_{2} \mathrm{O}(5 \mathrm{~mL})\end{array}$ & 6 days & $40^{\circ} \mathrm{C}$ & $5.2: 1$ \\
\hline 3. & $\begin{array}{c}91(0.0051 \mathrm{~g}) \\
\mathrm{NH}_{4} \mathrm{HCO}_{3}(6 \mathrm{~g}) \\
\mathrm{H}_{2} \mathrm{O}(5 \mathrm{~mL})\end{array}$ & 3 days & $40^{\circ} \mathrm{C}$ & $3.3: 1$ \\
\hline 4. & $\begin{array}{c}91(0.0051 \mathrm{~g}) \\
\mathrm{NH}_{4} \mathrm{HCO}_{3}(6 \mathrm{~g}) \\
\mathrm{H}_{2} \mathrm{O}(5 \mathrm{~mL})\end{array}$ & 6 days & $20^{\circ} \mathrm{C}$ & $1.9: 1$ \\
\hline 5. & $\begin{array}{c}91(0.2247 \mathrm{~g}) \\
\mathrm{NH}_{4} \mathrm{HCO}_{3}(0.7 \mathrm{~g}) \\
\mathrm{NH}_{4} \mathrm{HCO}_{3}(5 \mathrm{~mL}, \text { sat. aq })\end{array}$ & 3 days & $40^{\circ} \mathrm{C}$ & $1.6: 1$ \\
\hline 6. & $\begin{array}{c}91(0.2200 \mathrm{~g}, 0.2 \mathrm{M}), \\
\mathrm{NH}_{4} \mathrm{HCO}_{3}(0.08 \mathrm{~g} 0.2 \mathrm{M}), \\
\mathrm{NH}_{3}(5 \mathrm{~mL}, \mathrm{aq}, 35 \%)\end{array}$ & 24 hours & $40^{\circ} \mathrm{C}$ & $0.1: 1$ \\
\hline
\end{tabular}

Ratios are based on the integration values for the ${ }^{1} \mathrm{H}$ NMR signals of the anomeric protons. Product includes both amine 92 and carbamate 94 as the carbamate is in equilibrium with amine. ${ }^{140}$ Starting material includes both $\alpha$ and $\beta$ starting material. ${ }^{1} \mathrm{H}$ NMR values in $\mathrm{D}_{2} \mathrm{O}(\delta 4.79)$ : amine product $\left(\delta \mathrm{H}_{1 \beta}\right.$ $4.13, J=9.3 \mathrm{~Hz})$, carbamate $\left(\delta \mathrm{H}_{1 \beta} 4.71, J=9.7 \mathrm{~Hz}\right), \alpha$-starting material $\left(\delta \mathrm{H}_{1 \alpha} 5.15, J=3.4 \mathrm{~Hz}\right), \beta$-starting material $\left(\delta \mathrm{H}_{1 \beta} 4.66, J=8.5 \mathrm{~Hz}\right)$.

After each reaction was complete the water and ammonium bicarbonate were removed via repeated lyophilisation until a constant weight was reached. Unfortunately for entries 1-5 it was not possible to remove all of the ammonium bicarbonate by repeated lyophilisation (10 times), with between 70 and $100 \mathrm{mg}$ remaining. All samples were analysed by ${ }^{1} \mathrm{H}$ NMR spectroscopy to determine the ratio of starting material to product and whether any by-products were formed. The best results were achieved when a large excess of ammonium bicarbonate was used, and the reaction was conducted at $40^{\circ} \mathrm{C}$ (entries 1-3). As well as resulting in the poorest conversion the use of aqueous ammonia (entry 6) also resulted in several by-products that were not seen in the other reactions. These by-products were not characterised but were thought to be either the dimer $\mathbf{9 3}$ and/or products produced via either the Amadori rearrangement ${ }^{145-147}$ and/or the Lobry-de Bruyn-van Ekenstein Reaction ${ }^{148}$ due to the presence of excess ammonia. 
The crude reaction mixture of entry 2 was purified using a Dowex $\mathrm{H}^{+}$cation exchange resin column. Unreacted starting material was eluted with water and the desired glucosamine 92 was eluted with $5 \%$ aqueous ammonia. $\beta$-Glycosylamine 92 was obtained as a white amorphous solid after lyophilisation in a $68 \%$ yield. $31 \%$ of the starting material was also recovered, indicating that product hydrolysis had occurred under the acidic aqueous purification conditions (product:starting material, pre-column: 5.2:1, post-column: 2.2:1). Purification was required to remove the residual ammonium bicarbonate as the presence of ammonia in the subsequent acylation step is problematic because it reacts with the activated acid thus reducing the efficiency of the coupling reaction. ${ }^{143}$ The presence of unreacted starting material is not an issue in subsequent acylation reactions as the amine functionality is more nucleophilic and thus reacts

preferentially. ${ }^{143}$ Vetter and Gallop have reported that residual ammonium bicarbonate remaining after repeated lyophilisation can be removed by warming the glycosylamine in methanol until gas evolution ceases, followed by evaporation in vacuo. ${ }^{143}$

\subsubsection{FucGlcNAc and $\mathrm{Man}_{3}$ Anomeric Amine Formation}

With the method for forming an anomeric amine optimised, attention was turned back to the fully deprotected sugars $\mathbf{4 2}$ and $\mathbf{7 6}$. The fully deprotected sugars, $\mathbf{4 2}(4.7 \mathrm{mg})$ and $\mathbf{7 6}$ $(12.2 \mathrm{mg})$, were each dissolved in $5 \mathrm{~mL}$ of water and $6 \mathrm{~g}$ of ammonium bicarbonate was added to each reaction before the solutions were stirred for 6 days. The excess water and ammonium bicarbonate was removed by repetitive lyophilisation to yield the anomeric amines 95 and 96 (Scheme 42). Conversion to the respective glycosylamines was confirmed by HRMS(ESI) analysis $\left(95 \mathrm{~m} / z\right.$ calcld. for $\left[\mathrm{C}_{18} \mathrm{H}_{33} \mathrm{O}_{15} \mathrm{~N}+\mathrm{H}\right]^{+}:$: 504.1928, obsd.: 504.1930, $96 \mathrm{~m} / z$ calcld. for $\left[\mathrm{C}_{14} \mathrm{H}_{26} \mathrm{O}_{9} \mathrm{~N}_{2}+\mathrm{H}\right]^{+}: 367.1717$, obsd.: 367.1723$)$. The glycosylamines, 95 and $\mathbf{9 6}$, were not futher characterised due to the previously mentioned difficulties with characterising glycosylamines. 

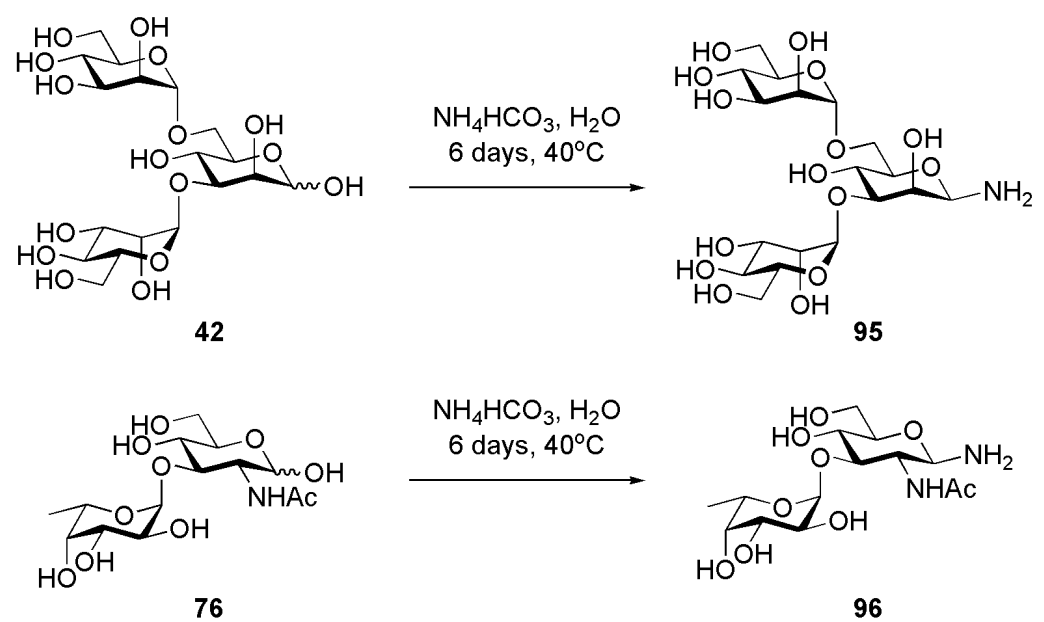

Scheme 42: Anomeric conversion of the $\mathrm{Man}_{3}$ trisaccharide $\mathbf{4 2}$ and the FucGlcNAc disaccharide $\mathbf{7 6}$ to form the anomeric amines 95 and 96 respectively.

\subsection{Future Work}

\subsubsection{Proposed Strategy for the Coupling to Latex Beads and/or Proteins}

With the successful synthesis of all three glycosylamines (GlcNAc monomer 92, FucGlcNAc 96, and $\mathrm{Man}_{3}$ 95) the final step is conjugation to either a protein or fluorescent latex bead via carboxylic acid residues (Scheme 43). The formation of the glycoconjugates was not conducted by the candidate due to time constraints. Coupling of the glycosylamines to the chosen proteins (KLH and OVA), which have had their native glycans cleaved, can be conducted using the procedures developed by Cohen-Anisfeld and Lansbury for the formation of $\beta$ - $N$-linked glycopeptides. ${ }^{83}$ These conditions have proved successful in the synthesis of a number of $\beta$ - $N$-linked glycopeptides, most notably in the work of Danishefsky and co-workers who have successfully attached synthetic 12-, 13-, and 15-mer oligosaccharides to synthetic peptides. ${ }^{76,77,79}$ The conditions developed by Cohen-Anisfeld and Lansbury involve treatment of the glycosylamine and peptide/protein with HBTU and hydroxybenzotriazole (HOBt) in dimethyl sulfoxide (DMSO). HBTU is used as the peptide coupling reagent. HOBt is used to prevent racemisation of the peptide and it also reduces formation of the aspartimide by-product. $N, N$-Diisopropylethylamine (DIPEA) can also be used in the reaction to deprotonate the carboxylic acid. However, in the case of peptides that are particularly prone to 
aspartimide formation it is often not added as it increases aspartimide formation. ${ }^{83}$ When DIPEA is not added the glycosylamine acts as the base to deprotonate the carboxylic acid. The reaction is conducted in DMSO as opposed to water as glycosylamines are readily hydrolysed under acidic or neutral aqueous condition. ${ }^{143}$ Once formed the glycoproteins can be analysed using NMR analysis ${ }^{149}$ and matrix-assisted laser desorption/ionization-time-of-flight (MALDI-TOF) mass spectrometry. ${ }^{150}$ Coupling of the glycosylamines to the carboxylic acid modified fluorescent beads can also be achieved using the procedures for coupling to proteins. However, as protein racemisation and aspartimide formation are not an issue when coupling to fluorescent beads, HOBt does not need to be added and also DIPEA can be added without the worry of increased aspartimide formation. The loading of the carbohydrates onto the fluorescent beads can be determined using the Morgan-Elson Assay. ${ }^{151-154}$ Once the glycoconjugates are formed, they will be tested for their ability to bias the Th response to a Th2 immune response using IL4/GFP reporter mice. This testing will be conducted at the Malaghan Institute of Medical Research, Wellington, New Zealand.

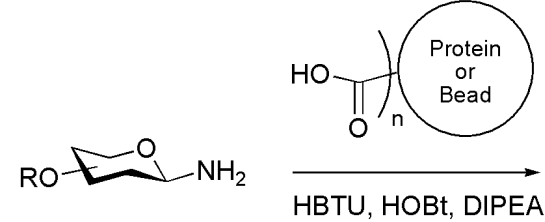

Glycosylamine

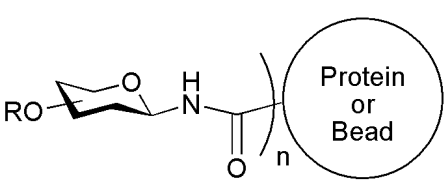

Protein or Bead Conjugate

Scheme 43: $\quad$ Proposed strategy for coupling the $\beta$-glycosylamines to either a protein or a fluorescent latex bead using the methodology developed by Cohen-Anisfeld and Lansbury. ${ }^{83}$ 


\section{CONCLUSION}

In this Masters project, significant progress was made towards the synthesis of the three target glycoconjugates $\mathbf{1 4}, \mathbf{1 5}$, and $\mathbf{1 6}$, with the successful synthesis of the three preceding glycosylamines. During the efforts towards the synthesis of the $\mathrm{Man}_{3}$ glycoconjugate 16 significant quantities of the mannose imidate building block 18 were produced. The gram quantities synthesised will be used by other members of our group for the synthesis of the target heptasaccharide glycoconjugates and other target glycoconjugates containing the $\mathrm{Man}_{3}(\mathrm{GlcNAc})_{2}$ pentasaccharide core. The mannose imidate building block was also shown to successfully give the desired $\alpha$-linkage due to neighbouring group participation of the 2-O-benzoyl group.

En route to the FucGlcNAc glycoconjugate 15, formation of the $\alpha-1,3$-fucose linkage was successfully optimised to enable both excellent yields and selectivity $(89 \%, \alpha: \beta=22.3: 1)$ on a large scale. Excess FucGlc $\left(\mathrm{N}_{3}\right)$ disaccharide 21 was produced which will be used by other members of our group in the synthesis of the target heptasaccharide glycoconjugates. The 4,6-benzylidene of the FucGlc $\left(\mathrm{N}_{3}\right)$ was also successfully opened $100 \%$ regioselectively to give the desired C-4 hydroxyl that is required for the formation of the larger carbohydrates.

It was determined that $N$-Troc protection of donor was required when forming the $\beta-1,4-$ linkage between the two GlcNAc residues. Low yields and poor selectivity $(23 \%, \alpha: \beta=$ 1:2.8) were obtained with the initially proposed azide donor. The use of the $N$-Troc protected donor resulted in formation of the desired $\beta$-linkage selectively. The discovery that $N$-Troc protection is required for successful glycosylation was an important finding as this coupling is the last glycosylation reaction in forming the larger oligosaccharide structures. It was also determined that GlcNAc acceptors with azide protection resulted in higher glycosylation yields than their $N$-Troc protected counterparts. Therefore azide protection was still favoured for the reducing end GlcNAc residue. 
The $\operatorname{Man}_{3}$ trisaccharide 17 and FucGlc $\left(\mathrm{N}_{3}\right)$ disaccharide 21 were both successfully fully deprotected. The conditions that were optimised for the deprotection of both sugars have established the deprotection strategy for the heptasaccharide and other larger truncations. The only reaction required for deprotection of the heptasaccharide that was not tested was the conversion of the $\mathrm{N}$-Troc group to an $\mathrm{N}$-acetate. The optimum conditions for the conversion of the GlcNAc monomer to the corresponding $\beta$-glycosylamine were determined and were used for conversion of the fully deprotected FucGlc disaccharide $\mathbf{7 6}$ and $\mathrm{Man}_{3}$ trisaccharide 42 to their corresponding $\beta$-glycosylamines 96 and $\mathbf{9 5}$. These conditions can be used for the synthesis of other target glycosylamines.

The knowledge gained and the intermediate compounds synthesised during this project will aid in the synthesis of the heptasaccharide glycoconjugate $\mathbf{1}$ and other truncated glycoconjugates which are being synthesised as part of the broader project looking at determining the molecular triggers of asthma. The synthesis of the three glycoconjugates proposed in this report will enable the first detailed insight into the relationship between $\mathrm{N}$-glycan structure and Th2 bias. This will increase the understanding of the asthmatic Th2 response and may lead to the identification of specific enzyme targets that will aid in the treatment and prevention of asthma and allergy. 


\section{EXPERIMENTAL}

\section{General}

Unless otherwise stated the following conditions apply. Reactions were conducted in flame-dried or ovendried glassware, under an inert atmosphere, using dry solvents. DCM was freshly distilled from phosphorus pentoxide, and toluene was stored over sodium. Acetic acid (AR, Univar), acetic anhydride (AR, Peking Chemical Works), pyridine (PA, Roth) and chloroform (AR, BDH) were used as received. Acetonitrile was freshly distilled from calcium hydride and THF was freshly distilled from lithium aluminium hydride. Methanol and DMF were distilled and stored over molecular sieves ( $3 \AA ̊)$. Ethyl acetate was distilled prior to use. Ethyl acetate and petroleum ether used for column chromatography were of technical grade and distilled prior to use. Concentration of solutions in vacuo was achieved using a rotary evaporator fitted to a vacuum pump, with a bath temperature of $45^{\circ} \mathrm{C}$. Residual solvents were removed using an Edwards E2M1.5 oil pump. Reaction progress was monitored using TLC performed on ALUGRAM SIL G/UV ${ }_{254}$ TLC plates using UV radiation ( $254 \mathrm{~nm}$ ) and/or $10 \%$ (v/v) sulfuric acid in methanol dip with subsequent heating to visualise the compounds. Purification by column chromatography was conducted using glass columns packed with silica gel (Pure Science Silica Gel 60, 40-63 micron) as the stationary phase and the solvent system as indicated. Purification by reverse phase column chromatography was conducted using either $\mathrm{C}_{8}$ (Accu BOND II OCTYL cartridges, $500 \mathrm{mg}, 3 \mathrm{~mL}$ ) or $\mathrm{C}_{18}$ (Accu BOND II ODS-C18 cartridges, $500 \mathrm{mg}, 3 \mathrm{~mL}$ ) pre-packed cartridges from Agilent Technologies as stated and the solvent system as indicated. Purification by size exclusion chromatography was conducted using a glass column $(180 \mathrm{~cm}$ heigh and $1.9 \mathrm{~cm}$ wide) packed with lipophilic Sephadex (Sigma Aldrich Sephadex ${ }^{\circledR}$ LH-20, 25-100 microns). Melting points (Mp) were obtained on a Gallenkamp Melting Point Apparatus. Optical rotation measurements were recorded using a Perkin-Elmer 241 Polarimeter at the sodium D-line at the stated temperature in a $1 \mathrm{dm}$, jacketed cell. IR spectra were recorded as thin films from $\mathrm{CHCl}_{3}$ or $\mathrm{MeOH}$ solutions using a Bruker Tensor 27 FTIR spectrometer ATR and are reported in wavenumbers $\left(\mathrm{cm}^{-1}\right)$. NMR spectra were recorded at $20^{\circ} \mathrm{C}$ in $\mathrm{CDCl}_{3}$ or $\mathrm{D}_{2} \mathrm{O}$ as indicated with a Varian Unity Inova 500 spectrometer $\left({ }^{1} \mathrm{H}\right.$ and

${ }^{13} \mathrm{C}$ at 500 and $125 \mathrm{MHz}$ respectively). ${ }^{1} \mathrm{H}-\mathrm{NMR}$ data is presented as follows: chemical shift expressed in ppm, multiplicity (s, singlet; bs, broad singlet; d, doublet; t, triplet; q, quartet; m, multiplet - range given; $\mathrm{m}_{\mathrm{c}}$, mulitplet centered - broad undefined peak), number of protons, coupling constants $(J)$ in Hertz, assignment of proton(s). Assignments are based on COSY, HSQC, and HMBC correlations. The ${ }^{1} \mathrm{H}-\mathrm{NMR}$ spectra are referenced to the residual solvent peak, $7.26 \mathrm{ppm}$ for $\mathrm{CDCl}_{3}$ and $4.79 \mathrm{ppm}$ for $\mathrm{D}_{2} \mathrm{O}$. The ${ }^{13} \mathrm{C}$ NMR are referenced to the solvent peak, $77.16 \mathrm{ppm}$ for $\mathrm{CDCl}_{3}\left({ }^{13} \mathrm{C}-\mathrm{NMR}\right.$ measured in $\mathrm{D}_{2} \mathrm{O}$ were not manually referenced). ${ }^{13} \mathrm{C}$-NMR spectra were proton decoupled. HRMS were recorded on a Waters Q-TOF Premier Tandem Mass Spectrometer using postive electro-spray ionisation. 


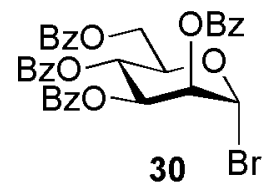

2,3,4,6-Tetra-O-benzoyl-a-D-mannopyranosyl bromide (30). Penta-benzoyl mannose 29 (13.50 g, $19.27 \mathrm{mmol}$ ) was dissolved in DCM (26 mL). After cooling the solution to $0^{\circ} \mathrm{C}$, acetic anhydride $(1.45 \mathrm{~mL}, 15.23 \mathrm{mmol}, 0.80$ equiv.) was slowly added to the solution followed by $\mathrm{HBr}(27.0 \mathrm{~mL}, 33 \%$ in $\mathrm{AcOH}, 163.8 \mathrm{mmol}, 8.5$

equiv.) The reaction mixture was allowed to stir at room temperature for $16 \mathrm{~h}$ upon which TLC-analysis (ethyl acetate) showed completion of the reaction. The reaction mixture was neutralised with sat. aq. $\mathrm{NaHCO}_{3}$ and $\mathrm{NaHCO}_{3}$ (s), extracted three times with $\mathrm{Et}_{2} \mathrm{O}$ (50 mL each), washed with water (3 times), brine, dried $\left(\mathrm{MgSO}_{4}\right)$, filtered and concentrated in vacuo to yield crude bromide $\mathbf{3 0}$ as a dark yellow oil $(13.25 \mathrm{~g})$ which was used without further purification. $R_{f} 0.35$ (ethyl acetate).

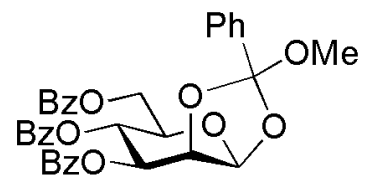

31

\section{3,4,6-Tri- $O$-benzoyl-1,2- $O$-( $\alpha$-methoxybenzylidene)- $\beta$-D-mannopyranose} (31). All of the crude bromide, 30, from the previous reaction (13.25 g, 19.27 $\mathrm{mmol})$ was dissolved in DCM $(14 \mathrm{~mL})$ and methanol $(14 \mathrm{~mL})$ and placed under a nitrogen atmosphere. 2,6-Lutidine $(6.90 \mathrm{~mL}, 69.6 \mathrm{mmol}, 3.6$ equiv.) was slowly added and the reaction mixture was allowed to stir for 16 hours. Once TLC-analysis (ethyl acetate) showed completion of the reaction, the reaction mixture was neutralised with sat. aq. $\mathrm{NaHCO}_{3}$, extracted with $\mathrm{DCM}$, washed with brine, dried $\left(\mathrm{MgSO}_{4}\right)$, filtered and concentrated in vacuo to yield crude orthoester $\mathbf{3 1}$ as a yellow oil (13.38 g) which was used without further purification. $R_{f}$ 0.59 (ethyl acetate).

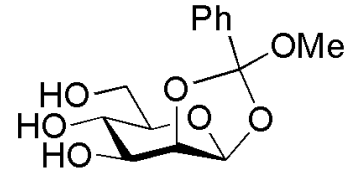

20

1,2-O-( $\alpha$-Methoxybenzylidene)- $\beta$-D-mannopyranose (20). All of the crude orthoester, 31, from the previous reaction $(13.38 \mathrm{~g}, \sim 19.27 \mathrm{mmol})$ was dissolved in DCM $(18 \mathrm{~mL})$ and methanol $(71 \mathrm{~mL})$. The $\mathrm{pH}$ of the solution was adjusted to $\mathrm{pH} \approx 9$ by the addition of sodium methoxide ( $11.5 \mathrm{~mL}, 0.5 \mathrm{M}$ in $\mathrm{MeOH})$. The reaction was stirred for $20 \mathrm{~h}$ until TLC-analysis (ethyl acetate) showed complete debenzoylation of the starting compound. The reaction mixture was concentrated in vacuo and purified by column chromatography (methanol in ethyl acetate, $0 \% \rightarrow 2 \%, \mathrm{v} / \mathrm{v}$ ) to yield $\mathbf{2 0}$ as a colourless oil $(3.89 \mathrm{~g}$, $68 \%$ over 3 steps). $R_{f} 0.16$ (ethyl acetate); ${ }^{1} \mathrm{H}-\mathrm{NMR}\left(500 \mathrm{MHz}, \mathrm{CDCl}_{3}\right): \delta 7.62-7.60$ (m, $2 \mathrm{H}, \mathrm{CH}$ arom.), 7.40-7.37 (m, 3H, CH arom.), 5.65 (d, $1 \mathrm{H}, J_{1,2}=2.9 \mathrm{~Hz}, \mathrm{H}-1$ ), 4.74 (t, $1 \mathrm{H}, J_{1,2}=J_{2,3}=3.0 \mathrm{~Hz}, \mathrm{H}-2$ ), 3.823.79 (m, 2H, H-3 and H-4), 3.70-3.67 (m, 2H, H-6a and H-6b), 3.35-3.32 (m, 1H, H-5), 3.32 (s, 3H, $\mathrm{CH}_{3}$ $\mathrm{OMe})$.

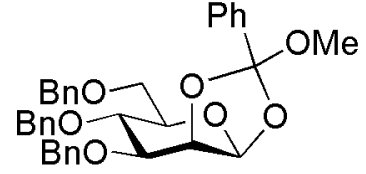

32

\section{3,4,6-Tri- $O$-benzyl-1,2- $O$-( $\alpha$-methoxybenzylidene)- $\beta$-D-mannopyranose}

(32). Orthoester 20 (1.94 g, $6.50 \mathrm{mmol})$ was coevaporated three times with $\mathrm{DMF}$, for the final coevaporation the solution was partially concentrated concentrated leaving $33 \mathrm{~mL} \mathrm{DMF}$ and placed under a nitrogen atmosphere. After cooling the solution to $0^{\circ} \mathrm{C}$, benzyl bromide $(2.78 \mathrm{~mL}, 23.4 \mathrm{mmol}, 3.6$ 
equiv.), sodium hydride (slow addition) (1.01 g, $60 \%$ in oil, $25.4 \mathrm{mmol}, 3.9$ equiv.) and TBAI (cat.) were added and the reaction mixture was allowed to stir for $4 \mathrm{~h}$ at room temperature. TLC-analysis (ethyl acetate/light petroleum ether, 1/2, v/v) showed completion of the reaction. The reaction mixture was quenched with methanol at $0^{\circ} \mathrm{C}$, concentrated in vacuo, dissolved in ethyl acetate, washed with water and brine, dried $\left(\mathrm{MgSO}_{4}\right)$, filtered and concentrated in vacuo. Purification by column chromatography (ethyl acetate/light petroleum ether, $1 / 20 \rightarrow 1 / 2, \mathrm{v} / \mathrm{v}$ ) yielded 32 as a colourless oil ( $2.99 \mathrm{~g}, 81 \%$ ). $R_{f} 0.35$ (ethyl acetate/light petroleum ether, $1 / 2, \mathrm{v} / \mathrm{v}) ;[\alpha]_{\mathrm{D}}{ }^{20}=-27.4^{\circ}\left(c 1.0, \mathrm{CHCl}_{3}\right)$; IR (thin film): 3062, 3031, 2911, 2866, 1496, 1453, 1365, 1273, 1089, 1059, 1026, 984, 915, 837, 796, 734, $696 \mathrm{~cm}^{-1}$; ${ }^{1} \mathrm{H}-\mathrm{NMR}(500 \mathrm{MHz}$, $\mathrm{CDCl}_{3}$ ): $\delta$ 7.72-7.70 (m, 2H, CH arom.), 7.46-7.44 (m, 2H, CH arom.), 7.39-7.24 (m, 16H, CH arom.), 5.51 $\left(\mathrm{d}, 1 \mathrm{H}, J_{1,2}=3.0 \mathrm{~Hz}, \mathrm{H}-1\right), 4.91\left(\mathrm{~d}, 1 \mathrm{H}, J_{\mathrm{a}, \mathrm{b}}=11.7 \mathrm{~Hz}, \mathrm{CH}-\mathrm{a} 4-O-\mathrm{Bn}\right), 4.88\left(\mathrm{~d}, 1 \mathrm{H}, J_{\mathrm{a}, \mathrm{b}}=12.0 \mathrm{~Hz}, \mathrm{CH}-\mathrm{a} 3-\right.$ $O$-Bn), $4.83\left(\mathrm{~d}, 1 \mathrm{H}, J_{\mathrm{a}, \mathrm{b}}=12.2 \mathrm{~Hz}\right.$, CH-b 3- $\left.O-\mathrm{Bn}\right), 4.70\left(\mathrm{t}, 1 \mathrm{H}, J_{1,2}=J_{2,3}=3.1 \mathrm{~Hz}, \mathrm{H}-2\right), 4.65\left(\mathrm{~d}, 1 \mathrm{H}, J_{\mathrm{a}, \mathrm{b}}=\right.$ $11.0 \mathrm{~Hz}, \mathrm{CH}-\mathrm{b} 4-O-\mathrm{Bn}), 4.44$ (d, 1H, $\left.J_{\mathrm{a}, \mathrm{b}}=12.2 \mathrm{~Hz}, \mathrm{CH}-\mathrm{a} 6-O-\mathrm{Bn}\right), 4.41$ (d, $J_{\mathrm{a}, \mathrm{b}}=12.0 \mathrm{~Hz}, 1 \mathrm{H}, \mathrm{CH}-\mathrm{b}$ 6- $O$ Bn), $3.96\left(\mathrm{t}, 1 \mathrm{H}, J_{3,4}=J_{4,5}=9.1 \mathrm{~Hz}, \mathrm{H}-4\right), 3.86\left(\mathrm{dd}, 1 \mathrm{H}, J_{2,3}=3.9, J_{3,4}=9.2 \mathrm{~Hz}, \mathrm{H}-3\right), 3.68\left(\mathrm{dd}, 1 \mathrm{H}, J_{5,6 \mathrm{a}}=\right.$ $\left.4.8, J_{6 \mathrm{a}, 6 \mathrm{~b}}=10.9 \mathrm{~Hz}, \mathrm{H}-6 \mathrm{a}\right), 3.59\left(\mathrm{dd}, 1 \mathrm{H}, J_{5,6 \mathrm{~b}}=2.4, J_{6 \mathrm{a}, 6 \mathrm{~b}}=11.0 \mathrm{~Hz}, \mathrm{H}-6 \mathrm{~b}\right), 3.51\left(\mathrm{ddd}, 1 \mathrm{H}, J_{4,5}=9.0, J_{5,6 \mathrm{a}}=\right.$ $\left.4.8, J_{5,6 \mathrm{~b}}=2.4 \mathrm{~Hz}, \mathrm{H}-5\right), 3.29$ (s, 3H, $\left.\mathrm{CH}_{3} \mathrm{OMe}\right) ;{ }^{13} \mathrm{C}-\mathrm{NMR}\left(125 \mathrm{MHz}, \mathrm{CDCl}_{3}\right): \delta 138.5\left(\mathrm{C}_{\mathrm{i}}\right.$ arom. 6-O-Bn), $138.4\left(\mathrm{C}_{\mathrm{i}}\right.$ arom. 4-O-Bn), $138.0\left(\mathrm{C}_{\mathrm{i}}\right.$ arom. 3-O-Bn), 136.7 ( $\mathrm{C}_{\mathrm{i}}$ arom.), 129.2 ( $\mathrm{CH}$ arom.), $128.6(\mathrm{CH}$ arom.), 128.5 (CH arom.), 128.4 (CH arom.), 128.2 (CH arom.), 128.1 (CH arom.), 128.1 (CH arom.), 128.1 (CH arom.), 127.9 ( $\mathrm{CH}$ arom.), 127.6 ( $\mathrm{CH}$ arom.), 127.5 ( $\mathrm{CH}$ arom.), 126.9 ( $\mathrm{CH}$ arom.), 122.6 ( $\mathrm{C}_{\mathrm{q}}$ orthoester), 98.0 (C-1), 78.6 (C-3), 76.5 (C-2), $75.2\left(\mathrm{CH}_{2} 4-O-\mathrm{Bn}\right), 75.2$ (C-5), 74.4 (C-4), $73.3\left(\mathrm{CH}_{2}\right.$ 6-O-Bn), 72.2 $\left(\mathrm{CH}_{2} 3-\mathrm{O}-\mathrm{Bn}\right), 69.2$ (C-6), $51.5\left(\mathrm{CH}_{3} \mathrm{OMe}\right)$; HRMS(ESI) $\mathrm{m} / z$ calcld. for $\left[\mathrm{C}_{35} \mathrm{H}_{36} \mathrm{O}_{7}+\mathrm{Na}\right]^{+}:$591.2359, obsd.: 591.2369.

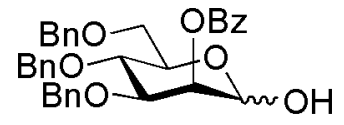

33

2- $O$-Benzoyl-3,4,6-tri- $O$-benzyl- $\alpha / \beta$-D-mannopyranose (33). Orthoester 32 $(3.25 \mathrm{~g}, 5.87 \mathrm{mmol})$ was dissolved in acetic acid/water $(100 \mathrm{~mL}, 4 / 1, \mathrm{v} / \mathrm{v})$ and the reaction mixture was stirred for $3 \mathrm{~h}$. When TLC-analysis (ethyl acetate/light petroleum ether, $1 / 3, \mathrm{v} / \mathrm{v}$ ) showed completion of the reaction, water was added and the white precipitate that formed was extracted 3 times with diethyl ether. The organic layers were combined and washed with sat. aq. $\mathrm{Na}_{2} \mathrm{CO}_{3}$ and brine, dried $\left(\mathrm{MgSO}_{4}\right)$, filtered and concentrated in vacuo. Purification by column chromatography (ethyl acetate/light petroleum ether, $1 / 5 \rightarrow 1 / 1$, v/v) yielded $\mathbf{3 3}$ as a colourless oil (2.60 g, 82\%). $R_{f} 0.20 / 0.12(\alpha / \beta)$ (ethyl acetate/light petroleum ether, 1/3, v/v); IR (thin film): 3343, 3088, 3064, 3031, 2929, 2903, 2868, 1721, 1496, 1453, 1362, 1269, 1177 1070, 1043, 1027, 975, $9115,826,793,749,737,711,698 \mathrm{~cm}^{-1}$; (NMR data given for the $\alpha$-anomer only, as only trace amounts of the $\beta$-anomer were detectable) ${ }^{1} \mathrm{H}-\mathrm{NMR}\left(500 \mathrm{MHz}, \mathrm{CDCl}_{3}\right.$ ): $\delta$ 8.08-8.06 (m, $2 \mathrm{H}, \mathrm{CH}$ arom.), 7.58-7.54 (m, 1H, CH arom.), 7.41-7.23 (m, 15H, CH arom.), 7.19-7.18 (m, 2H, $\mathrm{CH}$ arom.), 5.63 (dd, $1 \mathrm{H}, J_{1,2}=1.9, J_{2,3}=$ $2.9 \mathrm{~Hz}, \mathrm{H}-2), 5.35$ (s, $1 \mathrm{H}, \mathrm{H}-1), 4.88\left(\mathrm{~d}, 1 \mathrm{H}, J_{\mathrm{a}, \mathrm{b}}=11.0 \mathrm{~Hz}, \mathrm{CH}-\mathrm{a} 4-O-\mathrm{Bn}\right), 4.79$ (d, $1 \mathrm{H}, J_{\mathrm{a}, \mathrm{b}}=11.3 \mathrm{~Hz}, \mathrm{CH}-$ a 3-O-Bn), $4.67\left(\mathrm{~d}, 1 \mathrm{H}, J_{\mathrm{a}, \mathrm{b}}=12.0 \mathrm{~Hz}, \mathrm{CH}-\mathrm{a}\right.$ 6-O-Bn), $4.58\left(\mathrm{~d}, 1 \mathrm{H}, J_{\mathrm{a}, \mathrm{b}}=11.0 \mathrm{~Hz}, \mathrm{CH}-\mathrm{b} 3-O-\mathrm{Bn}\right), 4.55$ (d, $\left.J_{\mathrm{a}, \mathrm{b}}=12.2 \mathrm{~Hz}, 1 \mathrm{H}, \mathrm{CH}-\mathrm{b} 6-O-\mathrm{Bn}\right), 4.53\left(\mathrm{~d}, 1 \mathrm{H}, J_{\mathrm{a}, \mathrm{b}}=11.2 \mathrm{~Hz}, \mathrm{CH}-\mathrm{b} 4-O-\mathrm{Bn}\right), 4.17\left(\mathrm{dd}, 1 \mathrm{H}, J_{2,3}=3.2, J_{3,4}=\right.$ 
$9.3 \mathrm{~Hz}, \mathrm{H}-3$ ), $4.13\left(\mathrm{ddd}, 1 \mathrm{H}, J_{4,5}=9.8, J_{5,6 \mathrm{a}}=4.6, J_{5,6 \mathrm{~b}}=2.2 \mathrm{~Hz}, \mathrm{H}-5\right), 3.96\left(\mathrm{t}, 1 \mathrm{H}, J_{3,4}=J_{4,5}=9.6 \mathrm{~Hz}, \mathrm{H}-4\right.$ ), 3.79-3.77 (m, 2H, H-6a and H-6b), 3.26 (bs, $1 \mathrm{H}, 1-\mathrm{OH}) ;{ }^{13} \mathrm{C}-\mathrm{NMR}\left(125 \mathrm{MHz}, \mathrm{CDCl}_{3}\right): \delta 165.9(\mathrm{C}=\mathrm{O} 2-O-$ Bz), $138.4\left(\mathrm{C}_{\mathrm{i}}\right.$ arom. 4-O-Bn), $138.3\left(\mathrm{C}_{\mathrm{i}}\right.$ arom. 6-O-Bn), 138.1 ( $\mathrm{C}_{\mathrm{i}}$ arom. 3- $\left.O-\mathrm{Bn}\right), 133.3\left(\mathrm{C}_{\mathrm{i}}\right.$ arom. $\left.O-\mathrm{Bz}\right)$, 130.1 (CH arom.), 128.5 (CH arom.), 128.5 ( $\mathrm{CH}$ arom.), 128.2 (CH arom.), 127.9 (CH arom.), 127.8 (CH arom.), 127.8 (CH arom.), 127.8 ( $\mathrm{CH}$ arom.), 92.7 (C-1), 77.9 (C-3), $75.3\left(\mathrm{CH}_{2} 4-O-\mathrm{Bn}\right), 74.7$ (C-4), 73.6 $\left(\mathrm{CH}_{2}\right.$ 6-O-Bn), $71.7\left(\mathrm{CH}_{2}\right.$ 3-O-Bn), $71.6(\mathrm{C}-5), 69.6(\mathrm{C}-6), 69.5(\mathrm{C}-2)$; HRMS(ESI) $\mathrm{m} / z$ calcld. for $\left[\mathrm{C}_{34} \mathrm{H}_{34} \mathrm{O}_{7} \mathrm{~N}_{3} \mathrm{Si}+\mathrm{Na}\right]^{+}:$577.2202, obsd.: 577.2205.

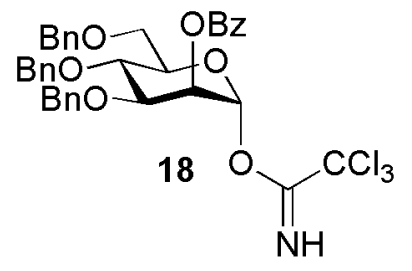

2- $O$-Benzoyl-3,4,6-tri- $O$-benzyl- $\alpha$-D-mannopyranosyl trichloroacetimidate (18). Hemiacetal $33(2.51 \mathrm{~g}, 4.65 \mathrm{mmol})$ was coevaporated three times with toluene and dissolved in DCM $(24 \mathrm{~mL})$ under a nitrogen atmosphere. After cooling the solution to $0^{\circ} \mathrm{C}$, trichloroacetonitrile ( $2.33 \mathrm{~mL}, 23.2 \mathrm{mmol}, 5.0$ equiv.) and $\mathrm{DBU}(0.070 \mathrm{~mL}$, $0.465 \mathrm{mmol}, 0.1$ equiv) were added and the reaction was stirred for $1.5 \mathrm{~h}$. After TLC-analysis (ethyl acetate/light petroleum ether, $1 / 2, \mathrm{v} / \mathrm{v}$ ) showed completion of the reaction, the reaction mixture was passed through a silica plug (eluted with ethyl acetate/light petroleum ether, $1 / 1, \mathrm{v} / \mathrm{v}$ ), concentrated in vacuo to give a pale yellow oil and purified by column chromatography (ethyl acetate/light petroleum ether, 1/10 $\rightarrow$ 1/1, v/v) to yield 18 as a colourless oil which crystalised upon refridgeration $(2.82 \mathrm{~g}, 89 \%, 99 \%$ based on starting material recovered). The imidate was stored in the freezer until it was used. $R_{f} 0.52$ (ethyl acetate/light petroleum ether, 1/2, v/v); IR (thin film): 3342, 3065, 3032, 2929, 2859, 1725, 1675, 1602, $1521,1497,1454,1362,1318,1264,1166,1095,1070,1028,973,910,839,797,733,709,699 \mathrm{~cm}^{-1} ;{ }^{1} \mathrm{H}-$ $\operatorname{NMR}\left(500 \mathrm{MHz}, \mathrm{CDCl}_{3}\right): \delta 8.70(\mathrm{~s}, 1 \mathrm{H}, \mathrm{NH}), 8.08\left(\mathrm{dd}, J=8.3 \mathrm{~Hz}, 2 \mathrm{H}, \mathrm{CH}\right.$ arom. 2-O-Bz), $7.57\left(\mathrm{t}, J_{\mathrm{m}, \mathrm{p}}=\right.$ 7.5, 1H, CH arom. 2-O-Bz), 7.39-7.21 (m, 17H, CH arom.), 6.41 (d, $\left.1 \mathrm{H}, J_{1,2}=3.2 \mathrm{~Hz}, \mathrm{H}-1\right), 5.74$ (dd, 1H, $\left.J_{2,3}=2.4 \mathrm{~Hz} J_{1,2}=3.2 \mathrm{~Hz}, \mathrm{H}-2\right), 4.89\left(\mathrm{~d}, 1 \mathrm{H}, J_{\mathrm{a}, \mathrm{b}}=10.7 \mathrm{~Hz}, \mathrm{CH}-\mathrm{a} 4-O-\mathrm{Bn}\right), 4.81\left(\mathrm{~d}, 1 \mathrm{H}, J_{\mathrm{a}, \mathrm{b}}=11.4 \mathrm{~Hz}\right.$, CH-a 3-O-Bn), 4.74 (d, $\left.1 \mathrm{H}, J_{\mathrm{a}, \mathrm{b}}=12.0 \mathrm{~Hz}, \mathrm{CH}-\mathrm{a} 6-O-\mathrm{Bn}\right), 4.62\left(\mathrm{~d}, 1 \mathrm{H}, J_{\mathrm{a}, \mathrm{b}}=12.0 \mathrm{~Hz}, \mathrm{CH}-\mathrm{b} 3-O-\mathrm{Bn}\right), 4.60$ $\left(\mathrm{d}, 1 \mathrm{H}, J_{\mathrm{a}, \mathrm{b}}=11.2 \mathrm{~Hz}, \mathrm{CH}-\mathrm{b} 4-O-\mathrm{Bn}\right), 4.54\left(\mathrm{~d}, J_{\mathrm{a}, \mathrm{b}}=11.9 \mathrm{~Hz}, 1 \mathrm{H}, \mathrm{CH}-\mathrm{b} 6-O-\mathrm{Bn}\right), 4.25\left(\mathrm{t}, 1 \mathrm{H}, J_{3,4}=J_{4,5}=\right.$ $9.7 \mathrm{~Hz}, \mathrm{H}-4), 4.16\left(\mathrm{dd}, 1 \mathrm{H}, J_{2,3}=3.2 \mathrm{~Hz}, J_{3,4}=9.5 \mathrm{~Hz}, \mathrm{H}-3\right), 4.05\left(\mathrm{ddd}, 1 \mathrm{H}, J_{5,6 \mathrm{~b}}=1.7 \mathrm{~Hz}, J_{5,6 \mathrm{a}}=3.4 \mathrm{~Hz}\right.$, $\left.J_{4,5}=9.8 \mathrm{~Hz}, \mathrm{H}-5\right), 3.92\left(\mathrm{dd}, 1 \mathrm{H}, J_{5,6 \mathrm{a}}=3.4 \mathrm{~Hz}, J_{6 \mathrm{a}, 6 \mathrm{~b}}=11.2 \mathrm{~Hz}, \mathrm{H}-6 \mathrm{a}\right), 3.78\left(\mathrm{dd}, 1 \mathrm{H}, J_{5,6 \mathrm{~b}}=1.7 \mathrm{~Hz}, J_{6 \mathrm{a}, 6 \mathrm{~b}}=\right.$ $11.3 \mathrm{~Hz}, \mathrm{H}-6 \mathrm{~b}) ;{ }^{13} \mathrm{C}-\mathrm{NMR}\left(125 \mathrm{MHz}, \mathrm{CDCl}_{3}\right): \delta 165.6(\mathrm{C}=\mathrm{O} 2-O-\mathrm{Bz}), 160.2(\mathrm{C}=\mathrm{N}), 138.6\left(\mathrm{C}_{\mathrm{i}}\right.$ arom. 6-O$\mathrm{Bn}), 138.2$ ( $\mathrm{C}_{\mathrm{i}}$ arom. 4-O-Bn), 137.7 ( $\mathrm{C}_{\mathrm{i}}$ arom. 3-O-Bn), 133.5 ( $\mathrm{C}_{\mathrm{i}}$ arom. $O$-Bz), $130.2(\mathrm{CH}$ arom.), 129.6 (CH arom.), 128.6 ( $\mathrm{CH}$ arom.), 128.5 (CH arom.), 128.5 (CH arom.), 128.4 (CH arom.), 128.4 (CH arom.), 128.0 (CH arom.), 128.0 (CH arom.), 127.6 (CH arom.), 95.5 (C-1), $90.9\left(\mathrm{CCl}_{3}\right), 77.4(\mathrm{C}-3), 75.7\left(\mathrm{CH}_{2} 4-\right.$ $O$-Bn), 74.7 (C-5), 73.8 (C-4), $73.6\left(\mathrm{CH}_{2}\right.$ 6-O-Bn), $72.0\left(\mathrm{CH}_{2} 3-O-\mathrm{Bn}\right), 68.7$ (C-6), 67.8 (C-2). HRMS(ESI) $m / z$ calcld. for $\left[\mathrm{C}_{36} \mathrm{H}_{34} \mathrm{O}_{7} \mathrm{NCl}_{3}+\mathrm{Na}\right]^{+}:$720.1299, obsd.: 720.1299 .

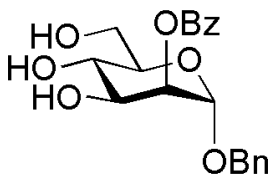

2-O-Benzoyl-1-O-benzyl-a-D-mannopyranose (19). Orthoester 20 (0.049 g, 0.166 $\mathrm{mmol})$ was coevaporated three times with toluene and dissolved in DCM $(0.90 \mathrm{~mL})$ 
under a nitrogen atmosphere. Benzyl alcohol $(0.17 \mathrm{~mL}, 16.6 \mathrm{mmol}, 10$ equiv. $)$ and CSA (0.001 g, 0.004 mmol, 0.03 equiv.) was added and the reaction was stirred for $18 \mathrm{~h}$. After TLC-analysis (ethyl acetate) showed completion of the reaction, the reaction was quenched with $0.10 \mathrm{~mL}$ triethylamine, washed with $\mathrm{NaHCO}_{3}$ and brine, dried $\left(\mathrm{MgSO}_{4}\right)$, and concentrated in vacuo. Purification by column chromatography (ethyl acetate/light petroleum ether, $1 / 5 \rightarrow 1 / 0, \mathrm{v} / \mathrm{v}$ ) yielded 19 as a colourless oil ( $0.028 \mathrm{~g}, 46 \%) . R_{f} 0.34$ (ethyl acetate); IR (thin film): 3401, 3033, 3016, 2908, 2893, 1654, 1431, 1317, 1272, 1215, 1118, 1068, 1027, 976, $713 \mathrm{~cm}^{-1}$; ${ }^{1} \mathrm{H}-\mathrm{NMR}$ (500 MHz, $\mathrm{CDCl}_{3}$ ): $\delta$ 8.04-8.02 (m, 2H, CH arom.), 7.60-7.56 (m, 1H, CH arom.), 7.47-7.43 (m, 2H, CH arom.), 7.39-7.30 (m, 4H, $\mathrm{CH}$ arom.), 7.18-7.14 (m, 1H, $\mathrm{CH}$ arom.), 5.40 $\left(\mathrm{dd}, 1 \mathrm{H}, J_{1,2}=1.7, J_{2,3}=3.4 \mathrm{~Hz}, \mathrm{H}-2\right), 5.05\left(\mathrm{~d}, 1 \mathrm{H}, J_{1,2}=1.7 \mathrm{~Hz}, \mathrm{H}-1\right), 4.74\left(\mathrm{~d}, 1 \mathrm{H}, J_{\mathrm{a}, \mathrm{b}}=11.8 \mathrm{~Hz}, \mathrm{CH}-\mathrm{a}\right.$ Bn), $4.56\left(\mathrm{~d}, 1 \mathrm{H}, J_{\mathrm{a}, \mathrm{b}}=11.7 \mathrm{~Hz}, \mathrm{CH}-\mathrm{b} \mathrm{Bn}\right), 4.19\left(\mathrm{dd}, 1 \mathrm{H}, J_{3,4}=9.5, J_{2,3}=3.4 \mathrm{~Hz}, \mathrm{H}-3\right), 4.03\left(\mathrm{t}, 1 \mathrm{H}, J_{3,4}=J\right.$ $\left.{ }_{4,5}=9.7 \mathrm{~Hz}, \mathrm{H}-4\right), 3.90$ (d, 2H, $J_{5,6}=3.7 \mathrm{~Hz}, \mathrm{H}-6 \mathrm{a}$ and H-6b), $3.76\left(\mathrm{dt}, 1 \mathrm{H}, J_{4,5}=9.8 \mathrm{~Hz}, J_{5,6}=3.6 \mathrm{~Hz}, \mathrm{H}-\right.$ 5), ${ }^{13} \mathrm{C}-\mathrm{NMR}\left(125 \mathrm{MHz}, \mathrm{CDCl}_{3}\right) \delta 166.2(\mathrm{C}=\mathrm{O} 2-\mathrm{O}-\mathrm{Bz}), 136.7$ (C arom.), 129.8 (CH arom.), $129.3(\mathrm{CH}$ arom.), 129.0 ( $\mathrm{CH}$ arom.), 128.6 ( $\mathrm{CH}$ arom.), 128.6 ( $\mathrm{CH}$ arom.), 128.2 ( $\mathrm{CH}$ arom.), 128.1 (CH arom.), 128.0 (CH arom.), 125.3 (CH arom.), 97.2 (C-1), 72.6 (C-2), 72.0 (C-5), 70.6 (C-3), $69.8\left(\mathrm{CH}_{2} \mathrm{Bn}\right), 68.6$ (C-4), 62.3 (C-6); HRMS(ESI) $\mathrm{m} / z$ calc. for $\left[\mathrm{C}_{20} \mathrm{H}_{22} \mathrm{O}_{7}+\mathrm{Na}\right]^{+}: 397.1264$, obsd.: 397.1262.

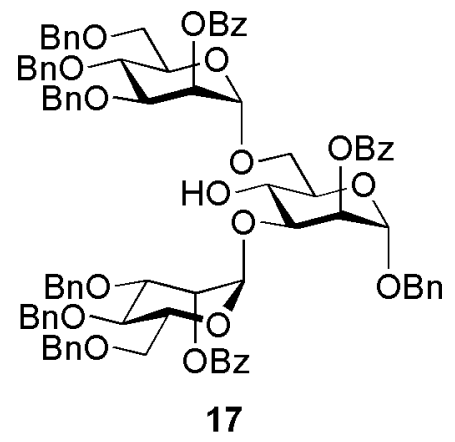

\section{Benzyl 2- $O$-benzoyl-3,6-di- $O$-(2- $O$-benzoyl-3,4,6-tri- $O$-benzyl- $\alpha$-D-} mannopyranosyl)- $\alpha$-D-mannopyranoside (17). Triol acceptor $19(0.225$ g, $0.601 \mathrm{mmol})$ and acetimidate donor $18(1.203 \mathrm{~g}, 1.722 \mathrm{mmol}, 2.9$ equiv.) were coevaporated three times with toluene and dissolved in DCM $(3.5 \mathrm{~mL})$ under a nitrogen atmosphere. After cooling the solution to $-40^{\circ} \mathrm{C}$, TMSOTf $(0.011 \mathrm{~mL}, 0.060 \mathrm{mmol}, 0.1$ equiv. $)$ was added dropwise and the reaction was stirred for $2 \mathrm{~h}$. After TLC-analysis (ethyl acetate/toluene, $1 / 6, \mathrm{v} / \mathrm{v}$ ) showed completion of the reaction, the reaction mixture was quenched with triethylamine $(0.2 \mathrm{~mL})$ at $-40^{\circ} \mathrm{C}$. The reaction mixture was then diluted with ethyl acetate and washed with sat. aq. $\mathrm{NaHCO}_{3}$ and brine, dried $\left(\mathrm{MgSO}_{4}\right)$, filtered and concentrated in vacuo. Purification by column chromatography using both ethyl acetate/light petroleum ether (ethyl acetate/light petroleum ether, $1 / 20 \rightarrow 1 / 2$, v/v) and DCM/light petroleum ether (DCM/light petroleum ether, $1 / 3 \rightarrow 1 / 0$, v/v) as the eluents was unsuccessful, as was purification by Sephadex ${ }^{\circledR}$ LH-20 sizeexclusion chromatography (DCM/methanol, 1/1, v/v). However, purification by column chromatography using ethyl acetate/toluene (ethyl acetate/toluene, $1 / 30 \rightarrow 1 / 10, \mathrm{v} / \mathrm{v}$ ) successfully yielded the trisaccharide 17 as a colourless oil $(0.097 \mathrm{~g}, 11 \%) . R_{f} 0.47$ (ethyl acetate/toluene, $\left.1 / 6, \mathrm{v} / \mathrm{v}\right) ;[\alpha]_{\mathrm{D}}{ }^{20}=-9.7^{\circ}\left(c 1.0, \mathrm{CHCl}_{3}\right)$; IR (thin film): 3464, 3088, 3064, 3031, 2929, 2867, 1721, 1602, 1585, 1496, 1453, 1360, 1317, 1267, 1210, 1176, 1109, 1097, 1072, 1044, 1028, 1002, 980, 911, 844, 803, 737, 711, $698 \mathrm{~cm}^{-1} ;{ }^{1} \mathrm{H}-\mathrm{NMR}(500 \mathrm{MHz}$, $\left.\mathrm{CDCl}_{3}\right): \delta 8.08-8.04(\mathrm{~m}, 2 \mathrm{H}, \mathrm{CH}$ arom. $\mathrm{OBz}), 8.00-7.98(\mathrm{~m}, 1 \mathrm{H}, \mathrm{CH}$ arom. $\mathrm{OBz}), 7.59-7.51(\mathrm{~m}, 2 \mathrm{H}, \mathrm{CH}$ arom.), 7.43-7.08 (m, 42H, CH arom.), 5.77 (dd, $\left.1 \mathrm{H}, J_{1^{\prime \prime}, 2^{\prime \prime}}=2.0, J_{2^{\prime \prime}, 3^{\prime \prime}}=3.0 \mathrm{~Hz}, \mathrm{H}-2^{\prime \prime}\right), 5.57\left(\mathrm{dd}, 1 \mathrm{H}, J_{1^{\prime}, 2^{\prime}}=\right.$ $\left.2.2, J_{2^{\prime}, 3^{\prime}}=2.9 \mathrm{~Hz}, \mathrm{H}-2^{\prime}\right), 5.52\left(\mathrm{dd}, 1 \mathrm{H}, J_{1,2}=1.7, J_{2,3}=2.4 \mathrm{~Hz}, \mathrm{H}-2\right), 5.37\left(\mathrm{~d}, 1 \mathrm{H}, J_{1^{\prime}, 2^{\prime}}=1.7 \mathrm{~Hz}, \mathrm{H}-1^{\prime}\right), 5.08$ 
$\left(\mathrm{d}, 1 \mathrm{H}, J_{1,2}=1.7 \mathrm{~Hz}, \mathrm{H}-1\right), 5.06\left(\mathrm{~d}, 1 \mathrm{H}, J_{1^{\prime \prime}, 2^{\prime \prime}}=1.7 \mathrm{~Hz}, \mathrm{H}-1^{\prime \prime}\right), 4.86$ (d, 1H, $\left.J_{\mathrm{a}, \mathrm{b}}=10.7 \mathrm{~Hz}, \mathrm{CH}-\mathrm{a} 4^{\prime \prime}-O-\mathrm{Bn}\right)$, $4.78\left(\mathrm{~d}, 1 \mathrm{H}, J_{\mathrm{a}, \mathrm{b}}=11.0 \mathrm{~Hz}, \mathrm{CH}-\mathrm{a} 3^{\prime \prime}-O-\mathrm{Bn}\right), 4.77\left(\mathrm{~d}, 1 \mathrm{H}, J_{\mathrm{a}, \mathrm{b}}=11.3 \mathrm{~Hz}, \mathrm{CH}-\mathrm{a} 4^{\prime}-O-\mathrm{Bn}\right), 4.74\left(\mathrm{~d}, 1 \mathrm{H}, J_{\mathrm{a}, \mathrm{b}}=\right.$ $\left.12.0 \mathrm{~Hz}, \mathrm{CH}-\mathrm{a} 6^{\prime \prime}-O-\mathrm{Bn}\right), 4.71\left(\mathrm{~d}, 1 \mathrm{H}, J_{\mathrm{a}, \mathrm{b}}=10.7 \mathrm{~Hz}, \mathrm{CH}-\mathrm{a} 6^{\prime}-O-\mathrm{Bn}\right), 4.70\left(\mathrm{~d}, 1 \mathrm{H}, J_{\mathrm{a}, \mathrm{b}}=12.0 \mathrm{~Hz}, \mathrm{CH}-\mathrm{a} 1-\right.$ $O$-Bn), $4.63\left(\mathrm{~d}, 1 \mathrm{H}, J_{\mathrm{a}, \mathrm{b}}=12.2 \mathrm{~Hz}, \mathrm{CH}-\mathrm{b} 6^{\prime \prime}-O-\mathrm{Bn}\right), 4.57$ (d, $\left.1 \mathrm{H}, J_{\mathrm{a}, \mathrm{b}}=11.3 \mathrm{~Hz}, \mathrm{CH}-\mathrm{a} 3^{\prime}-O-\mathrm{Bn}\right), 4.55(\mathrm{~d}, 1 \mathrm{H}$, $\left.J_{\mathrm{a}, \mathrm{b}}=11.8 \mathrm{~Hz}, \mathrm{CH}-\mathrm{b} 1-O-\mathrm{Bn}\right), 4.54\left(\mathrm{~d}, 1 \mathrm{H}, J_{\mathrm{a}, \mathrm{b}}=10.8 \mathrm{~Hz}, \mathrm{CH}-\mathrm{b} 4^{\prime \prime}-O-\mathrm{Bn}\right), 4.48\left(\mathrm{~d}, 1 \mathrm{H}, J_{\mathrm{a}, \mathrm{b}}=11.5 \mathrm{~Hz}, \mathrm{CH}-\right.$ b 3"-O-Bn), 4.47 (d, 1H, $\left.J_{\mathrm{a}, \mathrm{b}}=11.0 \mathrm{~Hz}, \mathrm{CH}-\mathrm{b} 4^{\prime}-O-\mathrm{Bn}\right), 4.47$ (d, $1 \mathrm{H}, J_{\mathrm{a}, \mathrm{b}}=11.9 \mathrm{~Hz}, \mathrm{CH}-\mathrm{b}$ 6'-O-Bn), 4.33 $\left(\mathrm{d}, 1 \mathrm{H}, J_{\mathrm{a}, \mathrm{b}}=10.9 \mathrm{~Hz}\right.$, CH-b 3'-O-Bn), 4.28-4.27 (m, 2H, H-3 and H-4), 4.14 (dd, $1 \mathrm{H}, J_{2^{\prime \prime}, 3^{\prime \prime}}=3.2, J_{3^{\prime \prime}, 4^{\prime \prime}}=9.3$ $\left.\mathrm{Hz}, \mathrm{H}-3^{\prime \prime}\right), 4.12\left(\mathrm{dd}, 1 \mathrm{H}, J_{5,6 \mathrm{a}}=3.9, J_{6 \mathrm{a}, 6 \mathrm{~b}}=11.5 \mathrm{~Hz}, \mathrm{H}-6 \mathrm{a}\right), 4.08\left(\mathrm{ddd}, 1 \mathrm{H}, J_{4^{\prime \prime}, 5^{\prime \prime}}=9.8, J_{5^{\prime \prime}, 6 \mathrm{~b}^{\prime \prime}}=2.2, J_{5^{\prime \prime}, 6 \mathrm{a}^{\prime \prime}}=\right.$ $\left.4.4 \mathrm{~Hz}, \mathrm{H}-5^{\prime \prime}\right), 4.05\left(\mathrm{t}, 1 \mathrm{H}, J_{3^{\prime}, 4^{\prime}}=J_{4^{\prime}, 5^{\prime}}=9.5 \mathrm{~Hz}, \mathrm{H}-4^{\prime}\right), 4.01$ (t, 1H, $\left.J_{3^{\prime \prime}, 4^{\prime \prime}}=J_{4^{\prime \prime}, 5^{\prime \prime}}=9.3 \mathrm{~Hz}, \mathrm{H}-4^{\prime \prime}\right), 3.97-3.93$ (m, 2H, H-3' and H-5'), 3.86-3.81 (m, 3H, H-5, H-6a", and H-6b"), 3.78 (dd, $1 \mathrm{H}, J_{5,6 \mathrm{~b}}=2.2, J_{6 \mathrm{a}, 6 \mathrm{~b}}=11.0$ $\mathrm{Hz}, \mathrm{H}-6 \mathrm{~b}), 3.75-3.69$ (m, 2H, H-6a', H-6b'); ${ }^{13} \mathrm{C}-\mathrm{NMR}\left(125 \mathrm{MHz}, \mathrm{CDCl}_{3}\right): \delta 165.8(\mathrm{C}=\mathrm{O} 2-O-\mathrm{Bz}), 165.7$ $\left(\mathrm{C}=\mathrm{O} 2^{\prime}-O-\mathrm{Bz}\right), 165.7\left(\mathrm{C}=\mathrm{O} 2^{\prime \prime}-O-\mathrm{Bz}\right), 138.9\left(\mathrm{C}_{\mathrm{i}}\right.$ arom. $\left.O-\mathrm{Bn}\right), 138.7\left(\mathrm{C}_{\mathrm{i}}\right.$ arom. $\left.O-\mathrm{Bn}\right), 138.3\left(\mathrm{C}_{\mathrm{i}}\right.$ arom. $O-$ Bn), $138.3\left(\mathrm{C}_{\mathrm{i}}\right.$ arom. $\left.O-\mathrm{Bn}\right), 138.2\left(\mathrm{C}_{\mathrm{i}}\right.$ arom. $\left.O-\mathrm{Bn}\right), 138.1\left(\mathrm{C}_{\mathrm{i}}\right.$ arom. $\left.O-\mathrm{Bn}\right), 137.1\left(\mathrm{C}_{\mathrm{i}}\right.$ arom. $\left.1-O-\mathrm{Bn}\right)$, $133.4\left(\mathrm{C}_{\mathrm{i}}\right.$ arom. $O$-Bz), $133.3\left(\mathrm{C}_{\mathrm{i}}\right.$ arom. $O$-Bz), $133.2\left(\mathrm{C}_{\mathrm{i}}\right.$ arom. $\left.O-\mathrm{Bz}\right), 130.1(\mathrm{CH}$ arom.), $130.1(\mathrm{CH}$ arom.), 129.9 (CH arom.), 128.7 ( $\mathrm{CH}$ arom.), 128.6 (CH arom.), 128.6 ( $\mathrm{CH}$ arom.), 128.5 (CH arom.), 128.5 ( $\mathrm{CH}$ arom.), 128.5 ( $\mathrm{CH}$ arom.), 128.4 ( $\mathrm{CH}$ arom.), 128.3 ( $\mathrm{CH}$ arom.), 128.2 (CH arom.), 128.1 (CH arom.), 128.1 ( $\mathrm{CH}$ arom.), 128.1 ( $\mathrm{CH}$ arom.), 128.0 ( $\mathrm{CH}$ arom.), 127.9 ( $\mathrm{CH}$ arom.), 127.8 (CH arom.), 127.7 (CH arom.), 127.7 ( $\mathrm{CH}$ arom.), 127.7 (CH arom.), 127.6 ( $\mathrm{CH}$ arom.), 127.5 ( $\mathrm{CH}$ arom.), 127.4 (CH arom.), 99.8 (C-1'), 98.3 (C-1"), 97.2 (C-1), 79.1 (C-3"), 78.1 (C-3'), 77.6 (C-3), $75.6\left(\mathrm{CH}_{2} 4^{\prime \prime}-O-\mathrm{Bn}\right), 74.6$ (C-4" and $\left.\mathrm{CH}_{2} 4^{\prime}-O-\mathrm{Bn}\right), 74.2$ (C-4'), $73.6\left(\mathrm{CH}_{2} 6^{\prime}-O-\mathrm{Bn}\right.$ and $\mathrm{CH}_{2}$ 6"-O-Bn), $72.6(\mathrm{C}-2), 72.5$ (C-5'), 72.3 (C-5"), $71.9\left(\mathrm{CH}_{2}\right.$ 3"-O-Bn), 71.9 (C-5 and $\mathrm{CH}_{2}$ 3'-O-Bn), $69.8\left(\mathrm{CH}_{2}\right.$ 1-O-Bn), $69.5\left(\mathrm{C}-2^{\prime}\right), 69.3\left(\mathrm{C}-2^{\prime \prime}\right)$, 69.2 (C-6"), 69.0 (C-6'), 67.1 (C-4), 66.7 (C-6); HRMS(ESI) $\mathrm{m} / z$ calcld. for $\left[\mathrm{C}_{88} \mathrm{H}_{86} \mathrm{O}_{19}+\mathrm{Na}\right]^{+}: 1469.5661$, obsd.: 1469.5668 .

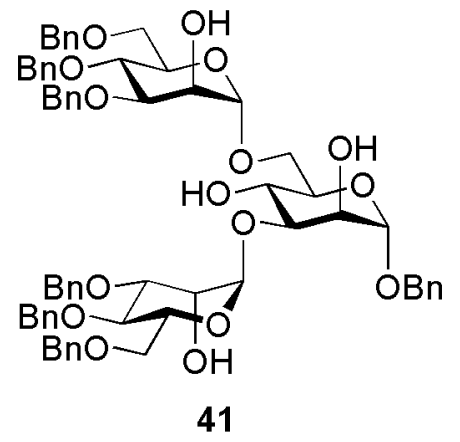

Benzyl 3,6-di- $O$-(3,4,6-tri- $O$-benzyl- $\alpha$-D-mannopyranosyl)- $\alpha$-Dmannopyranoside (41). Trisaccharide $17(0.0842,0.058 \mathrm{mmol})$ was dissolved in $\mathrm{DCM} / \mathrm{MeOH}(2 \mathrm{~mL}, 1 / 1, \mathrm{v} / \mathrm{v})$. After addition of sodium methoxide until the solution was $\mathrm{pH} \approx 9(0.40 \mathrm{~mL}, 0.04 \mathrm{M}$ in $\mathrm{MeOH})$, the reaction was stirred for 3 days until TLC-analysis (ethyl acetate) showed complete debenzoylation of the starting compound. The reaction mixture was neutralised with Dowex $\mathrm{H}^{+}$, filtered and concentrated in vacuo. Purification by column chromatography (ethyl acetate/light petroleum ether, $2 / 1 \rightarrow 5 / 1, \mathrm{v} / \mathrm{v}$ ) yielded 41 , as a colourless oil $(0.0491 \mathrm{~g}, 74 \%) . R_{f} 0.63$ (ethyl acetate); $[\alpha]_{\mathrm{D}}{ }^{20}=38.4^{\circ}$ (c 1.0, $\mathrm{CHCl}_{3}$ ); IR (thin film): 3436, 3088, 3063, 3031, 2920, 2871, 1496, 1454, 1364, 1319, 1267, 1210, 1041, 1027, 983, 909, 842, 816, 733, $697 \mathrm{~cm}^{-1} ;{ }^{1} \mathrm{H}-\mathrm{NMR}\left(500 \mathrm{MHz}, \mathrm{CDCl}_{3}\right): \delta$ 7.37-7.14 (m, 35H, CH arom.), 5.08 (d, 1H, $\left.J_{1^{\prime}, 2^{\prime}}=1.5 \mathrm{~Hz}, \mathrm{H}-1^{\prime}\right), 4.97$ (d, $\left.1 \mathrm{H}, J_{1^{\prime \prime}, 2^{\prime \prime}}=1.5 \mathrm{~Hz}, \mathrm{H}-1^{\prime \prime}\right), 4.82\left(\mathrm{~d}, 1 \mathrm{H}, J_{\mathrm{a}, \mathrm{b}}=11.2 \mathrm{~Hz}, \mathrm{CH}-\right.$ a 4'-O-Bn), $4.81\left(\mathrm{~d}, 1 \mathrm{H}, J_{\mathrm{a}, \mathrm{b}}=10.8 \mathrm{~Hz}, \mathrm{CH}-\mathrm{a} 4{ }^{\prime \prime}-O-\mathrm{Bn}\right), 4.71-4.63\left(\mathrm{~m}, 7 \mathrm{H}, \mathrm{H}-1, \mathrm{CH}-\mathrm{a} 1-O-\mathrm{Bn}, \mathrm{CH}-\mathrm{a} 3^{\prime}-O-\right.$ 
Bn, CH-b 3'-O-Bn, CH-a 3"-O-Bn, CH-b 3"-O-Bn , and CH-a 6"-O-Bn), 4.55 (d, 1H, $J_{\mathrm{a}, \mathrm{b}}=12.2 \mathrm{~Hz}, \mathrm{CH}-\mathrm{b}$ 6"-O-Bn), 4.53-4.47 (m, 4H, CH-b 4'-O-Bn, CH-b 4"-O-Bn, CH-a 6'-O-Bn, and CH-b 6'-O-Bn), 4.43 (d, $\left.1 \mathrm{H}, J_{\mathrm{a}, \mathrm{b}}=11.7 \mathrm{~Hz}, \mathrm{CH}-\mathrm{b} 1-O-\mathrm{Bn}\right), 4.23\left(\mathrm{ddd}, 1 \mathrm{H}, J_{4^{\prime}, 5^{\prime}}=10.0, J_{5^{\prime}, 6 \mathrm{~b}^{\prime}}=9.8, J_{5^{\prime}, 6 \mathrm{a}^{\prime}}=1.4 \mathrm{~Hz}, \mathrm{H}-5^{\prime}\right), 4.19-4.18$ (m, 2H, H-2 and H-2"), 4.07-4.04 (m, 2H, H-6a and H-2'), 3.95 (t, 1H, $\left.J_{3,4}=J_{4,5}=9.8 \mathrm{~Hz}, \mathrm{H}-4\right), 3.94-3.90$ (m, 3H, H-5, H-3', and H-3"), 3.85 (t, $\left.1 \mathrm{H}, J_{3^{\prime \prime}, 4^{\prime \prime}}=J_{4^{\prime \prime}, 5^{\prime \prime}}=9.3 \mathrm{~Hz}, \mathrm{H}-4^{\prime \prime}\right), 3.81\left(\mathrm{dd}, 1 \mathrm{H}, J_{2,3}=3.1, J_{3,4}=9.6\right.$ $\mathrm{Hz}, \mathrm{H}-3), 3.80\left(\mathrm{dd}, 1 \mathrm{H}, J_{5^{\prime}, 6 \mathrm{a}^{\prime}}=1.5, J_{6 \mathrm{a}^{\prime}, 6 \mathrm{~b}^{\prime}}=9.7 \mathrm{~Hz}, \mathrm{H}-6 \mathrm{a}^{\prime}\right), 3.75-3.72\left(\mathrm{~m}, 3 \mathrm{H}, \mathrm{H}-5{ }^{\prime \prime}, \mathrm{H}-6 \mathrm{a}^{\prime \prime}\right.$, and H-6b"), $3.67\left(\mathrm{dd}, 1 \mathrm{H}, J_{5,6 \mathrm{~b}}=1.9, J_{6 \mathrm{a}, 6 \mathrm{~b}}=10.7 \mathrm{~Hz}, \mathrm{H}-6 \mathrm{~b}\right), 3.58\left(\mathrm{dd}, 1 \mathrm{H}, J_{3^{\prime}, 4^{\prime}}=8.8, J_{4^{\prime}, 5^{\prime}}=10.0 \mathrm{~Hz}, \mathrm{H}-4^{\prime}\right), 3.50(\mathrm{dd}$, $\left.1 \mathrm{H}, J_{5^{\prime}, 6 \mathrm{~b}^{\prime}}=8.6, J_{6 \mathrm{a}^{\prime}, 6 \mathrm{~b}^{\prime}}=9.8 \mathrm{~Hz}, \mathrm{H}-6 \mathrm{~b}^{\prime}\right), 2.47(\mathrm{bs}, 3 \mathrm{H}, 3 \mathrm{xOH}) ;{ }^{13} \mathrm{C}-\mathrm{NMR}\left(125 \mathrm{MHz}, \mathrm{CDCl}_{3}\right): \delta 138.2\left(\mathrm{C}_{\mathrm{i}}\right.$ arom. $O$-Bn), 138.1 ( $\mathrm{C}_{\mathrm{i}}$ arom. $O$-Bn), 138.1 ( $\mathrm{C}_{\mathrm{i}}$ arom. $O$ - $\left.\mathrm{Bn}\right), 138.0\left(\mathrm{C}_{\mathrm{i}}\right.$ arom. $O$-Bn), $137.8\left(\mathrm{C}_{\mathrm{i}}\right.$ arom. $O-$ $\mathrm{Bn}), 137.4\left(\mathrm{C}_{\mathrm{i}}\right.$ arom. $O$-Bn), $137.4\left(\mathrm{C}_{\mathrm{i}}\right.$ arom. $\left.1-O-\mathrm{Bn}\right), 128.7(\mathrm{CH}$ arom.), $128.6(\mathrm{CH}$ arom.), $128.6(\mathrm{CH}$ arom.), 128.5 ( $\mathrm{CH}$ arom.), 128.5 ( $\mathrm{CH}$ arom.), 128.5 ( $\mathrm{CH}$ arom.), 128.3 ( $\mathrm{CH}$ arom.), 128.2 ( $\mathrm{CH}$ arom.), 128.2 ( $\mathrm{CH}$ arom.), 128.1 ( $\mathrm{CH}$ arom.), 128.0 ( $\mathrm{CH}$ arom.), 128.0 ( $\mathrm{CH}$ arom.), 128.0 ( $\mathrm{CH}$ arom.), 128.0 (CH arom.), 128.0 (CH arom.), 127.9 (CH arom.), 127.8 (CH arom.), 100.6 (C-1'), 99.8 (C-1), 99.5 (C-1"), 82.3 (C-3), 80.3 (C-3'), 80.3 (C-3"), $75.4\left(\mathrm{CH}_{2}\right.$ 4"-O-Bn), $75.0\left(\mathrm{CH}_{2} 4^{\prime}-O-\mathrm{Bn}\right), 74.8$ (C-4'), 74.5 (C-4"), 73.8 $\left(\mathrm{CH}_{2} 6^{\prime}-O-\mathrm{Bn}\right), 73.5\left(\mathrm{CH}_{2} 6^{\prime \prime}-O-\mathrm{Bn}\right), 72.5\left(\mathrm{CH}_{2} 3^{\prime \prime}-O-\mathrm{Bn}\right), 72.1\left(\mathrm{CH}_{2} 3^{\prime}-O-\mathrm{Bn}\right), 71.6\left(\mathrm{C}-5^{\prime}\right), 71.4\left(\mathrm{C}-5^{\prime \prime}\right)$, 71.2 (C-5), 69.7 (C-6'), 69.0 ( $\mathrm{CH}_{2}$ 1-O-Bn), 69.0 (C-2 and C-2'), 68.9 (C-6"), 68.4 (C-2"), 66.4 (C-6), 65.6 (C-4); HRMS(ESI) $m / z$ calcld. for $\left[\mathrm{C}_{67} \mathrm{H}_{74} \mathrm{O}_{16}+\mathrm{Na}\right]^{+}: 1157.4875$, obsd.: 1157.4882 .

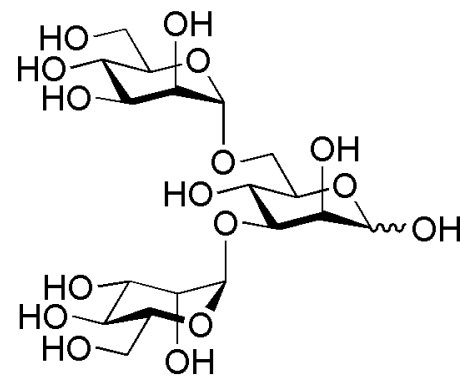

42

3,6-di- $\boldsymbol{O}$-( $\alpha$-D-mannopyranosyl)- $\alpha / \beta$-D-mannopyranose (42). To a solution of trisaccharide $41(0.0360 \mathrm{~g}, 0.0317 \mathrm{mmol})$ in $\mathrm{CHCl}_{3} / \mathrm{EtOH}$ $(0.50 \mathrm{~mL}, 3 / 2, \mathrm{v} / \mathrm{v})$ was added $\mathrm{Pd}(\mathrm{OH})_{2} / \mathrm{C}(0.0050 \mathrm{~g}, 20 \%$ catalyst, $0.0071 \mathrm{mmol}, 0.2$ equiv.). The reaction mixture was placed under a $\mathrm{H}_{2}$ atmosphere and stirred for 3 days, with extra $\mathrm{Pd}(\mathrm{OH})_{2} / \mathrm{C}(0.0050 \mathrm{~g})$ added after $24 \mathrm{~h}$. After TLC-analysis (30\% $\mathrm{MeOH}$ in ethyl acetate) showed completion of the reaction, the reaction mixture was filtered over celite, washed though with $\mathrm{MeOH}$ and $\mathrm{H}_{2} \mathrm{O}$, and concentrated in vacuo. Purification by $\mathrm{C}_{18}$ reverse phase column chromatography $\left(\mathrm{MeOH}\right.$ in $\mathrm{H}_{2} \mathrm{O}, 0 \% \rightarrow 2 \%$, v/v) yielded fully deprotected trisaccharide $\mathbf{4 2}$ as a white amorphous solid after lyophilisation $(0.0152 \mathrm{~g}, 95 \%)$. $R_{f}$ 0.19/0.13 ( $\alpha / \beta)$ (30\% MeOH in ethyl acetate, v/v); IR (thin film): 3323, 2935, 1454, 1377, 1274, 1048, 1019, 974, 918, 881, $809 \mathrm{~cm}^{-1}$; ${ }^{1} \mathrm{H}-\mathrm{NMR}\left(600 \mathrm{MHz}, \mathrm{D}_{2} \mathrm{O}\right): \delta 5.09$ (s, 1H), 5.07 (s, 2H), $4.87(\mathrm{~s}, 1 \mathrm{H}), 4.86$ (s, 1H), 4.85 (s, 1H), 4.04-3.30 (m, 36H); ${ }^{13} \mathrm{C}-\mathrm{NMR}\left(150 \mathrm{MHz}, \mathrm{D}_{2} \mathrm{O}\right): \delta 102.3,102.1,99.3,99.3,94.1$, 93.6, 80.5, 78.2, 73.9, 73.2, 73.2, 72.5, 72.5, 70.7, 70.6, 70.4, 70.4, 70.2, 70.2, 69.9, 69.7, 69.7, 66.6, 66.6, 66.6, 65.6, 65.5, 65.3, 65.2, 62.4, 60.8, 60.8; $\mathrm{HRMS(ESI)} \mathrm{m} / z$ calcld. for $\left[\mathrm{C}_{18} \mathrm{H}_{32} \mathrm{O}_{16}+\mathrm{Na}\right]^{+}: 527.1588$, obsd.: 527.1583 .

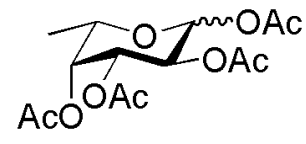

46
1,2,3,4-Tetra- $\boldsymbol{O}$-acetyl- $\boldsymbol{\alpha} / \boldsymbol{\beta}$-L-fucopyranose (46). L-Fucose (4.00 g, $24.4 \mathrm{mmol})$ was dissolved in acetic anhydride/pyridine $(75 \mathrm{~mL}, 1 / 2, \mathrm{v} / \mathrm{v})$ and the reaction 
mixture was stirred for $18 \mathrm{~h}$. TLC-analysis (ethyl acetate) showed complete acetylation of the starting material. The reaction mixture was concentrated in vасио, coevaporated three times with toluene, redissolved in ethyl acetate, washed with water and brine, dried $\left(\mathrm{MgSO}_{4}\right)$, filtered and concentrated in vacuo. The crude per-acetylated product $\mathbf{4 6}$ as a mixture of anomers $(\alpha: \beta, 1.9: 1)(8.4 \mathrm{~g})$ was used without further purification. $R_{f} 0.61$ (both anomers) (ethyl acetate); ${ }^{1} \mathrm{H}-\mathrm{NMR}\left(500 \mathrm{MHz}, \mathrm{CDCl}_{3}\right): \delta 6.34\left(\mathrm{~d}, 1 \mathrm{H}, J_{1,2}\right.$ $=2.7 \mathrm{~Hz}, \alpha-\mathrm{H}-1), 5.68\left(\mathrm{~d}, 1 \mathrm{H}, J_{1,2}=8.3 \mathrm{~Hz}, \beta-\mathrm{H}-1\right), 5.36-5.30(\mathrm{~m}, 4 \mathrm{H}, \alpha-\mathrm{H}-2, \alpha-\mathrm{H}-3, \alpha-\mathrm{H}-4, \beta-\mathrm{H}-2), 5.27$ $\left(\mathrm{d}, 1 \mathrm{H}, J_{3,4}=3.5 \mathrm{~Hz}, \beta-\mathrm{H}-4\right), 5.07$ (dd, $\left.1 \mathrm{H}, J_{2,3}=10.5, J_{3,4}=3.4 \mathrm{~Hz}, \beta-\mathrm{H}-3\right), 4.27$ (q, $1 \mathrm{H}, J_{5,6}=6.6 \mathrm{~Hz}, \alpha-\mathrm{H}-$ 5), 3.95 (q, $1 \mathrm{H}, J_{5,6}=6.4 \mathrm{~Hz}, \beta-\mathrm{H}-5$ ), 2.19 (s, 3H, $\mathrm{CH}_{3} \beta-O-\mathrm{Ac}$ ), 2.18 (s, 3H, $\mathrm{CH}_{3} \alpha-O-\mathrm{Ac}$ ), 2.16 (s, 3H, $\mathrm{CH}_{3} \alpha-O-\mathrm{Ac}$ ), 2.12 (s, 3H, $\mathrm{CH}_{3} \beta-O-\mathrm{Ac}$ ), 2.04 (s, 3H, $\mathrm{CH}_{3} \beta-O-\mathrm{Ac}$ ), 2.02 (s, 3H, $\mathrm{CH}_{3} \alpha-O-\mathrm{Ac}$ ), 2.00 (s, 3H, $\mathrm{CH}_{3} \alpha-O-\mathrm{Ac}$ ), 1.99 (s, 3H, $\mathrm{CH}_{3} \beta-O-\mathrm{Ac}$ ), 1.23 (d, 3H, $\left.J_{5,6}=6.4 \mathrm{~Hz}, \mathrm{CH}_{3} \beta-\mathrm{H}-6\right), 1.16$ (d, 3H, $J_{5,6}=6.6 \mathrm{~Hz}$, $\left.\mathrm{CH}_{3} \alpha-\mathrm{H}-6\right)$.

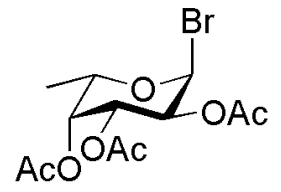

47

2,3,4-Tri- $\boldsymbol{O}$-acetyl- $\boldsymbol{\alpha}$-L-fucopyranosyl bromide (47). Crude 46 (8.4 g, $24.4 \mathrm{mmol}$ ) was dissolved in DCM $(16 \mathrm{~mL})$ and the solution cooled to $0^{\circ} \mathrm{C}$. $\mathrm{HBr}(16 \mathrm{~mL}, 33 \%$ in $\mathrm{AcOH}$ ) was then added slowly and the reaction mixture was stirred for $30 \mathrm{~min}$ at $0^{\circ} \mathrm{C}$. The reaction mixtue was then stirred for a further $1 \mathrm{~h} 45 \mathrm{~min}$ at room temperature. After TLC-analysis (ethyl acetate/light petroleum ether, 1/1, v/v) showed completion of the reaction, the reaction mixture was codistilled four times with toluene, resulting in crude fucobromide 47 as a viscous yellow oil $\left(9.05 \mathrm{~g}\right.$ ) which was used without further purification. $R_{f} 0.48$ (ethyl acetate/light petroleum ether, 1/1, v/v); ${ }^{1} \mathrm{H}-\mathrm{NMR}\left(500 \mathrm{MHz}, \mathrm{CDCl}_{3}\right): \delta 6.69\left(\mathrm{~d}, 1 \mathrm{H}, J_{1,2}=3.9 \mathrm{~Hz}, \mathrm{H}-1\right)$, $5.41\left(\mathrm{dd}, 1 \mathrm{H}, J_{2,3}=10.8, J_{3,4}=3.5 \mathrm{~Hz}, \mathrm{H}-3\right), 5.36\left(\mathrm{dd}, 1 \mathrm{H}, J_{3,4}=3.1, J_{4,5}=1.2 \mathrm{~Hz}, \mathrm{H}-4\right), 5.03\left(\mathrm{dd}, 1 \mathrm{H}, J_{1,2}=\right.$ 3.9, $\left.J_{2,3}=10.7 \mathrm{~Hz}, \mathrm{H}-2\right), 4.40$ (q, $1 \mathrm{H}, J_{5,6}=6.4 \mathrm{~Hz}, \mathrm{H}-5$ ), 2.17 (s, 3H, $\mathrm{CH}_{3} 4-O-\mathrm{Ac}$ ), 2.11 (s, 3H, $\mathrm{CH}_{3} 2-O-$ Ac), 2.01 (s, 3H, $\left.\mathrm{CH}_{3} 3-O-\mathrm{Ac}\right), 1.22$ (d, 3H, $\left.J_{5,6}=6.3 \mathrm{~Hz}, \mathrm{CH}_{3} \mathrm{H}-6\right) ;{ }^{13} \mathrm{C}-\mathrm{NMR}\left(125 \mathrm{MHz}, \mathrm{CDCl}_{3}\right): \delta 170.4$ $(\mathrm{C}=\mathrm{O}$ 4-O-Ac), $170.3(\mathrm{C}=\mathrm{O}$ 2-O-Ac), $170.0(\mathrm{C}=\mathrm{O}$ 3-O-Ac), $89.4(\mathrm{C}-1), 70.1(\mathrm{C}-4), 69.9(\mathrm{C}-5), 68.6(\mathrm{C}-3)$, 68.0 (C-2), $20.9\left(\mathrm{CH}_{3} 2-\mathrm{O}-\mathrm{Ac}\right), 20.8\left(\mathrm{CH}_{3} 3-\mathrm{O}-\mathrm{Ac}\right), 20.7\left(\mathrm{CH}_{3} 4-\mathrm{O}-\mathrm{Ac}\right), 15.7$ (C-6).

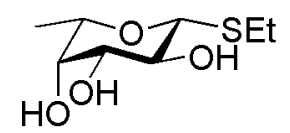

48

Ethyl $\boldsymbol{\alpha}$-L-thiofucopyranoside (48). To a solution of sodium hydride $(2.40 \mathrm{~g}, 60 \%$ in oil, $60.0 \mathrm{mmol}, 2.5$ equiv.) in DME (doubly distilled from lithium aluminium hydride) $(53 \mathrm{~mL})$ at $0^{\circ} \mathrm{C}$ was added ethanethiol $(5.40 \mathrm{~mL}, 101 \mathrm{mmol}, 4.1$ equiv.) slowly with vigorous stirring. After stirring for $30 \mathrm{~min}$, a solution of crude bromide

47 (9.01 g, $24.4 \mathrm{mmol})$ in DME (doubly distilled from lithium aluminium hydride) $(27 \mathrm{~mL}$ ) was added. The reaction mixture was allowed to stir for $3.5 \mathrm{~h}$ at room temperature. After TLC-analysis (ethyl acetate/light petroleum ether, 1/1, v/v) showed complete formation of the thioether, $\mathrm{MeOH}(80 \mathrm{~mL})$ and $\mathrm{NaOMe}$ were added to the reaction mixture until the $\mathrm{pH}$ was $>9$. The reaction mixture was stirred for a further $18 \mathrm{~h}$. TLCanalysis (15\% $\mathrm{MeOH}$ in ethyl acetate) showed complete de-acetylation. The reaction mixture was neutralised with Dowex $\mathrm{H}^{+}$, filtered, washed with $\mathrm{MeOH}$, and concentrated in vacuo. Purification by column chromatography (methanol in DCM, $0 \% \rightarrow 10 \%$, v/v) yielded 48 as a colourless oil $(3.43 \mathrm{~g}, 68 \%, 4$ steps) which was crystallised from diethyl ether to yield white fluffy crystals. $R_{f} 0.42$ (15\% methanol in 
ethyl acetate); $\mathrm{Mp} 60.0-66.5^{\circ} \mathrm{C}$ (from $\mathrm{Et}_{2} \mathrm{O}$ ); $[\alpha]_{\mathrm{D}}{ }^{20}=34.6^{\circ}$ (c 1.0, $\mathrm{CHCl}_{3}$ ); IR (thin film): 3376, 2978, 2930, 2870, 1652, 1544, 1497, 1454, 1378, 1263, 1161, 1090, 1044, 1027, 995, 910, 864, 808, 729, 697, $667 \mathrm{~cm}^{-1} ;{ }^{1} \mathrm{H}-\mathrm{NMR}\left(500 \mathrm{MHz}, \mathrm{CDCl}_{3}\right.$ ): $\delta 4.32-4.27$ (m, 1H, H-1), 3.79 (d, $\left.1 \mathrm{H}, J_{3,4}=2.5 \mathrm{~Hz}, \mathrm{H}-4\right), 3.68$ (qd, $\left.1 \mathrm{H}, J_{5,6}=6.6, J_{4,5}=1.0 \mathrm{~Hz}, \mathrm{H}-5\right), 3.64-3.60(\mathrm{~m}, 2 \mathrm{H}, \mathrm{H}-2$ and H-3), 2.80-2.68 (m, 2H, CH-a SEt and CH-b $\mathrm{SEt}$ ), 2.36 (bs, 3H, 3 x OH), 1.34 (d, $\left.3 \mathrm{H}, J_{5,6}=6.6 \mathrm{~Hz}, \mathrm{CH}_{3} \mathrm{H}-6\right), 1.32$ (t, $3 \mathrm{H}, J_{\mathrm{CH} 2, \mathrm{CH} 3}=7.3 \mathrm{~Hz}, \mathrm{CH}_{3} \mathrm{SEt}$ ); ${ }^{13} \mathrm{C}-\mathrm{NMR}\left(125 \mathrm{MHz}, \mathrm{CDCl}_{3}\right.$ ): $\delta 86.1$ (C-1), 75.2 (C-3), 74.9 (C-5), 71.8 (C-4), 70.5 (C-2), $24.7\left(\mathrm{CH}_{2} \mathrm{SEt}\right)$, 16.8 (C-6), $15.4\left(\mathrm{CH}_{3} \mathrm{SEt}\right)$; HRMS(ESI) $\mathrm{m} / z$ calcld. for $\left[\mathrm{C}_{8} \mathrm{H}_{16} \mathrm{O}_{4} \mathrm{~S}+\mathrm{Na}\right]^{+}: 231.0667$, obsd.: 231.0665 .

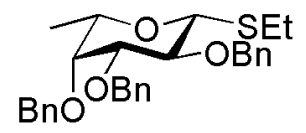

22

Ethyl 2,3,4-tri- $\boldsymbol{O}$-benzyl- $\boldsymbol{\beta}$-L-thiofucopyranoside (22). Thiofucoside 48 (1.13 g, $5.44 \mathrm{mmol}$ ) was coevaporated three times with DMF, for the final coevaporation the solution was partially concentrated concentrated leaving $27 \mathrm{~mL}$ DMF, and placed under a nitrogen atmosphere. After cooling the solution to $0^{\circ} \mathrm{C}$, benzyl bromide $(2.33 \mathrm{~mL}, 19.6 \mathrm{mmol}, 3.6$ equiv.), sodium hydride ( $0.849 \mathrm{~g}, 60 \%$ in oil, $21.2 \mathrm{mmol}, 3.9$ equiv.) and TBAI (cat.) were added and the reaction mixture was allowed to stir for $17 \mathrm{~h}$ at room temperature. After TLC-analysis (ethyl acetate/light petroleum ether, 1/5, v/v) showed completion of the reaction, the reaction mixture was quenched with methanol, concentrated in vacuo, dissolved in ethyl acetate, washed with water and brine, dried $\left(\mathrm{MgSO}_{4}\right)$, filtered and concentrated in vacuo. Purification by column chromatography (ethyl acetate/light petroleum ether, $1 / 35 \rightarrow 1 / 10, \mathrm{v} / \mathrm{v})$ yielded 22 as a colourless oil which crystallised upon refrigeration $(2.14 \mathrm{~g}, 82 \%)$. $R_{f} 0.36$ (ethyl acetate/light petroleum ether, $1 / 5$, v/v); Mp 51.0-52.1 ${ }^{\circ} \mathrm{C} ;$ Lit. $^{117} \mathrm{Mp} \mathrm{53}{ }^{\circ} \mathrm{C} ;[\alpha]_{\mathrm{D}}{ }^{24}=6.0^{\circ}(c 1.0$, $\mathrm{CHCl}_{3}$ ); IR (thin film): 3088, 3063, 3030, 2977, 2929, 2868, 1497, 1454, 1357, 1208, 1165, 1125, 1089, 1067, 1048, 912, 876, 697, $667 \mathrm{~cm}^{-1} ;{ }^{1} \mathrm{H}-\mathrm{NMR}\left(500 \mathrm{MHz}, \mathrm{CDCl}_{3}\right.$ ): $\delta$ 7.42-7.28 (m, 15H, CH arom.), 5.00 $\left(\mathrm{d}, 1 \mathrm{H}, J_{\mathrm{a}, \mathrm{b}}=11.7 \mathrm{~Hz}, \mathrm{CH}-\mathrm{a} 4-O-\mathrm{Bn}\right), 4.91\left(\mathrm{~d}, 1 \mathrm{H}, J_{\mathrm{a}, \mathrm{b}}=10.0 \mathrm{~Hz}, \mathrm{CH}-\mathrm{a} 2-O-\mathrm{Bn}\right), 4.81\left(\mathrm{~d}, 1 \mathrm{H}, J_{\mathrm{a}, \mathrm{b}}=10.3\right.$ $\mathrm{Hz}, \mathrm{CH}-\mathrm{b} 2-O-\mathrm{Bn}), 4.78$ (d, 1H, $\left.J_{\mathrm{a}, \mathrm{b}}=11.7 \mathrm{~Hz}, \mathrm{CH}-\mathrm{a} 3-O-\mathrm{Bn}\right), 4.75$ (d, 1H, $\left.J_{\mathrm{a}, \mathrm{b}}=12.0 \mathrm{~Hz}, \mathrm{CH}-\mathrm{b} 3-O-\mathrm{Bn}\right)$, $4.71\left(\mathrm{~d}, 1 \mathrm{H}, J_{\mathrm{a}, \mathrm{b}}=11.7 \mathrm{~Hz}\right.$, CH-b 4-O-Bn), $4.40\left(\mathrm{~d}, 1 \mathrm{H}, J_{1,2}=9.8 \mathrm{~Hz}, \mathrm{H}-1\right), 3.83\left(\mathrm{t}, 1 \mathrm{H}, J_{1,2}=J_{2,3}=9.5 \mathrm{~Hz}\right.$, $\mathrm{H}-2), 3.62\left(\mathrm{~d}, 1 \mathrm{H}, J_{3,4}=2.9 \mathrm{~Hz}, \mathrm{H}-4\right), 3.57\left(\mathrm{dd}, 1 \mathrm{H}, J_{2,3}=9.3, J_{3,4}=2.7 \mathrm{~Hz}, \mathrm{H}-3\right), 3.49$ (q, $1 \mathrm{H}, J_{5,6}=6.3 \mathrm{~Hz}$, $\mathrm{H}-5), 2.79\left(\mathrm{dq}, 1 \mathrm{H}, J_{\mathrm{a}, \mathrm{b}}=12.5, J_{\mathrm{a}, \mathrm{CH} 3}=7.6 \mathrm{~Hz}, \mathrm{CH}-\mathrm{SEt}\right), 2.72\left(\mathrm{dq}, 1 \mathrm{H}, J_{\mathrm{a}, \mathrm{b}}=12.5, J_{\mathrm{b}, \mathrm{CH} 3}=7.6 \mathrm{~Hz}, \mathrm{CH}-\mathrm{b}\right.$ $\mathrm{SEt}), 1.31\left(\mathrm{t}, 3 \mathrm{H}, J_{\mathrm{CH} 2, \mathrm{CH} 3}=7.6 \mathrm{~Hz}, \mathrm{CH}_{3} \mathrm{SEt}\right), 1.21\left(\mathrm{~d}, 3 \mathrm{H}, J_{5,6}=6.3 \mathrm{~Hz}, \mathrm{CH}_{3} \mathrm{H}-6\right) ;{ }^{13} \mathrm{C}-\mathrm{NMR}(125 \mathrm{MHz}$, $\left.\mathrm{CDCl}_{3}\right): \delta 138.8$ ( $\mathrm{C}_{\mathrm{i}}$ arom. 4-O-Bn), 138.6 ( $\mathrm{C}_{\mathrm{i}}$ arom. 3-O-Bn), 138.5 ( $\mathrm{C}_{\mathrm{i}}$ arom. 2-O-Bn), $128.6(\mathrm{CH}$ arom.), 128.4 (CH arom.), 128.3 ( $\mathrm{CH}$ arom.), 128.3 (CH arom.), 127.8 (CH arom.), 127.8 ( $\mathrm{CH}$ arom.), 127.7 (CH arom.), 127.6 (CH arom.), 85.1 (C-1), 84.6 (C-3), 78.5 (C-2), 76.6 (C-4), 75.8 ( $\left.\mathrm{CH}_{2} 2-O-\mathrm{Bn}\right), 74.7$ (C-5), $74.6\left(\mathrm{CH}_{2} 4-\mathrm{O}-\mathrm{Bn}\right), 73.0\left(\mathrm{CH}_{2} 3-\mathrm{O}-\mathrm{Bn}\right), 24.8\left(\mathrm{CH}_{2} \mathrm{SEt}\right), 17.4(\mathrm{C}-6), 15.1\left(\mathrm{CH}_{3} \mathrm{SEt}\right) ; \mathrm{HRMS}(\mathrm{ESI}) \mathrm{m} / \mathrm{z}$ calcld. for $\left[\mathrm{C}_{29} \mathrm{H}_{34} \mathrm{O}_{4} \mathrm{~S}+\mathrm{Na}\right]^{+}:$501.2076, obsd.: 501.2079.

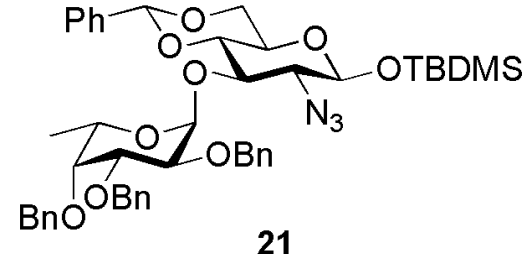

2-Azido-3-O-(2,3,4-tri- $O$-benzyl- $\alpha$-L-fucopyranosyl)-4,6- $O$ benzylidene-1- $O$-tert-butyldimethylsilyl-2-deoxy- $\beta$-Dglucopyranose (21). Glucosazide acceptor $23(0.473 \mathrm{~g}, 1.160$ mmol) and thiofucoside donor 22 ( $0.866 \mathrm{~g}, 1.810 \mathrm{mmol}, 1.6$ equiv.) 
were coevaporated three times with DMF, on the final co-evaporation the solution was concentrated to half volume leaving $12 \mathrm{~mL}$ of DMF. DCM (24 mL) was added and the solution stirred for $1.5 \mathrm{~h}$ in the presence of molecular sieves (type 4A) under a nitrogen atmosphere. Tetrapropylammonium bromide $(0.988 \mathrm{~g}$, $3.711 \mathrm{mmol}, 3.2$ equiv.) and copper(II) bromide $(0.829 \mathrm{~g}, 3.711 \mathrm{mmol}, 3.2$ equiv.) were added and stirring was continued for $50 \mathrm{~h}$. After TLC-analysis (ethyl acetate/toluene, 1/6, v/v) showed completion of the reaction, the reaction mixture was poured into sat. aq. $\mathrm{NaHCO}_{3}$, extracted with ethyl acetate and washed with sat. aq. $\mathrm{NH}_{4} \mathrm{Cl}$, and brine, dried $\left(\mathrm{MgSO}_{4}\right)$, filtered and concentrated in vacuo. Purification by column chromatography (ethyl acetate/light petroleum ether, 1/17, v/v) yielded disaccharide $\mathbf{2 1}(0.810 \mathrm{~g}, 85 \%)$ as a colourless oil. $R_{f} 0.68$ (ethyl acetate/toluene, $\left.1 / 6, \mathrm{v} / \mathrm{v}\right) ;[\alpha]_{\mathrm{D}}{ }^{20}=-66^{\circ}\left(c 0.1, \mathrm{CHCl}_{3}\right.$ ); IR (thin film): 3063 , 3029, 2930, 2860, 2111, 1455, 1361, 1262, 1217, 1180, 1099, 1040, 1000, 916, 841, $764 \mathrm{~cm}^{-1}$; ${ }^{1} \mathrm{H}-\mathrm{NMR}$ (500 MHz, $\mathrm{CDCl}_{3}$ ): $\delta$ 7.41-7.23 (m, 20H, CH arom.), 5.46 (s, $\left.1 \mathrm{H}, \mathrm{PhCH}\right), 5.39\left(\mathrm{~d}, 1 \mathrm{H}, J_{1^{\prime}, 2^{\prime}}=3.9 \mathrm{~Hz}, \mathrm{H}-1^{\prime}\right)$, $4.90\left(\mathrm{~d}, 1 \mathrm{H}, J_{\mathrm{a}, \mathrm{b}}=11.5 \mathrm{~Hz}, \mathrm{CH}-\mathrm{a} 4^{\prime}-O-\mathrm{Bn}\right), 4.85\left(\mathrm{~d}, 1 \mathrm{H}, J_{\mathrm{a}, \mathrm{b}}=11.5 \mathrm{~Hz}, \mathrm{CH}-\mathrm{a} 3^{\prime}-O-\mathrm{Bn}\right), 4.85\left(\mathrm{~d}, 1 \mathrm{H}, J_{\mathrm{a}, \mathrm{b}}=\right.$ $\left.12.0 \mathrm{~Hz}, \mathrm{CH}-\mathrm{a} 2^{\prime}-O-\mathrm{Bn}\right), 4.77$ (d, $\left.1 \mathrm{H}, J_{\mathrm{a}, \mathrm{b}}=12.0 \mathrm{~Hz}, \mathrm{CH}-\mathrm{b} 2^{\prime}-O-\mathrm{Bn}\right), 4.71\left(\mathrm{~d}, 1 \mathrm{H}, J_{\mathrm{a}, \mathrm{b}}=11.5 \mathrm{~Hz}, \mathrm{CH}-\mathrm{b} 3^{\prime}-\right.$ $O$-Bn), $4.55\left(\mathrm{~d}, 1 \mathrm{H}, J_{\mathrm{a}, \mathrm{b}}=11.5 \mathrm{~Hz}\right.$, CH-b 4'-O-Bn), $4.68\left(\mathrm{~d}, 1 \mathrm{H}, J_{1,2}=7.6 \mathrm{~Hz}, \mathrm{H}-1\right), 4.27\left(\mathrm{dd}, 1 \mathrm{H}, J_{5,6 \mathrm{a}}=\right.$ $\left.4.9, J_{6 \mathrm{a}, 6 \mathrm{~b}}=10.5 \mathrm{~Hz}, \mathrm{H}-6 \mathrm{a}\right), 4.08\left(\mathrm{q}, 1 \mathrm{H}, J_{5^{\prime}, 6^{\prime}}=6.1 \mathrm{~Hz}, \mathrm{H}-5^{\prime}\right), 4.05\left(\mathrm{dd}, 1 \mathrm{H}, J_{1^{\prime}, 2^{\prime}}=3.9, J_{2^{\prime}, 3^{\prime}}=10.3 \mathrm{~Hz}, \mathrm{H}-2^{\prime}\right)$, $3.91\left(\mathrm{dd}, 1 \mathrm{H}, J_{2^{\prime}, 3^{\prime}}=10.3, J_{3^{\prime}, 4^{\prime}}=2.9 \mathrm{~Hz}, \mathrm{H}-3^{\prime}\right), 3.76\left(\mathrm{t}, 1 \mathrm{H}, J_{5,6 \mathrm{~b}}=J_{6 \mathrm{a}, 6 \mathrm{~b}}=10.5 \mathrm{~Hz}, \mathrm{H}-6 \mathrm{~b}\right), 3.73\left(\mathrm{t}, 1 \mathrm{H}, J_{2,3}=\right.$ $\left.J_{3,4}=9.5 \mathrm{~Hz}, \mathrm{H}-3\right), 3.63\left(\mathrm{t}, 1 \mathrm{H}, J_{3,4}=J_{4,5}=9.3 \mathrm{~Hz}, \mathrm{H}-4\right), 3.52\left(\mathrm{dd}, 1 \mathrm{H}, J_{1,2}=7.8, J_{2,3}=9.8 \mathrm{~Hz}, \mathrm{H}-2\right), 3.50$ $\left(\mathrm{d}, 1 \mathrm{H}, J_{3^{\prime}, 4^{\prime}}=2.4 \mathrm{~Hz}, \mathrm{H}-4^{\prime}\right), 3.43\left(\mathrm{td}, 1 \mathrm{H}, J_{4,5}=J_{5,6 \mathrm{~b}}=9.5, J_{5,6 \mathrm{a}}=4.9 \mathrm{~Hz}, \mathrm{H}-5\right), 0.94\left(\mathrm{~s}, 9 \mathrm{H}, 3 \times \mathrm{CH}_{3} \mathrm{Si}{ }^{\mathrm{t}} \mathrm{Bu}\right)$, $0.69\left(\mathrm{~d}, 3 \mathrm{H}, J_{5^{\prime}, 6^{\prime}}=6.3 \mathrm{~Hz}, \mathrm{CH}_{3} \mathrm{H}-6^{\prime}\right), 0.17\left(\mathrm{~s}, 3 \mathrm{H}, \mathrm{CH}_{3} \mathrm{SiMe}_{\mathrm{a}}\right), 0.16\left(\mathrm{~s}, 3 \mathrm{H}, \mathrm{CH}_{3} \mathrm{SiMe}_{\mathrm{b}}\right) ;{ }^{13} \mathrm{C}-\mathrm{NMR}(125$ $\left.\mathrm{MHz}, \mathrm{CDCl}_{3}\right): \delta 139.1$ ( $\mathrm{C}_{\mathrm{i}}$ arom. 3'-O-Bn), 138.8 ( $\mathrm{C}_{\mathrm{i}}$ arom. 4'-O-Bn), $138.5\left(\mathrm{C}_{\mathrm{i}}\right.$ arom. 2'-O-Bn), $137.3\left(\mathrm{C}_{\mathrm{i}}\right.$ arom. $\mathrm{PhCH}), 129.3$ (CH arom.), 128.5 ( $\mathrm{CH}$ arom.), 128.4 ( $\mathrm{CH}$ arom.), $128.4(\mathrm{CH}$ arom.), 128.3 (CH arom.), 128.2 ( $\mathrm{CH}$ arom.), 128.1 ( $\mathrm{CH}$ arom.), 127.7 ( $\mathrm{CH}$ arom.), 127.6 ( $\mathrm{CH}$ arom.), 127.5 ( $\mathrm{CH}$ arom.), 127.5 (CH arom.), 126.4 (CH arom.), $102.2(\mathrm{PhCH}), 98.1$ (C-1), 97.6 (C-1'), 79.6 (C-4), 79.5 (C-3'), 78.0 (C-4'), 75.8 (C-2'), $75.0\left(\mathrm{CH}_{2} 4^{\prime}-O-\mathrm{Bn}\right), 74.2$ (C-3), $73.2\left(\mathrm{CH}_{2} 2^{\prime}-O-\mathrm{Bn}\right.$ and $\left.\mathrm{CH}_{2} 3^{\prime}-O-\mathrm{Bn}\right), 69.5(\mathrm{C}-2), 68.8$ (C-6), 66.9 (C-5), $66.5\left(\mathrm{C}-5^{\prime}\right), 25.7\left(\mathrm{CH}_{3} \mathrm{Si}^{\mathrm{t}} \mathrm{Bu}\right), 18.1\left(\mathrm{C}_{\mathrm{q}} \mathrm{Si} \mathrm{Bu}^{\mathrm{t}} \mathrm{Bu}\right), 16.2\left(\mathrm{C}-6^{\prime}\right),-4.2\left(\mathrm{CH}_{3} \mathrm{SiMe}_{\mathrm{a}}\right),-4.9\left(\mathrm{CH}_{3}\right.$ $\mathrm{SiMe}_{\mathrm{b}}$ ); HRMS(ESI) $m / z$ calcld. for $\left[\mathrm{C}_{46} \mathrm{H}_{57} \mathrm{O}_{9} \mathrm{~N}_{3} \mathrm{Si}+\mathrm{Na}\right]^{+}:$: 846.3762, obsd.: 846.3765 .

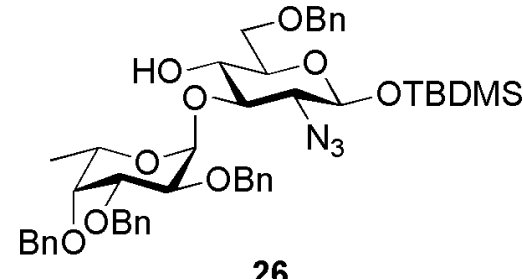

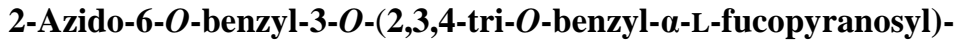
1-O-tert-butyldimethylsilyl-2-deoxy- $\beta$-D-glucopyranose

(26).

Disaccharide 21 (0.288 g, $0.350 \mathrm{mmol})$ was coevaporated three times with toluene and dissolved in DCM $(1.75 \mathrm{~mL})$. The solution was stirred for $1 \mathrm{~h}$ in the presence of molecular sieves (type 4A)

under a nitrogen atmosphere. After cooling the solution to $0^{\circ} \mathrm{C}$, triethylsilane $(0.333 \mathrm{~mL}, 2.097 \mathrm{mmol}, 6.0$ equiv.) was added and the reaction mixture was stirred for 10 mins. TFAA $(0.049 \mathrm{~mL}, 0.350 \mathrm{mmol}, 1.0$ equiv.) followed by TFA $(0.135 \mathrm{~mL}, 1.748 \mathrm{mmol}, 5.0$ equiv. $)$ were then added and the reaction mixture was stirred for 30 mins at $0^{\circ} \mathrm{C}$. The reaction mixture was allowed to warm to room temperature and stirred for a further $2 \mathrm{~h}$. After TLC-analysis (ethyl acetate/toluene, 1/6, v/v) showed completion of the reaction, the 
reaction mixture was neutralised with sat. aq. $\mathrm{NaHCO}_{3}$ and the aqueous layer extracted twice with DCM. The organic layers were combined, dried $\left(\mathrm{MgSO}_{4}\right)$, filtered and concentrated in vacuo. Purification by column chromatography (ethyl acetate/light petroleum ether, $1 / 10 \rightarrow 1 / 7, \mathrm{v} / \mathrm{v}$ ) yielded $\mathbf{2 6}$ as a colourless oil $(0.225 \mathrm{~g}, 78 \%) \cdot R_{f} 0.56$ (ethyl acetate/toluene, $\left.1 / 6, \mathrm{v} / \mathrm{v}\right) ;[\alpha]_{\mathrm{D}}{ }^{24}=-35.4^{\circ}\left(c 1.0, \mathrm{CHCl}_{3}\right) ; \mathrm{IR}$ (thin film): 3410, 3089, 3064, 3031, 2929, 2857, 2110, 1497, 1454, 1389, 1361, 1311, 1255, 1206, 1170, 1133, 1081, 1063, 1027, 958, 839, 783, 735, $696 \mathrm{~cm}^{-1} ;{ }^{1} \mathrm{H}-\mathrm{NMR}\left(500 \mathrm{MHz}, \mathrm{CDCl}_{3}\right.$ ): $\delta$ 7.40-7.27 (m, 20H, CH arom.), $5.04\left(\mathrm{~d}, 1 \mathrm{H}, J_{1^{\prime}, 2^{\prime}}=3.9 \mathrm{~Hz}, \mathrm{H}-1^{\prime}\right), 4.99\left(\mathrm{~d}, 1 \mathrm{H}, J_{\mathrm{a}, \mathrm{b}}=11.2 \mathrm{~Hz}, \mathrm{CH}-\mathrm{a} 4^{\prime}-O-\mathrm{Bn}\right), 4.87\left(\mathrm{~d}, 1 \mathrm{H}, J_{\mathrm{a}, \mathrm{b}}=12.0 \mathrm{~Hz}\right.$, CH-a 3'-O-Bn), $4.78\left(\mathrm{~d}, 1 \mathrm{H}, J_{\mathrm{a}, \mathrm{b}}=11.7 \mathrm{~Hz}, \mathrm{CH}-\mathrm{a} 2^{\prime}-O-\mathrm{Bn}\right), 4.76\left(\mathrm{~d}, 1 \mathrm{H}, J_{\mathrm{a}, \mathrm{b}}=11.7 \mathrm{~Hz}, \mathrm{CH}-\mathrm{b} 2^{\prime}-O-\mathrm{Bn}\right)$, $4.76\left(\mathrm{~d}, 1 \mathrm{H}, J_{\mathrm{a}, \mathrm{b}}=12.2 \mathrm{~Hz}\right.$, CH-b 3'-O-Bn), $4.65\left(\mathrm{~d}, 1 \mathrm{H}, J_{\mathrm{a}, \mathrm{b}}=11.5 \mathrm{~Hz}, \mathrm{CH}-\mathrm{b} 4^{\prime}-O-\mathrm{Bn}\right), 4.61\left(\mathrm{~d}, 1 \mathrm{H}, J_{\mathrm{a}, \mathrm{b}}=\right.$ $12.2 \mathrm{~Hz}, \mathrm{CH}-\mathrm{a} 6-O-\mathrm{Bn}), 4.57\left(\mathrm{~d}, 1 \mathrm{H}, J_{\mathrm{a}, \mathrm{b}}=12.2 \mathrm{~Hz}, \mathrm{CH}-\mathrm{b} 6-O-\mathrm{Bn}\right), 4.50\left(\mathrm{~d}, 1 \mathrm{H}, J_{1,2}=7.6 \mathrm{~Hz}, \mathrm{H}-1\right), 4.14-$ $4.09\left(\mathrm{~m}, 2 \mathrm{H}, \mathrm{H}-2^{\prime}\right.$ and H-5'), $3.94\left(\mathrm{dd}, 1 \mathrm{H}, J_{2^{\prime}, 3^{\prime}}=10.0, J_{3^{\prime}, 4^{\prime}}=2.7 \mathrm{~Hz}, \mathrm{H}-3^{\prime}\right), 3.77\left(\mathrm{dd}, 1 \mathrm{H}, J_{5,6 \mathrm{a}}=2.5, J_{6 \mathrm{a}, 6 \mathrm{~b}}=\right.$ $11.0 \mathrm{~Hz}, \mathrm{H}-6 \mathrm{a}), 3.67$ (s, 1H, H-4'), $3.66\left(\mathrm{dd}, 1 \mathrm{H}, J_{5,6 \mathrm{~b}}=5.6, J_{6 \mathrm{a}, 6 \mathrm{~b}}=10.7 \mathrm{~Hz}, \mathrm{H}-6 \mathrm{~b}\right), 3.49$ (t, 1H, $J_{3,4}=J_{4,5}=$ $8.8 \mathrm{~Hz}, \mathrm{H}-4), 3.38$ (ddd, $\left.1 \mathrm{H}, J_{4,5}=9.6, J_{5,6 \mathrm{a}}=2.6, J_{5,6 \mathrm{~b}}=5.4 \mathrm{~Hz}, \mathrm{H}-5\right), 3.32\left(\mathrm{dd}, 1 \mathrm{H}, J_{1,2}=7.6, J_{2,3}=10.0\right.$ $\mathrm{Hz}, \mathrm{H}-2), 3.24\left(\mathrm{dd}, 1 \mathrm{H}, J_{2,3}=10.0, J_{3,4}=8.5 \mathrm{~Hz}, \mathrm{H}-3\right), 1.13$ (d, 3H, $\left.J_{5^{\prime}, 6^{\prime}}=6.4 \mathrm{~Hz}, \mathrm{CH}_{3} \mathrm{H}-6^{\prime}\right), 0.93$ (s, 9H, 3 $\left.\times \mathrm{CH}_{3} \mathrm{Si}{ }^{\mathrm{t}} \mathrm{Bu}\right), 0.17\left(\mathrm{~s}, 3 \mathrm{H}, \mathrm{CH}_{3} \mathrm{SiMe}_{\mathrm{a}}\right), 0.16\left(\mathrm{~s}, 3 \mathrm{H}, \mathrm{CH}_{3} \mathrm{SiMe}_{\mathrm{b}}\right) ;{ }^{13} \mathrm{C}-\mathrm{NMR}\left(125 \mathrm{MHz}, \mathrm{CDCl}_{3}\right): \delta 138.9\left(\mathrm{C}_{\mathrm{i}}\right.$ arom. 3'- $O-\mathrm{Bn}), 138.5$ ( $\mathrm{C}_{\mathrm{i}}$ arom. 2'-O-Bn), 138.5 ( $\mathrm{C}_{\mathrm{i}}$ arom. 4'-O-Bn), $138.4\left(\mathrm{C}_{\mathrm{i}}\right.$ arom. 6- $\left.O-\mathrm{Bn}\right), 128.6(\mathrm{CH}$ arom.), 128.5 ( $\mathrm{CH}$ arom.), 128.5 ( $\mathrm{CH}$ arom.), 128.4 ( $\mathrm{CH}$ arom.), 128.4 (CH arom.), 128.0 (CH arom.), 127.8 ( $\mathrm{CH}$ arom.), 127.8 ( $\mathrm{CH}$ arom.), 127.7 (CH arom.), 127.7 ( $\mathrm{CH}$ arom.), 127.6 ( $\mathrm{CH}$ arom.), 98.4 (C-1'), 97.4 (C-1), 85.0 (C-3), 78.8 (C-3'), 77.6 (C-4'), 75.8 (C-2'), $75.1(\mathrm{C}-5), 75.0\left(\mathrm{CH}_{2} 4^{\prime}-O-\mathrm{Bn}\right), 73.6\left(\mathrm{CH}_{2} 6-\right.$ $O$-Bn), 73.3 (2'-O-Bn and 3'-O-Bn), 69.7 (C-6), $69.3(\mathrm{C}-4), 68.1\left(\mathrm{C}-5{ }^{\prime}\right), 67.2(\mathrm{C}-2), 25.8\left(\mathrm{CH}_{3} \mathrm{Si}^{\mathrm{t}} \mathrm{Bu}\right), 18.1$

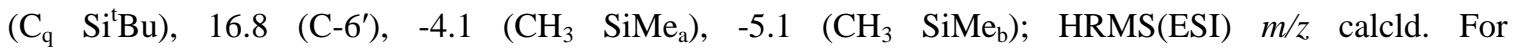
$\left[\mathrm{C}_{46} \mathrm{H}_{59} \mathrm{O}_{9} \mathrm{~N}_{3} \mathrm{Si}+\mathrm{Na}\right]^{+}:$848.3918, obsd.: 848.3919 .

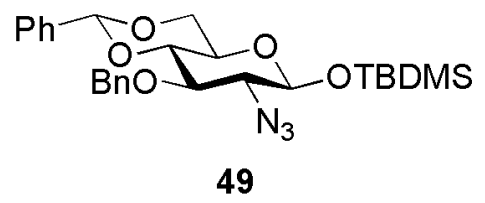

\section{2-Azido-3-O-benzyl-4,6-O-benzylidene-1-O-tert-butyldimethylsilyl-} 2-deoxy- $\beta$-D-glucopyranose (49). Glucosazide 23 (1.06 g, $2.60 \mathrm{mmol}$ ) was coevaporated three times with DMF, on the final co-evaporation the solution was concentrated to half volume leaving $13 \mathrm{~mL}$ of DMF.

The solution was placed under a nitrogen atmosphere. After cooling the solution to $0^{\circ} \mathrm{C}$, benzyl bromide ( $0.372 \mathrm{~mL}, 3.13 \mathrm{mmol}, 1.2$ equiv.), sodium hydride $(0.125 \mathrm{~g}, 60 \%$ in oil, $3.13 \mathrm{mmol}, 1.2$ equiv.) and TBAI (cat.) were added and the reaction mixture was allowed to stir for $2.5 \mathrm{~h}$ at room temperature. TLC-analysis (ethyl acetate/light petroleum ether, 1/5, v/v) showed completion of the reaction. The reaction mixture was quenched with methanol, concentrated in vacuo, dissolved in ethyl acetate, washed with water, sat. aq. $\mathrm{NaHCO}_{3}$ and brine, dried $\left(\mathrm{MgSO}_{4}\right)$, filtered and concentrated in vacuo. Purification by column chromatography (ethyl acetate/light petroleum ether, $1 / 20 \rightarrow 1 / 10$, v/v) yielded 49 as a colourless oil which formed white crystals upon standing $(1.11 \mathrm{~g}, 86 \%) . R_{f} 0.66$ (ethyl acetate/light petroleum ether, $1 / 5$, v/v); Mp 100.6-101.5 ${ }^{\circ}$; $[\alpha]_{\mathrm{D}}{ }^{20}=-81.5^{\circ}\left(c 1.0, \mathrm{CHCl}_{3}\right)$; IR (thin film): 3091, 3066, 3035, 2956, 2930, 2884, 2859, 2110, 1454, 1389, 1364, 1256, 1179, 1096, 1003, 919, 841, $784 \mathrm{~cm}^{-1} ;{ }^{1} \mathrm{H}-\mathrm{NMR}\left(500 \mathrm{MHz}, \mathrm{CDCl}_{3}\right): \delta$ 
7.49-7.47 (m, 2H, CH arom.), 7.40-7.38 (m, 5H, CH arom.), 7.35-7.26 (m, 3H, CH arom.), 5.57 (s, 1H, PhCH), $4.91\left(\mathrm{~d}, 1 \mathrm{H}, J_{\mathrm{a}, \mathrm{b}}=11.2 \mathrm{~Hz}, \mathrm{CH}-\mathrm{a} \mathrm{Bn}\right), 4.80\left(\mathrm{~d}, 1 \mathrm{H}, J_{\mathrm{a}, \mathrm{b}}=11.2 \mathrm{~Hz}, \mathrm{CH}-\mathrm{b} \mathrm{Bn}\right), 4.59$ (d, 1H, $J_{1,2}=7.8$ $\mathrm{Hz}, \mathrm{H}-1), 4.30\left(\mathrm{dd}, 1 \mathrm{H}, J_{5,6 \mathrm{a}}=5.1, J_{6 \mathrm{a}, 6 \mathrm{~b}}=10.5 \mathrm{~Hz}, \mathrm{H}-6 \mathrm{a}\right), 4.08\left(\mathrm{t}, 1 \mathrm{H}, J_{5,6 \mathrm{~b}}=J_{6 \mathrm{a}, 6 \mathrm{~b}}=10.3 \mathrm{~Hz}, \mathrm{H}-6 \mathrm{~b}\right), 3.72$ $\left(\mathrm{t}, 1 \mathrm{H}, J_{3,4}=J_{4,5}=9.3 \mathrm{~Hz}, \mathrm{H}-4\right), 3.52\left(\mathrm{t}, 1 \mathrm{H}, J_{2,3}=J_{3,4}=9.5 \mathrm{~Hz}, \mathrm{H}-3\right), 3.39\left(\mathrm{td}, 1 \mathrm{H}, J_{4,5}=J_{5,6 \mathrm{~b}}=10.0, J_{5,6 \mathrm{a}}=\right.$ $5.1 \mathrm{~Hz}, \mathrm{H}-5), 3.38\left(\mathrm{dd}, 1 \mathrm{H}, J_{1,2}=7.6, J_{2,3}=9.5 \mathrm{~Hz}, \mathrm{H}-2\right), 0.95\left(\mathrm{~s}, 9 \mathrm{H}, 3 \times \mathrm{CH}_{3} \mathrm{Si}^{\mathrm{t}} \mathrm{Bu}\right), 0.17\left(\mathrm{~s}, 3 \mathrm{H}, \mathrm{CH}_{3}\right.$ $\left.\mathrm{SiMe}_{\mathrm{a}}\right), 0.16\left(\mathrm{~s}, 3 \mathrm{H}, \mathrm{CH}_{3} \mathrm{SiMe}_{\mathrm{b}}\right) ;{ }^{13} \mathrm{C}-\mathrm{NMR}\left(125 \mathrm{MHz}, \mathrm{CDCl}_{3}\right): \delta 138.1\left(\mathrm{C}_{\mathrm{i}}\right.$ arom. Bn), $137.3\left(\mathrm{C}_{\mathrm{i}}\right.$ arom. $\mathrm{PhCH}$ ), 129.2 ( $\mathrm{CH}$ arom.), 128.5 ( $\mathrm{CH}$ arom.), 128.4 ( $\mathrm{CH}$ arom.), 128.3 ( $\mathrm{CH}$ arom.), 128.0 (CH arom.), 126.2 (CH arom.), $101.5(\mathrm{PhCH}), 97.6(\mathrm{C}-1), 81.8$ (C-4), 78.9 (C-3), $75.0\left(\mathrm{CH}_{2} \mathrm{Bn}\right), 68.9(\mathrm{C}-2), 68.7$ (C-6), 66.5 (C-5), $25.7\left(\mathrm{CH}_{3} \mathrm{Si}^{\mathrm{t}} \mathrm{Bu}\right), 18.1\left(\mathrm{C}_{\mathrm{q}} \mathrm{Si}^{\mathrm{t}} \mathrm{Bu}\right),-4.2\left(\mathrm{CH}_{3} \mathrm{SiMe}_{\mathrm{a}}\right),-5.1\left(\mathrm{CH}_{3} \mathrm{SiMe}_{\mathrm{b}}\right)$; HRMS(ESI) $\mathrm{m} / z$ calcld. for $\left[\mathrm{C}_{26} \mathrm{H}_{35} \mathrm{O}_{5} \mathrm{~N}_{3} \mathrm{Si}+\mathrm{Na}\right]^{+}: 520.2244$, obsd.: 520.2240 .

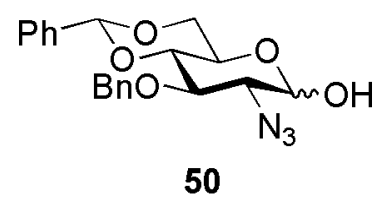

2-Azido-3- $O$-benzyl-4,6- $O$-benzylidene-2-deoxy- $\alpha / \beta$-D-glucopyranose (50).

Glucosazide $49(0.79 \mathrm{~g}, 1.59 \mathrm{mmol})$ was dissolved in THF $(18.0 \mathrm{~mL})$ in a plastic vial. After addition of HF.pyridine $(1.99 \mathrm{~mL}, 70 \%$ in pyridine, 14.1 mmol, 8.8 eq.), the reaction mixture was left for $22 \mathrm{~h}$. After TLC-analysis

(ethyl acetate/light petroleum ether, 1/7, v/v) showed complete deprotection, the reaction mixture was neutralised with sat. aq. $\mathrm{NaHCO}_{3}$, extracted with ethyl acetate three times, washed with brine, dried $\left(\mathrm{MgSO}_{4}\right)$, filtered and concentrated in vacuo. Purification by column chromatography (ethyl acetate/light petroleum ether, $1 / 10 \rightarrow 1 / 3, \mathrm{v} / \mathrm{v}$ ) yielded lactol $\mathbf{5 0}$ as a white amorphous solid upon concentration in vacuo ( $0.63 \mathrm{~g}$, quantitative) as a 1:1 mixture of $\alpha$ - and $\beta$-isomers. $R_{f} 0.09$ (ethyl acetate/light petroleum ether, $1 / 7$, $\mathrm{v} / \mathrm{v}) ;[\alpha]_{\mathrm{D}}{ }^{21}=-48.1^{\circ}\left(c 1.0, \mathrm{CHCl}_{3}\right)$; IR (thin film): 3403, 3089, 3065, 3034, 2914, 2872, 2110, 1497, 1454, 1371, 1314, 1277, 1171, 1093, 997, 916, 750, $697 \mathrm{~cm}^{-1}$; $\boldsymbol{\alpha - 5 0 : ~}{ }^{1} \mathrm{H}-\mathrm{NMR}\left(500 \mathrm{MHz}, \mathrm{CDCl}_{3}\right): \delta$ 7.51-7.47 (m, 2H, CH arom.), 7.42-7.37 (m, 5H, $\mathrm{CH}$ arom.), 7.36-7.28 (m, 3H, $\mathrm{CH}$ arom.), 5.60 (s, 1H, $\mathrm{PhCH}$ ), 5.30 $\left(\mathrm{t}, 1 \mathrm{H}, J_{\mathrm{OH}, 1}=J_{1,2}=3.4 \mathrm{~Hz}, \mathrm{H}-1\right), 4.97\left(\mathrm{~d}, 1 \mathrm{H}, J_{\mathrm{a}, \mathrm{b}}=11.0 \mathrm{~Hz}, \mathrm{CH}-\mathrm{a} \mathrm{Bn}\right), 4.81\left(\mathrm{~d}, 1 \mathrm{H}, J_{\mathrm{a}, \mathrm{b}}=11.0 \mathrm{~Hz}, \mathrm{CH}-\mathrm{b}\right.$ Bn), $4.29\left(\mathrm{dd}, 1 \mathrm{H}, J_{5,6 \mathrm{a}}=5.1, J_{6 \mathrm{a}, 6 \mathrm{~b}}=10.3 \mathrm{~Hz}, \mathrm{H}-6 \mathrm{a}\right), 4.13\left(\mathrm{td}, 1 \mathrm{H}, J_{4,5}=J_{5,6 \mathrm{~b}}=9.9, J_{5,6 \mathrm{a}}=4.9 \mathrm{~Hz}, \mathrm{H}-5\right)$, $4.11\left(\mathrm{t}, 1 \mathrm{H}, J_{2,3}=J_{3,4}=9.5 \mathrm{~Hz}, \mathrm{H}-3\right), 3.75\left(\mathrm{t}, 1 \mathrm{H}, J_{5,6 \mathrm{~b}}=J_{6 \mathrm{a}, 6 \mathrm{~b}}=10.3 \mathrm{~Hz}, \mathrm{H}-6 \mathrm{~b}\right), 3.73\left(\mathrm{t}, 1 \mathrm{H}, J_{3,4}=J_{4,5}=9.4\right.$ $\mathrm{Hz}, \mathrm{H}-4), 3.50\left(\mathrm{ddd}, 1 \mathrm{H}, J_{\mathrm{OH}, 2}=1.2, J_{1,2}=3.7, J_{2,3}=10.0 \mathrm{~Hz}, \mathrm{H}-2\right), 2.88\left(\mathrm{dd}, 1 \mathrm{H}, J_{\mathrm{OH}, 1}=3.3, J_{\mathrm{OH}, 2}=1.1\right.$ $\mathrm{Hz}, \mathrm{OH}) ;{ }^{13} \mathrm{C}-\mathrm{NMR}\left(125 \mathrm{MHz}, \mathrm{CDCl}_{3}\right): \delta 137.9\left(\mathrm{C}_{\mathrm{i}}\right.$ arom. $\left.\mathrm{Bn}\right), 137.3\left(\mathrm{C}_{\mathrm{i}}\right.$ arom. $\left.\mathrm{PhCH}\right), 129.2(\mathrm{CH}$ arom.), 128.6 ( $\mathrm{CH}$ arom.), 128.5 (CH arom.), 128.4 ( $\mathrm{CH}$ arom.), 128.1 (CH arom.), 126.1 (CH arom.), 101.6 (PhCH), 92.9 (C-1), 82.9 (C-4), 76.3 (C-3), $75.2\left(\mathrm{CH}_{2} \mathrm{Bn}\right), 68.6$ (C-6), 63.7 (C-2), $62.9(\mathrm{C}-5)$; $\boldsymbol{\beta}-50:{ }^{1} \mathrm{H}-$ NMR (500 MHz, $\mathrm{CDCl}_{3}$ ): $\delta$ 7.51-7.47 (m, 2H, CH arom.), 7.42-7.37 (m, 5H, CH arom.), 7.36-7.28 (m, 3H, $\mathrm{CH}$ arom.), 5.59 (s, 1H, PhCH), $4.94\left(\mathrm{~d}, 1 \mathrm{H}, J_{\mathrm{a}, \mathrm{b}}=11.2 \mathrm{~Hz}, \mathrm{CH}-\mathrm{a} \mathrm{Bn}\right), 4.80\left(\mathrm{~d}, 1 \mathrm{H}, J_{\mathrm{a}, \mathrm{b}}=11.2 \mathrm{~Hz}, \mathrm{CH}-\mathrm{b}\right.$ $\mathrm{Bn}), 4.68\left(\mathrm{dd}, 1 \mathrm{H}, J_{\mathrm{OH}, 1}=5.4, J_{1,2}=8.0 \mathrm{~Hz}, \mathrm{H}-1\right), 4.34\left(\mathrm{dd}, 1 \mathrm{H}, J_{5,6 \mathrm{a}}=5.1, J_{6 \mathrm{a}, 6 \mathrm{~b}}=10.5 \mathrm{~Hz}, \mathrm{H}-6 \mathrm{a}\right), 3.80(\mathrm{t}$, $\left.1 \mathrm{H}, J_{5,6 \mathrm{~b}}=J_{6 \mathrm{a}, 6 \mathrm{~b}}=10.3 \mathrm{~Hz}, \mathrm{H}-6 \mathrm{~b}\right), 3.74\left(\mathrm{t}, 1 \mathrm{H}, J_{3,4}=J_{4,5}=9.3 \mathrm{~Hz}, \mathrm{H}-4\right), 3.62\left(\mathrm{t}, 1 \mathrm{H}, J_{2,3}=J_{3,4}=9.4 \mathrm{~Hz}, \mathrm{H}-\right.$ 3), $3.45\left(\mathrm{td}, 1 \mathrm{H}, J_{4,5}=J_{5,6 \mathrm{~b}}=9.7, J_{5,6 \mathrm{a}}=5.0 \mathrm{~Hz}, \mathrm{H}-5\right), 3.42\left(\mathrm{dd}, 1 \mathrm{H}, J_{1,2}=8.1, J_{2,3}=9.3 \mathrm{~Hz}, \mathrm{H}-2\right), 3.36(\mathrm{~d}$, $\left.1 \mathrm{H}, J_{\mathrm{OH}, 1}=5.4 \mathrm{~Hz}, \mathrm{OH}\right) ;{ }^{13} \mathrm{C}-\mathrm{NMR}\left(125 \mathrm{MHz}, \mathrm{CDCl}_{3}\right): \delta 137.8\left(\mathrm{C}_{\mathrm{i}}\right.$ arom. $\left.\mathrm{Bn}\right), 137.2\left(\mathrm{C}_{\mathrm{i}}\right.$ arom. $\left.\mathrm{PhCH}\right)$, 129.3 (CH arom.), 128.6 (CH arom.), 128.5 (CH arom.), 128.4 (CH arom.), 128.1 (CH arom.), 126.1 (CH 
arom.), 101.5 (PhCH), 96.7 (C-1), 81.7 (C-4), 79.2 (C-3), $75.1\left(\mathrm{CH}_{2} \mathrm{Bn}\right), 69.1$ (C-6), 67.5 (C-2), 66.6 (C5); $\mathrm{HRMS}(\mathrm{ESI}) \mathrm{m} / z$ calcld. for $\left[\mathrm{C}_{20} \mathrm{H}_{21} \mathrm{O}_{5} \mathrm{~N}_{3}+\mathrm{Na}\right]^{+}: 406.1379$, obsd.: 406.1381 .

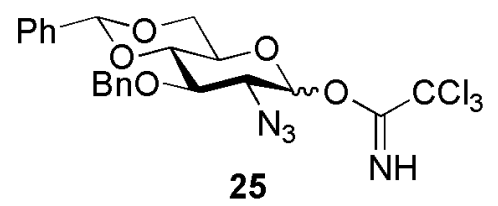

molecular sieves (type 4A), trichloroacetonitrile $(0.131 \mathrm{~mL}, 1.30 \mathrm{mmol}, 5.0$ equiv.) and caesium carbonate (cat.), the reaction was stirred for $20 \mathrm{~h}$. After TLC-analysis (ethyl acetate/light petroleum ether, 1/4, v/v) showed completion of the reaction, the reaction mixture was filtered, concentrated in vacuo and purified by column chromatography (ethyl acetate/light petroleum ether, $1 / 10 \rightarrow 1 / 5$, v/v) to yield 25- $\alpha$ as a colourless oil and 25- $\beta$ as a white amorphous solid upon concentration in vacuo $(0.1371 \mathrm{~g}, 99 \%)$. The imidate was stored in the freezer until it was used. $\boldsymbol{\alpha - 2 5}: R_{f} 0.45$ (ethyl acetate/light petroleum ether, 1/4, v/v); IR (thin film): 3339, 3090, 3066, 3034, 2934, 2868, 2112, 1674, 1454, 1371, 1281, 1135, 1069, 1019, 988, 910, 837, 796, 748, $698 \mathrm{~cm}^{-1} ;{ }^{1} \mathrm{H}-\mathrm{NMR}\left(500 \mathrm{MHz} \mathrm{CDCl}_{3}\right): \delta 8.75$ (s, 1H, NH), 7.52-7.49 (m, 2H, CH arom.), 7.43-7.30 (m, 8H, CH arom.), 6.38 (d, 1H, $\left.J_{1,2}=3.7 \mathrm{~Hz}, \mathrm{H}-1\right), 5.63(\mathrm{~s}, 1 \mathrm{H}, \mathrm{PhCH}), 5.04\left(\mathrm{~d}, 1 \mathrm{H}, J_{\mathrm{a}, \mathrm{b}}=10.7\right.$ $\mathrm{Hz}, \mathrm{CH}-\mathrm{a} \mathrm{Bn}), 4.85$ (d, 1H, $\left.J_{\mathrm{a}, \mathrm{b}}=10.7 \mathrm{~Hz}, \mathrm{CH}-\mathrm{b} \mathrm{Bn}\right), 4.35$ (dd, 1H, J5,6a $\left.=5.1, J_{6 \mathrm{a}, 6 \mathrm{~b}}=10.5 \mathrm{~Hz}, \mathrm{H}-6 \mathrm{a}\right), 4.19$ $\left(\mathrm{t}, 1 \mathrm{H}, J_{2,3}=J_{3,4}=9.5 \mathrm{~Hz}, \mathrm{H}-3\right), 4.07\left(\mathrm{td}, 1 \mathrm{H}, J_{4,5}=J_{5,6 \mathrm{~b}}=10.0, J_{5,6 \mathrm{a}}=5.0 \mathrm{~Hz}, \mathrm{H}-5\right), 3.85\left(\mathrm{t}, 1 \mathrm{H}, J_{3,4}=J_{4,5}=\right.$ $9.5 \mathrm{~Hz}, \mathrm{H}-4), 3.79\left(\mathrm{t}, 1 \mathrm{H}, J_{5,6 \mathrm{~b}}=J_{6 \mathrm{a}, 6 \mathrm{~b}}=10.5 \mathrm{~Hz}, \mathrm{H}-6 \mathrm{~b}\right), 3.73\left(\mathrm{dd}, 1 \mathrm{H}, J_{1,2}=3.7, J_{2,3}=9.8 \mathrm{~Hz}, \mathrm{H}-2\right) ;{ }^{13} \mathrm{C}-$ NMR (125 MHz, $\left.\mathrm{CDCl}_{3}\right): \delta 161.0(\mathrm{C}=\mathrm{N}), 137.7\left(\mathrm{C}_{\mathrm{i}}\right.$ arom. $\left.\mathrm{Bn}\right), 137.0\left(\mathrm{C}_{\mathrm{i}}\right.$ arom. PhCH), $129.3(\mathrm{CH}$ arom.), 128.6 (CH arom.), 128.5 ( $\mathrm{CH}$ arom.), 128.4 (CH arom.), 128.2 (CH arom.), 126.0 (CH arom.), 101.6 (PhCH), 95.0 (C-1), $90.8\left(\mathrm{CCl}_{3}\right), 82.3$ (C-4), 76.4 (C-3), $75.4\left(\mathrm{CH}_{2} \mathrm{Bn}\right), 68.7$ (C-6), $65.3(\mathrm{C}-5), 62.5(\mathrm{C}-2)$; 及-25: $R_{f} 0.53$ (ethyl acetate/light petroleum ether, 1/4, v/v); IR (thin film): 3323, 3088, 3066, 3035, 2920, 2868, 2853, 2110, 1678, 1453, 1369, 1303, 1279, 1209, 1068, 1027, 914, 837, 804, 735, $695 \mathrm{~cm}^{-1}$; ${ }^{1} \mathrm{H}-\mathrm{NMR}$ $\left(500 \mathrm{MHz} \mathrm{CDCl}_{3}\right): \delta 8.77(\mathrm{~s}, 1 \mathrm{H}, \mathrm{NH}), 7.50-7.47$ (m, 2H, CH arom.), 7.43-7.29 (m, 8H, CH arom.), 5.59 (s, 1H, PhCH), 5.72-5.70 (m, 1H, H-1), $4.96\left(\mathrm{~d}, 1 \mathrm{H}, J_{\mathrm{a}, \mathrm{b}}=11.2 \mathrm{~Hz}, \mathrm{CH}-\mathrm{a} \mathrm{Bn}\right), 4.83\left(\mathrm{~d}, 1 \mathrm{H}, J_{\mathrm{a}, \mathrm{b}}=11.2 \mathrm{~Hz}\right.$, CH-b Bn), $4.41\left(\mathrm{dd}, 1 \mathrm{H}, J_{5,6 \mathrm{a}}=4.9, J_{6 \mathrm{a}, 6 \mathrm{~b}}=10.5 \mathrm{~Hz}, \mathrm{H}-6 \mathrm{a}\right), 3.83\left(\mathrm{t}, 1 \mathrm{H}, J_{5,6 \mathrm{~b}}=J_{6 \mathrm{a}, 6 \mathrm{~b}}=10.5 \mathrm{~Hz}, \mathrm{H}-6 \mathrm{~b}\right), 3.82-$ $3.78(\mathrm{~m}, 1 \mathrm{H}, \mathrm{H}-4), 3.74-3.68\left(\mathrm{~m}, 2 \mathrm{H}, \mathrm{H}-2\right.$ and H-3), $3.58\left(\mathrm{td}, 1 \mathrm{H}, J_{4,5}=J_{5,6 \mathrm{~b}}=10.0, J_{5,6 \mathrm{a}}=4.9 \mathrm{~Hz}, \mathrm{H}-5\right)$;

${ }^{13} \mathrm{C}-\mathrm{NMR}\left(125 \mathrm{MHz}, \mathrm{CDCl}_{3}\right): \delta 161.1(\mathrm{C}=\mathrm{N}), 137.7\left(\mathrm{C}_{\mathrm{i}}\right.$ arom. Bn), $137.1\left(\mathrm{C}_{\mathrm{i}}\right.$ arom. $\left.\mathrm{PhCH}\right), 129.3(\mathrm{CH}$ arom.), 128.6 (CH arom.), 128.5 (CH arom.), 128.3 (CH arom.), 128.1 (CH arom.), 126.1 (CH arom.), $101.6(\mathrm{PhCH}), 96.9(\mathrm{C}-1), 90.5\left(\mathrm{CCl}_{3}\right), 81.3(\mathrm{C}-4), 79.2(\mathrm{C}-3), 75.2\left(\mathrm{CH}_{2} \mathrm{Bn}\right), 68.5(\mathrm{C}-6), 67.1(\mathrm{C}-5), 65.7$ (C-2).

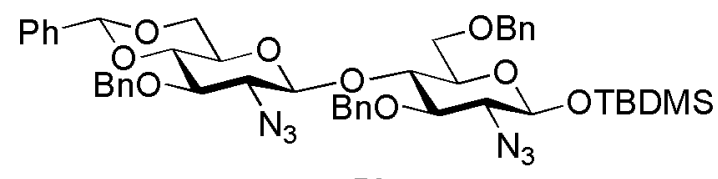

53
2-Azido-4-O-(2-azido-3- $O$-benzyl-4,6-Obenzylidene-2-deoxy- $\beta$-D-glucopyranosyl)-3,6-di- $O$ benzyl-1-O-tert-butyldimethylsilyl-2-deoxy- $\beta$-Dglucopyranose (53). Glucosazide acceptor $52(0.050$ 
g, $0.100 \mathrm{mmol})$ and acetimidate donor $25(0.109 \mathrm{~g}, 0.200 \mathrm{mmol}, 2.0$ equiv. $)$ were coevaporated three times with toluene and dissolved in acetonitrile $(1.0 \mathrm{~mL})$ under a nitrogen atmosphere. The solution was stirred for $1 \mathrm{~h}$ in the presence of molecular sieves (type $4 \mathrm{~A})$ ). After cooling the solution to $0^{\circ} \mathrm{C}$, TMSOTf $(0.0018$ $\mathrm{mL}$ or $1.8 \mu \mathrm{L}, 0.010 \mathrm{mmol}, 0.1$ equiv.) was added dropwise and the reaction mixture was stirred for 30 mins. The reaction mixture was allowed to warm to room temperature and stirred for a further $18 \mathrm{~h}$. After, TLC-analysis (ethyl acetate/light petroleum ether, 1/5, v/v) showed completion of the reaction, the reaction mixture was quenched with triethylamine $(0.1 \mathrm{~mL})$, diluted with ethyl acetate, washed with sat. aq. $\mathrm{NaHCO}_{3}$, brine, dried $\left(\mathrm{MgSO}_{4}\right)$, filtered and concentrated in vacuo. Purification by column chromatography (ethyl acetate/light petroleum ether, $1 / 20 \rightarrow 1 / 10$, v/v) yielded disaccharide $\mathbf{5 3}$ as a 1:2.8 mixture of $\alpha$ - and $\beta$-isomers as a colourless oil $(0.019 \mathrm{~g}, 23 \%)$. The $\alpha$ - and $\beta$-isomers were separated by column chromatography (DCM) $\left(\alpha-R_{f} 0.37\right.$ (DCM), $\beta-R_{f} 0.18$ (DCM)). $R_{f} 0.48$ (ethyl acetate/light petroleum ether, $1 / 5, \mathrm{v} / \mathrm{v}) ;[\alpha]_{\mathrm{D}}{ }^{24}=-43.6^{\circ}\left(c 1.0, \mathrm{CHCl}_{3}\right)$; IR (thin film): 3066, 3034, 2927, 2857, 2110, 1497, 1455, 1363, 1275, 1219, 1171, 1094, 1068, 1029, 1003, 965, 840, 773, $697 \mathrm{~cm}^{-1} ;{ }^{1} \mathrm{H}-\mathrm{NMR}$ (500 $\mathrm{MHz}, \mathrm{CDCl}_{3}$ ): $\delta$ 7.48-7.46 (m, 2H, CH arom.), 7.41-7.28 (m, 18H, CH arom.), 5.49 (s, 1H, $\mathrm{PhCH}$ ), 4.90 (d, $\left.1 \mathrm{H}, J_{\mathrm{a}, \mathrm{b}}=11.0 \mathrm{~Hz}, \mathrm{CH}-\mathrm{a} 3^{\prime}-O-\mathrm{Bn}\right), 4.85\left(\mathrm{~d}, 1 \mathrm{H}, J_{\mathrm{a}, \mathrm{b}}=10.7 \mathrm{~Hz}, \mathrm{CH}-\mathrm{a} 3-O-\mathrm{Bn}\right), 4.76\left(\mathrm{~d}, 1 \mathrm{H}, J_{\mathrm{a}, \mathrm{b}}=11.5 \mathrm{~Hz}\right.$, CH-b 3'-O-Bn), 4.74 (d, 1H, $J_{\mathrm{a}, \mathrm{b}}=11.2 \mathrm{~Hz}$, CH-b 3-O-Bn), 4.70 (d, $1 \mathrm{H}, J_{\mathrm{a}, \mathrm{b}}=12.2 \mathrm{~Hz}, \mathrm{CH}-\mathrm{a}$ 6-O-Bn), 4.51 $\left(\mathrm{d}, 1 \mathrm{H}, J_{\mathrm{a}, \mathrm{b}}=12.0 \mathrm{~Hz}, \mathrm{CH}-\mathrm{b} 6-O-\mathrm{Bn}\right), 4.50\left(\mathrm{~d}, 1 \mathrm{H}, J_{1,2}=7.6 \mathrm{~Hz}, \mathrm{H}-1\right), 4.41\left(\mathrm{~d}, 1 \mathrm{H}, J_{1^{\prime}, 2^{\prime}}=8.1 \mathrm{~Hz}, \mathrm{H}-1^{\prime}\right)$, $4.12\left(\mathrm{dd}, 1 \mathrm{H}, J_{5^{\prime}, 6 \mathrm{a}^{\prime}}=5.1, J_{6 \mathrm{a}^{\prime}, 6 \mathrm{~b}^{\prime}}=10.5 \mathrm{~Hz}, \mathrm{H}-6 \mathrm{a}^{\prime}\right), 4.06-4.02(\mathrm{~m}, 1 \mathrm{H}, \mathrm{H}-4), 3.93\left(\mathrm{dd}, 1 \mathrm{H}, J_{5,6 \mathrm{a}}=3.3, J_{6 \mathrm{a}, 6 \mathrm{~b}}=\right.$ $11.4 \mathrm{~Hz}, \mathrm{H}-6 \mathrm{a}), 3.73\left(\mathrm{dd}, 1 \mathrm{H}, J_{5,6 \mathrm{~b}}=1.6, J_{6 \mathrm{a}, 6 \mathrm{~b}}=11.1 \mathrm{~Hz}, \mathrm{H}-6 \mathrm{~b}\right.$ ), $3.60\left(\mathrm{t}, 1 \mathrm{H}, J_{3^{\prime}, 4^{\prime}}=J_{4^{\prime}, 5^{\prime}}=9.3 \mathrm{~Hz}, \mathrm{H}-4^{\prime}\right)$, $3.44\left(\mathrm{t}, 1 \mathrm{H}, J_{5^{\prime}, 6 \mathrm{~b}^{\prime}}=J_{6 \mathrm{a}^{\prime}, 6 \mathrm{~b}^{\prime}}=10.4 \mathrm{~Hz}, \mathrm{H}-6 \mathrm{~b}^{\prime}\right), 3.43\left(\mathrm{t}, 1 \mathrm{H}, J_{2^{\prime}, 3^{\prime}}=J_{3^{\prime}, 4^{\prime}}=9.2 \mathrm{~Hz}, \mathrm{H}-3^{\prime}\right), 3.41\left(\mathrm{ddd}, 1 \mathrm{H}, J_{4,5}=\right.$ 9.8, $\left.J_{5,6 \mathrm{~b}}=1.7, J_{5,6 \mathrm{a}}=3.2 \mathrm{~Hz}, \mathrm{H}-5\right), 3.35-3.30\left(\mathrm{~m}, 2 \mathrm{H}, \mathrm{H}-2\right.$ and H-3), $3.34\left(\mathrm{dd}, 1 \mathrm{H}, J_{1^{\prime}, 2^{\prime}}=8.3, J_{2^{\prime}, 3^{\prime}}=9.5 \mathrm{~Hz}\right.$, $\left.\mathrm{H}-2^{\prime}\right), 3.10\left(\mathrm{td}, 1 \mathrm{H}, J_{4^{\prime}, 5^{\prime}}=J_{5^{\prime}, 6 \mathrm{~b}^{\prime}}=9.6, J_{5^{\prime}, 6 \mathrm{a}^{\prime}}=5.0 \mathrm{~Hz}, \mathrm{H}-5^{\prime}\right), 0.94\left(\mathrm{~s}, 9 \mathrm{H}, 3 \times \mathrm{CH}_{3} \mathrm{Si}{ }^{\mathrm{t}} \mathrm{Bu}\right), 0.17\left(\mathrm{~s}, 3 \mathrm{H}, \mathrm{CH}_{3}\right.$ $\mathrm{SiMe}_{\mathrm{a}}$ ), 0.16 (s, 3H, $\left.\mathrm{CH}_{3} \mathrm{SiMe}_{\mathrm{b}}\right) ;{ }^{13} \mathrm{C}-\mathrm{NMR}\left(125 \mathrm{MHz}, \mathrm{CDCl}_{3}\right): \delta 138.7\left(\mathrm{C}_{\mathrm{i}}\right.$ arom. 3-O-Bn), $138.2\left(\mathrm{C}_{\mathrm{i}}\right.$ arom. 6-O-Bn), 138.0 ( $\mathrm{C}_{\mathrm{i}}$ arom. 3'-O-Bn), $137.4\left(\mathrm{C}_{\mathrm{i}}\right.$ arom. $\left.\mathrm{PhCH}\right), 129.2$ (CH arom.), 128.6 ( $\mathrm{CH}$ arom.), 128.6 (CH arom.), 128.4 (CH arom.), 128.4 (CH arom.), 128.3 (CH arom.), 128.1 (CH arom.), 128.0 (CH arom.), 128.0 (CH arom.), 127.9 ( $\mathrm{CH}$ arom.), 127.8 ( $\mathrm{CH}$ arom.), 126.2 ( $\mathrm{CH}$ arom.), 101.5 ( $\mathrm{PhCH}), 101.4$ (C-1'), 97.3 (C-1), 81.9 (C-4'), 81.2 (C-3), 79.4 (C-3'), 76.6 (C-4), 75.3 ( $\mathrm{CH}_{2}$ 3-O-Bn), 75.1 (C-5), 75.0 $\left(\mathrm{CH}_{2} 3^{\prime}-\mathrm{O}-\mathrm{Bn}\right), 73.7\left(\mathrm{CH}_{2}\right.$ 6-O-Bn), 68.7 (C-6'), 68.5 (C-2), 68.3 (C-6), $66.9\left(\mathrm{C}-2^{\prime}\right), 66.2\left(\mathrm{C}-5^{\prime}\right), 25.8\left(\mathrm{CH}_{3}\right.$ $\left.\mathrm{Si}^{t} \mathrm{Bu}\right), \quad 18.2 \quad\left(\mathrm{C}_{\mathrm{q}} \quad \mathrm{Si}{ }^{\mathrm{t} B u}\right), \quad-4.1 \quad\left(\mathrm{CH}_{3} \quad \mathrm{SiMe}_{\mathrm{a}}\right), \quad-4.9 \quad\left(\mathrm{CH}_{3} \quad \mathrm{SiMe}_{\mathrm{b}}\right) ; \quad \mathrm{HRMS}(\mathrm{ESI}) \quad m / z$ calcld. for $\left[\mathrm{C}_{46} \mathrm{H}_{56} \mathrm{O}_{9} \mathrm{~N}_{6} \mathrm{Si}+\mathrm{Na}\right]^{+}:$887.3776, obsd.: 887.3767.

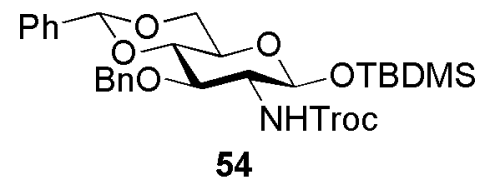

3-O-Benzyl-4,6-O-benzylidene-1-O-tert-butyldimethylsilyl-2-deoxy2-(2,2,2-trichloroethoxycarbonylamido)- $\beta$-D-glucopyranose $\quad(54)$.

Glucosazide 49 (0.0356 g, $0.0715 \mathrm{mmol})$ was dissolved in THF (3.60

$\mathrm{mL})$. Sodium hydroxide $(0.50 \mathrm{~mL}, 1 \mathrm{M}(\mathrm{aq}), 0.50 \mathrm{mmol}, 7$ equiv.) and trimethyl phosphine $(0.43 \mathrm{~mL}, 1 \mathrm{M}$ in THF, $0.43 \mathrm{mmol}, 6$ equiv.) was added and the reaction mixture was stirred for $2 \mathrm{~h}$ at room temperature. After TLC-analysis (ethyl acetate/light petroleum ether, 1/5, v/v) showed complete reduction of the azide 
starting material, 2,2,2-trichloroethyl chloroformate $(0.050 \mathrm{~mL}, 0.363 \mathrm{mmol}, 5$ equiv. $)$ was added and the reaction mixture was then stirred for a further $3 \mathrm{~h}$, with extra 2,2,2-trichloroethyl chloroformate $(0.050 \mathrm{~mL}$, $0.363 \mathrm{mmol}, 5$ equiv.) added after $2.5 \mathrm{~h}$. When TLC-analysis (ethyl acetate/light petroleum ether, 1/5, v/v) showed completion of the reaction the reaction mixture was washed with sat. aq. $\mathrm{NaHCO}_{3}$ and brine, dried $\left(\mathrm{MgSO}_{4}\right)$, filtered and concentrated in vacuo. Purification by column chromatography (ethyl acetate/light petroleum ether, $1 / 30 \rightarrow 1 / 20, \mathrm{v} / \mathrm{v})$ yielded $\mathbf{5 4}$ as a colourless oil $(0.0364 \mathrm{~g}, 79 \%) . R_{f} 0.35$ (ethyl acetate/light petroleum ether, $1 / 5, \mathrm{v} / \mathrm{v}) ;[\alpha]_{\mathrm{D}}{ }^{18}=-40.2^{\circ}\left(c 1.0, \mathrm{CHCl}_{3}\right)$; IR (thin film): 3338, 3066, 3034, 2954, 2930, 2858, 1717, 1541, 1498, 1453, 1388, 1320, 1282, 1248, 1182, 1128, 1084, 1013, 978, 912 , 839, 783, 733, $696 \mathrm{~cm}^{-1}$; ${ }^{1} \mathrm{H}-\mathrm{NMR}\left(500 \mathrm{MHz}, \mathrm{CDCl}_{3}\right.$ ): $\delta$ 7.51-7.49 (m, 2H, CH arom.), 7.42-7.36 (m, 3H, $\mathrm{CH}$ arom.), 7.32-7.27 (m, 5H, CH arom.), 5.58 (s, 1H, PhCH), 5.03 (d, 1H, $\left.J_{2, \mathrm{NH}}=6.9 \mathrm{~Hz}, \mathrm{NH}\right), 4.93$ (d, $\left.1 \mathrm{H}, J_{1,2}=7.8 \mathrm{~Hz}, \mathrm{H}-1\right), 4.90\left(\mathrm{~d}, 1 \mathrm{H}, J_{\mathrm{a}, \mathrm{b}}=11.7 \mathrm{~Hz}, \mathrm{CH}-\mathrm{a} \mathrm{Bn}\right), 4.71-4.63$ (m, 3H, CH-b Bn, CH-a Troc, and CH-b Troc), 4.31 (dd, $\left.1 \mathrm{H}, J_{5,6 \mathrm{a}}=4.9, J_{6 \mathrm{a}, 6 \mathrm{~b}}=10.5 \mathrm{~Hz}, \mathrm{H}-6 \mathrm{a}\right), 3.99$ (t, $\left.1 \mathrm{H}, J_{2,3}=J_{3,4}=8.8 \mathrm{~Hz}, \mathrm{H}-3\right), 3.81(\mathrm{t}$, $\left.1 \mathrm{H}, J_{5,6 \mathrm{~b}}=J_{6 \mathrm{a}, 6 \mathrm{~b}}=10.2 \mathrm{~Hz}, \mathrm{H}-6 \mathrm{~b}\right), 3.75\left(\mathrm{t}, 1 \mathrm{H}, J_{3,4}=J_{4,5}=9.3 \mathrm{~Hz}, \mathrm{H}-4\right), 3.47\left(\mathrm{td}, 1 \mathrm{H}, J_{4,5}=J_{5,6 \mathrm{~b}}=9.7, J_{5,6 \mathrm{a}}\right.$ $=5.1 \mathrm{~Hz}, \mathrm{H}-5), 3.33\left(\mathrm{q}, 1 \mathrm{H}, J_{1,2}=J_{2,3}=J_{2, \mathrm{NH}}=8.3 \mathrm{~Hz}, \mathrm{H}-2\right), 0.88\left(\mathrm{~s}, 9 \mathrm{H}, 3 \times \mathrm{CH}_{3} \mathrm{Si}^{\mathrm{t}} \mathrm{Bu}\right), 0.10\left(\mathrm{~s}, 3 \mathrm{H}, \mathrm{CH}_{3}\right.$ $\mathrm{SiMe}_{\mathrm{a}}$ ), 0.08 (s, 3H, $\mathrm{CH}_{3} \mathrm{SiMe}_{\mathrm{b}}$ ); ${ }^{13} \mathrm{C}-\mathrm{NMR}\left(125 \mathrm{MHz}, \mathrm{CDCl}_{3}\right): \delta 154.0$ (C=O Troc), $138.3\left(\mathrm{C}_{\mathrm{i}}\right.$ arom. Bn), $137.5\left(\mathrm{C}_{\mathrm{i}}\right.$ arom. $\left.\mathrm{PhCH}\right), 129.2$ ( $\mathrm{CH}$ arom.), 128.5 ( $\mathrm{CH}$ arom.), 128.4 ( $\mathrm{CH}$ arom.), 128.4 ( $\mathrm{CH}$ arom.), 127.9 (CH arom.), 126.2 (CH arom.), 101.4 ( $\mathrm{PhCH}$ ), 96.1 (C-1), 95.5 ( $\mathrm{CCl}_{3}$ Troc), 82.8 (C-4), 76.3 (C-3), 74.7 $\left(\mathrm{CH}_{2}\right.$ Troc), $74.4\left(\mathrm{CH}_{2} \mathrm{Bn}\right), 68.9(\mathrm{C}-6), 66.2(\mathrm{C}-5), 60.2(\mathrm{C}-2), 25.7\left(\mathrm{CH}_{3} \mathrm{Si}^{\mathrm{t}} \mathrm{Bu}\right), 18.0\left(\mathrm{C}_{\mathrm{q}} \mathrm{Si}^{\mathrm{t}} \mathrm{Bu}\right),-4.1\left(\mathrm{CH}_{3}\right.$ $\left.\mathrm{SiMe}_{\mathrm{a}}\right),-5.2\left(\mathrm{CH}_{3} \mathrm{SiMe}_{\mathrm{b}}\right)$; HRMS(ESI) $\mathrm{m} / z$ calcld. for $\left[\mathrm{C}_{29} \mathrm{H}_{38} \mathrm{O}_{7} \mathrm{~N}_{1} \mathrm{SiCl}_{3}+\mathrm{Na}\right]^{+}: 668.1381$, obsd.: 668.1379.

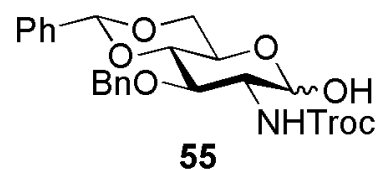

a plastic vial. After addition of HF.pyridine $(0.242 \mathrm{~mL}, 70 \%$ in pyridine, $1.79 \mathrm{mmol}, 8.8$ eq.), the reaction mixture was left for $18 \mathrm{~h}$. After TLC-analysis (ethyl acetate/light petroleum ether, 1/1, v/v) showed complete deprotection, the reaction mixture was neutralised with sat. aq. $\mathrm{NaHCO}_{3}$, extracted with $\mathrm{DCM}$ three times, washed with brine, dried $\left(\mathrm{MgSO}_{4}\right)$, filtered and concentrated in vacuo. Purification by column chromatography (ethyl acetate/light petroleum ether, 1/10 $\rightarrow$ 1/2, v/v) yielded lactol $\mathbf{5 5}$ as a white amorphous solid upon concentration in vacuo $(0.0932 \mathrm{~g}, 90 \%) . R_{f} 0.40$ and 0.34 (ethyl acetate/light petroleum ether, $1 / 1, \mathrm{v} / \mathrm{v}) ;[\alpha]_{\mathrm{D}}^{21}=-31.1^{\circ}\left(c 1.0, \mathrm{CHCl}_{3}\right)$; IR (thin film): 3598, 3309, 3065, 3034, 2922, 2870, 1712, 1546, 1497, 1453, 1368, 1308, 1283, 1245, 1172, 1126, 1089, 1030, 1016, 984, 968, 914, 817, $775,745,695 \mathrm{~cm}^{-1}$; (NMR data given for the $\alpha$-anomer only, as only trace amounts of the $\beta$-anomer were detectable) ${ }^{1} \mathrm{H}-\mathrm{NMR}\left(500 \mathrm{MHz}, \mathrm{CDCl}_{3}\right.$ ): $\delta$ 7.52-7.50 (m, 2H, $\mathrm{CH}$ arom.), 7.42-7.27 (m, 8H, CH arom.), $5.60(\mathrm{~s}, 1 \mathrm{H}, \mathrm{PhCH}), 5.26\left(\mathrm{t}, 1 \mathrm{H}, J_{\mathrm{OH}, 1}=J_{1,2}=3.4 \mathrm{~Hz}, \mathrm{H}-1\right), 5.19\left(\mathrm{~d}, 1 \mathrm{H}, J_{2, \mathrm{NH}}=9.5 \mathrm{~Hz}, \mathrm{NH}\right), 4.93(\mathrm{~d}, 1 \mathrm{H}$, $\left.J_{\mathrm{a}, \mathrm{b}}=11.9 \mathrm{~Hz}, \mathrm{CH}-\mathrm{a} \mathrm{Bn}\right), 4.79\left(\mathrm{~d}, 1 \mathrm{H}, J_{\mathrm{a}, \mathrm{b}}=11.9 \mathrm{~Hz}, \mathrm{CH}-\mathrm{a}\right.$ Troc $), 4.70\left(\mathrm{~d}, 1 \mathrm{H}, J_{\mathrm{a}, \mathrm{b}}=12.2 \mathrm{~Hz}, \mathrm{CH}-\mathrm{b} \mathrm{Bn}\right)$, $4.68\left(\mathrm{~d}, 1 \mathrm{H}, J_{\mathrm{a}, \mathrm{b}}=12.0 \mathrm{~Hz}, \mathrm{CH}-\mathrm{b}\right.$ Troc), $4.28\left(\mathrm{dd}, 1 \mathrm{H}, J_{5,6 \mathrm{a}}=4.9, J_{6 \mathrm{a}, 6 \mathrm{~b}}=10.2 \mathrm{~Hz}, \mathrm{H}-6 \mathrm{a}\right), 4.06\left(\mathrm{td}, 1 \mathrm{H}, J_{4,5}=\right.$ $\left.J_{5,6 \mathrm{~b}}=9.7, J_{5,6 \mathrm{a}}=4.9 \mathrm{~Hz}, \mathrm{H}-5\right), 3.97\left(\mathrm{td}, 1 \mathrm{H}, J_{1,2}=3.4, J_{2,3}=J_{2, \mathrm{NH}}=9.5 \mathrm{~Hz}, \mathrm{H}-2\right), 3.82-3.75(\mathrm{~m}, 3 \mathrm{H}, \mathrm{H}-3$, 
$\mathrm{H}-4$, and $\mathrm{H}-6 \mathrm{~b}), 3.12\left(\mathrm{~d}, 1 \mathrm{H}, J_{\mathrm{OH}, 1}=2.4, \mathrm{OH}\right) ;{ }^{13} \mathrm{C}-\mathrm{NMR}\left(125 \mathrm{MHz}, \mathrm{CDCl}_{3}\right): \delta 154.6(\mathrm{C}=\mathrm{O}$ Troc $), 138.3\left(\mathrm{C}_{\mathrm{i}}\right.$ arom. $\mathrm{Bn}), 137.4$ ( $\mathrm{C}_{\mathrm{i}}$ arom. $\left.\mathrm{PhCH}\right), 129.2$ ( $\mathrm{CH}$ arom.), 128.5 (CH arom.), $128.4(\mathrm{CH}$ arom.), $128.1(\mathrm{CH}$ arom.), 127.9 (CH arom.), 126.1 (CH arom.), 101.5 (PhCH), 95.5 ( $\mathrm{CCl}_{3}$ Troc), 92.8 (C-1), 83.0 (C-4), 75.6 (C-3), 74.9 ( $\mathrm{CH}_{2}$ Troc), 74.5 ( $\mathrm{CH}_{2} \mathrm{Bn}$ ), 69.1 (C-6), 62.9 (C-5), 55.2 (C-2); HRMS(ESI) m/z calcld. for $\left[\mathrm{C}_{23} \mathrm{H}_{24} \mathrm{O}_{7} \mathrm{~N}+\mathrm{Na}\right]^{+}:$554.0516, obsd.: .554.0516

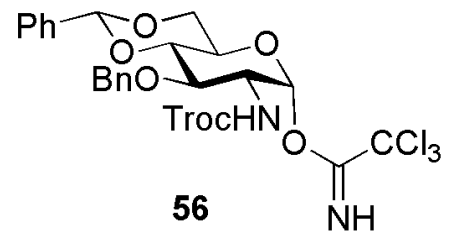

3-O-Benzyl-4,6-O-benzylidene-2-deoxy-2-(2,2,2trichloroethoxycarbonylamido)- $\alpha$-D-glucopyranosyl

under a nitrogen atmosphere. The solution was stirred for $30 \mathrm{mins}$ in the presence of molecular sieves (type 4A). Trichloroacetonitrile ( $0.279 \mathrm{~mL}, 2.78 \mathrm{mmol}, 16.0$ equiv.) and caesium carbonate (cat.) were added and the reaction was stirred for $6 \mathrm{~h}$. After TLC-analysis (ethyl acetate/light petroleum ether, 1/1, v/v) showed completion of the reaction, the reaction mixture was filtered and purified directly by column chromatography (ethyl acetate/light petroleum ether, $1 / 10 \rightarrow 1 / 1, \mathrm{v} / \mathrm{v}$ ) to yield $\mathbf{5 6}$ as a colourless oil ( 0.116 $\mathrm{g}, 99 \%$ ). The imidate was stored in the freezer until it was used. $R_{f} 0.61$ (ethyl acetate/light petroleum ether, 1/1, v/v); IR (thin film): 3427, 3337, 3067, 3033, 2931, 2869, 1734, ,1675, 1515, 1453, 1379, 1279, 1140, 1084, 1066, 1026, 967, 907, 823, 794, 731, 697, $673 \mathrm{~cm}^{-1}$; ${ }^{1} \mathrm{H}-\mathrm{NMR}\left(500 \mathrm{MHz}, \mathrm{CDCl}_{3}\right): \delta 8.68(\mathrm{~s}$, 1H, NH Imidate), 7.53-7.51 (m, 2H, CH arom.), 7.43-7.28 (m, 8H, $\mathrm{CH}$ arom.), 6.35 (d, 1H, $J_{1,2}=3.7 \mathrm{~Hz}$, H-1), $5.64(\mathrm{~s}, 1 \mathrm{H}, \mathrm{PhCH}), 5.00\left(\mathrm{~d}, 1 \mathrm{H}, J_{\mathrm{a}, \mathrm{b}}=11.7 \mathrm{~Hz}, \mathrm{CH}-\mathrm{a} \mathrm{Bn}\right), 4.75$ (d, 1H, $J_{\mathrm{a}, \mathrm{b}}=11.9 \mathrm{~Hz}, \mathrm{CH}-\mathrm{a}$ Troc), $4.72\left(\mathrm{~d}, 1 \mathrm{H}, J_{\mathrm{a}, \mathrm{b}}=12.0 \mathrm{~Hz}, \mathrm{CH}-\mathrm{b} \mathrm{Bn}\right), 4.71\left(\mathrm{~d}, 1 \mathrm{H}, J_{2, \mathrm{NH}}=8.8 \mathrm{~Hz}, \mathrm{NH}\right.$ Troc $), 4.68\left(\mathrm{~d}, 1 \mathrm{H}, J_{\mathrm{a}, \mathrm{b}}=12.0 \mathrm{~Hz}\right.$, CH-b Troc), 4.35 (dd, $\left.1 \mathrm{H}, J_{5,6 \mathrm{a}}=4.9, J_{6 \mathrm{a}, 6 \mathrm{~b}}=10.3 \mathrm{~Hz}, \mathrm{H}-6 \mathrm{a}\right), 4.16\left(\mathrm{dd}, 1 \mathrm{H}, J_{1,2}=3.4, J_{2,3}=J_{2, \mathrm{NH}}=9.7 \mathrm{~Hz}\right.$, $\mathrm{H}-2), 3.98\left(\mathrm{td}, 1 \mathrm{H}, J_{4,5}=J_{5,6 \mathrm{~b}}=9.8, J_{5,6 \mathrm{a}}=4.9 \mathrm{~Hz}, \mathrm{H}-5\right), 3.90-3.83\left(\mathrm{~m}, 2 \mathrm{H}, \mathrm{H}-3\right.$ and H-4), $3.81\left(\mathrm{t}, 1 \mathrm{H}, J_{5,6 \mathrm{~b}}=\right.$ $\left.J_{6 \mathrm{a}, 6 \mathrm{~b}}=10.2 \mathrm{~Hz}, \mathrm{H}-6 \mathrm{~b}\right) ;{ }^{13} \mathrm{C}-\mathrm{NMR}\left(125 \mathrm{MHz}, \mathrm{CDCl}_{3}\right): \delta 160.7(\mathrm{C}=\mathrm{N}), 154.3(\mathrm{C}=\mathrm{O}$ Troc $), 137.8\left(\mathrm{C}_{\mathrm{i}}\right.$ arom. $\mathrm{Bn}), 137.1$ ( $\mathrm{C}_{\mathrm{i}}$ arom. $\left.\mathrm{PhCH}\right), 129.3$ ( $\mathrm{CH}$ arom.), 128.7 ( $\mathrm{CH}$ arom.), 128.5 ( $\mathrm{CH}$ arom.), 128.5 (CH arom.), 128.3 (CH arom.), 126.1 (CH arom.), 101.5 ( $\mathrm{PhCH}), 95.7$ (C-1), 95.4 ( $\mathrm{CCl}_{3}$ Troc), 90.9 ( $\mathrm{CCl}_{3}$ Imidate), 82.2 (C-4), 74.8 ( $\mathrm{CH}_{2}$ Troc), $74.6\left(\mathrm{CH}_{2} \mathrm{Bn}\right), 74.5$ (C-3), 68.7 (C-6), 65.6 (C-5), 54.6 (C-2); HRMS(ESI) $\mathrm{m} / \mathrm{z}$ calcld. for $\left[\mathrm{C}_{25} \mathrm{H}_{24} \mathrm{O}_{7} \mathrm{~N}_{2} \mathrm{Cl}_{6}+\mathrm{Na}\right]^{+}:$696.9612, obsd.: 696.9605

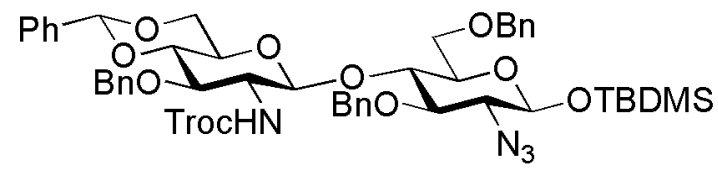

57

\section{2-Azido-3,6-di- $O$-benzyl-4- $O$-[3-O-benzyl-4,6- $O$ - benzylidene-2-deoxy-2-(2,2,2- trichloroethoxycarbonylamido)- $\beta$-D- glucopyranosyl]-1-O-tert-butyldimethylsilyl-2-}

deoxy- $\beta$-D-glucopyranose (57). Glucosazide acceptor $52(0.042 \mathrm{~g}, 0.084 \mathrm{mmol})$ and acetimidate donor 56 $(0.105 \mathrm{~g}, 0.155 \mathrm{mmol}, 1.8$ equiv.) were coevaporated three times with toluene and dissolved in DCM (0.5 $\mathrm{mL}$ ) under a nitrogen atmosphere. The solution was stirred for $30 \mathrm{mins}$ in the presence of molecular sieves (type 4A). After cooling the solution to $-40^{\circ} \mathrm{C}$, TMSOTf $(0.0015 \mathrm{~mL}$ or $1.5 \mu \mathrm{L}, 0.010 \mathrm{mmol}, 0.1$ equiv.) 
was added dropwise and the reaction mixture was allowed to warm slowly to $-10^{\circ} \mathrm{C}$ over $1 \mathrm{~h} 15$ mins with stirring. After, TLC-analysis (ethyl acetate/light petroleum ether, 1/3, v/v) showed completion of the reaction, the reaction mixture was quenched with triethylamine $(0.1 \mathrm{~mL})$, diluted with ethyl acetate, washed with sat. aq. $\mathrm{NaHCO}_{3}$, brine, dried $\left(\mathrm{MgSO}_{4}\right)$, filtered and concentrated in vacuo. Purification by column chromatography (ethyl acetate/light petroleum ether, $1 / 20 \rightarrow 1 / 5$, v/v) yielded disaccharide 57 as a colourless oil $(0.063 \mathrm{~g}, 74 \%) . R_{f} 0.41$ (ethyl acetate/light petroleum ether, 1/3, v/v); IR (thin film): 3353, 3065, 3033, 2929, 2859, 2111, 1713, 1539, 1497, 1454, 1386, 1369, 1313, 1252, 1172, 1064, 1028, 1010, 957, 912, 838, 783, 733, $694 \mathrm{~cm}^{-1} ;{ }^{1} \mathrm{H}-\mathrm{NMR}\left(500 \mathrm{MHz}, \mathrm{CDCl}_{3}\right): \delta$ 7.50-7.48 (m, 2H, CH arom.), 7.41-7.28 (m, 17H, CH arom.), 7.12 (t, 1H, $J_{\mathrm{a}, \mathrm{b}}=6.9 \mathrm{~Hz}, \mathrm{CH}$ arom.), $5.48(\mathrm{~s}, 1 \mathrm{H}, \mathrm{PhCH}), 4.87\left(\mathrm{~d}, 2 \mathrm{H}, J_{\mathrm{a}, \mathrm{b}}=11.4 \mathrm{~Hz}\right.$, CH-a 3'-O-Bn and CH-a 3-O-Bn), $4.80\left(\mathrm{~d}, 1 \mathrm{H}, J_{\mathrm{a}, \mathrm{b}}=12.2 \mathrm{~Hz}, \mathrm{CH}-\mathrm{a} 6-O-\mathrm{Bn}\right), 4.78\left(\mathrm{~d}, 1 \mathrm{H}, J_{\mathrm{a}, \mathrm{b}}=12.2 \mathrm{~Hz}\right.$, CH-a Troc), 4.73 (d, 1H, $\left.J_{\mathrm{a}, \mathrm{b}}=11.0 \mathrm{~Hz}, \mathrm{CH}-\mathrm{b} 3-O-\mathrm{Bn}\right), 4.65$ (d, 2H, $J_{\mathrm{a}, \mathrm{b}}=12.0 \mathrm{~Hz}, \mathrm{CH}-\mathrm{b}$ Troc and CH-b 3'$O$-Bn), 4.45 (d, 1H, $\left.J_{1,2}=7.4 \mathrm{~Hz}, \mathrm{H}-1\right), 4.35$ (d, $\left.1 \mathrm{H}, J_{\mathrm{a}, \mathrm{b}}=11.9 \mathrm{~Hz}, \mathrm{CH}-\mathrm{b} 6-O-\mathrm{Bn}\right), 4.35$ (d, $1 \mathrm{H}, J_{1^{\prime}, 2^{\prime}}=8.5$ $\left.\mathrm{Hz}, \mathrm{H}-1^{\prime}\right), 4.08\left(\mathrm{dd}, 1 \mathrm{H}, J_{5^{\prime}, 6 \mathrm{a}^{\prime}}=4.9, J_{6 \mathrm{a}^{\prime}, 6 \mathrm{~b}^{\prime}}=10.2 \mathrm{~Hz}, \mathrm{H}-6 \mathrm{a}^{\prime}\right), 3.93\left(\mathrm{t}, 1 \mathrm{H}, J_{3,4}=J_{4,5}=9.8 \mathrm{~Hz}, \mathrm{H}-4\right), 3.73(\mathrm{dd}$, $\left.1 \mathrm{H}, J_{5,6 \mathrm{a}}=2.7, J_{6 \mathrm{a}, 6 \mathrm{~b}}=11.5 \mathrm{~Hz}, \mathrm{H}-6 \mathrm{a}\right), 3.60\left(\mathrm{t}, 1 \mathrm{H}, J_{3^{\prime}, 4^{\prime}}=J_{4^{\prime}, 5^{\prime}}=9.3 \mathrm{~Hz}, \mathrm{H}-4^{\prime}\right), 3.53-3.46(\mathrm{~m}, 2 \mathrm{H}, \mathrm{H}-6 \mathrm{~b}$ and H-2'), 3.38-3.26 (m, 5H, H-2, H-3, H-5, H-3', and H-6b'), 3.16 (td, $1 \mathrm{H}, J_{4^{\prime}, 5^{\prime}}=J_{5^{\prime}, 6 \mathrm{~b}^{\prime}}=9.8, J_{5^{\prime}, 6 \mathrm{a}^{\prime}}=4.9 \mathrm{~Hz}, \mathrm{H}-$ $\left.5^{\prime}\right), 0.94$ (s, 9H, $\left.3 \times \mathrm{CH}_{3} \mathrm{Si}{ }^{\mathrm{t} B u}\right), 0.16$ (s, 3H, $\left.\mathrm{CH}_{3} \mathrm{SiMe}_{\mathrm{a}}\right), 0.15$ (s, 3H, $\left.\mathrm{CH}_{3} \mathrm{SiMe}_{\mathrm{b}}\right) ;{ }^{13} \mathrm{C}-\mathrm{NMR}(125 \mathrm{MHz}$, $\left.\mathrm{CDCl}_{3}\right): \delta 154.2\left(\mathrm{C}=\mathrm{O}\right.$ Troc), $138.7\left(\mathrm{C}_{\mathrm{i}}\right.$ arom. 3-O-Bn), $138.3\left(\mathrm{C}_{\mathrm{i}}\right.$ arom. 3'-O-Bn), 137.8 ( $\mathrm{C}_{\mathrm{i}}$ arom. 6-O-Bn), $137.3\left(\mathrm{C}_{\mathrm{i}}\right.$ arom. $\left.\mathrm{PhCH}\right), 129.4$ ( $\mathrm{CH}$ arom.), $129.2(\mathrm{CH}$ arom.), $129.0(\mathrm{CH}$ arom.), 128.5 (CH arom.), 128.5 (CH arom.), 128.4 ( $\mathrm{CH}$ arom.), 128.3 ( $\mathrm{CH}$ arom.), 128.0 (CH arom.), 128.0 ( $\mathrm{CH}$ arom.), 127.7 (CH arom.), 127.6 (CH arom.), 126.1 (CH arom.), $101.2(\mathrm{PhCH}), 101.1$ (C-1'), 97.4 (C-1), $95.7\left(\mathrm{CCl}_{3} \mathrm{Troc}\right), 82.3$ (C4'), 81.1 (C-3), 77.7 (C-3'), 76.7 (C-4), $75.2\left(\mathrm{CH}_{2} 3-\mathrm{O}-\mathrm{Bn}\right), 74.7\left(\mathrm{CH}_{2} \mathrm{Troc}\right), 74.5$ (C-5), $74.2\left(\mathrm{CH}_{2} 3^{\prime}-\mathrm{O}-\right.$ $\mathrm{Bn}), 73.7\left(\mathrm{CH}_{2}\right.$ 6-O-Bn), 68.7 (C-6'), $68.4(\mathrm{C}-2), 67.7$ (C-6), $65.7\left(\mathrm{C}-5^{\prime}\right), 57.8\left(\mathrm{C}-2^{\prime}\right), 25.8\left(\mathrm{CH}_{3} \mathrm{Si}^{\mathrm{t}} \mathrm{Bu}\right)$, $18.2\left(\mathrm{C}_{\mathrm{q}} \mathrm{Si}{ }^{\mathrm{t}} \mathrm{Bu}\right),-4.1\left(\mathrm{CH}_{3} \mathrm{SiMe}_{\mathrm{a}}\right),-5.0\left(\mathrm{CH}_{3} \mathrm{SiMe}_{\mathrm{b}}\right)$; HRMS(ESI) $\mathrm{m} / z$ calcld. for $\left[\mathrm{C}_{49} \mathrm{H}_{59} \mathrm{O}_{11} \mathrm{~N}_{4} \mathrm{Cl}_{3} \mathrm{Si}+\mathrm{Na}\right]^{+}$: 1035.2913, obsd.: 1035.2908.
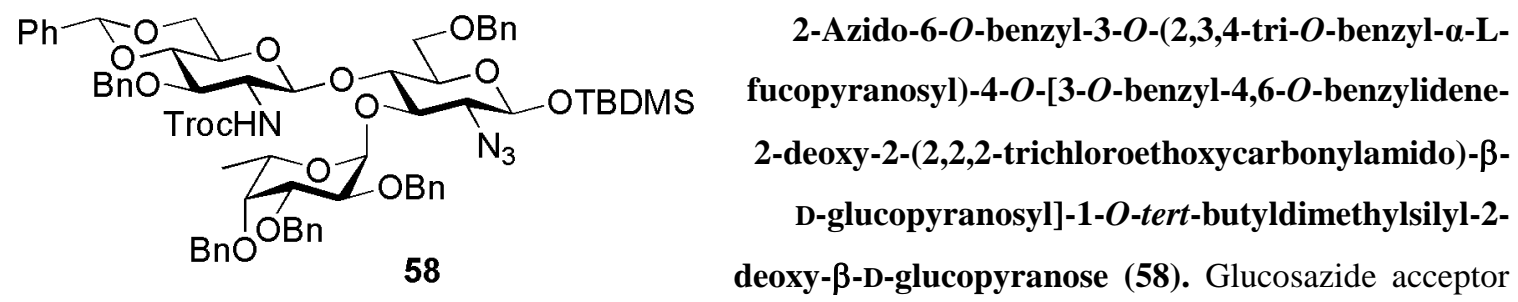

26 (0.0781 g, $0.0948 \mathrm{mmol})$ and acetimidate donor 56 (0.0946 g, $0.140 \mathrm{mmol}, 1.47$ equiv.) were coevaporated three times with toluene and dissolved in DCM $(0.50 \mathrm{~mL})$ under a nitrogen atmosphere. After cooling the solution to $-40^{\circ} \mathrm{C}$, TMSOTf $(0.0017 \mathrm{~mL}$ or $1.7 \mu \mathrm{L}, 0.0095 \mathrm{mmol}, 0.1$ equiv. $)$ was added dropwise and the reaction mixture was stirred for $1 \mathrm{~h}$. After, TLC-analysis (ethyl acetate/light petroleum ether, $1 / 5, \mathrm{v} / \mathrm{v}$ ) showed completion of the reaction, the reaction mixture was quenched with triethylamine $(0.1 \mathrm{~mL})$ at $-40^{\circ} \mathrm{C}$. The reaction mixture was then diluted with ethyl acetate and washed with sat. aq. $\mathrm{NaHCO}_{3}$ and brine, dried $\left(\mathrm{MgSO}_{4}\right)$, filtered and concentrated in vacuo. Purification by column 
chromatography (ethyl acetate/light petroleum ether, 1/15 $\rightarrow$ 1/5, v/v) yielded trisaccharide $\mathbf{5 8}$ as a colourless oil $(0.0907 \mathrm{~g}, 72 \%) . R_{f} 0.65$ (ethyl acetate/light petroleum ether, $\left.1 / 2, \mathrm{v} / \mathrm{v}\right) ;[\alpha]_{\mathrm{D}}{ }^{20}=-37.5^{\circ}(c 1.0$, $\mathrm{CHCl}_{3}$ ); IR (thin film): 3387, 3064, 3031, 2950, 2929, 2859, 2111, 1732, 1605, 1524, 1497, 1454, 1363, 1311, 1256, 1216, 1169, 1097, 1066, 1041, 1029, 1010, 839, 750, 736, $697 \mathrm{~cm}^{-1}$; ${ }^{1} \mathrm{H}-\mathrm{NMR}(500 \mathrm{MHz}$, $\mathrm{CDCl}_{3}$ ): $\delta$ 7.51-7.17 (m, 30H, CH arom.), $5.55\left(\mathrm{~d}, 1 \mathrm{H}, J_{1^{\prime}, 2^{\prime}}=3.7 \mathrm{~Hz}, \mathrm{H}-1^{\prime}\right), 5.34(\mathrm{~s}, 1 \mathrm{H}, \mathrm{PhCH}), 5.05(\mathrm{~d}$, $\left.1 \mathrm{H}, J_{\mathrm{a}, \mathrm{b}}=11.5 \mathrm{~Hz}, \mathrm{CH}-\mathrm{a} 4^{\prime}-O-\mathrm{Bn}\right), 4.99\left(\mathrm{~d}, 1 \mathrm{H}, J_{\mathrm{a}, \mathrm{b}}=12.2 \mathrm{~Hz}, \mathrm{CH}-\mathrm{a} 3^{\prime}-O-\mathrm{Bn}\right), 4.87\left(\mathrm{~d}, 1 \mathrm{H}, J_{\mathrm{a}, \mathrm{b}}=11.9 \mathrm{~Hz}\right.$, CH-a 2'-O-Bn), $4.83\left(\mathrm{~d}, 1 \mathrm{H}, J_{\mathrm{a}, \mathrm{b}}=12.0 \mathrm{~Hz}, \mathrm{CH}-\mathrm{a} 3^{\prime \prime}-O-\mathrm{Bn}\right), 4.81$ (d, $\left.1 \mathrm{H}, J_{\mathrm{a}, \mathrm{b}}=12.7 \mathrm{~Hz}, \mathrm{CH}-\mathrm{b} 3^{\prime}-O-\mathrm{Bn}\right)$, $4.79\left(\mathrm{~d}, 1 \mathrm{H}, J_{\mathrm{a}, \mathrm{b}}=12.2 \mathrm{~Hz}, \mathrm{CH}-\mathrm{a} 6-O-\mathrm{Bn}\right), 4.78\left(\mathrm{~d}, 1 \mathrm{H}, J_{\mathrm{a}, \mathrm{b}}=12.0 \mathrm{~Hz}, \mathrm{CH}-\mathrm{b} 2^{\prime}-O-\mathrm{Bn}\right), 4.73\left(\mathrm{~d}, 1 \mathrm{H}, J_{\mathrm{a}, \mathrm{b}}=\right.$ $11.9 \mathrm{~Hz}, \mathrm{CH}-\mathrm{a}$ Troc), 4.71 (d, 1H, $\left.J_{\mathrm{a}, \mathrm{b}}=11.5 \mathrm{~Hz}, \mathrm{CH}-\mathrm{b} 4^{\prime}-O-\mathrm{Bn}\right), 4.67$ (d, 1H, $J_{\mathrm{a}, \mathrm{b}}=12.0 \mathrm{~Hz}, \mathrm{CH}-\mathrm{b}$ Troc), $4.62\left(\mathrm{~d}, 1 \mathrm{H}, J_{\mathrm{a}, \mathrm{b}}=11.7 \mathrm{~Hz}, \mathrm{CH}-\mathrm{b} 3^{\prime \prime}-O-\mathrm{Bn}\right), 4.58\left(\mathrm{q}, 1 \mathrm{H}, J_{5,6}=6.6 \mathrm{~Hz}, \mathrm{H}-5^{\prime}\right), 4.54\left(\mathrm{~d}, 1 \mathrm{H}, J_{1,2}=7.5 \mathrm{~Hz}, \mathrm{H}-\right.$ 1), $4.41\left(\mathrm{~d}, 1 \mathrm{H}, J_{1^{\prime \prime}, 2^{\prime \prime}}=7.9 \mathrm{~Hz}, \mathrm{H}-1^{\prime \prime}\right), 4.36\left(\mathrm{~d}, 1 \mathrm{H}, J_{\mathrm{a}, \mathrm{b}}=12.0 \mathrm{~Hz}, \mathrm{CH}-\mathrm{b} 6-O-\mathrm{Bn}\right), 4.24\left(\mathrm{dd}, 1 \mathrm{H}, J_{5^{\prime \prime}, 6 \mathrm{a}^{\prime \prime}}=4.9\right.$, $\left.J_{6 \mathrm{a}^{\prime \prime}, 6 \mathrm{~b}^{\prime \prime}}=10.2 \mathrm{~Hz}, \mathrm{H}-6 \mathrm{a}^{\prime \prime}\right), 4.12\left(\mathrm{dd}, 1 \mathrm{H}, J_{1^{\prime}, 2^{\prime}}=3.9, J_{2^{\prime}, 3^{\prime}}=10.3 \mathrm{~Hz}, \mathrm{H}-2^{\prime}\right), 4.04\left(\mathrm{~d}, 1 \mathrm{H}, J_{2^{\prime \prime}, \mathrm{NH}}=6.8 \mathrm{~Hz}, \mathrm{NH}\right)$, $3.97\left(\mathrm{t}, 1 \mathrm{H}, J_{3,4}=J_{4,5}=9.5 \mathrm{~Hz}, \mathrm{H}-4\right), 3.92\left(\mathrm{dd}, 1 \mathrm{H}, J_{2^{\prime}, 3^{\prime}}=10.2, J_{3^{\prime}, 4^{\prime}}=2.7 \mathrm{~Hz}, \mathrm{H}-3^{\prime}\right), 3.73\left(\mathrm{dd}, 1 \mathrm{H}, J_{5,6 \mathrm{a}}=\right.$ 2.2, $\left.J_{6 \mathrm{a}, 6 \mathrm{~b}}=11.0 \mathrm{~Hz}, \mathrm{H}-6 \mathrm{a}\right), 3.69\left(\mathrm{~s}, 1 \mathrm{H}, \mathrm{H}-4^{\prime}\right), 3.57\left(\mathrm{t}, 1 \mathrm{H}, J_{2,3}=J_{3,4}=9.8 \mathrm{~Hz}, \mathrm{H}-3\right), 3.50\left(\mathrm{~d}, 1 \mathrm{H}, J_{6 \mathrm{a}, 6 \mathrm{~b}}=\right.$ $11.3 \mathrm{~Hz}, \mathrm{H}-6 \mathrm{~b}$ ), 3.47 (dd, 1H, $J_{1,2}=7.9, J_{2,3}=10.3 \mathrm{~Hz}, \mathrm{H}-2$ ), 3.37-3.25 (m, 5H, H-5, H-2", H-3", H-4", and H-6"b), $3.13\left(\mathrm{td}, 1 \mathrm{H}, J_{4^{\prime \prime}, 5^{\prime \prime}}=J_{5^{\prime \prime}, 6 \mathrm{~b}^{\prime \prime}}=9.5, J_{5^{\prime \prime}, 6 \mathrm{a}^{\prime \prime}}=4.9 \mathrm{~Hz}, \mathrm{H}-5^{\prime \prime}\right), 1.23$ (d, 3H, $\left.J_{5^{\prime}, 6^{\prime}}=6.6 \mathrm{~Hz}, \mathrm{CH}_{3} \mathrm{H}-6^{\prime}\right), 0.95$ (s, 9H, $3 \times \mathrm{CH}_{3} \mathrm{Si}^{\mathrm{t}} \mathrm{Bu}$ ), 0.17 (s, 3H, $\mathrm{CH}_{3} \mathrm{SiMe}_{\mathrm{a}}$ ), 0.16 (s, 3H, $\mathrm{CH}_{3} \mathrm{SiMe}_{\mathrm{b}}$ ); ${ }^{13} \mathrm{C}-\mathrm{NMR}\left(125 \mathrm{MHz}, \mathrm{CDCl}_{3}\right.$ ): $\delta$ $153.9(\mathrm{C}=\mathrm{O}$ Troc $), 139.4\left(\mathrm{C}_{\mathrm{i}}\right.$ arom. 3'-O-Bn), $138.9\left(\mathrm{C}_{\mathrm{i}}\right.$ arom. 4'-O-Bn), $138.4\left(\mathrm{C}_{\mathrm{i}}\right.$ arom. 2'-O-Bn), 138.2 $\left(\mathrm{C}_{\mathrm{i}}\right.$ arom. 3"-O-Bn), $137.6\left(\mathrm{C}_{\mathrm{i}}\right.$ arom. 6-O-Bn), $137.2\left(\mathrm{C}_{\mathrm{i}}\right.$ arom. $\left.\mathrm{PhCH}\right), 129.2(\mathrm{CH}$ arom. $), 129.0(\mathrm{CH}$ arom.), 128.6 ( $\mathrm{CH}$ arom.), 128.5 ( $\mathrm{CH}$ arom.), 128.5 ( $\mathrm{CH}$ arom.), 128.4 ( $\mathrm{CH}$ arom.), 128.3 ( $\mathrm{CH}$ arom.), 128.3 (CH arom.), 128.0 (CH arom.), 127.7 (CH arom.), 127.6 ( $\mathrm{CH}$ arom.), 127.5 (CH arom.), 126.9 (CH arom.), 126.1 (CH arom.), 101.2 (PhCH), 100.6 (C-1"), 97.7 (C-1), 96.8 (C-1'), 95.7 ( $\left.\mathrm{CCl}_{3} \mathrm{Troc}\right), 82.6$ (C4"), 79.4 (C-3'), 79.3 (C-4'), 77.8 (C-3"), 76.3 (C-2'), $75.2\left(\mathrm{CH}_{2} 4^{\prime}-\mathrm{O}-\mathrm{Bn}\right), 74.8$ (C-5), $74.6\left(\mathrm{CH}_{2}\right.$ Troc), 74.5 (C-3), $74.3\left(\mathrm{CH}_{2} 3^{\prime \prime}-O-\mathrm{Bn}\right), 74.0$ (C-4), $73.9\left(\mathrm{CH}_{2} 6-O-\mathrm{Bn}\right), 73.2\left(\mathrm{CH}_{2} 3^{\prime}-O-\mathrm{Bn}\right), 73.2\left(\mathrm{CH}_{2} 2^{\prime}-O-\mathrm{Bn}\right)$, 68.8 (C-6"), 68.6 (C-2), 68.0 (C-6), $66.2\left(\mathrm{C}-5^{\prime}\right), 65.6\left(\mathrm{C}-5{ }^{\prime \prime}\right), 57.5\left(\mathrm{C}-2^{\prime \prime}\right), 25.8\left(\mathrm{CH}_{3} \mathrm{Si}^{\mathrm{t}} \mathrm{Bu}\right), 18.1\left(\mathrm{C}_{\mathrm{q}} \mathrm{Si}^{\mathrm{t}} \mathrm{Bu}\right)$, $16.9\left(\mathrm{C}-66^{\prime}\right),-4.2\left(\mathrm{CH}_{3} \mathrm{SiMe}_{\mathrm{a}}\right),-4.9\left(\mathrm{CH}_{3} \mathrm{SiMe}_{\mathrm{b}}\right)$; HRMS(ESI) $\mathrm{m} / z$ calcld. for $\left[\mathrm{C}_{69} \mathrm{H}_{81} \mathrm{O}_{15} \mathrm{~N}_{4} \mathrm{Cl}_{3} \mathrm{Si}+\mathrm{Na}\right]^{+}$: 1361.4431 obsd.: 1361.4424 .

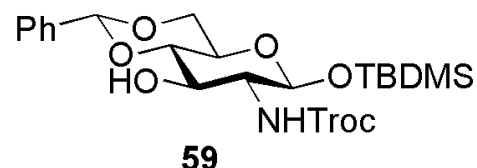

59
4,6-O-Benzylidene-1-O-tert-butyldimethylsilyl-2-deoxy-2-(2,2,2trichloroethoxycarbonylamido)- $\beta$-D-glucopyranose

(59). Glucosazide 23 ( $0.086 \mathrm{~g}, 0.212 \mathrm{mmol})$ was coevaporated three times $\mathrm{mL}, 1 \mathrm{M}$ in THF, $1.21 \mathrm{mmol}, 5$ equiv.) was added and the reaction mixture was stirred for $10 \mathrm{mins}$ at $0^{\circ} \mathrm{C}$ and a further $1 \mathrm{~h}$ at room temperature. After TLC-analysis (ethyl acetate/light petroleum ether, 1/1, v/v) showed complete reduction of the azide, 2,2,2-trichloroethyl chloroformate $(0.058 \mathrm{~mL}, 0.424 \mathrm{mmol}, 2$ equiv.) and sodium hydroxide $1 \mathrm{M}(\mathrm{aq})$ (reaction solution $\mathrm{pH} \approx 8$ ) were added and the reaction mixture was stirred for another $23 \mathrm{~h}$. Additional 2,2,2-trichloroethyl chloroformate ( $0.015 \mathrm{~mL}, 0.106 \mathrm{mmol}, 0.5 \mathrm{equiv}$.), 
(0.015 mL, $0.106 \mathrm{mmol}, 0.5$ equiv.), (0.029 mL, $0.212 \mathrm{mmol}, 1$ equiv.) and sodium hydroxide $1 \mathrm{M}$ (aq) (to adjust reaction solution to $\mathrm{pH} \approx 8$ ) were added after $2 \mathrm{~h}, 5 \mathrm{~h}$, and $22.5 \mathrm{~h}$ respectively. After TLC-analysis (ethyl acetate/light petroleum ether, 1/1, v/v) showed completion of the reaction, the reaction mixture was neutralised with sat. aq. $\mathrm{NaHCO}_{3}$ and brine, dried $\left(\mathrm{MgSO}_{4}\right)$, filtered and concentrated in vacuo. Purification by column chromatography (ethyl acetate/light petroleum ether, $1 / 20 \rightarrow 1 / 5$, v/v) yielded pure 59 as a colourless oil $(0.072 \mathrm{~g}, 61 \%) . R_{f} 0.60$ (ethyl acetate/light petroleum ether, $\left.1 / 1, \mathrm{v} / \mathrm{v}\right) ;[\alpha]_{\mathrm{D}}^{22}=-24.3^{\circ}(c 1.0$, $\mathrm{CHCl}_{3}$ ); IR (thin film): 3358, 3325, 3065, 3032, 2929, 2857, 1721, 1538, 1497, 1454, 1387, 1361, 1308, 1250, 1173, 1093, 1040, 1028, 1012, 916, 839, 783, 733, $697 \mathrm{~cm}^{-1} ;{ }^{1} \mathrm{H}-\mathrm{NMR}\left(500 \mathrm{MHz}, \mathrm{CDCl}_{3}\right): \delta 7.50-$ 7.48 (m, 2H, CH-m arom.), 7.40-7.36 (m, 3H, CH- $o$ and $\mathrm{CH}-p$ arom.), 5.54 (s, 1H, PhCH), 5.16 (d, $1 \mathrm{H}$, $\left.J_{2, \mathrm{NH}}=8.1 \mathrm{~Hz}, \mathrm{NH}\right), 4.86\left(\mathrm{~d}, 1 \mathrm{H}, J_{1,2}=7.5 \mathrm{~Hz}, \mathrm{H}-1\right), 4.73\left(\mathrm{~d}, 1 \mathrm{H}, J_{\mathrm{a}, \mathrm{b}}=12.0 \mathrm{~Hz}, \mathrm{CH}-\mathrm{a}\right.$ Troc$), 4.67(\mathrm{~d}, 1 \mathrm{H}$, $J_{\mathrm{a}, \mathrm{b}}=11.9 \mathrm{~Hz}$, CH-b Troc), $4.30\left(\mathrm{dd}, 1 \mathrm{H}, J_{5,6 \mathrm{a}}=5.2, J_{6 \mathrm{a}, 6 \mathrm{~b}}=10.5 \mathrm{~Hz}, \mathrm{H}-6 \mathrm{a}\right), 3.78\left(\mathrm{t}, 1 \mathrm{H}, J_{5,6 \mathrm{~b}}=J_{6 \mathrm{a}, 6 \mathrm{~b}}=\right.$ $10.3 \mathrm{~Hz}, \mathrm{H}-6 \mathrm{~b}), 4.05\left(\mathrm{t}, 1 \mathrm{H}, J_{2,3}=J_{3,4}=9.3 \mathrm{~Hz}, \mathrm{H}-3\right), 3.57\left(\mathrm{t}, 1 \mathrm{H}, J_{3,4}=J_{4,5}=9.3 \mathrm{~Hz}, \mathrm{H}-4\right), 3.47\left(\mathrm{td}, 1 \mathrm{H}, J_{4,5}\right.$ $\left.=J_{5,6 \mathrm{~b}}=9.8, J_{5,6 \mathrm{a}}=4.9 \mathrm{~Hz}, \mathrm{H}-5\right), 3.37\left(\mathrm{q}, 1 \mathrm{H}, J_{1,2}=J_{2,3}=J_{2, \mathrm{NH}}=8.0 \mathrm{~Hz}, \mathrm{H}-2\right), 0.89\left(\mathrm{~s}, 9 \mathrm{H}, 3 \times \mathrm{CH}_{3} \mathrm{Si}^{\mathrm{t}} \mathrm{Bu}\right)$, $0.12\left(\mathrm{~s}, 3 \mathrm{H}, \mathrm{CH}_{3} \mathrm{SiMe}_{\mathrm{a}}\right), 0.11\left(\mathrm{~s}, 3 \mathrm{H}, \mathrm{CH}_{3} \mathrm{SiMe}_{\mathrm{b}}\right) ;{ }^{13} \mathrm{C}-\mathrm{NMR}\left(125 \mathrm{MHz}, \mathrm{CDCl}_{3}\right): \delta 154.6(\mathrm{C}=\mathrm{O} \mathrm{Troc})$, 137.2 (C $\mathrm{C}_{\mathrm{i}}$ arom.), 129.5 (CH-p arom.), 128.5 (CH-o arom.), 126.6 (CH-m arom.), 102.0 (PhCH), 96.3 (C-1), $95.3\left(\mathrm{CCl}_{3}\right.$ Troc), 81.6 (C-4), 74.9 ( $\mathrm{CH}_{2}$ Troc), 70.8 (C-3), 68.8 (C-6), 66.3 (C-5), $60.8(\mathrm{C}-2), 25.7\left(\mathrm{CH}_{3}\right.$ $\left.\mathrm{Si}^{\mathrm{t}} \mathrm{Bu}\right), \quad 18.0 \quad\left(\mathrm{C}_{\mathrm{q}} \quad \mathrm{Si}{ }^{\mathrm{t}} \mathrm{Bu}\right), \quad-4.0 \quad\left(\mathrm{CH}_{3} \quad \mathrm{SiMe}_{\mathrm{a}}\right), \quad-5.1 \quad\left(\mathrm{CH}_{3} \quad \mathrm{SiMe}_{\mathrm{b}}\right) ; \quad \mathrm{HRMS}(\mathrm{ESI}) \quad m / z \quad$ calcld. for $\left[\mathrm{C}_{22} \mathrm{H}_{32} \mathrm{O}_{7} \mathrm{NCl}_{3} \mathrm{Si}+\mathrm{Na}\right]^{+}:$578.0911, obsd.: 578.0918 .

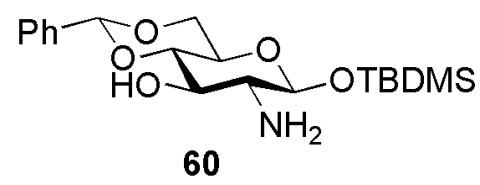

60
2-Amino-4,6-O-benzylidene-1- $O$-tert-butyldimethylsilyl-2-deoxy- $\beta$ D-glucopyranose (60). Glucosazide 23 (0.099 g, $0.242 \mathrm{mmol})$ was coevaporated three times with toluene and dissolved in THF (1.21

$\mathrm{mL})$. After cooling the solution to $0^{\circ} \mathrm{C}$, trimethyl phosphine $(1.21 \mathrm{~mL}, 1 \mathrm{M}$ in $\mathrm{THF}, 1.21 \mathrm{mmol}, 5$ equiv.) was added and the reaction mixture was stirred for $10 \mathrm{mins}$ at $0^{\circ} \mathrm{C}$ and a further $2 \mathrm{~h}$ at room temperature. After TLC-analysis (ethyl acetate/light petroleum ether, 1/1, v/v) showed completion of the reaction, sodium hydroxide (1.21 mL, 1M (aq), $1.21 \mathrm{mmol}, 5$ equiv.) was added and the reaction mixture was stirred for 5 mins and was then washed with sat. aq. $\mathrm{NaHCO}_{3}$, then water and brine, dried $\left(\mathrm{MgSO}_{4}\right)$, filtered and concentrated in vacuo to yield crude amine 60 (0.0924 g) which was then used without further purification.

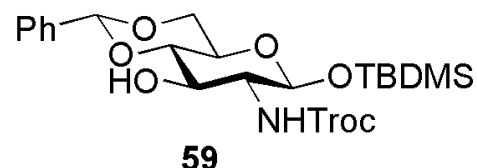

59
4,6-O-Benzylidene-1-O-tert-butyldimethylsilyl-2-deoxy-2-(2,2,2trichloroethoxycarbonylamido)- $\beta$-D-glucopyranose (59). Crude glucosamine 60 (0.0427 $\mathrm{g}, 0.112 \mathrm{mmol})$ was dissolved in pyridine (1.0

$\mathrm{mL})$ and 2,2,2-trichloroethyl chloroformate $(0.042 \mathrm{~mL}, 0.303 \mathrm{mmol}, 2.5$ equiv.) was added and the reaction mixture was stirred for $1 \mathrm{~h} 40$ mins. After TLC-analysis (ethyl acetate/light petroleum ether, 1/1, v/v) showed completion of the reaction, $\mathrm{MeOH}$ was added and the reaction mixture was concentrated in vacuo. Purification by column chromatography (ethyl acetate/light petroleum ether, $1 / 20 \rightarrow 1 / 5$, v/v) yielded pure 59 as a colourless oil (0.031 g, 46\% over 2 steps). (4,6- $O$-benzylidene-1-O-tert-butyldimethylsilyl-2-deoxy- 
3-O-(2,2,2-trichloroethoxycarbonyl)-2-(2,2,2-trichloroethoxycarbonylamido)- $\beta$-D-glucopyranose (61), was also isolated, $0.022 \mathrm{~g}, 25 \%$ over 2 steps). Characterisation is as above.

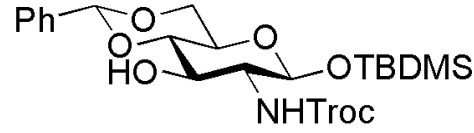

59

4,6-O-Benzylidene-1-O-tert-butyldimethylsilyl-2-deoxy-2-(2,2,2trichloroethoxycarbonylamido)- $\beta$-D-glucopyranose (59). Crude glucosamine 60 (0.0497 $\mathrm{g}, 0.130 \mathrm{mmol})$ was dissolved in DCM (1.0

$\mathrm{mL})$. Diisopropylethylamine $(0.045 \mathrm{~mL}, 0.260 \mathrm{mmol}, 2$ equiv.) and 2,2,2-trichloroethyl chloroformate ( $0.027 \mathrm{~mL}, 0.195 \mathrm{mmol}, 1.5$ equiv.) were added and the reaction mixture was stirred for $1 \mathrm{~h} 15 \mathrm{mins}$. After TLC-analysis (ethyl acetate/light petroleum ether, 1/1, v/v) showed completion of the reaction, $\mathrm{MeOH}$ was added and the reaction mixture was concentrated in vacuo. Purification by column chromatography (ethyl acetate/light petroleum ether, $1 / 20 \rightarrow 1 / 5, \mathrm{v} / \mathrm{v})$ yielded pure $\mathbf{5 9}$ as a colourless oil $(0.053 \mathrm{~g}, 73 \%$ over 2 steps). Characterisation is as above.

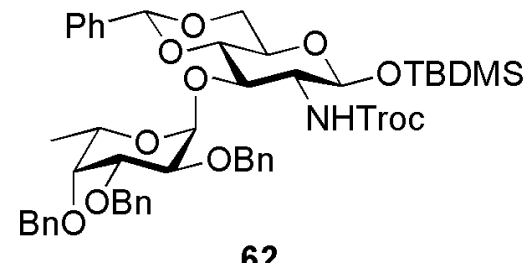

62

\section{3-O-(2,3,4-Tri- $O$-benzyl- $\alpha$-L-fucopyranosyl)-4,6- $O$-benzylidene-} 1-O-tert-butyldimethylsilyl-2-deoxy-2-(2,2,2trichloroethoxycarbonylamido)- $\beta$-D-glucopyranose (62). $N$-Troc protected acceptor $59(0.0240 \mathrm{~g}, 0.0431 \mathrm{mmol})$ and thiofucoside donor 22 (0.0371 g, $0.0776 \mathrm{mmol}, 1.8$ equiv.) were coevaporated three times with DMF, on the final time the solution was coevaporated to half volume leaving $0.35 \mathrm{~mL}$ of DMF. DCM $(0.35 \mathrm{~mL})$ was added and the solution stirred for 45 mins in the presence of molecular sieves (type 4A) under a nitrogen atmosphere. Tetrapropylammonium bromide $(0.0367 \mathrm{~g}, 0.138 \mathrm{mmol}, 3.2 \mathrm{equiv}$.) was added and to solution stirred for $1 \mathrm{~h}$ before copper(II) bromide (0.0308 g, $0.138 \mathrm{mmol}, 3.2$ equiv.) was added and stirring was continued for another $70 \mathrm{~h}$. After TLC-analysis (ethyl acetate/light petroleum ether, $1 / 4, \mathrm{v} / \mathrm{v}$ ) showed completion of the reaction, the reaction mixture was neutralised with sat. aq. $\mathrm{NaHCO}_{3}$ and the aqueous layer extracted twice with ethyl acetate. The organic layers were combined, washed with sat aq. $\mathrm{NH}_{4} \mathrm{Cl}$, and brine, dried $\left(\mathrm{MgSO}_{4}\right)$, filtered and concentrated in vacuo. Purification by column chromatography (ethyl acetate/light petroleum ether, $1 / 20 \rightarrow 1 / 5$, v/v) yielded disaccharide 62 as a colourless oil $(0.0242 \mathrm{~g}, 58 \%, \alpha: \beta, 16.8: 1)$. The $\alpha$ and $\beta$ anomers were separated by column chromatography (DCM). $R_{f} 0.30$ (ethyl acetate/light petroleum ether, $\left.1 / 4, \mathrm{v} / \mathrm{v}\right) ;[\alpha]_{\mathrm{D}}^{24}=-51^{\circ}(c 0.1$, $\mathrm{CHCl}_{3}$ ); IR (thin film): 3361, 3064, 3032, 2928, 2857, 1739, 1533, 1498, 1455, 1389, 1363, 1341, 1312, 1250, 1160, 1101, 1046, 1029, 914, 840, 783, 737, $698 \mathrm{~cm}^{-1} ;{ }^{1} \mathrm{H}-\mathrm{NMR}\left(500 \mathrm{MHz}, \mathrm{CDCl}_{3}\right): \delta$ 7.45-7.24 (m, $20 \mathrm{H}, \mathrm{CH}$ arom.), 5.48 (s, 1H, PhCH), $5.24\left(\mathrm{~d}, 1 \mathrm{H}, J_{2, \mathrm{NH}}=7.4 \mathrm{~Hz}, \mathrm{NH}\right), 5.15\left(\mathrm{~d}, 1 \mathrm{H}, J_{1^{\prime}, 2^{\prime}}=3.4 \mathrm{~Hz}, \mathrm{H}-1^{\prime}\right)$, $4.98\left(\mathrm{~d}, 1 \mathrm{H}, J_{1,2}=7.8 \mathrm{~Hz}, \mathrm{H}-1\right), 4.91\left(\mathrm{~d}, 1 \mathrm{H}, J_{\mathrm{a}, \mathrm{b}}=11.4 \mathrm{~Hz}, \mathrm{CH}-\mathrm{a} 4^{\prime}-O-\mathrm{Bn}\right), 4.85\left(\mathrm{~d}, 1 \mathrm{H}, J_{\mathrm{a}, \mathrm{b}}=11.2 \mathrm{~Hz}, \mathrm{CH}-\right.$ a $\left.2^{\prime}-O-B n\right), 4.84\left(\mathrm{~d}, 1 \mathrm{H}, J_{\mathrm{a}, \mathrm{b}}=11.5 \mathrm{~Hz}, \mathrm{CH}-\mathrm{a} 3^{\prime}-O-\mathrm{Bn}\right), 4.73\left(\mathrm{~d}, 1 \mathrm{H}, J_{\mathrm{a}, \mathrm{b}}=11.7 \mathrm{~Hz}, \mathrm{CH}-\mathrm{b} 3^{\prime}-O-\mathrm{Bn}\right), 4.71$ (d, $1 \mathrm{H}, J_{\mathrm{a}, \mathrm{b}}=11.3 \mathrm{~Hz}, \mathrm{CH}-\mathrm{a}$ Troc), $4.67\left(\mathrm{~d}, 1 \mathrm{H}, J_{\mathrm{a}, \mathrm{b}}=11.2 \mathrm{~Hz}, \mathrm{CH}-\mathrm{b} 2^{\prime}-O-\mathrm{Bn}\right), 4.58$ (d, $1 \mathrm{H}, J_{\mathrm{a}, \mathrm{b}}=11.5 \mathrm{~Hz}, \mathrm{CH}-$ b $\left.4^{\prime}-O-B n\right), 4.52\left(\mathrm{~d}, 1 \mathrm{H}, J_{\mathrm{a}, \mathrm{b}}=12.0 \mathrm{~Hz}, \mathrm{CH}-\mathrm{b}\right.$ Troc), $4.28\left(\mathrm{dd}, 1 \mathrm{H}, J_{5,6 \mathrm{a}}=4.8, J_{6 \mathrm{a}, 6 \mathrm{~b}}=10.4 \mathrm{~Hz}, \mathrm{H}-6 \mathrm{a}\right), 4.22$ $\left(\mathrm{t}, 1 \mathrm{H}, J_{2,3}=J_{3,4}=9.8 \mathrm{~Hz}, \mathrm{H}-3\right), 4.07\left(\mathrm{q}, 1 \mathrm{H}, J_{5^{\prime}, 6^{\prime}}=6.3 \mathrm{~Hz}, \mathrm{H}-5^{\prime}\right), 4.05\left(\mathrm{dd}, 1 \mathrm{H}, J_{1^{\prime}, 2^{\prime}}=3.6, J_{2^{\prime}, 3^{\prime}}=10.0 \mathrm{~Hz}\right.$, 
H-2'), $3.92\left(\mathrm{dd}, 1 \mathrm{H}, J_{2^{\prime}, 3^{\prime}}=10.2, J_{3^{\prime}, 4^{\prime}}=2.6 \mathrm{~Hz}, \mathrm{H}-3^{\prime}\right), 3.75\left(\mathrm{t}, 1 \mathrm{H}, J_{5,6 \mathrm{~b}}=J_{6 \mathrm{a}, 6 \mathrm{~b}}=10.3 \mathrm{~Hz}, \mathrm{H}-6 \mathrm{~b}\right), 3.60(\mathrm{t}, 1 \mathrm{H}$, $\left.J_{3,4}=J_{4,5}=9.3 \mathrm{~Hz}, \mathrm{H}-4\right), 3.56\left(\mathrm{~d}, 1 \mathrm{H}, J_{3^{\prime}, 4^{\prime}}=1.7 \mathrm{~Hz}, \mathrm{H}-4^{\prime}\right), 3.47-3.43(\mathrm{~m}, 1 \mathrm{H}, \mathrm{H}-5), 3.20\left(\mathrm{q}, 1 \mathrm{H}, J_{1,2}=J_{2,3}=\right.$ $\left.J_{2, \mathrm{NH}}=8.0 \mathrm{~Hz}, \mathrm{H}-2\right), 0.85$ (s, $\left.9 \mathrm{H}, 3 \times \mathrm{CH}_{3} \mathrm{Si}^{\mathrm{t}} \mathrm{Bu}\right), 0.80\left(\mathrm{~d}, 3 \mathrm{H}, J_{5^{\prime}, 6^{\prime}}=6.4 \mathrm{~Hz}, \mathrm{CH}_{3} \mathrm{H}-6^{\prime}\right), 0.06\left(\mathrm{~s}, 3 \mathrm{H}, \mathrm{CH}_{3}\right.$ $\mathrm{SiMe}_{\mathrm{a}}$ ), 0.04 (s, 3H, $\left.\mathrm{CH}_{3} \mathrm{SiMe}_{\mathrm{b}}\right) ;{ }^{13} \mathrm{C}-\mathrm{NMR}\left(125 \mathrm{MHz}, \mathrm{CDCl}_{3}\right): \delta 153.9(\mathrm{C}=\mathrm{O}$ Troc $), 139.0\left(\mathrm{C}_{\mathrm{i}}\right.$ arom. 3'-O$\mathrm{Bn}), 138.7\left(\mathrm{C}_{\mathrm{i}}\right.$ arom. 4'-O-Bn), $138.6\left(\mathrm{C}_{\mathrm{i}}\right.$ arom. 2'-O-Bn), $137.4\left(\mathrm{C}_{\mathrm{i}}\right.$ arom. $\left.\mathrm{PhCH}\right), 129.2(\mathrm{CH}$ arom. $), 128.7$ (CH arom.), 128.5 (CH arom.), 128.5 ( $\mathrm{CH}$ arom.), 128.4 (CH arom.), 128.3 (CH arom.), 128.3 (CH arom.), 128.2 (CH arom.), 128.0 (CH arom.), 127.7 (CH arom.), 127.6 (CH arom.), 127.6 (CH arom.), 127.5 (CH arom.), 126.3 (CH arom.), 101.8 (PhCH), 98.0 (C-1'), 95.7 (C-1), 95.3 ( $\mathrm{CCl}_{3}$ Troc), 80.7(C-4), 79.6 (C-3'), 77.9 (C-4'), 77.3 (C-2'), $75.0\left(\mathrm{CH}_{2} 4^{\prime}-O-\mathrm{Bn}\right), 74.8\left(\mathrm{CH}_{2}\right.$ Troc), $74.4(\mathrm{C}-3), 73.8\left(\mathrm{CH}_{2} 2^{\prime}-O-\mathrm{Bn}\right), 73.1\left(\mathrm{CH}_{2}\right.$ 3'-O-Bn), 68.9 (C-6), 66.9 (C-5'), 66.3 (C-5), $61.4(\mathrm{C}-2), 25.7\left(\mathrm{CH}_{3} \mathrm{Si}^{\mathrm{t}} \mathrm{Bu}\right), 18.0\left(\mathrm{C}_{\mathrm{q}} \mathrm{Si}^{\mathrm{t}} \mathrm{Bu}\right), 16.4\left(\mathrm{C}-6^{\prime}\right),-$ $4.1\left(\mathrm{CH}_{3} \mathrm{SiMe}_{\mathrm{a}}\right),-5.2\left(\mathrm{CH}_{3} \mathrm{SiMe}_{\mathrm{b}}\right)$; HRMS(ESI) $\mathrm{m} / z$ calcld. for $\left[\mathrm{C}_{49} \mathrm{H}_{60} \mathrm{O}_{11} \mathrm{NCl}_{3} \mathrm{Si}+\mathrm{Na}\right]^{+}:$994.2899, obsd.: 994.2901.

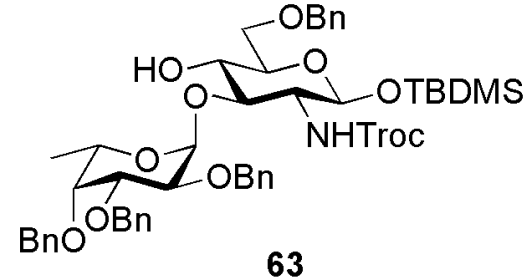

6-O-Benzyl-3- $O$-(2,3,4-tri- $O$-benzyl- $\alpha-L-f u c o p y r a n o s y l)-1-O$ tert-butyldimethylsilyl-2-deoxy-2-(2,2,2-

\section{trichloroethoxycarbonylamido)- $\beta$-D-glucopyranose}

(63).

Disaccharide 62 (0.028 g, $0.029 \mathrm{mmol})$ was coevaporated three times with toluene and dissolved in DCM $(0.50 \mathrm{~mL})$ under a

nitrogen atmosphere. After cooling the solution to $0^{\circ} \mathrm{C}$, triethylsilane $(0.028 \mathrm{~mL}, 0.173 \mathrm{mmol}, 6.0$ equiv.) was added and the reaction mixture was stirred for 10 mins. TFAA (0.004 mL, 0.029 mmol, 1.0 equiv.) was added and the reaction mixture was stirred for another $10 \mathrm{mins}$. TFA $(0.011 \mathrm{~mL}, 0.144 \mathrm{mmol}, 5.0$ equiv.) was then added and the reaction mixture was stirred for a further $3.5 \mathrm{~h}$. The reaction mixture was allowed to warm to room temperature and stirred for a further $2 \mathrm{~h}$. After TLC-analysis (ethyl acetate/light petroleum ether, 1/4, v/v) showed completion of the reaction, the reaction mixture was neutralised with sat. aq. $\mathrm{NaHCO}_{3}$ and the aqueous layer extracted twice with DCM. The organic layers were combined, washed with brine, dried $\left(\mathrm{MgSO}_{4}\right)$, filtered and concentrated in vacuo. Purification by column chromatography (ethyl acetate/light petroleum ether, $1 / 15 \rightarrow 1 / 7, \mathrm{v} / \mathrm{v})$ yielded 63 as a colourless oil $(0.017 \mathrm{~g}, 60 \%) . R_{f} 0.25$ (ethyl acetate/light petroleum ether, $1 / 4, \mathrm{v} / \mathrm{v}) ;[\alpha]_{\mathrm{D}}{ }^{24}=-24.2^{\circ}\left(c 1.0, \mathrm{CHCl}_{3}\right)$; IR (thin film): 3394, 3089, 3064, 3031, 2927, 2856, 1733, 1524, 1497, 1454, 1362, 1306, 1252, 1134, 1082, 1028, 945, 912, 839, 783, 735, $697 \mathrm{~cm}^{-1} ;{ }^{1} \mathrm{H}-\mathrm{NMR}\left(500 \mathrm{MHz}, \mathrm{CDCl}_{3}\right): \delta 7.40-7.28(\mathrm{~m}, 20 \mathrm{H}, \mathrm{CH}$ arom. $), 5.20\left(\mathrm{~d}, 1 \mathrm{H}, J_{2, \mathrm{NH}}=6.1 \mathrm{~Hz}\right.$, $\mathrm{NH}), 4.95\left(\mathrm{~d}, 1 \mathrm{H}, J_{\mathrm{a}, \mathrm{b}}=11.7 \mathrm{~Hz}, \mathrm{CH}-\mathrm{a} 4^{\prime}-O-\mathrm{Bn}\right), 4.94\left(\mathrm{~d}, 1 \mathrm{H}, J_{1^{\prime}, 2^{\prime}}=3.7 \mathrm{~Hz}, \mathrm{H}-1^{\prime}\right), 4.86\left(\mathrm{~d}, 1 \mathrm{H}, J_{1,2}=5.8\right.$ $\mathrm{Hz}, \mathrm{H}-1), 4.82\left(\mathrm{~d}, 1 \mathrm{H}, J_{\mathrm{a}, \mathrm{b}}=11.7 \mathrm{~Hz}, \mathrm{CH}-\mathrm{a} 3^{\prime}-O-\mathrm{Bn}\right), 4.80\left(\mathrm{~d}, 1 \mathrm{H}, J_{\mathrm{a}, \mathrm{b}}=11.7 \mathrm{~Hz}, \mathrm{CH}-\mathrm{a} 2^{\prime}-O-\mathrm{Bn}\right), 4.73(\mathrm{~d}$, $\left.1 \mathrm{H}, J_{\mathrm{a}, \mathrm{b}}=11.8 \mathrm{~Hz}, \mathrm{CH}-\mathrm{b} 3^{\prime}-O-\mathrm{Bn}\right), 4.68\left(\mathrm{~d}, 1 \mathrm{H}, J_{\mathrm{a}, \mathrm{b}}=11.9 \mathrm{~Hz}, \mathrm{CH}-\mathrm{b} 2^{\prime}-O-\mathrm{Bn}\right), 4.63-4.58$ (m, 4H, CH-b 4'$O-\mathrm{Bn}, \mathrm{CH}-\mathrm{a}$ 6-O-Bn, CH-b 6-O-Bn, and $\mathrm{CH}-\mathrm{a}$ Troc), 4.47 (d, $1 \mathrm{H}, J_{\mathrm{a}, \mathrm{b}}=7.5 \mathrm{~Hz}, \mathrm{CH}-\mathrm{b}$ Troc), 4.10 (q, $1 \mathrm{H}$, $\left.J_{5^{\prime}, 6^{\prime}}=6.1 \mathrm{~Hz}, \mathrm{H}-5^{\prime}\right), 4.06\left(\mathrm{dd}, 1 \mathrm{H}, J_{1^{\prime}, 2^{\prime}}=3.6, J_{2^{\prime}, 3^{\prime}}=10.2 \mathrm{~Hz}, \mathrm{H}-2^{\prime}\right), 3.94\left(\mathrm{dd}, 1 \mathrm{H}, J_{2^{\prime}, 3^{\prime}}=10.3, J_{3^{\prime}, 4^{\prime}}=2.4 \mathrm{~Hz}\right.$, H-3'), $3.78\left(\mathrm{dd}, 1 \mathrm{H}, J_{5,6 \mathrm{a}}=1.5, J_{6 \mathrm{a}, 6 \mathrm{~b}}=10.7 \mathrm{~Hz}, \mathrm{H}-6 \mathrm{a}\right), 3.69-3.66$ (m, 3H, H-3, H-6b, and H-4'), 3.50-3.44 $\left(\mathrm{m}, 2 \mathrm{H}, \mathrm{H}-4\right.$ and H-5), $3.27\left(\mathrm{q}, 1 \mathrm{H}, J_{1,2}=J_{2,3}=J_{2, \mathrm{NH}}=7.6 \mathrm{~Hz}, \mathrm{H}-2\right), 1.14\left(\mathrm{~d}, 3 \mathrm{H}, J_{5^{\prime}, 6^{\prime}}=6.6 \mathrm{~Hz}, \mathrm{CH}_{3} \mathrm{H}-6^{\prime}\right)$, 
0.88 (s, 9H, $3 \times \mathrm{CH}_{3} \mathrm{Si}^{\mathrm{t}} \mathrm{Bu}$ ), 0.13 (s, 3H, $\mathrm{CH}_{3} \mathrm{SiMe}_{\mathrm{a}}$ ), 0.09 (s, 3H, $\mathrm{CH}_{3} \mathrm{SiMe}_{\mathrm{b}}$ ); ${ }^{13} \mathrm{C}-\mathrm{NMR}(125 \mathrm{MHz}$, $\left.\mathrm{CDCl}_{3}\right): \delta 154.1\left(\mathrm{C}=\mathrm{O}\right.$ Troc), $138.7\left(\mathrm{C}_{\mathrm{i}}\right.$ arom. 3'-O-Bn), $138.5\left(\mathrm{C}_{\mathrm{i}}\right.$ arom. 6-O-Bn), $138.4\left(\mathrm{C}_{\mathrm{i}}\right.$ arom. 4'-O$\mathrm{Bn}$ ), 138.4 ( $\mathrm{C}_{\mathrm{i}}$ arom. 2'-O-Bn), 128.7 ( $\mathrm{CH}$ arom.), 128.6 (CH arom.), 128.5 (CH arom.), 128.4 (CH arom.), 128.4 ( $\mathrm{CH}$ arom.), 128.3 (CH arom.), 128.1 ( $\mathrm{CH}$ arom.), 127.9 (CH arom.), 127.8 ( $\mathrm{CH}$ arom.), 127.6 (CH arom.), 127.6 (CH arom.), 127.6 ( $\mathrm{CH}$ arom.), 98.3 (C-1'), 95.7 (C-1), $95.5\left(\mathrm{CCl}_{3}\right.$ Troc), 88.1 (C-3), 73.3 (C3'), 77.5 (C-4'), 76.1 (C-2'), $75.1\left(\mathrm{CH}_{2} 4^{\prime}-O-\mathrm{Bn}\right), 74.9$ (C-5), 74.6 ( $\mathrm{CH}_{2}$ Troc), 74.0 (2'-O-Bn), $73.6\left(\mathrm{CH}_{2}\right.$ 6$O$-Bn), 73.3 (3'-O-Bn), $70.1(\mathrm{C}-4), 69.8(\mathrm{C}-6), 68.1\left(\mathrm{C}-5^{\prime}\right), 58.6(\mathrm{C}-2), 25.8\left(\mathrm{CH}_{3} \mathrm{Si}^{\mathrm{t}} \mathrm{Bu}\right), 18.1\left(\mathrm{C}_{\mathrm{q}} \mathrm{Si}^{\mathrm{t}} \mathrm{Bu}\right)$, $16.8\left(\mathrm{C}-66^{\prime}\right),-4.0\left(\mathrm{CH}_{3} \mathrm{SiMe}_{\mathrm{a}}\right),-5.2\left(\mathrm{CH}_{3} \mathrm{SiMe}_{\mathrm{b}}\right)$; HRMS(ESI) $\mathrm{m} / \mathrm{z}$ calcld. for $\left[\mathrm{C}_{49} \mathrm{H}_{62} \mathrm{O}_{11} \mathrm{NCl}_{3} \mathrm{Si}+\mathrm{Na}\right]^{+}$: 996.3055, obsd.: 996.3055 .

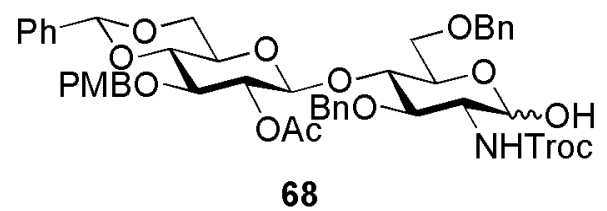

\section{3-O-(2-O-Acetyl-4,6-O-benzylidene-3-O-para-} methoxybenzyl- $\beta$-D-glucopyranosyl)-3,6-di- $O$-benzyl-2deoxy-2-(2,2,2-trichloroethoxycarbonylamido)- $\alpha / \beta-D-$ glucopyranose (68). Disaccharide $64(0.107 \mathrm{~g}, 0.101 \mathrm{mmol})$ was dissolved in THF $(1.0 \mathrm{~mL})$ in a plastic container. After addition of HF.pyridine $(0.126 \mathrm{~mL}, 70 \%$ in pyridine, $0.889 \mathrm{mmol}, 8.8 \mathrm{eq}$.), the reaction mixture was left for $26 \mathrm{~h}$. After TLC-analysis (ethyl acetate/light petroleum ether, $1 / 2, \mathrm{v} / \mathrm{v}$ ) showed complete deprotection, the reaction mixture was neutralised with sat. aq. $\mathrm{NaHCO}_{3}$, extracted with ethyl acetate three times, the combined organic layers were then washed with brine, dried $\left(\mathrm{MgSO}_{4}\right)$, filtered and concentrated in vacuo. Purification by column chromatography (ethyl acetate/light petroleum ether, $1 / 10 \rightarrow 1 / 2$, v/v) yielded lactol 68 as a white amorphous solid upon concentration in vacuo $(0.0880 \mathrm{~g}, 92 \%) . R_{f} 0.09$ and 0.06 (ethyl acetate/light petroleum ether, $1 / 2, \mathrm{v} / \mathrm{v}) ;[\alpha]_{\mathrm{D}}{ }^{21}=+10.3^{\circ}\left(c 1.0, \mathrm{CHCl}_{3}\right)$; IR (thin film): 3421, 3322, 3065, 3033, 2934, $2873,1743,1612,1513,1454,1368,1313,1231,1172,1090,1059,1029,967,909,817,731,697,669 \mathrm{~cm}^{-}$

${ }^{1}$; (NMR data given for the $\alpha$-anomer only, as only trace amounts of the $\beta$-anomer were detectable) ${ }^{1} \mathrm{H}$ NMR (500 MHz, $\left.\mathrm{CDCl}_{3}\right): \delta$ 7.49-7.47 (m, 2H, CH arom.), 7.42-7.25 (m, 13H, CH arom.), 7.19 (d, 2H, $J_{\mathrm{a}, \mathrm{b}}$ $=8.6 \mathrm{~Hz}, \mathrm{CH}$ arom. PMB), $6.86\left(\mathrm{~d}, 2 \mathrm{H}, J_{\mathrm{a}, \mathrm{b}}=8.8 \mathrm{~Hz}, \mathrm{CH}\right.$ arom. PMB), $5.46(\mathrm{~s}, 1 \mathrm{H}, \mathrm{CHPh}), 5.25(\mathrm{~d}, 1 \mathrm{H}$, $\left.J_{1,2}=3.1 \mathrm{~Hz}, \mathrm{H}-1\right), 5.07\left(\mathrm{~d}, 1 \mathrm{H}, J_{2^{\prime}, \mathrm{NH}}=9.5 \mathrm{~Hz}, \mathrm{NH}\right), 4.93\left(\mathrm{t}, 1 \mathrm{H}, J_{1^{\prime}, 2^{\prime}}=J_{2^{\prime}, 3^{\prime}}=8.7 \mathrm{~Hz}, \mathrm{H}-2^{\prime}\right), 4.88(\mathrm{~d}, 1 \mathrm{H}$, $\left.J_{\mathrm{a}, \mathrm{b}}=11.5 \mathrm{~Hz}, \mathrm{CH}-\mathrm{a} 3-O-\mathrm{Bn}\right), 4.77\left(\mathrm{~d}, 1 \mathrm{H}, J_{\mathrm{a}, \mathrm{b}}=11.7 \mathrm{~Hz}, \mathrm{CH}-\mathrm{a} 3^{\prime}-O \mathrm{PMB}\right), 4.73\left(\mathrm{~d}, 1 \mathrm{H}, J_{\mathrm{a}, \mathrm{b}}=12.0 \mathrm{~Hz}, \mathrm{CH}-\right.$ a Troc), $4.72\left(\mathrm{~d}, 1 \mathrm{H}, J_{\mathrm{a}, \mathrm{b}}=12.2 \mathrm{~Hz}, \mathrm{CH}-\mathrm{a} 6-O-\mathrm{Bn}\right), 4.61\left(\mathrm{~d}, 2 \mathrm{H}, J_{\mathrm{a}, \mathrm{b}}=11.7 \mathrm{~Hz}, \mathrm{CH}-\mathrm{b} 3-O-\mathrm{Bn}\right.$ and CH-b Troc), 4.57 (d, $1 \mathrm{H}, J_{\mathrm{a}, \mathrm{b}}=11.8 \mathrm{~Hz}$, CH-b 3'-O-PMB), 4.44 (d, $\left.1 \mathrm{H}, J_{1^{\prime}, 2^{\prime}}=8.5 \mathrm{~Hz}, \mathrm{H}-1^{\prime}\right), 4.42\left(\mathrm{~d}, 1 \mathrm{H}, J_{\mathrm{a}, \mathrm{b}}=\right.$ $12.2 \mathrm{~Hz}, \mathrm{CH}-\mathrm{b} 6-O-\mathrm{Bn}), 4.15$ (dd, $\left.1 \mathrm{H}, J_{6 \mathrm{a}^{\prime}, 6 \mathrm{~b}^{\prime}}=10.5 \mathrm{~Hz}, J_{5^{\prime}, 6 \mathrm{a}^{\prime}}=4.9 \mathrm{~Hz}, \mathrm{H}-6 \mathrm{a}^{\prime}\right), 3.95-3.86$ (m, 3H, H-2, H-4, and H-5), 3.80 (s, 3H, OMe PMB), 3.72 (dd, 1H, $\left.J_{6 \mathrm{a}, 6 \mathrm{~b}}=10.4 \mathrm{~Hz}, J_{5,6 \mathrm{a}}=3.1 \mathrm{~Hz}, \mathrm{H}-6 \mathrm{a}\right), 3.64-3.58$ (m, 3H, H-3, H-6b, and H-4'), 3.51 (t, $\left.1 \mathrm{H}, J_{2^{\prime}, 3^{\prime}}=J_{3^{\prime}, 4^{\prime}}=9.0 \mathrm{~Hz}, \mathrm{H}-3^{\prime}\right), 3.38$ (t, 1H, $\left.J_{5^{\prime}, 6 \mathrm{~b}^{\prime}}=J_{6 \mathrm{a}^{\prime}, 6 \mathrm{~b}^{\prime}}=10.2 \mathrm{~Hz}, \mathrm{H}-6 \mathrm{~b}^{\prime}\right)$, $3.20(\mathrm{bs}, 1 \mathrm{H}, \mathrm{OH}), 3.16\left(\mathrm{td}, 1 \mathrm{H}, J_{4^{\prime}, 5^{\prime}}=J_{5^{\prime}, 6 \mathrm{~b}^{\prime}}=9.6 \mathrm{~Hz}, J_{5^{\prime}, 6 \mathrm{a}^{\prime}}=4.9 \mathrm{~Hz}, \mathrm{H}-5^{\prime}\right), 1.94(\mathrm{~s}, 3 \mathrm{H}, \mathrm{OMe} \mathrm{Ac}) ;{ }^{13} \mathrm{C}-$ NMR (125MHz, $\left.\mathrm{CDCl}_{3}\right): \delta 169.4$ (C=O Ac), 159.4 (C-p arom. PMB), 154.5 (C=O Troc), $138.7\left(\mathrm{C}_{\mathrm{i}}\right.$ arom. 3-O-Bn), 137.7 ( $\mathrm{C}_{\mathrm{i}}$ arom. 6-O-Bn), 137.4 ( $\mathrm{C}_{\mathrm{i}}$ arom. $\left.\mathrm{PhCH}\right), 130.5$ ( $\mathrm{CH}$ arom.), 129.6 (CH arom.), 129.2 (CH arom.), 128.7 ( $\mathrm{CH}$ arom.), 128.4 ( $\mathrm{CH}$ arom.), 128.3 (CH arom.), 128.2 ( $\mathrm{CH}$ arom.), 127.8 (CH arom.), 
127.6 (CH arom.), 126.1 (CH arom.), 113.8 (C arom. PMB), 101.3 ( $\mathrm{PhCH}), 100.9$ (C-1'), $95.5\left(\mathrm{CCl}_{3}\right.$ Troc), 91.9 (C-1), 81.8 (C-4'), 78.0 (C-3'), $77.4(\mathrm{C}-4), 77.0(\mathrm{C}-3), 74.7\left(\mathrm{CH}_{2} 3-O-\mathrm{Bn}\right.$ and $\mathrm{CH}_{2}$ Troc), $73.8\left(\mathrm{CH}_{2} 6-\right.$ $O$-Bn), 73.8 ( $\mathrm{CH}_{2}$ 3'-O-PMB), 73.5 (C-2'), 70.8 (C-5), 68.6 (C-6'), 67.8 (C-6), 66.1 (C-5'), 55.4 (OMe PMB), 54.9 (C-2), $21.0\left(\mathrm{CH}_{3} 2^{\prime}-\mathrm{O}\right.$-Ac); HRMS(ESI) $\mathrm{m} / \mathrm{z}$ calcld. for $\left[\mathrm{C}_{46} \mathrm{H}_{50} \mathrm{O}_{14} \mathrm{NCl}_{3}+\mathrm{Na}\right]^{+}: 968.2195$, obsd.: 968.2195 .

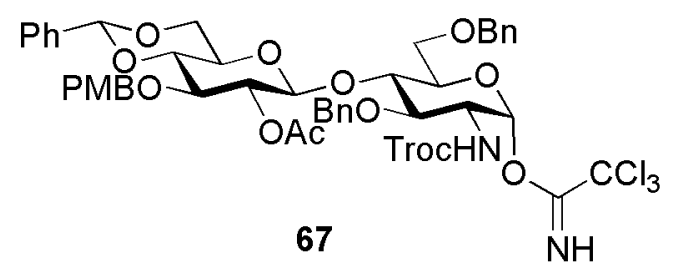

3-O-(2-O-Acetyl-4,6-O-benzylidene-3-O-paramethoxybenzyl- $\beta$-D-glucopyranosyl)-3,6-di- $O$-benzyl2-deoxy-2-(2,2,2-trichloroethoxycarbonylamido)- $\alpha$-Dglucopyranosyl trichloroacetimidate (67). Lactol 68 $(0.070 \mathrm{~g}, 0.074 \mathrm{mmol})$ was coevaporated three times with toluene and dissolved in DCM $(1.0 \mathrm{~mL})$ under a nitrogen atmosphere. Trichloroacetonitrile $(0.074 \mathrm{~mL}$, $0.735 \mathrm{mmol}, 10.0$ equiv.) and caesium carbonate (cat.) were added and the reaction was stirred for $15 \mathrm{~h}$. After TLC-analysis (ethyl acetate/light petroleum ether, 1/1, v/v) showed completion of the reaction, the reaction mixture was filtered and purified directly by column chromatography (ethyl acetate/light petroleum ether, $1 / 10 \rightarrow 1 / 2, \mathrm{v} / \mathrm{v})$ to yield 67 as a colourless oil upon concentration in vacuo $(0.040 \mathrm{~g}$, $50 \%$ ). The imidate was stored in the freezer until it was used. $R_{f} 0.56$ (ethyl acetate/light petroleum ether, 1/1, v/v); IR (thin film): 3420, 3340, 3088, 3064, 3033, 2955, 2925, 2871, 1729, 1673, 1612, 1587, 1513, 1455, 1368, 1302, 1277, 1230, 1173, 1091, 1061, 1029, 1010, 969, 916, 822, 797, 737, $698 \mathrm{~cm}^{-1}$; ${ }^{1} \mathrm{H}-\mathrm{NMR}$ (500 MHz, $\mathrm{CDCl}_{3}$ ): $\delta 8.63$ (s, 1H, NH), 7.50-7.48 (m, 2H, CH arom.), 7.43-7.27 (m, 13H, CH arom.), 7.19 $\left(\mathrm{d}, 2 \mathrm{H}, J_{\mathrm{a}, \mathrm{b}}=8.8 \mathrm{~Hz}, \mathrm{CH}\right.$ arom. PMB), $6.86\left(\mathrm{~d}, 2 \mathrm{H}, J_{\mathrm{a}, \mathrm{b}}=8.8 \mathrm{~Hz}, \mathrm{CH}\right.$ arom. PMB), $6.34\left(\mathrm{~d}, 1 \mathrm{H}, J_{1,2}=3.5\right.$ $\mathrm{Hz}, \mathrm{H}-1), 5.50\left(\mathrm{~d}, 1 \mathrm{H}, J_{2^{\prime}, \mathrm{NH}}=8.8 \mathrm{~Hz}, \mathrm{NH}\right), 5.49(\mathrm{~s}, 1 \mathrm{H}, \mathrm{CHPh}), 4.95\left(\mathrm{dd}, 1 \mathrm{H}, J_{1^{\prime}, 2^{\prime}}=8.3, J_{2^{\prime}, 3^{\prime}}=9.3 \mathrm{~Hz}, \mathrm{H}-\right.$ 2'), $4.89\left(\mathrm{~d}, 1 \mathrm{H}, J_{\mathrm{a}, \mathrm{b}}=11.7 \mathrm{~Hz}, \mathrm{CH}-\mathrm{a} 3-O-\mathrm{Bn}\right), 4.78\left(\mathrm{~d}, 1 \mathrm{H}, J_{\mathrm{a}, \mathrm{b}}=11.7 \mathrm{~Hz}, \mathrm{CH}-\mathrm{a} 3^{\prime}-O \mathrm{PMB}\right), 4.74(\mathrm{~d}, 1 \mathrm{H}$, $\left.J_{\mathrm{a}, \mathrm{b}}=11.9 \mathrm{~Hz}, \mathrm{CH}-\mathrm{a} 6-O-\mathrm{Bn}\right), 4.70\left(\mathrm{~d}, 1 \mathrm{H}, J_{\mathrm{a}, \mathrm{b}}=12.0 \mathrm{~Hz}, \mathrm{CH}-\mathrm{a}\right.$ Troc $), 4.66\left(\mathrm{~d}, 1 \mathrm{H}, J_{\mathrm{a}, \mathrm{b}}=12.0 \mathrm{~Hz}, \mathrm{CH}-\mathrm{b} 3-\right.$ $O$-Bn), $4.63\left(\mathrm{~d}, 1 \mathrm{H}, J_{\mathrm{a}, \mathrm{b}}=12.0 \mathrm{~Hz}, \mathrm{CH}-\mathrm{b}\right.$ Troc), $4.58\left(\mathrm{~d}, 1 \mathrm{H}, J_{\mathrm{a}, \mathrm{b}}=11.5 \mathrm{~Hz}, \mathrm{CH}-\mathrm{b} 3^{\prime}-O-\mathrm{PMB}\right), 4.51(\mathrm{~d}, 1 \mathrm{H}$, $\left.J_{1^{\prime}, 2^{\prime}}=8.0 \mathrm{~Hz}, \mathrm{H}-1^{\prime}\right), 4.41\left(\mathrm{~d}, 1 \mathrm{H}, J_{\mathrm{a}, \mathrm{b}}=11.9 \mathrm{~Hz}, \mathrm{CH}-\mathrm{b} 6-O-\mathrm{Bn}\right), 4.23\left(\mathrm{dd}, 1 \mathrm{H}, J_{6 \mathrm{a}^{\prime}, 6 \mathrm{~b}^{\prime}}=10.7 \mathrm{~Hz}, J_{5^{\prime}, 6 \mathrm{a}^{\prime}}=5.1\right.$ $\left.\mathrm{Hz}, \mathrm{H}-6 \mathrm{a}^{\prime}\right), 4.14\left(\mathrm{t}, 1 \mathrm{H}, J_{3,4}=J_{4,5}=9.5 \mathrm{~Hz}, \mathrm{H}-4\right), 4.05\left(\mathrm{dd}, 1 \mathrm{H}, J_{1,2}=3.7, J_{2,3}=8.5 \mathrm{~Hz}, \mathrm{H}-2\right), 3.80(\mathrm{~s}, 3 \mathrm{H}$, OMe PMB), 3.79-3.71 (m, 2H, H-5 and H-6a), 3.68-3.61 (m, 3H, H-3, H-6b, and H-4'), 3.51 (t, $1 \mathrm{H}, J_{2^{\prime}, 3^{\prime}}=$ $\left.J_{3^{\prime}, 4^{\prime}}=9.3 \mathrm{~Hz}, \mathrm{H}-3^{\prime}\right), 3.48\left(\mathrm{t}, 1 \mathrm{H}, J_{5^{\prime}, 6 \mathrm{~b}^{\prime}}=J_{6 \mathrm{a}^{\prime}, 6 \mathrm{~b}^{\prime}}=9.3 \mathrm{~Hz}, \mathrm{H}-6 \mathrm{~b}^{\prime}\right), 3.20\left(\mathrm{td}, 1 \mathrm{H}, J_{4^{\prime}, 5^{\prime}}=J_{5^{\prime}, 6 \mathrm{~b}^{\prime}}=9.8 \mathrm{~Hz}, J_{5^{\prime}, 6 \mathrm{a}}=\right.$ $\left.4.9 \mathrm{~Hz}, \mathrm{H}-5^{\prime}\right), 1.91$ (s, 3H, OMe Ac); ${ }^{13} \mathrm{C}-\mathrm{NMR}\left(125 \mathrm{MHz}, \mathrm{CDCl}_{3}\right): \delta 169.2(\mathrm{C}=\mathrm{O} \mathrm{Ac}), 160.7(\mathrm{C}=\mathrm{N}), 159.4$ (C-p arom. $\mathrm{PMB}$ ), 154.2 (C=O Troc), $138.2\left(\mathrm{C}_{\mathrm{i}}\right.$ arom. 3-O-Bn), $137.7\left(\mathrm{C}_{\mathrm{i}}\right.$ arom. 6-O-Bn), $137.3\left(\mathrm{C}_{\mathrm{i}}\right.$ arom. $\mathrm{PhCH}$ ), 130.4 ( $\mathrm{CH}$ arom.), 129.6 ( $\mathrm{CH}$ arom.), 129.6 (CH arom.), 129.2 ( $\mathrm{CH}$ arom.), 128.7 (CH arom.), 128.7 (CH arom.), 128.5 (CH arom.), 128.4 (CH arom.), 128.4 (CH arom.), 128.0 (CH arom.), 127.8 (CH arom.), 126.1 (CH arom.), 113.9 (C arom. PMB), 101.3 (PhCH), 100.9 (C-1'), 95.6 (C-1), 95.5 ( $\mathrm{CCl}_{3}$ Troc), $91.9\left(\mathrm{CCl}_{3}\right.$ imidate), 81.8 (C-4'), 78.1 (C-3'), 76.5 (C-4), 75.4 (C-3), $74.7\left(\mathrm{CH}_{2}\right.$ Troc), $74.6\left(\mathrm{CH}_{2} 3-O-\mathrm{Bn}\right)$, $73.8\left(\mathrm{CH}_{2}\right.$ 6-O-Bn and $\mathrm{CH}_{2}$ 3'-O-PMB), 73.6 (C-5), 73.4 (C-2'), 68.7 (C-6'), 67.0 (C-6), 66.1 (C-5'), 55.4 (OMe PMB), $54.3(\mathrm{C}-2), 21.0\left(\mathrm{CH}_{3} 2^{\prime}-O-\mathrm{Ac}\right)$. 


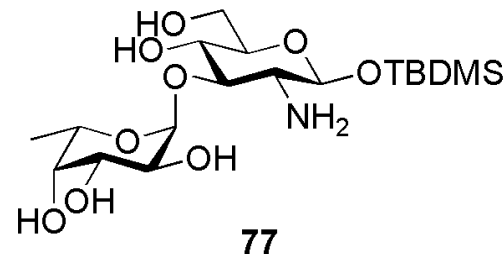

purged with $\mathrm{H}_{2}$ gas twice and placed under a $\mathrm{H}_{2}$ atmosphere (4 bar) and stirred for $2.5 \mathrm{~h}$. After TLCanalysis (DCM/methanol/ethanol/ $\mathrm{NH}_{3}$ (30\% aq.), 55/2/2/1, v/v/v/v) showed completion of the reaction, the reaction mixture was diluted with ethanol, filtered over celite and concentrated in vacuo. Crude disaccharide 77 was used without further purification. $R_{f} 0.03$ (DCM/methanol/ethanol/ $\mathrm{NH}_{3}$ (30\% aq.), $55 / 2 / 2 / 1, \mathrm{v} / \mathrm{v} / \mathrm{v} / \mathrm{v})$.

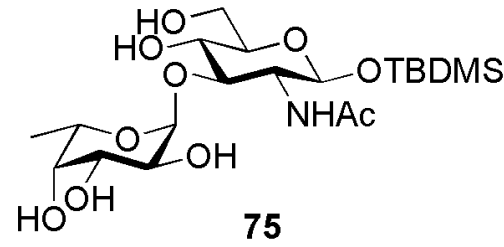

2-Acetamido-1-O-tert-butyldimethylsilyl-2-deoxy-3-O-( $\alpha$-Lfucopyranosyl)- $\beta$-D-glucopyranose (75). To a solution of crude disaccharide $77(0.0123 \mathrm{~g})$ in methanol $(1 \mathrm{~mL})$ was added acetic anhydride $(0.060 \mathrm{~mL}, 0.63 \mathrm{mmol}, 36$ equiv. $)$ and $\mathrm{K}_{2} \mathrm{CO}_{3}(0.017 \mathrm{~g}$, $0.12 \mathrm{mmol}, 6.9$ equiv.). The reaction mixture was stirred for 4 days, added after 24 h. After TLC-analysis (DCM/methanol/ethanol/NH $\mathrm{NH}_{3}(30 \%$ aq.), 15/2/2/1, v/v/v/v) showed completion of the reaction, the reaction mixture was concentrated in vacuo. Purification by column chromatography (DCM/methanol/ethanol/ $\mathrm{NH}_{3}$ (30\% aq.), 55/2/2/1 $\rightarrow$ 5/2/2/1, v/v/v/v) yielded disaccharide 75 as a colourless oil (0.0073 g, 61\% 2 steps). $R_{f} 0.17$ (DCM/methanol/ethanol/ $\mathrm{NH}_{3}(30 \%$ aq.), 15/2/2/1, v/v/v/v); ${ }^{1} \mathrm{H}-\mathrm{NMR}\left(500 \mathrm{MHz}, \mathrm{CDOD}_{3}\right): \delta 4.95\left(\mathrm{~d}, 1 \mathrm{H}, J_{1^{\prime}, 2^{\prime}}=4.2 \mathrm{~Hz}, \mathrm{H}-1^{\prime}\right), 4.71\left(\mathrm{~d}, 1 \mathrm{H}, J_{1,2}=8.0 \mathrm{~Hz}, \mathrm{H}-1\right)$, $4.31\left(\mathrm{q}, 1 \mathrm{H}, J_{5^{\prime}, 6^{\prime}}=6.6 \mathrm{~Hz}, \mathrm{H}-5^{\prime}\right), 3.89\left(\mathrm{dd}, 1 \mathrm{H}, J_{5,6 \mathrm{a}}=1.9, J_{6 \mathrm{a}, 6 \mathrm{~b}}=12.4 \mathrm{~Hz}, \mathrm{H}-6 \mathrm{a}\right), 3.81\left(\mathrm{dd}, 1 \mathrm{H}, J_{2^{\prime}, 3^{\prime}}=10.2\right.$, $\left.J_{3^{\prime}, 4^{\prime}}=3.1 \mathrm{~Hz}, \mathrm{H}-3^{\prime}\right), 3.78-3.74\left(\mathrm{~m}, 2 \mathrm{H}, \mathrm{H}-2\right.$ and H-4'), $3.71\left(\mathrm{dd}, 1 \mathrm{H}, J_{5,6 \mathrm{~b}}=5.6, J_{6 \mathrm{a}, 6 \mathrm{~b}}=12.4 \mathrm{~Hz}, \mathrm{H}-6 \mathrm{~b}\right)$, $3.66\left(\mathrm{dd}, 1 \mathrm{H}, J_{1^{\prime}, 2^{\prime}}=4.2, J_{2^{\prime}, 3^{\prime}}=10.2 \mathrm{~Hz}, \mathrm{H}-2^{\prime}\right), 3.59\left(\mathrm{t}, 1 \mathrm{H}, J_{2,3}=J_{3,4}=10.3 \mathrm{~Hz}, \mathrm{H}-3\right), 3.49\left(\mathrm{t}, 1 \mathrm{H}, J_{3,4}=J_{4,5}\right.$ $=10.0 \mathrm{~Hz}, \mathrm{H}-4), 3.44\left(\mathrm{ddd}, 1 \mathrm{H}, J_{5,6 \mathrm{a}}=10.1, J_{5,6 \mathrm{a}}=1.8, J_{5,6 \mathrm{~b}}=5.3 \mathrm{~Hz}, \mathrm{H}-5\right), 2.00\left(\mathrm{~s}, 3 \mathrm{H}, \mathrm{CH}_{3} N-\mathrm{Ac}\right), 1.13$ $\left(\mathrm{d}, 3 \mathrm{H}, J_{5^{\prime}, 6^{\prime}}=6.6 \mathrm{~Hz}, \mathrm{H}-6^{\prime}\right), 0.86\left(\mathrm{~s}, 9 \mathrm{H}, 3 \times \mathrm{CH}_{3} \mathrm{Si}{ }^{\mathrm{t} B u}\right), 0.12$ (s, 3H, $\mathrm{CH}_{3} \mathrm{SiMe}_{\mathrm{a}}$ ), $0.11\left(\mathrm{~s}, 3 \mathrm{H}, \mathrm{CH}_{3} \mathrm{SiMe}_{\mathrm{b}}\right.$ ); HRMS(ESI) $m / z$ calcld. for $\left[\mathrm{C}_{20} \mathrm{H}_{39} \mathrm{O}_{10} \mathrm{NSi}+\mathrm{Na}\right]^{+}:$504.2241, obsd.: 504.2236.

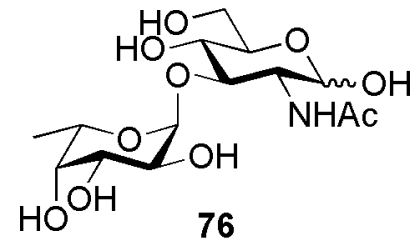

2-Acetamido-2-deoxy-3-O-( $\alpha$-L-fucopyranosyl)- $\alpha / \beta$-D-glucopyranose (76). Disaccharide $75(0.007 \mathrm{~g}, \quad 0.015 \mathrm{mmol})$ was dissolved in $\mathrm{AcOH} / \mathrm{H}_{2} \mathrm{O} / \mathrm{THF}(0.50 \mathrm{~mL}, 3: 1: 1)$ and stirred at room temperature for $72 \mathrm{~h}$ and then at $65^{\circ} \mathrm{C}$ for a further 6 hours. TLC-analysis (DCM/methanol/ethanol/ $\mathrm{NH}_{3} \quad(30 \%$ aq.), 15/2/2/1, v/v/v/v) showed formation of product (reaction was incomplete). The reaction mixture was concentrated in vacuo. ${ }^{1} \mathrm{H}$ NMR analysis of the crude reaction mixture showed the presence of product as well as L-fucose and starting 
material. HRMS(ESI) confirmed that product was present in the crude reaction mixture. $R_{f} 0.01$ (DCM/methanol/ethanol/ $\mathrm{NH}_{3}$ (30\% aq.), 15/2/2/1, v/v/v/v); $\mathrm{HRMS(ESI)} \mathrm{m} / z$ calcld. for $\left[\mathrm{C}_{14} \mathrm{H}_{25} \mathrm{O}_{10} \mathrm{~N}+\mathrm{Na}\right]^{+}$: 390.1376, obsd.: 390.1378 .

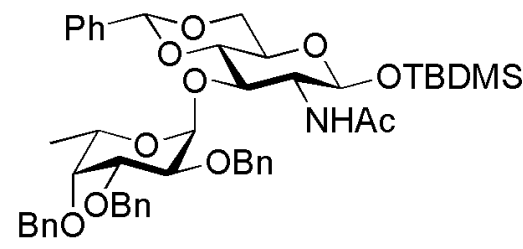

78

\section{2-Acetamido-3-O-(2,3,4-tri- $O$-benzyl- $\alpha$-L-fucopyranosyl)-4,6- $O$ -} benzylidene-1- $O$-tert-butyldimethylsilyl-2-deoxy- $\beta$-Dglucopyranose (78). Azide $21(0.0334 \mathrm{~g}, 0.0715 \mathrm{mmol})$ was coevaporated three times with toluene and dissolved in dissolved in THF $(0.20 \mathrm{~mL})$ under a nitrogen atmosphere. After cooling the

solution to $0^{\circ} \mathrm{C}$, trimethyl phosphine $(0.203 \mathrm{~mL}, 1 \mathrm{M}$ in THF, $0.203 \mathrm{mmol}, 5$ equiv.) was added and the reaction mixture was stirred for $15 \mathrm{mins}$ at $0^{\circ} \mathrm{C}$ and a further $3 \mathrm{~h}$ at room temperature. After TLC-analysis (ethyl acetate/light petroleum ether, 1/2, v/v) showed complete reduction of the azide, sodium hydroxide $(0.30 \mathrm{~mL}, 1 \mathrm{M}(\mathrm{aq}))$ was added and the reaction mixture was stirred for another 20 mins. The reaction mixture was diluted with ethyl acetate and washed with sat. aq. $\mathrm{NaHCO}_{3}$, dried $\left(\mathrm{MgSO}_{4}\right)$, filtered and concentrated in vacuo. The resulting crude amine was then dissolved in acetic acid anhydride/pyridine $(0.75 \mathrm{~mL}, 1 / 2, \mathrm{v} / \mathrm{v})$ and stirred for $72 \mathrm{~h}$. After TLC-analysis (ethyl acetate/light petroleum ether, 1/2, v/v) showed complete acetylation of the amine the reaction mixture was concentrated in vacuo, dissolved in ethyl acetate washed with sat. aq. $\mathrm{NaHCO}_{3}, \mathrm{H}_{2} \mathrm{O}$, and brine, dried $\left(\mathrm{MgSO}_{4}\right)$, filtered and concentrated in vacuo. Purification by column chromatography (ethyl acetate/light petroleum ether, 1/17 $\rightarrow 1 / 3$, v/v) yielded acetamide 78 as a colourless oil $(0.0267 \mathrm{~g}, 79 \%) . R_{f} 0.33$ (ethyl acetate/light petroleum ether, 1/2, $\mathrm{v} / \mathrm{v}) ;[\alpha]_{\mathrm{D}}{ }^{20}=-86.2^{\circ}\left(c 1.0, \mathrm{CHCl}_{3}\right)$; IR (thin film): 3281, 3088, 3064, 3032, 2930, 2858, 1660, 1543, 1497, 1455, 1389, 1371, 1311, 1253, 1208, 1182, 1097, 1028, 1004, 913, 840, 783, 736, $698 \mathrm{~cm}^{-1}$; ${ }^{1} \mathrm{H}-\mathrm{NMR}$ (500 $\mathrm{MHz}, \mathrm{CDCl}_{3}$ ): $\delta 7.48-7.24\left(\mathrm{~m}, 20 \mathrm{H}, \mathrm{CH}\right.$ arom.), $5.51\left(\mathrm{~d}, 1 \mathrm{H}, J_{2, \mathrm{NH}}=8.5 \mathrm{~Hz}, \mathrm{NH}\right), 5.50(\mathrm{~s}, 1 \mathrm{H}, \mathrm{PhCH}), 5.08$ $\left(\mathrm{d}, 1 \mathrm{H}, J_{1^{\prime}, 2^{\prime}}=3.7 \mathrm{~Hz}, \mathrm{H}-1^{\prime}\right), 5.01\left(\mathrm{~d}, 1 \mathrm{H}, J_{1,2}=7.8 \mathrm{~Hz}, \mathrm{H}-1\right), 4.93\left(\mathrm{~d}, 1 \mathrm{H}, J_{\mathrm{a}, \mathrm{b}}=11.5 \mathrm{~Hz}, \mathrm{CH}-\mathrm{a} 2^{\prime}-O-\mathrm{Bn}\right)$, $4.92\left(\mathrm{~d}, 1 \mathrm{H}, J_{\mathrm{a}, \mathrm{b}}=11.4 \mathrm{~Hz}, \mathrm{CH}-\mathrm{a} 4^{\prime}-O-\mathrm{Bn}\right), 4.75$ (s, 2H, CH-a 3'-O-Bn and CH-b 3'- $\left.O-\mathrm{Bn}\right), 4.64\left(\mathrm{~d}, 1 \mathrm{H}, J_{\mathrm{a}, \mathrm{b}}\right.$ $\left.=11.7 \mathrm{~Hz}, \mathrm{CH}-\mathrm{b} 2^{\prime}-O-\mathrm{Bn}\right), 4.59\left(\mathrm{~d}, 1 \mathrm{H}, J_{\mathrm{a}, \mathrm{b}}=11.7 \mathrm{~Hz}, \mathrm{CH}-\mathrm{b} 4^{\prime}-O-\mathrm{Bn}\right), 4.28\left(\mathrm{dd}, 1 \mathrm{H}, J_{5,6 \mathrm{a}}=4.9, J_{6 \mathrm{a}, 6 \mathrm{~b}}=\right.$ $10.5 \mathrm{~Hz}, \mathrm{H}-6 \mathrm{a}), 4.26$ (t, $\left.1 \mathrm{H}, J_{2,3}=J_{3,4}=9.6 \mathrm{~Hz}, \mathrm{H}-3\right), 4.09-4.05\left(\mathrm{~m}, 2 \mathrm{H}, \mathrm{H}-2^{\prime}\right.$ and H-5'), $3.94\left(\mathrm{dd}, 1 \mathrm{H}, J_{2^{\prime}, 3^{\prime}}=\right.$ $\left.10.0, J_{3^{\prime}, 4^{\prime}}=2.4 \mathrm{~Hz}, \mathrm{H}-3^{\prime}\right), 3.76\left(\mathrm{t}, 1 \mathrm{H}, J_{5,6 \mathrm{~b}}=J_{6 \mathrm{a}, 6 \mathrm{~b}}=10.3 \mathrm{~Hz}, \mathrm{H}-6 \mathrm{~b}\right), 3.61\left(\mathrm{~s}, 1 \mathrm{H}, \mathrm{H}-4^{\prime}\right), 3.59\left(\mathrm{t}, 1 \mathrm{H}, J_{3,4}=\right.$ $\left.J_{4,5}=9.0 \mathrm{~Hz}, \mathrm{H}-4\right), 3.49\left(\mathrm{td}, 1 \mathrm{H}, J_{4,5}=J_{5,6 \mathrm{~b}}=9.5, J_{5,6 \mathrm{a}}=4.8 \mathrm{~Hz}, \mathrm{H}-5\right), 3.35\left(\mathrm{q}, 1 \mathrm{H}, J_{1,2}=J_{2,3}=J_{2, \mathrm{NH}}=7.8\right.$ $\mathrm{Hz}, \mathrm{H}-2), 1.60$ (s, $3 \mathrm{H}, \mathrm{CH}_{3} N-\mathrm{Ac}$ ), 0.86 (s, 9H, $3 \times \mathrm{CH}_{3} \mathrm{Si}^{\mathrm{t}} \mathrm{Bu}$ ), 0.85 (d, 3H, $\left.J_{5^{\prime}, 6^{\prime}}=6.1 \mathrm{~Hz}, \mathrm{CH}_{3} \mathrm{H}-6^{\prime}\right), 0.07$ (s, 3H, $\mathrm{CH}_{3} \mathrm{SiMe}_{\mathrm{a}}$ ), 0.03 (s, 3H, $\mathrm{CH}_{3} \mathrm{SiMe}_{\mathrm{b}}$ ); ${ }^{13} \mathrm{C}-\mathrm{NMR}\left(125 \mathrm{MHz}, \mathrm{CDCl}_{3}\right.$ ): $\delta 170.3$ (C=O N-Ac), 139.1 $\left(\mathrm{C}_{\mathrm{i}}\right.$ arom. 2'-O-Bn), 138.9 ( $\mathrm{C}_{\mathrm{i}}$ arom. 3'-O-Bn), $138.8\left(\mathrm{C}_{\mathrm{i}}\right.$ arom. 4'-O-Bn), $137.6\left(\mathrm{C}_{\mathrm{i}}\right.$ arom. $\left.\mathrm{PhCH}\right), 129.1$ (CH arom.), 128.8 (CH arom.), 128.6 (CH arom.), 128.6 (CH arom.), 128.4 (CH arom.), 128.3 (CH arom.), 128.1 ( $\mathrm{CH}$ arom.), 127.9 (CH arom.), 127.7 ( $\mathrm{CH}$ arom.), 127.5 ( $\mathrm{CH}$ arom.), 126.4 ( $\mathrm{CH}$ arom.), 101.7 ( $\mathrm{PhCH}$ ), 98.4 (C-1'), 95.9 (C-1), 81.2 (C-4), 79.9 (C-3'), 77.9 (C-4'), 77.5 (C-2'), 75.3 (C-3), 75.1 ( $^{2}$ 4' $_{2}-$ $O$-Bn), $74.1\left(\mathrm{CH}_{2} 2^{\prime}-O-\mathrm{Bn}\right), 72.8\left(\mathrm{CH}_{2} 3^{\prime}-O-\mathrm{Bn}\right), 69.1$ (C-6), $67.1\left(\mathrm{C}-5^{\prime}\right), 66.4(\mathrm{C}-5), 60.5(\mathrm{C}-2), 25.7\left(\mathrm{CH}_{3}\right.$ 
$\left.\mathrm{Si} i^{t} \mathrm{Bu}\right), 23.4\left(\mathrm{CH}_{3} \mathrm{~N}-\mathrm{Ac}\right), 18.0\left(\mathrm{C}_{\mathrm{q}} \mathrm{Si}{ }^{\mathrm{t}} \mathrm{Bu}\right), 16.5\left(\mathrm{C}-6^{\prime}\right),-4.1\left(\mathrm{CH}_{3} \mathrm{SiMe}_{\mathrm{a}}\right),-5.2\left(\mathrm{CH}_{3} \mathrm{SiMe}_{\mathrm{b}}\right) ; \operatorname{HRMS}(\mathrm{ESI})$ $\mathrm{m} / z$ calcld. for $\left[\mathrm{C}_{48} \mathrm{H}_{61} \mathrm{O}_{10} \mathrm{NSi}+\mathrm{Na}\right]^{+}:$862.3962, obsd.: 862.3967.

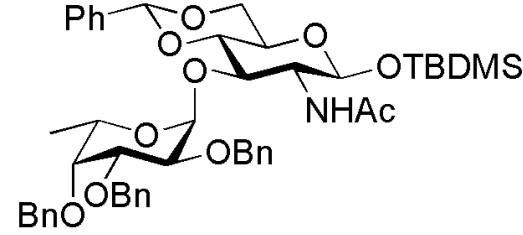

78
2-Acetamido-3- $O$-(2,3,4-tri- $O$-benzyl- $\alpha$-L-fucopyranosyl)-4,6- $O$ benzylidene-1-O-tert-butyldimethylsilyl-2-deoxy- $\beta$-Dglucopyranose (78). Azide 21 (0.0287 g, $0.0348 \mathrm{mmol})$ was coevaporated three times with toluene and dissolved in $\mathrm{AcOH}: \mathrm{Ac}_{2} \mathrm{O}: \mathrm{THF}(0.70 \mathrm{~mL}, 3: 2: 1)$ under a nitrogen atmosphere.

After cooling the solution to $0^{\circ} \mathrm{C}$, activated $\mathrm{Zn}(0.0068 \mathrm{~g}, 0.105 \mathrm{mmol}, 3.0$ equiv.) was added and the reaction mixture was stirred for $24 \mathrm{~h}$, with additional activated $\mathrm{Zn}(0.0070 \mathrm{~g}, 0.107 \mathrm{mmol}, 3.0$ equiv.) added after $7 \mathrm{~h}$. After, TLC-analysis (ethyl acetate/light petroleum ether, 1/2, v/v) showed completion of the reaction, the reaction mixture was filtered through celite and washed with ethyl actate and concentrated in vacuo. Purification by column chromatography (ethyl acetate/light petroleum ether, $1 / 10 \rightarrow 1 / 3, \mathrm{v} / \mathrm{v}$ ) yielded acetamide $21(0.0076 \mathrm{~g}, 26 \%)$ as colourless oil. Characterisation is as above.

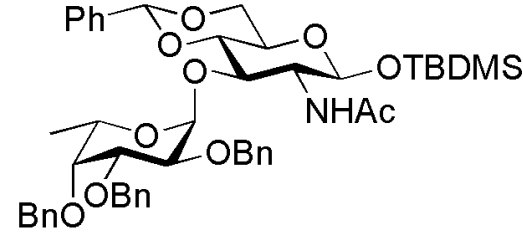

78
2-Acetamido-3-O-(2,3,4-tri- $O$-benzyl- $\alpha$-L-fucopyranosyl)-4,6- $O$ benzylidene-1-O-tert-butyldimethylsilyl-2-deoxy- $\beta$-Dglucopyranose (78). Azide $21(0.0260 \mathrm{~g}, 0.0316 \mathrm{mmol})$ was coevaporated three times with toluene and dissolved in dissolved in pyridine $(0.17 \mathrm{~mL})$ under a nitrogen atmosphere. After cooling the

solution to $0^{\circ} \mathrm{C}$, thioacetic acid $(0.17 \mathrm{~mL})$ was slowly added and the reaction mixture was stirred for 30 mins at $0^{\circ} \mathrm{C}$ and a further $24 \mathrm{~h}$ at room temperature. After TLC-analysis (ethyl acetate/light petroleum ether, $1 / 2, v / v)$ showed completion of the reaction, the reaction mixture was concentrated in vacuo. Purification by column chromatography (ethyl acetate/light petroleum ether, $1 / 10 \rightarrow 1 / 3$, v/v) yielded amino acetate 78 as a colourless oil $(0.0164 \mathrm{~g}, 62 \%)$. Characterisation is as above.

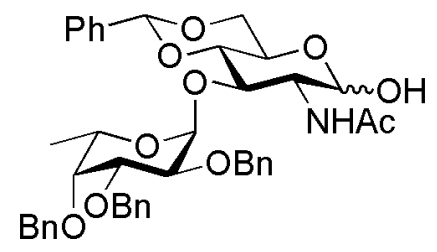

86

2-Acetamido-3-O-(2,3,4-tri- $O$-benzyl- $\alpha$-L-fucopyranosyl)-4,6- $O$ benzylidene-2-deoxy- $\alpha / \beta$-D-glucopyranose (86). Disaccharide 78 (0.148 $\mathrm{g}, 0.176 \mathrm{mmol})$ was dissolved in THF $(2.2 \mathrm{~mL})$ in a plastic container. After addition of HF.pyridine $(0.220 \mathrm{~mL}, 70 \%$ in pyridine, $1.552 \mathrm{mmol}$, 8.8 eq.), the reaction mixture was left for $18 \mathrm{~h}$. After TLC-analysis (ethyl acetate/light petroleum ether, 1/1, v/v) showed complete deprotection, the reaction mixture was neutralised with sat. aq. $\mathrm{NaHCO}_{3}$, extracted with ethyl acetate, washed with brine, dried $\left(\mathrm{MgSO}_{4}\right)$, filtered and concentrated in vacuo. Purification by column chromatography (ethyl acetate/light petroleum ether, 1/2 $\rightarrow$ 2/1, v/v) yielded lactol 86 as a white amorphous solid upon concentration in vacuo $(0.125 \mathrm{~g}, 98 \%)$. $R_{f} 0.08$ (ethyl acetate/light petroleum ether, $1 / 1, \mathrm{v} / \mathrm{v}) ;[\alpha]_{\mathrm{D}}{ }^{20}=-110.4^{\circ}\left(c 1.0, \mathrm{CHCl}_{3}\right.$ ); IR (thin film): 3310, 3089, 3064, 3032, 2978, 2933, 2870, 1653, 1542, 1497, 1454, 1372, 1313, 1276, 1210, 1173, 1088, 1048, 1027, 
998, 909, 813, 729, $696 \mathrm{~cm}^{-1} ;{ }^{1} \mathrm{H}-\mathrm{NMR}\left(500 \mathrm{MHz}, \mathrm{CDCl}_{3}\right): \delta$ 7.56-7.53 (m, $2 \mathrm{H}-\alpha$ and $2 \mathrm{H}-\beta, \mathrm{CH}$ arom.), $7.45\left(\mathrm{~d}, 1 \mathrm{H}, J_{2, \mathrm{NH}}=3.4 \mathrm{~Hz}, \mathrm{NH}-\beta\right), 7.43-7.27\left(\mathrm{~m}, 18 \mathrm{H}-\alpha\right.$ and $18 \mathrm{H}-\beta, \mathrm{CH}$ arom.), $6.78\left(\mathrm{~d}, 1 \mathrm{H}, J_{2, \mathrm{NH}}=5.9\right.$ $\mathrm{Hz}, \mathrm{NH}-\alpha), 5.60$ (s, 1H, PhCH- $\beta$ ), 5.59 (s, 1H, PhCH- $\alpha$ ), 5.51 (d, 1H, $\left.J_{1,2}=3.4 \mathrm{~Hz}, \mathrm{H}-1-\alpha\right), 5.23$ (d, 1H, $\left.J_{1^{\prime}, 2^{\prime}}=3.4 \mathrm{~Hz}, \mathrm{H}-1^{\prime}-\alpha\right), 5.19\left(\mathrm{~d}, 1 \mathrm{H}, J_{1^{\prime}, 2^{\prime}}=3.5 \mathrm{~Hz}, \mathrm{H}-1^{\prime}-\beta\right), 4.98\left(\mathrm{~d}, 1 \mathrm{H}, J_{\mathrm{a}, \mathrm{b}}=11.5 \mathrm{~Hz}, \mathrm{CH}-\mathrm{a} 4^{\prime}-\beta-O-\mathrm{Bn}\right)$, $4.92\left(\mathrm{~d}, 1 \mathrm{H}, J_{\mathrm{a}, \mathrm{b}}=11.5 \mathrm{~Hz}, \mathrm{CH}-\mathrm{a} 4^{\prime}-\alpha-O-\mathrm{Bn}\right), 4.89\left(\mathrm{~d}, 1 \mathrm{H}, J_{\mathrm{a}, \mathrm{b}}=10.0 \mathrm{~Hz}, \mathrm{CH}-\mathrm{a} 2^{\prime}-\beta-O-\mathrm{Bn}\right), 4.79\left(\mathrm{~d}, 1 \mathrm{H}, J_{\mathrm{a}, \mathrm{b}}\right.$ $\left.=11.7 \mathrm{~Hz}, \mathrm{CH}-\mathrm{a} 3^{\prime}-\beta-O-\mathrm{Bn}\right), 4.78\left(\mathrm{~d}, 1 \mathrm{H}, J_{\mathrm{a}, \mathrm{b}}=10.3 \mathrm{~Hz}, \mathrm{CH}-\mathrm{a} 2^{\prime}-\alpha-O-\mathrm{Bn}\right), 4.74\left(\mathrm{~d}, 1 \mathrm{H}, J_{\mathrm{a}, \mathrm{b}}=12.0 \mathrm{~Hz}, \mathrm{CH}-\right.$ a $\left.3^{\prime}-\alpha-O-\mathrm{Bn}\right), 4.73\left(\mathrm{~d}, 1 \mathrm{H}, J_{\mathrm{a}, \mathrm{b}}=10.2 \mathrm{~Hz}, \mathrm{CH}-\mathrm{b} 2^{\prime}-\alpha-O-\mathrm{Bn}\right), 4.71\left(\mathrm{~d}, 2 \mathrm{H}, J_{\mathrm{a}, \mathrm{b}}=10.8 \mathrm{~Hz}, \mathrm{CH}-\mathrm{b} 3^{\prime}-\alpha-O-\mathrm{Bn}\right.$ and CH-b 2'- $\beta-O-\mathrm{Bn}), 4.68\left(\mathrm{~d}, 1 \mathrm{H}, J_{\mathrm{a}, \mathrm{b}}=11.7 \mathrm{~Hz}, \mathrm{CH}-\mathrm{b} 4^{\prime}-\beta-O-\mathrm{Bn}\right), 4.66\left(\mathrm{~d}, 1 \mathrm{H}, J_{\mathrm{a}, \mathrm{b}}=11.5 \mathrm{~Hz}, \mathrm{CH}-\mathrm{b} 4^{\prime}-\alpha-\right.$ $O$-Bn), $4.65\left(\mathrm{~d}, 2 \mathrm{H}, J_{\mathrm{a}, \mathrm{b}}=11.5 \mathrm{~Hz}\right.$, CH-b 3'- $\left.\beta-O-\mathrm{Bn}\right), 4.51\left(\mathrm{~d}, 1 \mathrm{H}, J_{1,2}=8.0 \mathrm{~Hz}, \mathrm{H}-1-\beta\right), 4.40\left(\mathrm{dd}, 1 \mathrm{H}, J_{5,6 \mathrm{a}}=\right.$ $\left.4.8, J_{6 \mathrm{a}, 6 \mathrm{~b}}=10.5 \mathrm{~Hz}, \mathrm{H}-6 \mathrm{a}-\beta\right), 4.28\left(\mathrm{dd}, 1 \mathrm{H}, J_{5,6 \mathrm{a}}=4.9, J_{6 \mathrm{a}, 6 \mathrm{~b}}=10.3 \mathrm{~Hz}, \mathrm{H}-6 \mathrm{a}-\alpha\right), 4.16\left(\mathrm{t}, 1 \mathrm{H}, J_{2,3}=J_{3,4}=9.7\right.$ $\mathrm{Hz}, \mathrm{H}-3-\alpha), 4.16\left(\mathrm{dd}, 1 \mathrm{H}, J_{1^{\prime}, 2^{\prime}}=3.6, J_{2^{\prime}, 3^{\prime}}=10.0 \mathrm{~Hz}, \mathrm{H}-2^{\prime}-\beta\right), 4.11-4.03$ (m, 4H, H-5- $\alpha, \mathrm{H}-2^{\prime}-\alpha, \mathrm{H}-5^{\prime}-\alpha$ and $\left.\mathrm{H}-5^{\prime}-\beta\right), 3.96\left(\mathrm{ddd}, 1 \mathrm{H}, J_{1,2}=3.7, J_{2,3}=9.8, J_{2, \mathrm{NH}}=5.9 \mathrm{~Hz}, \mathrm{H}-2-\alpha\right), 3.92\left(\mathrm{dd}, 1 \mathrm{H}, J_{2^{\prime}, 3^{\prime}}=10.0, J_{3^{\prime}, 4^{\prime}}=2.4 \mathrm{~Hz}\right.$, H-3'- $\alpha$ ), $3.89\left(\mathrm{dd}, 1 \mathrm{H}, J_{2^{\prime}, 3^{\prime}}=10.0, J_{3^{\prime}, 4^{\prime}}=2.4 \mathrm{~Hz}, \mathrm{H}-3^{\prime}-\beta\right), 3.84\left(\mathrm{t}, 1 \mathrm{H}, J_{5,6 \mathrm{~b}}=J_{6 \mathrm{a}, 6 \mathrm{~b}}=10.2 \mathrm{~Hz}, \mathrm{H}-6 \mathrm{~b}-\beta\right), 3.77-$ 3.73 (m, 3H, H-6b- $\alpha$, H-3- $\beta$, and H-4'- $\beta$ ), 3.70 (td, $\left.1 \mathrm{H}, J_{1,2}=J_{2,3}=7.8, J_{2, \mathrm{NH}}=3.6 \mathrm{~Hz}, \mathrm{H}-2-\beta\right), 3.67$ (s, 1H, H-4'- $\alpha$ ), 3.64 (t, $\left.1 \mathrm{H}, J_{3,4}=J_{4,5}=9.3 \mathrm{~Hz}, \mathrm{H}-4-\alpha\right), 3.63\left(\mathrm{t}, 1 \mathrm{H}, J_{3,4}=J_{4,5}=9.8 \mathrm{~Hz}, \mathrm{H}-4-\beta\right), 3.42\left(\mathrm{td}, 1 \mathrm{H}, J_{4,5}=\right.$ $\left.J_{5,6 \mathrm{~b}}=9.7, J_{5,6 \mathrm{a}}=4.8 \mathrm{~Hz}, \mathrm{H}-5-\beta\right), 1.55$ (s, 3H, $\left.\mathrm{CH}_{3} N-\mathrm{Ac}-\beta\right), 1.51$ (s, 3H, $\left.\mathrm{CH}_{3} N-\mathrm{Ac}-\alpha\right), 1.15$ (d, 3H, $J_{5^{\prime}, 6^{\prime}}=$ $\left.6.3 \mathrm{~Hz}, \mathrm{CH}_{3} \mathrm{H}-6^{\prime}-\beta\right), 1.06\left(\mathrm{~d}, 3 \mathrm{H}, J_{5^{\prime}, 6^{\prime}}=6.4 \mathrm{~Hz}, \mathrm{CH}_{3} \mathrm{H}-6^{\prime}-\alpha\right) ;{ }^{13} \mathrm{C}-\mathrm{NMR}\left(125 \mathrm{MHz}, \mathrm{CDCl}_{3}\right): \delta 175.4(\mathrm{C}=\mathrm{O}$ $N$-Ac- $\alpha), 170.9(\mathrm{C}=\mathrm{O} N-\mathrm{Ac}-\beta), 138.5\left(\mathrm{C}_{\mathrm{i}}\right.$ arom. 3'- $\left.\alpha-O-\mathrm{Bn}\right), 138.4\left(\mathrm{C}_{\mathrm{i}}\right.$ arom. 4'- $\left.\alpha-O-\mathrm{Bn}\right), 138.2\left(\mathrm{C}_{\mathrm{i}}\right.$ arom. 4'$\beta-O-\mathrm{Bn}), 138.1$ ( $\mathrm{C}_{\mathrm{i}}$ arom. 3'- $\left.\beta-O-\mathrm{Bn}\right), 137.5\left(\mathrm{C}_{\mathrm{i}}\right.$ arom. 2'- $\left.\alpha-O-\mathrm{Bn}\right), 137.3\left(\mathrm{C}_{\mathrm{i}}\right.$ arom. $\left.\mathrm{PhCH}-\alpha\right), 137.1\left(\mathrm{C}_{\mathrm{i}}\right.$ arom. PhCH- $\beta$ ), 136.9 ( $\mathrm{C}_{\mathrm{i}}$ arom. 2'- $\left.\beta-O-\mathrm{Bn}\right), 129.0$ (CH arom.), 129.0 ( $\mathrm{CH}$ arom.), 128.9 ( $\mathrm{CH}$ arom.), 128.9 (CH arom.), 128.7 ( $\mathrm{CH}$ arom.), 128.7 (CH arom.), 128.5 (CH arom.), 128.5 (CH arom.), 128.4 (CH arom.), 128.3 (CH arom.), 128.3 ( $\mathrm{CH}$ arom.), 128.2 (CH arom.), 128.2 ( $\mathrm{CH}$ arom.), 128.0 ( $\mathrm{CH}$ arom.), 127.9 (CH arom.), 127.7 ( $\mathrm{CH}$ arom.), 127.7 ( $\mathrm{CH}$ arom.), 127.3 ( $\mathrm{CH}$ arom.), 127.3 ( $\mathrm{CH}$ arom.), 125.9 ( $\mathrm{CH}$ arom.), 125.8 (CH arom.), 100.9 (PhCH- $\alpha$ ), 100.7 (PhCH- $\beta$ ), 100.2 (C-1'- $\beta$ ), 99.4 (C-1'- $\alpha$ ), 99.2 (C-1- $\beta$ ), 91.8 (C-1-

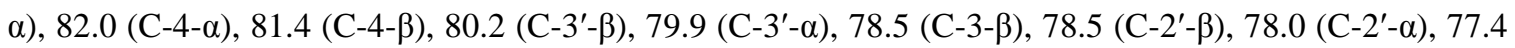
(C-4'- $\alpha), 76.9$ (C-4'- $\beta), 75.6\left(\mathrm{CH}_{2} 2^{\prime}-\beta-O-\mathrm{Bn}\right), 75.1\left(\mathrm{CH}_{2} 4^{\prime}-\beta-O-\mathrm{Bn}\right.$ and $\left.\mathrm{C}-3-\alpha\right), 75.0\left(\mathrm{CH}_{2} 4^{\prime}-\alpha-O-\mathrm{Bn}\right)$, $74.6\left(\mathrm{CH}_{2} 2^{\prime}-\alpha-O-\mathrm{Bn}\right), 73.1\left(\mathrm{CH}_{2} 3^{\prime}-\alpha-O-\mathrm{Bn}\right), 72.8\left(\mathrm{CH}_{2} 3^{\prime}-\beta-O-\mathrm{Bn}\right), 70.0(\mathrm{C}-6-\alpha), 68.5(\mathrm{C}-6-\beta), 68.2\left(\mathrm{C}-5^{\prime}-\right.$ $\beta), 67.7\left(\mathrm{C}-5^{\prime}-\alpha\right), 66.5(\mathrm{C}-5-\beta), 63.0(\mathrm{C}-5-\alpha), 58.4(\mathrm{C}-2-\beta), 54.9(\mathrm{C}-2-\alpha), 22.5\left(\mathrm{CH}_{3} \mathrm{~N}-\mathrm{Ac}-\alpha\right), 22.0\left(\mathrm{CH}_{3} \mathrm{~N}-\right.$ Ac- $\beta$ ), 16.9 (C-6'- $\beta$ ), 16.7 (C-6'- $\alpha$ ); HRMS(ESI) $m / z$ calcld. for $\left[\mathrm{C}_{42} \mathrm{H}_{47} \mathrm{O}_{10} \mathrm{~N}+\mathrm{Na}\right]^{+}:$748.3098, obsd.: 748.3099 .

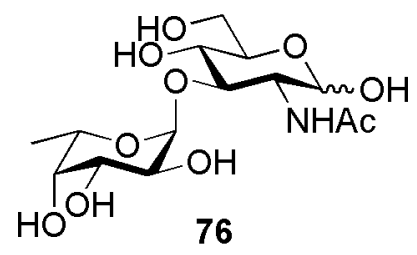

\section{2-Acetamido-2-deoxy-3- $O$-( $\alpha$-L-fucopyranosyl)- $\alpha / \beta$-D-glucopyranose}

(76). To a solution of disaccharide $78(0.0264 \mathrm{~g}, 0.0364 \mathrm{mmol})$ in EtOH/ethyl acetate $(1.2 \mathrm{~mL}, 1 / 1, \mathrm{v} / \mathrm{v})$ was added $\mathrm{Pd}(\mathrm{OH})_{2} / \mathrm{C}(0.0100 \mathrm{~g}$, $20 \%$ catalyst, $0.0138 \mathrm{mmol}, 0.4$ equiv.). The reaction mixture was placed under a $\mathrm{H}_{2}$ atmosphere and stirred for $7.5 \mathrm{~h}$. After TLC-analysis (30\%

$\mathrm{MeOH}$ in ethyl acetate) showed completion of the reaction, the reaction mixture was filtered over celite, 
washed though with $\mathrm{MeOH}$ and $\mathrm{H}_{2} \mathrm{O}$, and concentrated in vacuo. Purification by $\mathrm{C}_{18}$ reverse phase column chromatography ( $\mathrm{MeOH}$ in $\mathrm{H}_{2} \mathrm{O}, 0 \% \rightarrow 2 \%$, v/v) yielded fully deprotected disaccharide $\mathbf{7 6}$ as a white amorphous solid after lyophilisation $(0.0123 \mathrm{~g}, 92 \%) . R_{f} 0.24(30 \% \mathrm{MeOH}$ in ethyl acetate, $\mathrm{v} / \mathrm{v}) ;[\alpha]_{\mathrm{D}}{ }^{18}=-$ $91.5^{\circ}$ (c 1.0, $\mathrm{H}_{2} \mathrm{O}$ ); IR (thin film): 3286, 2980, 2922, 1635, 1555, 1429, 1377, 1315, 1257, 1165, 1123, $1071,1018,996,916,813,788,732,695 \mathrm{~cm}^{-1}$; ${ }^{1} \mathrm{H}-\mathrm{NMR}\left(600 \mathrm{MHz}, \mathrm{D}_{2} \mathrm{O}\right): \delta 5.09\left(\mathrm{~d}, 1 \mathrm{H}, J_{1,2}=3.5 \mathrm{~Hz}, \mathrm{H}-\right.$ $1-\alpha), 4.97\left(\mathrm{~d}, 1 \mathrm{H}, J_{1^{\prime}, 2^{\prime}}=4.1 \mathrm{~Hz}, \mathrm{H}-1^{\prime}-\alpha\right), 4.93\left(\mathrm{~d}, 1 \mathrm{H}, J_{1^{\prime}, 2^{\prime}}=4.2 \mathrm{~Hz}, \mathrm{H}-1^{\prime}-\beta\right), 4.67$ (d, 1H, $J_{1,2}=8.4 \mathrm{~Hz}, \mathrm{H}-1-$ $\beta), 4.30\left(\mathrm{q}, 1 \mathrm{H}, J_{5^{\prime}, 6^{\prime}}=6.5 \mathrm{~Hz}, \mathrm{H}-5^{\prime}-\alpha\right), 4.28\left(\mathrm{q}, 1 \mathrm{H}, J_{5^{\prime}, 6^{\prime}}=6.4 \mathrm{~Hz}, \mathrm{H}-5^{\prime}-\beta\right), 4.00\left(\mathrm{dd}, 1 \mathrm{H}, J_{1,2}=3.5, J_{2,3}=\right.$ $10.5, \mathrm{H}-2-\alpha), 3.87\left(\mathrm{dd}, 1 \mathrm{H}, J_{5,6 \mathrm{a}}=2.0, J_{6 \mathrm{a}, 6 \mathrm{~b}}=12.1 \mathrm{~Hz}, \mathrm{H}-6 \mathrm{a}-\beta\right), 3.85\left(\mathrm{ddd}, 1 \mathrm{H}, J_{4,5}=9.5, J_{5,6 \mathrm{a}}=2.2, J_{5,6 \mathrm{~b}}=\right.$ $5.2 \mathrm{~Hz}, \mathrm{H}-5-\alpha), 3.81\left(\mathrm{dd}, 1 \mathrm{H}, J_{5,6 \mathrm{a}}=2.2, J_{6 \mathrm{a}, 6 \mathrm{~b}}=12.4 \mathrm{~Hz}, \mathrm{H}-6 \mathrm{a}-\alpha\right), 3.79-3.73\left(\mathrm{~m}, 7 \mathrm{H}, \mathrm{H}-3-\alpha, \mathrm{H}-6 \mathrm{~b}-\alpha, \mathrm{H}-3^{\prime}-\right.$ $\alpha, \mathrm{H}-4^{\prime}-\alpha, \mathrm{H}-2-\beta, \mathrm{H}-3^{\prime}-\beta$, and H-4'- $\beta$ ), 3.70 (dd, $\left.1 \mathrm{H}, J_{5,6 \mathrm{~b}}=5.7, J_{6 \mathrm{a}, 6 \mathrm{~b}}=12.3 \mathrm{~Hz}, \mathrm{H}-6 \mathrm{~b}-\beta\right), 3.66-3.63(\mathrm{~m}, 2 \mathrm{H}$, H-2' $-\alpha$ and H-2'- $\beta$ ), 3.58 (dd, $\left.1 \mathrm{H}, J_{2,3}=8.7, J_{3,4}=10.0 \mathrm{~Hz}, \mathrm{H}-3-\beta\right), 3.52\left(\mathrm{t}, 1 \mathrm{H}, J_{3,4}=J_{4,5}=9.4 \mathrm{~Hz}, \mathrm{H}-4-\alpha\right)$, $3.48\left(\mathrm{t}, 1 \mathrm{H}, J_{3,4}=J_{4,5}=8.6 \mathrm{~Hz}, \mathrm{H}-4-\beta\right), 3.43\left(\mathrm{ddd}, 1 \mathrm{H}, J_{4,5}=9.8, J_{5,6 \mathrm{a}}=2.0 J_{5,6 \mathrm{~b}}=5.6 \mathrm{~Hz}, \mathrm{H}-5-\beta\right), 1.98(\mathrm{~s}$, $6 \mathrm{H}, \mathrm{CH}_{3} N-\mathrm{Ac}-\alpha$ and $\mathrm{CH}_{3} N$-Ac- $\beta$ ), $1.12\left(\mathrm{~d}, 3 \mathrm{H}, J_{5^{\prime}, 6^{\prime}}=6.6 \mathrm{~Hz}, \mathrm{CH}_{3} \mathrm{H}-6^{\prime}-\alpha\right), 1.11\left(\mathrm{~d}, 3 \mathrm{H}, J_{5^{\prime}, 6^{\prime}}=6.4 \mathrm{~Hz}\right.$, $\left.\mathrm{CH}_{3} \mathrm{H}-66^{\prime}-\beta\right) ;{ }^{13} \mathrm{C}-\mathrm{NMR}\left(150 \mathrm{MHz}, \mathrm{D}_{2} \mathrm{O}\right): \delta 174.6(\mathrm{C}=\mathrm{O} N-\mathrm{Ac}-\beta), 174.4(\mathrm{C}=\mathrm{O} N-\mathrm{Ac}-\alpha), 99.9\left(\mathrm{C}-1^{\prime}-\beta\right), 99.6$ (C-1'- $\alpha$ ), 94.6 (C-1- $\beta$ ), 90.9 (C-1- $\alpha$ ), 80.4 (C-3- $\beta$ ), 77.8 (C-3- $\alpha$ ), 75.8 (C-5- $\beta$ ), 71.7 (C-4'- $\alpha$ ), 71.7 (C-4'- $\beta$ ),

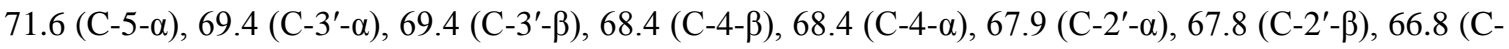
5'- $\beta$ ), 66.7 (C-5'- $\alpha), 60.6(\mathrm{C}-6-\beta), 60.4(\mathrm{C}-6-\alpha), 56.2(\mathrm{C}-2-\beta), 53.5(\mathrm{C}-2-\alpha), 22.1\left(\mathrm{CH}_{3} N-\mathrm{Ac}-\beta\right), 21.8\left(\mathrm{CH}_{3}\right.$ $N$-Ac- $\alpha$ ), 15.1 (C-6'- $\alpha), 15.0\left(\mathrm{C}-6^{\prime}-\beta\right)$; HRMS(ESI) $m / z$ calcld. for $\left[\mathrm{C}_{14} \mathrm{H}_{25} \mathrm{O}_{10} \mathrm{~N}+\mathrm{Na}\right]^{+}: 390.1376$, obsd.: 390.1376.

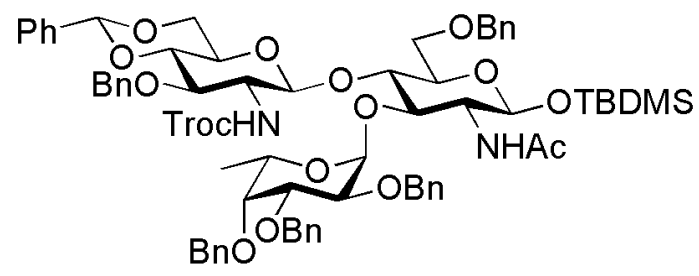

87
2-Acetamido-6- $O$-benzyl-3- $O$-(2,3,4-tri- $O$-benzyl- $\alpha$ L-fucopyranosyl)-4- $O$-[3-O-benzyl-4,6-Obenzylidene-2-deoxy-2-(2,2,2trichloroethoxycarbonylamido)- $\beta$-Dglucopyranosyl]-1-O-tert-butyldimethylsilyl-2-

$0.0646 \mathrm{mmol})$ was coevaporated three times with toluene and dissolved in dissolved in pyridine $(0.35 \mathrm{~mL})$ under a nitrogen atmosphere. After cooling the solution to $0^{\circ} \mathrm{C}$, thioacetic acid $(0.35 \mathrm{~mL})$ was slowly added and the reaction mixture was stirred for 10 mins at $0^{\circ} \mathrm{C}$ and a further $25 \mathrm{~h}$ at room temperature. After TLCanalysis (ethyl acetate/light petroleum ether, 1/2, v/v) showed completion of the reaction, the reaction mixture was concentrated in vacuo. Purification by column chromatography (ethyl acetate/light petroleum ether, $1 / 10 \rightarrow 1 / 2$, v/v) yielded acetamide 87 as a colourless oil $(0.0628 \mathrm{~g}, 71 \%) . R_{f} 0.31$ (ethyl acetate/light petroleum ether, 1/2, v/v); IR (thin film): 3327, 3223, 3063, 3031, 2929, 2859, 1720, 1650, 1544, 1497, 1454, 1376, 1311, 1290, 1258, 1219, 1173, 1097, 1066, 1034, 1028, 1005, 949, 922, 902, 837, 821, 772, 734, $696 \mathrm{~cm}^{-1}$; ${ }^{1} \mathrm{H}-\mathrm{NMR}\left(500 \mathrm{MHz}, \mathrm{CDCl}_{3}\right.$ ): $\delta$ 7.51-7.50 (m, 2H, CH arom.), 7.45-7.27 (m, 27H, CH arom.), 7.22-7.18 (m, 1H, CH arom.), 5.92 (bs, $1 \mathrm{H}, \mathrm{NH} N$-Ac), 5.46 (s, 1H, PhCH), 5.11 (d, 1H, $J_{1^{\prime}, 2^{\prime}}=3.4$ $\left.\mathrm{Hz}, \mathrm{H}-1^{\prime}\right), 4.99$ (d, 1H, $\left.J_{\mathrm{a}, \mathrm{b}}=11.7 \mathrm{~Hz}, \mathrm{CH}-\mathrm{a} 4^{\prime}-O-\mathrm{Bn}\right), 4.89$ (d, 1H, $\left.J_{\mathrm{a}, \mathrm{b}}=11.2 \mathrm{~Hz}, \mathrm{CH}-\mathrm{a} 2^{\prime}-O-\mathrm{Bn}\right), 4.86$ (d, 
$\left.1 \mathrm{H}, J_{\mathrm{a}, \mathrm{b}}=12.0 \mathrm{~Hz}, \mathrm{CH}-\mathrm{a} 3^{\prime \prime}-O-\mathrm{Bn}\right), 4.81\left(\mathrm{~d}, 1 \mathrm{H}, J_{\mathrm{a}, \mathrm{b}}=12.2 \mathrm{~Hz}, \mathrm{CH}-\mathrm{a} 3^{\prime}-O-\mathrm{Bn}\right), 4.81\left(\mathrm{~d}, 1 \mathrm{H}, J_{1,2}=7.1 \mathrm{~Hz}\right.$, H-1), $4.76\left(\mathrm{~d}, 1 \mathrm{H}, J_{\mathrm{a}, \mathrm{b}}=12.2 \mathrm{~Hz}\right.$, CH-b 3'-O-Bn), 4.73 (d, 1H, $J_{\mathrm{a}, \mathrm{b}}=12.0 \mathrm{~Hz}, \mathrm{CH}-\mathrm{a}$ Troc), 4.68 (d, 1H, $J_{\mathrm{a}, \mathrm{b}}$ $=12.2 \mathrm{~Hz}, \mathrm{CH}-\mathrm{b}$ Troc), 4.67 (d, 2H, $J_{\mathrm{a}, \mathrm{b}}=11.7 \mathrm{~Hz}, \mathrm{CH}-\mathrm{b} 2^{\prime}-O-\mathrm{Bn}$ and CH-b 4'-O-Bn), $4.65\left(\mathrm{~d}, 1 \mathrm{H}, J_{\mathrm{a}, \mathrm{b}}=\right.$ $12.0 \mathrm{~Hz}, \mathrm{CH}-\mathrm{b}$ 3"-O-Bn), 4.62 (d, 1H, $J_{\mathrm{a}, \mathrm{b}}=12.0 \mathrm{~Hz}, \mathrm{CH}-\mathrm{a}$ 6-O-Bn), 4.54 (bs, $1 \mathrm{H}, \mathrm{NH} N$-Troc), 4.52 (d, $\left.1 \mathrm{H}, J_{1^{\prime \prime}, 2^{\prime \prime}}=8.1 \mathrm{~Hz}, \mathrm{H}-1^{\prime \prime}\right), 4.42\left(\mathrm{~d}, 1 \mathrm{H}, J_{\mathrm{a}, \mathrm{b}}=11.9 \mathrm{~Hz}, \mathrm{CH}-\mathrm{b}\right.$ 6-O-Bn), 4.23-4.20 (m, 2H, H-5' and H-6a"), $4.07\left(\mathrm{dd}, 1 \mathrm{H}, J_{1^{\prime}, 2^{\prime}}=3.6, J_{2^{\prime}, 3^{\prime}}=10.0 \mathrm{~Hz}, \mathrm{H}-2^{\prime}\right), 4.00\left(\mathrm{t}, 1 \mathrm{H}, J_{2,3}=J_{3,4}=7.3 \mathrm{~Hz}, \mathrm{H}-3\right), 3.93\left(\mathrm{t}, 1 \mathrm{H}, J_{3,4}=J_{4,5}=\right.$ $7.3 \mathrm{~Hz}, \mathrm{H}-4), 3.87$ (d, 1H, $J_{2^{\prime}, 3^{\prime}}=9.8, \mathrm{H}-3^{\prime}$ ), 3.69-3.64 (m, 3H, H-6a, H-6b, and H-4'), 3.58-3.49 (m, 4H, H2, H-3", H-4", and H-6"b), 3.45-3.39 (m, 2H, H-5 and H-2"), 3.23 (td, $1 \mathrm{H}, J_{4^{\prime}, 5^{\prime}}=J_{5^{\prime}, 6 \mathrm{~b}^{\prime}}=9.5, J_{5^{\prime}, 6 \mathrm{a}^{\prime}}=4.2 \mathrm{~Hz}$, H-5"), 1.72 (s, 3H, $\mathrm{CH}_{3} N$-Ac), 1.14 (d, 3H, $\left.J_{5^{\prime}, 6^{\prime}}=6.1 \mathrm{~Hz}, \mathrm{CH}_{3} \mathrm{H}-6^{\prime}\right), 0.85$ (s, 9H, $3 \times \mathrm{CH}_{3} \mathrm{Si}^{\mathrm{t}} \mathrm{Bu}$ ), 0.06 (s, $3 \mathrm{H}, \mathrm{CH}_{3} \mathrm{SiMe}_{\mathrm{a}}$ ), 0.02 (s, 3H, $\left.\mathrm{CH}_{3} \mathrm{SiMe}_{\mathrm{b}}\right) ;{ }^{13} \mathrm{C}-\mathrm{NMR}\left(125 \mathrm{MHz}, \mathrm{CDCl}_{3}\right): \delta 170.0(\mathrm{C}=\mathrm{O} \mathrm{N}-\mathrm{Ac}), 154.3(\mathrm{C}=\mathrm{O}$ Troc), 139.0 ( $\mathrm{C}_{\mathrm{i}}$ arom. 3'-O-Bn), 138.8 ( $\mathrm{C}_{\mathrm{i}}$ arom. 2'-O-Bn), 138.8 ( $\mathrm{C}_{\mathrm{i}}$ arom. 4'-O-Bn), $138.2\left(\mathrm{C}_{\mathrm{i}}\right.$ arom. 3"$O$-Bn), 138.0 ( $\mathrm{C}_{\mathrm{i}}$ arom. 6-O-Bn), $137.3\left(\mathrm{C}_{\mathrm{i}}\right.$ arom. $\left.\mathrm{PhCH}\right), 129.2$ ( $\mathrm{CH}$ arom.), $128.8(\mathrm{CH}$ arom.), $128.7(\mathrm{CH}$ arom.), 128.6 ( $\mathrm{CH}$ arom.), 128.6 ( $\mathrm{CH}$ arom.), 128.5 ( $\mathrm{CH}$ arom.), 128.4 ( $\mathrm{CH}$ arom.), 128.4 ( $\mathrm{CH}$ arom.), 128.2 (CH arom.), 128.2 (CH arom.), 128.1 (CH arom.), 128.0 ( $\mathrm{CH}$ arom.), 127.7 (CH arom.), 127.7 (CH arom.), 127.3 (CH arom.), 126.1 ( $\mathrm{CH}$ arom.), $101.3(\mathrm{PhCH}), 99.9$ (C-1"), 98.0 (C-1'), 95.2 ( $\mathrm{CCl}_{3}$ Troc), 92.3 (C-1), 82.6 (C-4"), 79.6 (C-3'), 78.1 (C-4'), 77.4 (C-2'), 76.9 (C-3"), 76.0 (C-3), $75.0\left(\mathrm{CH}_{2} 4^{\prime}-O-\mathrm{Bn}\right)$, $74.7\left(\mathrm{CH}_{2}\right.$ Troc), 74.3 ( $\left.\mathrm{CH}_{2} 3^{\prime \prime}-O-\mathrm{Bn}\right), 74.2$ (C-4 and $\left.\mathrm{C}-5\right), 73.9\left(\mathrm{CH}_{2} 2^{\prime}-O-\mathrm{Bn}\right), 73.7\left(\mathrm{CH}_{2} 6-O-\mathrm{Bn}\right), 72.8$ $\left(\mathrm{CH}_{2} 3^{\prime}-\mathrm{O}-\mathrm{Bn}\right), 69.2(\mathrm{C}-6), 68.8\left(\mathrm{C}-6^{\prime \prime}\right), 66.7\left(\mathrm{C}-5^{\prime}\right), 65.8\left(\mathrm{C}-5{ }^{\prime \prime}\right), 57.8\left(\mathrm{C}-2\right.$ and $\left.\mathrm{C}-2^{\prime \prime}\right), 25.8\left(\mathrm{CH}_{3} \mathrm{Si}^{\mathrm{t}} \mathrm{Bu}\right)$, $18.0\left(\mathrm{C}_{\mathrm{q}} \mathrm{Si}{ }^{\mathrm{t}} \mathrm{Bu}\right), 17.1\left(\mathrm{C}-6^{\prime}\right),-4.2\left(\mathrm{CH}_{3} \mathrm{SiMe}_{\mathrm{a}}\right),-5.2\left(\mathrm{CH}_{3} \mathrm{SiMe}_{\mathrm{b}}\right) ; \mathrm{HRMS}(\mathrm{ESI}) \mathrm{m} / \mathrm{z}$ calcld. for $\left[\mathrm{C}_{71} \mathrm{H}_{85} \mathrm{O}_{16} \mathrm{~N}_{2} \mathrm{Cl}_{3} \mathrm{Si}+\mathrm{Na}\right]^{+}$: 1377.4632 obsd.: 1377.4646 .

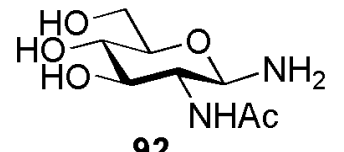

92
2-Acetamido-2-deoxy- $\beta$-D-glucopyranosylamine (92). $N$-Acetylglucosamine

(91) $(0.109 \mathrm{~g}, 0.493 \mathrm{mmol})$ was dissolved in water $(5.0 \mathrm{~mL})$ and $\mathrm{NH}_{4} \mathrm{HCO}_{3}(6.0$

g) was added. The reaction was stirred at $40^{\circ} \mathrm{C}$ in a sealed vessel for 6 days. The

vessel was opened periodically to remove the liberated $\mathrm{CO}_{2}$. After completion, the excess ammonium bicarbonate and water were removed via repetitive lyophilisation $(10$ times, $5 \mathrm{~mL}$ of water added each time) until the mass of the product became constant $(0.204 \mathrm{~g})$. The crude amine was further purified by Dowex $\mathrm{H}^{+}$exchange resin column chromatography $\left(\mathrm{NH}_{3}\right.$ in water, $\left.0 \% \rightarrow 5 \%, \mathrm{v} / \mathrm{v}\right)$ which yielded 92 , in the $\mathrm{NH}_{3}$ fractions, as a white amorphous solid after lyophilisation $(0.074 \mathrm{~g}, 68 \%)$. Starting material was eluted in the water fractions $(0.034 \mathrm{~g}, 31 \%) . R_{f} 0.57$ (isopropanol/water/ $\left.\mathrm{NH}_{3}, 7 / 2 / 1, \mathrm{v} / \mathrm{v}\right) ;{ }^{1} \mathrm{H}-\mathrm{NMR}(500 \mathrm{MHz}$, $\left.\mathrm{D}_{2} \mathrm{O}\right): \delta 4.13\left(\mathrm{~d}, 1 \mathrm{H}, J_{1,2}=9.3 \mathrm{~Hz}, \mathrm{H}-1\right), 3.87\left(\mathrm{dd}, 1 \mathrm{H}, J_{5,6 \mathrm{a}}=1.2, J_{6 \mathrm{a}, 6 \mathrm{~b}}=12.2 \mathrm{~Hz}, \mathrm{H}-6 \mathrm{a}\right), 3.71-3.67(\mathrm{~m}, 1 \mathrm{H}$, H-6b), 3.59 (t, 1H, $J_{1,2}=J_{2,3}=9.8 \mathrm{~Hz}, \mathrm{H}-2$ ), 3.53-3.46 (m, 1H, H-3), 3.42-3.37 (m, 2H, H-4 and H-5), 2.02 (s, 3H, $\mathrm{CH}_{3} N$-Ac); ${ }^{13} \mathrm{C}-\mathrm{NMR}\left(125 \mathrm{MHz}, \mathrm{D}_{2} \mathrm{O}\right): \delta 175.9$ (C=O N-Ac), 85.4 (C-1), $78.0(\mathrm{C}-5), 75.8(\mathrm{C}-3)$, 71.3 (C-4), 62.1 (C-6), 57.5 (C-2), $23.5\left(\mathrm{CH}_{3} \mathrm{~N}\right.$-Ac). HRMS(ESI) $\mathrm{m} / z$ calcld. for $\left[\mathrm{C}_{8} \mathrm{H}_{16} \mathrm{O}_{5} \mathrm{~N}_{2}+\mathrm{Na}\right]^{+}$: 243.0957, obsd.: 243.0951 . 


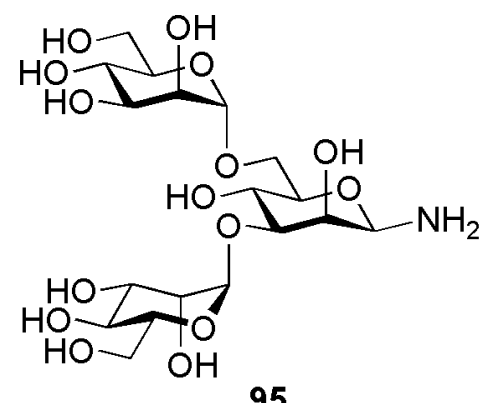

obsd.: 504.1930

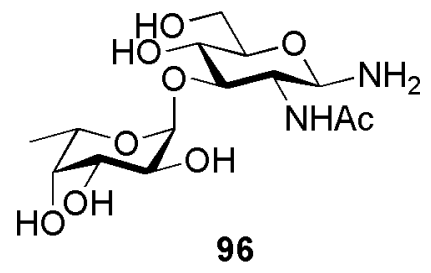

2-Acetamido-2-deoxy-3- $O$-( $\alpha$-L-fucopyranosyl)- $\alpha / \beta-D-$ glucopyranosylamine (96). Disaccharide 76 (0.0122 g, $0.0332 \mathrm{mmol})$ was dissolved in water $(5.0 \mathrm{~mL})$ and $\mathrm{NH}_{4} \mathrm{HCO}_{3}(6.0 \mathrm{~g})$ was added. The reaction was stirred at $40^{\circ} \mathrm{C}$ in a sealed vessel for 6 days. The vessel was opened periodically to remove the liberated $\mathrm{CO}_{2}$. After completion, the excess ammonium bicarbonate and water were removed via repetitive lyophilisation to yield 96. HRMS(ESI) $m / z$ calcld. for $\left[\mathrm{C}_{14} \mathrm{H}_{26} \mathrm{O}_{9} \mathrm{~N}_{2}+\mathrm{H}\right]^{+}: 367.1717$, obsd.: 367.1723 . 


\section{REFERENCES}

(1) von Pirquet, C., Allergie Münch. Med. Wochenschr. 1906, 53, 1457-1458.

(2) Janeway, C. A.; Travers, P.; Walport, M.; Schlomchik, M. J. Immunobiology: The Immune System in Health and Disease; 6th ed.; Garland Science Publishing, 2005.

(3) Larché, M.; Akdis, C. A.; Valenta, R., Immunological mechanisms of allergen-specific immunotherapy Nat. Rev. Immunol. 2006, 6, 761-771.

World Health Organisation - Asthma, http://www.who.int/respiratory/asthma/en, 9 October 2008

(5) Gould, H. J.; Sutton, B. J., IgE in allergy and asthma today Nat. Rev. Immunol. 2008, 8, 205- 217.

(6) Kim, H. Y.; DeKruyff, R. H.; Umetsu, D. T., The many paths to asthma: phenotype shaped by innate and adaptive immunity Nat. Immunol. 2010, 11, 577-584.

(7) Masoli, M.; Fabian, D.; Holt, S.; Beasley, R. "Global Burden of Asthma," Global Initiative for Asthma, 2004.

(8) Asthma and Respiratory Foundation of New Zealand, http://www.asthmanz.co.nz/in_new_zealand.php, 9 October 2008

(9) American Academy of Allergy Asthma \& Immunology, http://www.aaaai.org/patients/resources/fastfacts/asthma_healthcare.stm, 9 October 2008

(10) Cohn, L.; Elias, J. A.; Chupp, G. L., ASTHMA: Mechanisms of Disease Persistence and Progression Ann. Rev. Immunol. 2004, 22, 789-815.

(11) Pearce, E. J.; MacDonald, A. S., The immunobiology of schistosomiasis Nat. Rev. Immunol. 2002, 2, 499-511.

(12) Gause, W. C.; Urban, J. F.; Stadecker, M. J., The immune response to parasitic helminths: insights from murine models Trends Immunol. 2003, 24, 269-277.

(13) Hayes, K. S.; Bancroft, A. J.; Grencis, R. K., Immune-mediated regulation of chronic intestinal nematode infection Immunol. Rev. 2004, 201, 75-88.

(14) Coyle, A. J.; Kohler, G.; Tsuyuki, S.; Brombacher, F.; Kopf, M., Eosinophils are not required to induce airway hyperresponsiveness after nematode infection Eur. J. Immunol. 1998, 28, 2640-2647.

(15) Min, B.; Prout, M.; Hu-Li, J.; Zhu, J. F.; Jankovic, D.; Morgan, E. S.; Urban, J. F.; Dvorak, A. M.; Finkelman, F. D.; LeGros, G.; Paul, W. E., Basophils produce IL-4 and accumulate in tissues after infection with a Th2-inducing parasite J. Exp. Med. 2004, 200, 507-517.

(16) Ramalingam, T. R.; Reiman, R. M.; Wynn, T. A., Exploiting worm and allergy models to understand Th2 cytokine biology Curr. Opin. Allergy Clin. Immunol. 2005, 5, 392-398.

(17) Barnes, P. J., Sensitive to modern life Nature 2006, 442, 513.

(18) Check, E., Link from hygiene to allergies gains support Nature 2004, 428, 354. 
(19) Hawrylowicz, C.; Ryanna, K., The early beginnings Nat. Med. 2010, 16, 274-275.

(20) Galli, S. J.; Tsai, M.; Piliponsky, A. M., The development of allergic inflamation Nature 2008, 454, 445-454.

(21) Harnett, W.; Harnett, M. M., Helminth-derived immunomodulators: can understanding the worm produce the pill? Nat. Rev. Immunol. 2010, 10, 278-284.

(22) Lambrecht, B. N.; Veerman, M. D.; Coyle, A. J.; Gutierrez-Ramo, J.-C.; Thielemans, K.; Pauwels, R. A., Myeloid dendritic cells induce Th2 responses to inhaled antigen, leading to eosinophilic airway inflamation $J$. Clin. Invest. 2000, 106, 551-559.

(23) Mowen, K. A.; Glimcher, L. H., Signaling pathways in Th2 development Immunol. Rev. 2004, 202, 203-222.

(24) Sokol, C. L.; Barton, G. M.; Farr, A. G.; Medzhitov, R., A mechanism for the initiation of allergen-induced $\mathrm{T}$ helper type 2 resposes Nat. Immunol. 2008, 9, 310-318.

(25) Paul, W. E.; Zhu, J., How are $\mathrm{T}_{\mathrm{H}} 2$-type immune responses initiated and amplified? Nat. Rev. Immunol. 2010, 10, 225-235.

(26) van Panhuys, N.; Tang, S.-C.; Prout, M.; Camberis, M.; Scarlett, D.; Roberts, J.; Hu-Li, J.; Paul, W. E.; Gros, G. L., In vivo studies fail to reveal a role for IL-4 or STAT6 signaling in Th2 lymphocyte differentiation PNAS 2008, 105, 12423-12428.

(27) Yamane, H.; Zhu, J.; Paul, W. E., Independent roles for IL-2 and GATA-3 in stimulating naive $\mathrm{CD}^{+} \mathrm{T}$ cells to generate a Th2-inducing cytokine environment J. Exp. Med. 2005, 202, 793-804.

(28) Perrigoue, J. G.; Saenz, S. A.; Siracusa, M. C.; Allenspach, E. J.; Taylor, B. C.; Giacomin, P. R.; Nair, M. G.; Du, Y.; Zaph, C.; Rooijen, N. v.; Comeau, M. R.; Pearce, E. J.; Laufer, T. M.; Artis, D., MHC class IIdependent basophil-CD4 ${ }^{+} \mathrm{T}$ cell interactions promote $\mathrm{T}_{\mathrm{H}} 2$ cytokinedependent immunity Nat. Immunol. 2009, 10, 697-705.

(29) Yoshimoto, T.; Yasuda, K.; Tanaka, H.; Nakahira, M.; Imai, Y.; Fujimori, Y.; Nakanishi, K., Basophils contribute to $\mathrm{T}_{\mathrm{H}} 2-\mathrm{IgE}$ responses in vivo via IL-4 production and presentation of peptide-MHC class II complexes to $\mathrm{CD}^{+}{ }^{+} \mathrm{T}$ cells Nat. Immunol. 2009, 10, 706-712.

(30) Sokol, C. L.; Chu, N.-Q.; Yu, S.; Nish, S. A.; Laufer, T. M.; Medzhitov, R., Basophils function as antigen-presenting cells for an allergen-induced $\mathrm{T}$ helper type 2 response Nat. Immunol. 2009, 10, 713-720.

(31) Anthony, R. M.; Rutitzky, L. I.; Urban Jr, J. F.; Stadecker, M. J.; Gause, W. C., Protective immune mechanisms in helminth infection Nat. Rev. Immunol. 2007, 7, 975-987.

(32) Lemanske, R. F.; Busse, W. W., Asthma: Clinical expression and molecular mechanisms J. Allergy Clin. Immunol. 2010, 125, 95-102.

(33) Barnes, P. J., Current issues for establishing inhaled corticosteroids as the antiinflammatory agents of choice in asthma J. Allergy Clin. Immunol. 1998, 101, 427-433. 
(34) Chan, A. C.; Carter, P. J., Therapeutic antibodies for autoimmunity and inflammation Nat. Rev. Immunol. 2010, 10, 301-316.

(35) Lloyd, C. M.; Saglani, S., The emerging epithelium Nat. Med. 2010, 16, 273-274.

(36) van Ree, R.; Cabanes-Macheteau, M.; Akkerdaas, J.; Milazzo, J. P.; Loutelier-Bourhis, C.; Rayon, C.; Villalba, M.; Koppelman, S.; Aalberse, R.; Rodriguez, R.; Faye, L.; Lerouge, P., beta(1,2)-xylose and alpha(1,3)fucose residues have a strong contribution in $\mathrm{IgE}$ binding to plant glycoallergens J. Biol. Chem. 2000, 275, 11451-11458.

(37) Okano, M.; Kimura, Y.; Kino, K.; Michigami, Y.; Sakamoto, S.; Sugata, Y.; Maeda, M.; Matsuda, F.; Kimura, M.; Ogawa, T.; Nishizaki, K., Roles of major oligosaccharides on Cry $\mathrm{j} 1$ in human immunoglobulin $\mathrm{E}$ and $\mathrm{T}$ cell responses Clin. Exp. Allergy 2004, 34, 770-778.

(38) Wilson, I. B. H., Glycosylation of proteins in plants and invertebrates Curr. Opin. Struct. Biol. 2002, 12, 569-577.

(39) Kimura, Y.; Yoshiie, T.; Kit, W. K.; Maeda, M.; Kimura, M.; Tan, S. H., Structural features of $\mathrm{N}$-glycans linked to glycoproteins from oil palm pollen, an allergenic pollen Biosci. Biotechnol. Biochem. 2003, 67, 22322239.

(40) Faveeuw, C.; Mallevaey, T.; Paschinger, K.; Wilson, I. B. H.; Fontaine, J.; Mollicone, R.; Oriol, R.; Altmann, F.; Lerouge, P.; Capron, M.; Trottein, F., Schistosome N-glycans containing core alpha 3-fucose and core beta 2xylose epitopes are strong inducers of Th2 responses in mice Eur. J. Immunol. 2003, 33, 1271-1281.

(41) Thomas, P. G.; Harn, D. A., Immune biasing by helminth glycans Cell. Microbiol. 2004, 6, 13-22.

(42) Shreffler, W. G.; Castro, R. R.; Kucuk, Z. Y.; Charlop-Powers, Z.; Grishina, G.; Yoo, S.; Burks, A. W.; Sampson, H. A., The major glycoprotein allergen from Arachis hypogaea, Ara $h$ 1, is a ligand of dendritic cell-specific ICAM-grabbing nonintegrin and acts as a Th2 adjuvant in vitro $J$. Immunol. 2006, 177, 3677-3685.

(43) Poltl, G.; Ahrazem, O.; Paschinger, K.; Ibanez, M. D.; Salcedo, G.; Wilson, I. B. H., Molecular and immunological characterization of the glycosylated orange allergen Cit s 1 Glycobiology 2007, 17, 220-230.

(44) Fotisch, K.; Vieths, S., N- and O-linked oligosaccharides of allergenic glycoproteins Glycoconjugate J. 2001, 18, 373-390.

(45) Sturm, A.; Bergwerff, A. A.; Vliegenthart, J. F. G., H-1-Nmr Structural Determination of the N-Linked Carbohydrate Chains on Glycopeptides Obtained from the Bean Lectin Phytohemagglutinin Eur. J. Biochem. 1992, 204, 313-316.

(46) Mizoguchi, A.; Takasaki, S.; Maeda, S.; Kobata, A., Changes in Asparagine-Linked Sugar Chains of Human Promyelocytic LeukemicCells (Hl-60) During Monocytoid Differentiation and Myeloid Differentiation - Appearance of High Mannose-Type Oligosaccharides in Neutral Fraction J. Biol. Chem. 1984, 259, 1943-1948. 
(47) Jones, C. J. P.; Jauniaux, E.; Stoddart, R. W., Glycans of the Early Human Yolk-Sac Histochemical J. 1995, 27, 210-221.

(48) Shiyan, S. D.; Bovin, N. V., Carbohydrate composition and immunomodulatory activity of different glycoforms of alpha(1)-acid glycoprotein Glycoconjugate J. 1997, 14, 631-638.

(49) Butters, T. D.; Yudkin, B.; Jacob, G. S.; Jones, I. M., Structural characterization of the N-linked oligosaccharides derived from HIVgp120 expressed in lepidopteran cells Glycoconjugate J. 1998, 15, 83-88.

(50) Griffiths, A. J.; Davies, D. B., Type-Specific Carbohydrate Antigens of Pathogenic Bacteria. Part 1: Enterobacteriaceae Carbohydr. Polym. 1991, 14, 241-280.

(51) Griffiths, A. J.; Davies, D. B., Type-Specific Carbohydrate Antigens of Pathogenic Bacteria. Part 2 Carbohydr. Polym. 1991, 14, 339-365.

(52) Tawill, S.; Le Goff, L.; Ali, F.; Blaxter, M.; Allen, J. E., Both free-living and parasitic nematodes induce a characteristic Th2 response that is dependent on the presence of intact glycans Infect. Immun. 2004, 72, 398407.

(53) Maizels, R. M.; Balic, A.; Gomez-Escobar, N.; Nair, M.; Taylor, M. D.; Allen, J. E., Helminth parasites - masters of regulation Immunol. Rev. 2004, 201, 89-116.

(54) Figdor, C. G.; Kooyk, Y. v.; Adema, G. J., C-type lectin receptors on dendritic cells and Langerhans cells Nat. Rev. Immunol. 2002, 2, 77-84.

(55) Okano, M.; Nishizaki, K.; Satoskar, A. R.; Yoshino, T.; Masuda, Y.; Harn, D. A., Involvement of carbohydrate on phospholipase A(2), a bee-venom allergen, in in vivo antigen-specific IgE synthesis in mice Allergy 1999, 54, 811-818.

(56) Aalberse, R. C.; Koshte, V.; Clemens, J. G. J., Immunoglobulin-E Antibodies That Crossreact with Vegetable Foods, Pollen, and Hymenoptera Venom J. Allergy Clin. Immunol. 1981, 68, 356-364.

(57) Wilson, I. B. H.; Harthill, J. E.; Mullin, N. P.; Ashford, D. A.; Altmann, F., Core alpha 1,3-fucose is a key part of the epitope recognized by antibodies reacting against plant $\mathrm{N}$-linked oligosaccharides and is present in a wide variety of plant extracts Glycobiology 1998, 8, 651-661.

(58) van Die, I.; Gomord, V.; Kooyman, F. N. J.; van den Berg, T. K.; Cummings, R. D.; Vervelde, L., Core alpha 1 -> 3-fucose is a common modification of $\mathrm{N}$-glycans in parasitic helminths and constitutes an important epitope for IgE from Haemonchus contortus infected sheep FEBS Lett. 1999, 463, 189-193.

(59) Aalberse, R. C.; Akkerdaas, J. H.; Ree, R. v., Cross-reactivity of IgE antibodies to allergens Allergy 2001, 56, 478-490.

(60) Bublin, M.; Radauer, C.; Wilson, I. B. H.; Kraft, D.; Scheiner, O.; Breiteneder, H.; Hoffmann-Sommergruber, K., Cross-reactive N-glycans of Api g 5, a high molecular weight glycoprotein allergen from celery, are required for immunoglobulin $\mathrm{E}$ binding and activation of effector cells from allergic patients FASEB J. 2003, 17, 1697-1720. 
(61) Okano, M.; Satoskar, A. R.; Nishizaki, K.; Abe, M.; Harn, D. A., Induction of Th2 responses and IgE is largely due to carbohydrates functioning as adjuvants on Schistosoma mansoni egg antigens $J$. Immunol. 1999, 163, 6712-6717.

(62) Paschinger, K.; Fabini, G.; Schuster, D.; Rendic, D.; Wilson, I. B. H., Definition of immunogenic carbohydrate epitopes Acta Biochim. Pol. 2005, 52, 629-632.

(63) Bertozzi, C. R.; Kiessling, L. L., Chemical glycobiology Science 2001, 291, 2357-2364.

(64) Dwek, R. A., Glycobiology: Toward Understanding the Function of Sugars Chem. Rev. 1996, 96, 683-720.

(65) Rudd, P. M.; Elliott, T.; Cresswell, P.; Wilson, I. A.; Dwek, R. A., Glycosylation and the Immune System Science 2001, 291, 2370-2376.

(66) Talbot, P.; Shur, B. D.; Myles, D. G., Cell Adhesion and Fertilization: Steps in Oocyte Transport, Sperm-Zona Pellucida Interactions, and Sperm-Egg Fusion Biol. Reprod. 2003, 68, 1-9.

(67) Varki, A., Biological roles of oligosaccharides: all of the theories are correct Glycobiology 1993, 3, 97-130.

(68) Helenius, A.; Aebi, M., Intracellular Functions of N-Linked Glycans Science 2001, 291, 2364-2369.

(69) Nishiwaki, K.; Kubota, Y.; Chigira, Y.; Roy, S. K.; Suzuki, M.; Schvarzstein, M.; Jigami, Y.; Hisamoto, N.; Matsumoto, K., An NDPase links ADAM protease glycosylation with organ morphogenesis in $\mathrm{C}$. elegans. Nat. Cell. Biol. 2004, 6, 31-37.

(70) Matsuo, I.; Nakahara, Y.; Ito, Y.; Nukada, T.; Nakahara, Y.; Ogawa, T., Synthesis of a Glycopeptide Carrying a N-linked Core Pentasaccharide Bioorg. Med. Chem. 1995, 3, 1455-1463.

(71) Guo, Z.-W.; Nakahara, Y.; Nakahara, Y.; Ogawa, T., Solid-Phase Synthesis of the CD52 Glycopeptide Carrying an N-Linked Core Pentasaccharide Structure Angew. Chem. Int. Ed. 1997, 36, 1464-1466.

(72) Unverzagt, C.; Kunz, H., Synthesis of glycopeptides and neoglycoproteins containing the fucosylated linkage region of N-glycoproteins Bioorg. Med. Chem. 1994, 2, 1189-1201.

(73) Unverzagt, C., A Modular System for the Synthesis of Complex NGlycans Angew. Chem. Int. Ed. 1997, 36, 1989-1992.

(74) Unverzagt, C., Chemoenzymatic synthesis of a sialylated diantennary Nglycan linked to asparagine Carbohydr. Res. 1998, 302, 423-431.

(75) Danishefsky, S. J.; Hu, S.; Cirillo, P. F.; Eckhardt, M.; Seeberger, P. H., A Highly Convergent Total Synthetic Route to Glycopeptides Carrying a High-Mannose Core Pentasaccharide Domain N-linked to a Natural Peptide Motif Chem. Eur. J. 1997, 3, 1617-1628.

(76) Wang, Z. G.; Warren, J. D.; Dudkin, V. Y.; Zhang, X. F.; Iserloh, U.; Visser, M.; Eckhardt, M.; Seeberger, P. H.; Danishefsky, S. J., A highly convergent synthesis of an $\mathrm{N}$-linked glycopeptide presenting the H-type 2 human blood group determinant Tetrahedron 2006, 62, 4954-4978. 
(77) Nagorny, P.; Fasching, B.; Li, X.; Chen, G.; Ausseda, B.; Danishefsky, S. J., Toward Fully Synthetic Homogeneous $\beta$-Human Follicle-Stimulating Hormone $(\beta$-hFSH) with a Biantennary N-Linked Dodecasaccharide. Synthesis of $\beta$-hFSH with Chitobiose Units at the Natural Linkage Sites $J$. Am. Chem. Soc. 2009, 131, 5792-5799.

(78) Wang, Z. G.; Zhang, X. F.; Live, D.; Danishefsky, S. J., From Glycals to Glycopeptides: A Convergent and Stereoselective Total Synthesis of a High Mannose N-Linked Glycopeptide Angew. Chem. Int. Ed. 2000, 39, 3652-3656.

(79) Wang, P.; Zhu, J.; Yuan, Y.; Danishefsky, S. J., Total Syntheis of the 2,6Sialylated Immunoglobulin $\mathrm{G}$ glycopeptide Fragment in Homogeneous Form J. Am. Chem. Soc. 2009, 131, 16669-16671.

(80) Likhosherstov, L. M.; Novikova, O. S.; Derevitskaja, V. A.; Kochetkov, N. K., A New Simple Synthesis of Amino Sugar Beta-D-Glycosylamines Carbohydr. Res. 1986, 146, C1-C5.

(81) Davis, B. G., Synthesis of Glycoproteins Chem. Rev. 2002, 102, 579-601. (82) Gamblin, D. P.; Scanlan, E. M.; Davis, B. G., Glycoprotein Synthesis: An Update Chem. Rev. 2009, 109, 131-163.

(83) Cohen-Anisfeld, S. T.; Lansbury, P. T., A Practical, Convergent Method for Glycopeptide Synthesis J. Am. Chem. Soc. 1993, 115, 10531-10537.

(84) Seeberger, P. H.; Cirillo, P. F.; Hu, S. H.; Beebe, X.; Bilodeau, M. T.; Danishefsky, S. J., Synthesis of the pentasaccharide core structure of asparagine-linked glycoprotein oligosaccharides by the glycal assembly method Enantiomer 1996, 1, 311-323.

(85) Schmidt, R. R., New Methods for the Synthesis of Glycosides and Oligosaccharides - Are There Alternatives to the Koenigs-Knorr Method Angew. Chem. Int. Ed. 1986, 25, 212-235.

(86) Becker, B.; Furneaux, R. H.; Reck, F.; Zubkov, O. A., A simple synthesis of 8-(methoxycarbonyl)octyl 3,6-di- $O$-( $\alpha$-D-mannopyranosyl)- $\alpha$-Dmannopyranoside and derivatives and their use in the preparation of neoglycoconjugates Carbohydr. Res. 1999, 315, 148-158.

(87) Furneaux, R. H.; Pakulski, Z.; Tyler, P. C., New mannotriosides and trimannosides as potential ligands for mannose-specific binding proteins Can. J. Chem. 2002, 80, 964-972.

(88) Utille, J.-P.; Priem, B., Synthesis of allyl 2-O-( $\alpha$-L-arabinofuranosyl)-6$O$-( $\alpha$-D-mannopyranosyl)- $\beta$-D-mannopyranoside, a unique plant $N$-glycan motif containing arabinose Carbohydr. Res. 2000, 329, 431-439.

(89) Roy, R.; Page, D.; Figueroa-Pérez, S.; Bencomo, V. V., Effect of shape, size, and valency of multivalent mannosides on their binding properties to phytohemagglutinins Glycoconjugate J. 1998, 15, 251-263.

(90) Cmoch, P.; Pakulski, Z.; Swaczynova, J.; Strnad, M., Synthesis of lupanetype saponins bearing mannosyl and 3,6-branched trimannosyl residues and their evaluation as anticancer agents Carbohydr. Res. 2008, 343, 9951003.

(91) Ness, R. K.; Fletcher, H. G.; Hudson, C. S., The Reaction of 2,3,4,6Tetrabenzoyl- $\alpha$-D-glucopyranosyl Byromide and 2,3,4,6-Tetrabenzoyl- $\alpha$ - 
D-mannopyraosyl Bromide with Methanol. Certain Benzoylated Derivatives of D-Glucose and D-Mannose J. Am. Chem. Soc. 1950, 72, 2200-2205.

(92) Hölemann, A.; Stocker, B. L.; Seeberger, P. H., Synthesis of a Core Arabinomannan Oligosaccharide of Mycobacterium tuberculosis J. Org. Chem. 2006, 71, 8071-8088.

(93) Sato, S.; Mori, M.; Ito, Y.; Ogawa, T., An Efficient Approach to OGlycosides through $\mathrm{CuBr}_{2}-\mathrm{Bu}_{4} \mathrm{NBr}$ Mediated Activation of Glycosides Carbohydr. Res. 1986, 155, C6-C10.

(94) van Roon, A. M. M.; Aguilera, B.; Cuenca, F.; van Remoortere, A.; van der Marel, G. A.; Deelder, A. M.; Overkleeft, H. S.; Hokke, C. H., Synthesis and antibody-binding studies of a series of parasite fucooligosaccharides Bioorg. Med. Chem. 2005, 13, 3553-3564.

(95) Shao, N.; Xue, J.; Guo, Z. W., Chemical synthesis of CD52 glycopeptides containing the acid-labile fucosyl linkage J. Org. Chem. 2003, 68, 90039011.

(96) Mukherjee, D.; Sarkar, S. K.; Chattopadhyay, P.; Chowdhury, U. S., Synthesis of two Lewis(x) trisaccharides using regiospecific glycosylation reactions J. Carbohydr. Chem. 2005, 24, 251-259.

(97) Tanaka, H.; Ishida, T.; Matoba, N.; Tsukamoto, H.; Yamada, H.; Takahashi, T., Efficient polymer-assisted strategy for the deprotection of protected oligosaccharides Angew. Chem. Int. Ed. 2006, 45, 6349-6352.

(98) Hada, N.; Sonoda, Y.; Takeda, T., Synthesis of a novel glycosphingolipid from the millipede, Parafontaria laminata armigera, and the assembly of its carbohydrate moiety into multivalent structures Carbohydr. Res. 2006, 341, 1341-1352.

(99) Liao, L.; Auzanneau, F. I., The amide group in $\mathrm{N}$-acetylglucosamine glycosyl acceptors affects glycosylation outcome J. Org. Chem. 2005, 70, 6265-6273.

(100) Kunz, H.; Unverzagt, C., Protecting-Group-Dependent Stability of Intersaccharide Bonds - Synthesis of a Fucosyl-Chitobiose Glycopeptide Angew. Chem. Int. Ed. 1988, 27, 1697-1699.

(101) Peters, S.; Lowary, T. L.; Hindsgaul, O.; Meldal, M.; Bock, K., SolidPhase Synthesis of a Fucosylated Glycopeptide of Human Factor-Ix with a Fucose-Alpha-(1-]O)-Serine Linkage J. Chem. Soc.-Perkin Trans. 1 1995, 3017-3022.

(102) Dulery, V.; Renaudet, O.; Philouze, C.; Dumy, P., alpha and beta LFucopyranosyl oxyamines: key intermediates for the preparation of fucose-containing glycoconjugates by oxime ligation Carbohydr. Res. 2007, 342, 894-900.

(103) Ruttens, B.; Kovac, P., A facile synthesis of armed and disarmed colitose thioglycosides Synthesis-Stuttgart 2004, 2505-2508.

(104) Murakata, C.; Ogawa, T., Synthetic Studies on Cell-Surface Glycans .83. Stereoselective Synthesis of Glycobiosyl Phosphatidylinositol, a Part Structure of the Glycosyl-Phosphatidylinositol (Gpi) Anchor of Trypanosoma-Brucei Carbohydr. Res. 1992, 234, 75-91. 
(105) Kinzy, W.; Schmidt, R. R., Synthesis of the Trisaccharide of the Repeating Unit of the Capsular Polysaccharide of Neisseria-Meningitidis (Serogroup-L) Liebigs Ann. Chem. 1985, 1537-1545.

(106) Orgueira, H. A.; Bartolozzi, A.; Schell, P.; Litjens, R.; Palmacci, E. R.; Seeberger, P. H., Modular synthesis of heparin oligosaccharides Chem. Eur. J. 2003, 9, 140-169.

(107) Vankar, Y. D.; Vankar, P. S.; Behrendt, M.; Schmidt, R. R., Synthesis of Beta-O-Glycosides Using Enol Ether and Imidate Derived Leaving Groups - Emphasis on the Use of Nitriles as a Solvent Tetrahedron 1991, 47, 9985-9992.

(108) Toepfer, A.; Schmidt, R. R., An Efficient Synthesis of the Lewis X (Le(X)) Antigen Family Tetrahedron Lett. 1992, 33, 5161-5164.

(109) Zemplen, G.; Pascu, E., The saponification acetyl sugar and relative substances Ber. Dtsch. Chem. Ges. 1929, 62, 1613-1614.

(110) Mackay, E., Deciphering the Molecular Fingerprint of Allergens BSc (Hons) Report, Victoria University of Wellington, 2009.

(111) Figueroa-Pérez, S.; Verez-Bencomo, V., Synthesis of Neoglycolipids Containing Oligosaccharides Based on 3,6-Branched- $\alpha$-DMannopyranosides as the Carbohydrate Moieties J. Carbohydr. Chem. 1998, 17, 851-868.

(112) Haines, A. H., The selctive removal of protecting groups in carbohydrate chemistry Adv. Carbohydr. Chem. Biochem. 1976, 33, 11-109.

(113) Zhu, Y.; Kong, F., A facile and effective synthesis of $\alpha-(1 \rightarrow 6)$-linked mannose di-, tri-, tetra-, hexa-, octa-, and dodecasaccharides, and $\beta$ $(1 \rightarrow 6)$-linked glucose di-, tri-, tetra-, hexa-, and octasaccharides using sugar trichloroacetimidates as the donors and unprotected or partially protected glycosides as the acceptors Carbohydr. Res. 2001, 332, 1-21.

(114) Premathilake, H. D.; Mydock, L. K.; Demchenko, A. V., Superarming Common Glycosyl Donors by Simple 2-O-Benzoyl-3,4,6-tri- $O$-benzyl Protection J. Org. Chem. 2010, 75, 1095-1100.

(115) Aspinall, G. O.; Krishnamurthy, T. N., Base-catalyzed Degradations of Carbohydrates. VII. Alkaline Degradation of 3,6-Di- $O$-substituted Hexoses Can. J. Chem. 1975, 53, 2171-2177.

(116) Ichikawa, Y.; Sim, M. M.; Wong, C. H., Efficient chemical synthesis of GDP-fucose J. Org. Chem. 1992, 57, 2943-2946.

(117) Lonn, H., Synthesis of a Tri-Saccharide and a Hepta-Saccharide Which Contain Alpha-L-Fucopyranosyl Groups and Are Part of the Complex Type of Carbohydrate Moiety of Glycoproteins Carbohydr. Res. 1985, 139, 105-113.

(118) Haslett, G. W., A Sweet Approach to Asthma and Allergy BSc (Hons) Report, Victoria University of Wellington, 2008.

(119) Rabbani, S.; Compostella, F.; Franchini, L.; Wagner, B.; Panza, L.; Ernst, B., Synthetic potential of fucosyltransferase III for the synthesis of fluorescent-labeled milk oligosaccharides J. Carbohydr. Chem. 2005, 24, 789-807. 
(120) Ratner, D. M.; Swanson, E. R.; Seeberger, P. H., Automated synthesis of a protected $N$-linked glycoprotein core pentasaccharide Org. Lett. 2003, 5, 4717-4720.

(121) Guindon, Y.; Girard, Y.; Berthiaume, S.; Gorys, V.; Lemieux, R.; Yoakim, C., Dialkyl and Diaryl Boron Halides - Reductive Opening of Benzylidene Acetals Can. J. Chem.-Rev. Can. Chim. 1990, 68, 897-902.

(122) Levy, D. E.; Fügedi, P. The Organic Chemistry of Sugars; 1st ed.; CRC Press, 2006.

(123) Paulsen, H., Advances in Selective Chemical Syntheses of Complex Oligosaccharides Angew. Chem. Int. Ed. 1982, 21, 155-173.

(124) Crich, D.; Dudkin, V., Why are the hydroxy groups of partially protected $\mathrm{N}$-acetylglucosamine derivatives such poor glycosyl accepters, and what can be done about it? A comparative study of the reactivity of N-acetyl-, N-phthalimido-, and 2-azido-2-deoxy-glucosamine derivatives in glycosylation. 2-picolinyl ethers as reactivity-enhancing replacements for benzyl ethers J. Am. Chem. Soc. 2001, 123, 6819-6825.

(125) Ellervik, U.; Magnusson, G., Glycosylation with N-Troc-protected glycosyl donors Carbohydr. Res. 1996, 280, 251-260.

(126) Koizumi, A.; Hada, N.; Kaburaki, A.; Yamano, K.; Schweizer, F.; Takeda, T., Synthetic studies on the carbohydrate moiety of the antigen from the parasite Echinococcus multilocularis Carbohydr. Res. 2009, 344, 856-868.

(127) Staudinger, H.; Meyer, J., On new organic phosphorus bonding III Phosphine methylene derivatives and phosphinimine Helv. Chim. Acta 1919, 2, 635-646.

(128) Nyffeler, P. T.; Liang, C. H.; Koeller, K. M.; Wong, C. H., The chemistry of amine-azide interconversion: Catalytic diazotransfer and regioselective azide reduction J. Am. Chem. Soc. 2002, 124, 10773-10778.

(129) Probert, M. A.; Milton, M. J.; Harris, R.; Schenkman, S.; Brown, J. M.; Homans, S. W.; Field, R. A., Chemoenzymatic synthesis of GM(3), Lewis $\mathrm{x}$ and sialyl Lewis $\mathrm{x}$ oligosaccharides in C-13-enriched form Tetrahedron Lett. 1997, 38, 5861-5864.

(130) Florent, J. C.; Monneret, C., Rearrangement of Methyl-3,6-DideoxyAlpha-D-Arabino-Hexopyranosides in Presence of Benzaldehyde and Lewis Acid Carbohydr. Res. 1980, 81, 225-238.

(131) Hasegawa, A.; Tanahashi, E.; Goh, Y.; Kiso, M., Studies on Immunoadjuvant Active Compounds .19. Synthesis of 4-Acetamido-NAcetyl-4-Deoxy and 4,6-Di(Acetamido)-N-Acetyl-4,6-DideoxyMuramoyl-L-Alanyl-D-Isoglutamine Derivatives Carbohydr. Res. 1982, 103, 273-280.

(132) Ishida, H.; Imai, Y.; Kiso, M.; Hasegawa, A.; Sakurai, T.; Azuma, I., Studies on Immunoadjuvant-Active Compounds .41. Synthesis and Immunoadjuvant Activity of 2,2'-O-[2,2'-Diacetamido-2,3,2',3'Tetradeoxy-6,6'-Di-O-(2-Tetradecylhex Adecanoyl)-Alpha,Alpha'Trehalose-3,3'-Diyl]Bis(N-D-Lactoyl-L-Alanyl-D-I Soglutamine) Carbohydr. Res. 1989, 195, 59-66. 
(133) Albers, P.; Pietsch, J.; Parker, S. F., Poisoning and deactivation of palladium catalysts J. Mol. Catal. A: Chem. 2001, 173, 275-286.

(134) Corey, E. J.; Venkateswarlu, A., Protection of hydroxyl groups as tertbutyldimethylsilyl derivatives J. Am. Chem. Soc. 1972, 94, 6190-6191.

(135) Nakahara, Y.; Nakahara, Y.; Ogawa, T., Solid-phase synthesis of an $O$ linked glycopeptide based on a benzyl-protected glycan approach Carbohydr. Res. 1996, 292, 71-81.

(136) Mukhopadhyay, B.; Roy, N., Synthesis of the pentasaccharide related to the repeating unit of the antigen from Shigella dysenteriae type 4 in the form of its methyl ester 2-(trimethylsilyl)ethyl glycoside Carbohydr. Res. 2003, 338, 589-596.

(137) Pratt, M. R.; Bertozzi, C. R., Syntheses of 6-Sulfo Sialyl Lewis X Glycans Corresponding to the 1-Selectin Ligand "Sulfoadhesin" Org. Lett. 2004, 6, 2345-2348.

(138) Matsuoka, K.; Yamaguchi, H.; Koyama, T.; Hatano, K.; Terunuma, D., Synthetic construction of a fucosyl chitobiose as an allergen-associated carbohydrate epitope and the glycopolymer involving highly clustered trisaccharidic sequences Tetrahedron Lett. 2010, 51, 2529-2532.

(139) Likhosherstov, L. M.; Novikova, O. S.; Shibaev, V. N., New effiecient synthesis of $\beta$-glucosylamines of mono- and disaccharides with the use of ammonium cabamate Dokl. Chem. 2002, 383, 89-92.

(140) Lubineau, A.; Auge, J.; Drouillat, B., Improved Synthesis of Glycosylamines and a Straightforward Preparation of NAcylglycosylamines as Carbohydrate-Based Detergents Carbohydr. Res. 1995, 266, 211-219.

(141) Shin, I.; Jung, H. J.; Lee, M. R., Chemoselective ligation of maleimidosugars to peptides/protein for the preparation of neoglycopeptides/neoglycoprotein Tetrahedron Lett. 2001, 42, 1325-1328.

(142) Miller, J. S.; Dudkin, V. Y.; Lyon, G. J.; Muir, T. W.; Danishefsky, S. J., Towards fully synthetic $N$-linked glycoproteins Angew. Chem. Int. Ed. 2003, 42, 431-434.

(143) Vetter, D.; Gallop, M. A., Strategies for the Synthesis and Screening of Glycoconjugates. 1. A Library of Glycosylamines Bioconj. Chem. 1995, 6, 316-318.

(144) Paul, B.; Korytnyk, W., Synthesis of 2-Acetamido-3,4,6-Tri-O-Acetyl-2Deoxy-Beta-D-Glucopyranosylamine and Dimer Formation Carbohydr. Res. 1978, 67, 457-468.

(145) Amadori, M., The product of the condensation of glucose and pphenetidine Atti Accad. Nazl. Lincei 1929, 9, 68-73.

(146) Amadori, M., The condensation product of glucose and p-anisidine Atti Accad. Nazl. Lincei 1929, 9, 226-230.

(147) Kuhn, R.; Dansi, A., Concerning a molecular transformation of Nglucosides Ber. Dtsch. Chem. Ges. 1936, 69, 1745-1754.

(148) Angyal, S. J. In Glycoscience: epimerisation, isomerisation and rearrangement reactions of carbohydrates; Springer-Verlag: Berlin, 2001; Vol. 215, p 1-14. 
(149) Yamaguchi, Y.; Walchli, M.; Nagano, M.; Kato, K., A ${ }^{13}$ C-detection NMR approach for large glycoproteins Carbohydr. Res. 2009, 344, 535-538.

(150) Patwa, T.; Li, C.; Simeone, D. M.; Lubman, D. M., Glycoprotein analysis using protein microarrays and mass spectrometry Mass Spectrom. Rev. 2010, 29, 830-844.

(151) Morgan, W. T. J.; Elson, L. A., A colorimetric method for the determination of $\mathrm{N}$-acetyl-glucosamine and $\mathrm{N}$-acetylchondrosamine Biochem. J. 1934, 28, 988-995.

(152) Chen, G. C.; Johnson, B. R., Improved Colorimetric Determination of Cell Wall Chitin in Wood Decay Fungi Appl. Environ. Microbiol. 1983, 46, 1316.

(153) Eissig, J. L.; Storminger, J. L.; Leloir, L. F., A Modified Colorimetric Method for the Estimation of N-Acetylamino Sugars J. Biol. Chem. 1955, 217, 959-966.

(154) Takahashi, T.; Ikegami-Kawai, M.; Okuda, R.; Suzuki, K., A fluorimetric Morgan-Elson assay method for hyaluronidase activity Anal. Biochem. 2003, 322, 257-263. 


\section{APPENDIX}

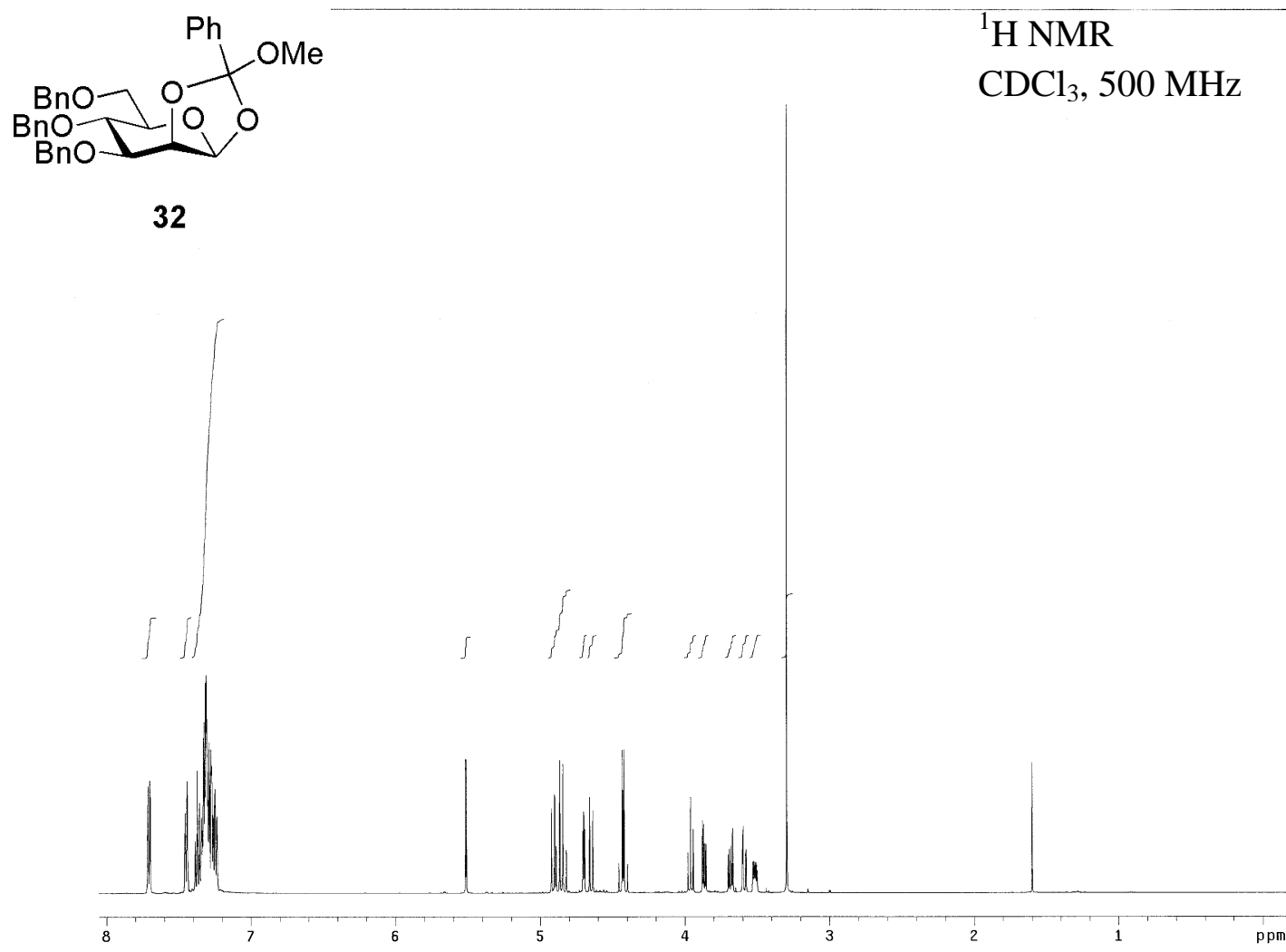

${ }^{13} \mathrm{C}$ NMR

$\mathrm{CDCl}_{3}, 125 \mathrm{MHz}$

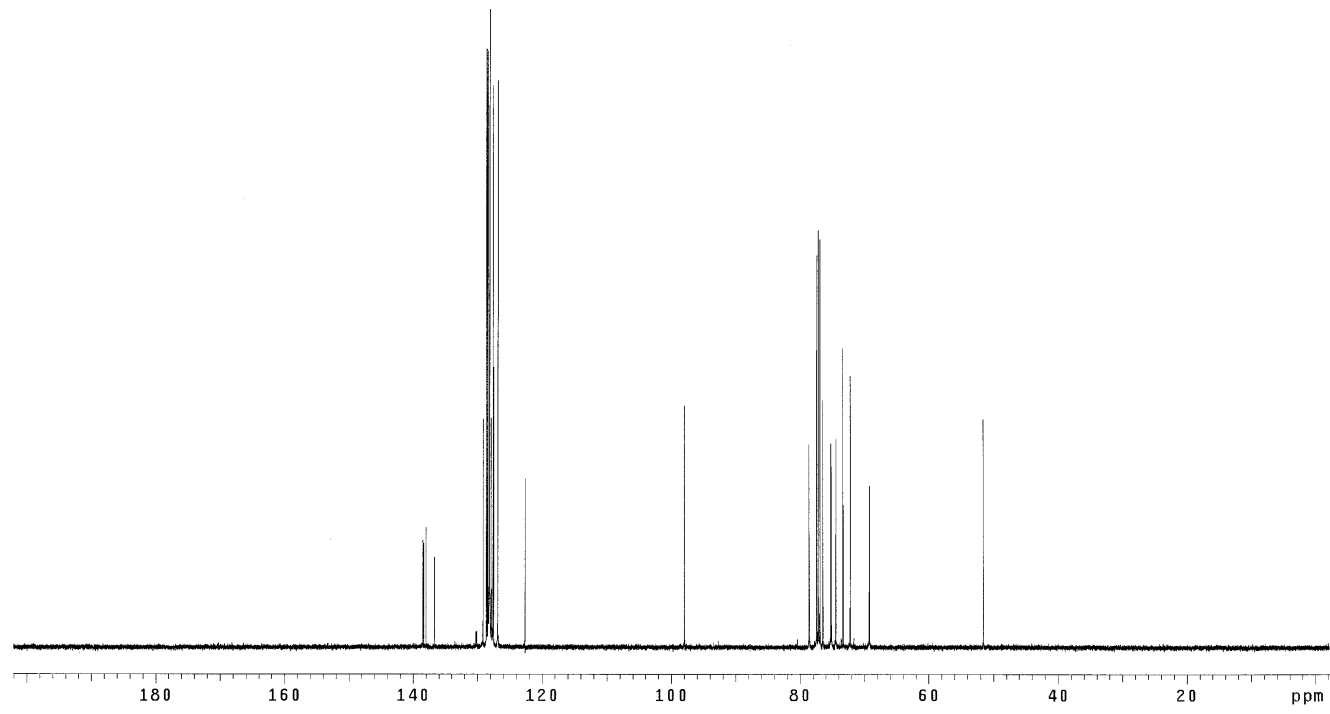




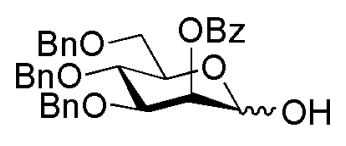

${ }^{1} \mathrm{H}$ NMR

$\mathrm{CDCl}_{3}, 500 \mathrm{MHz}$

33

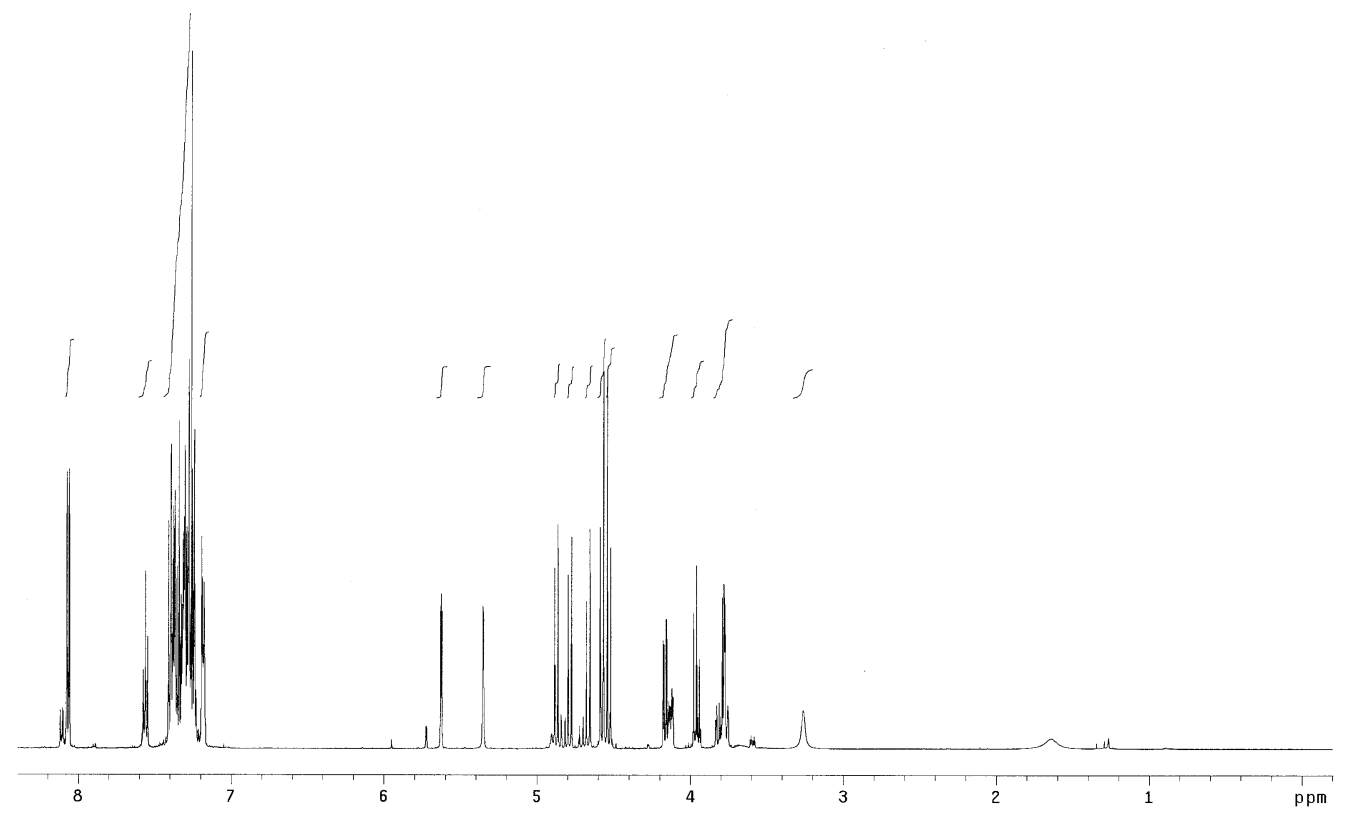

${ }^{13} \mathrm{C}$ NMR

$\mathrm{CDCl}_{3}, 125 \mathrm{MHz}$

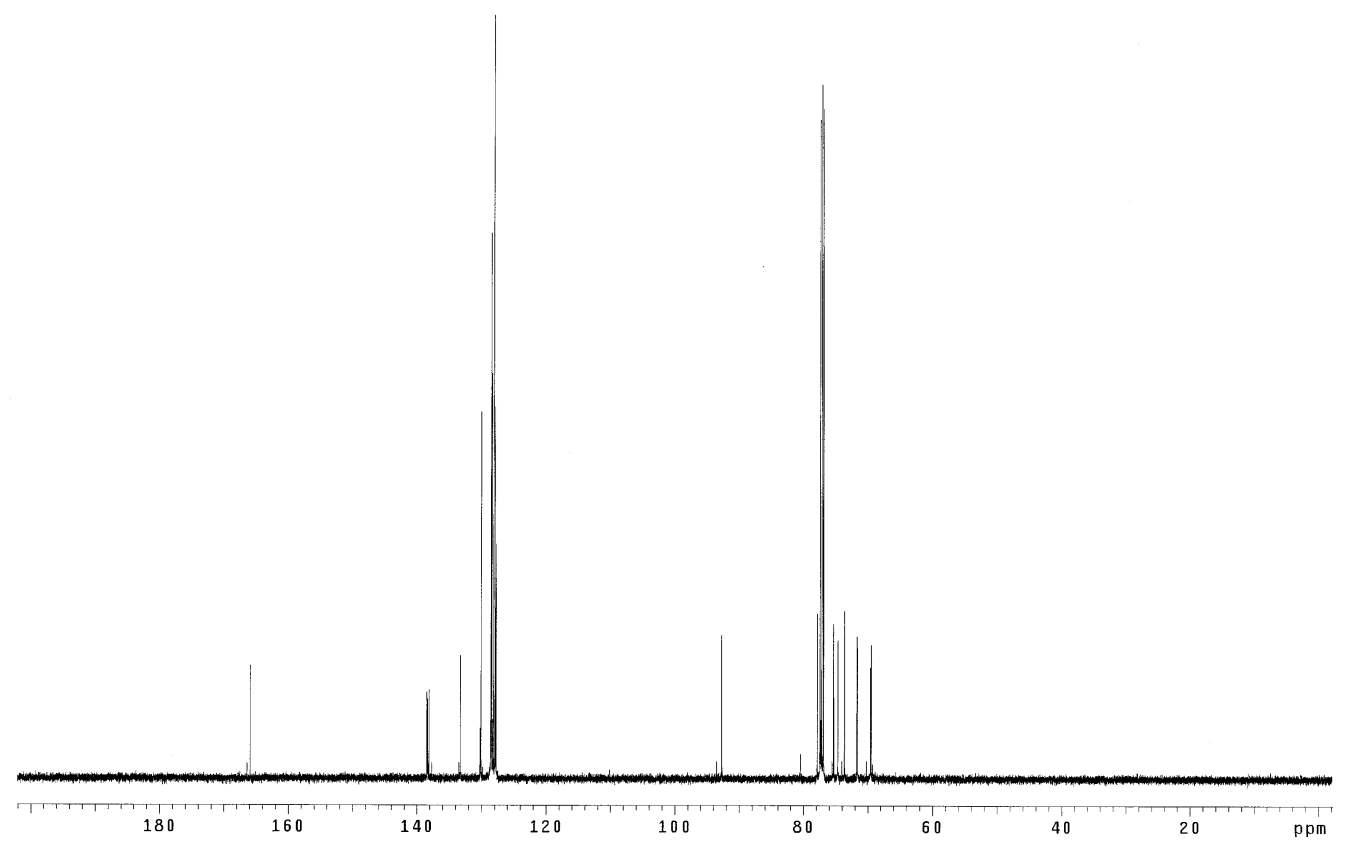



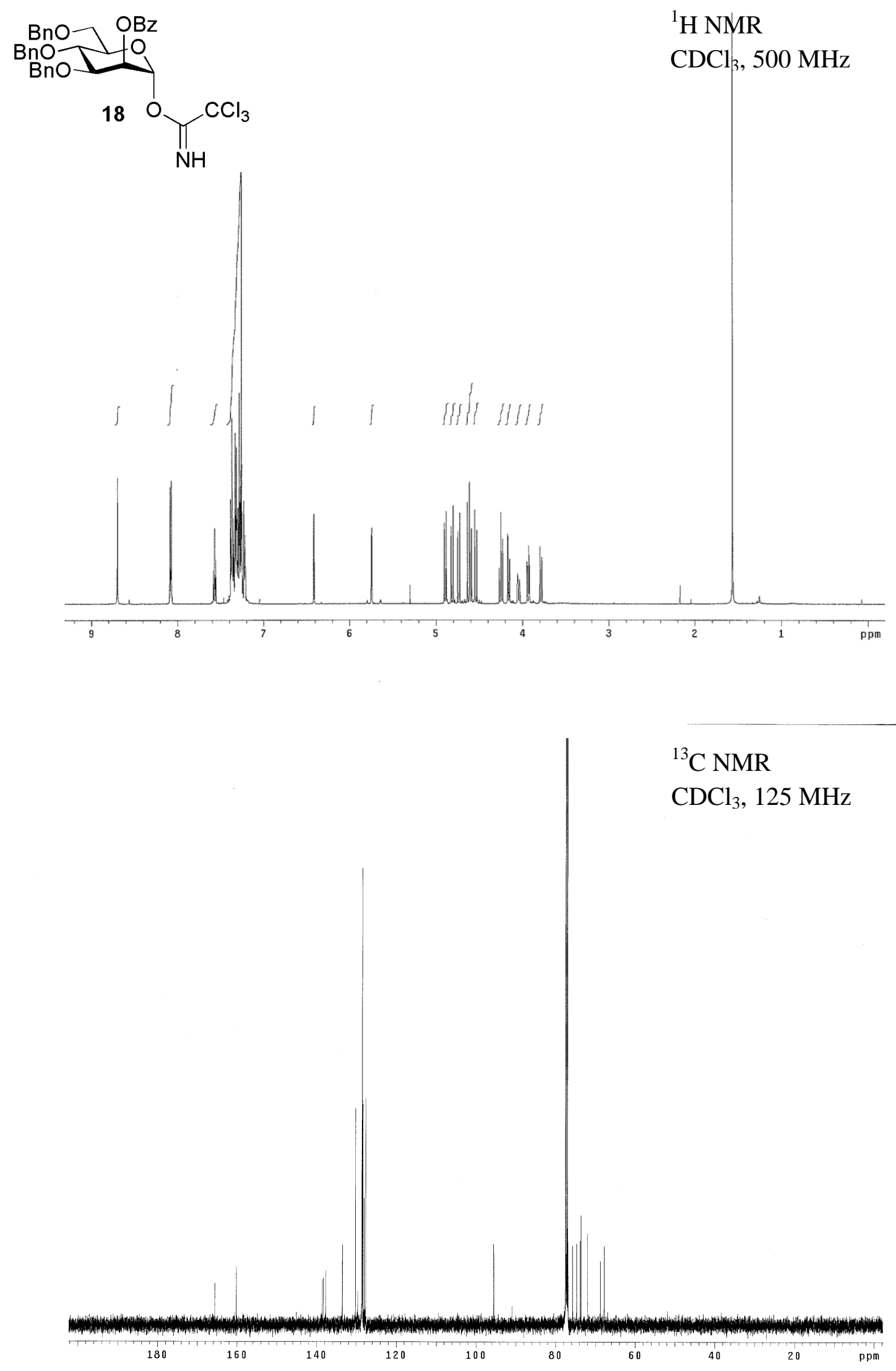


$$
\text { OBn }
$$

19

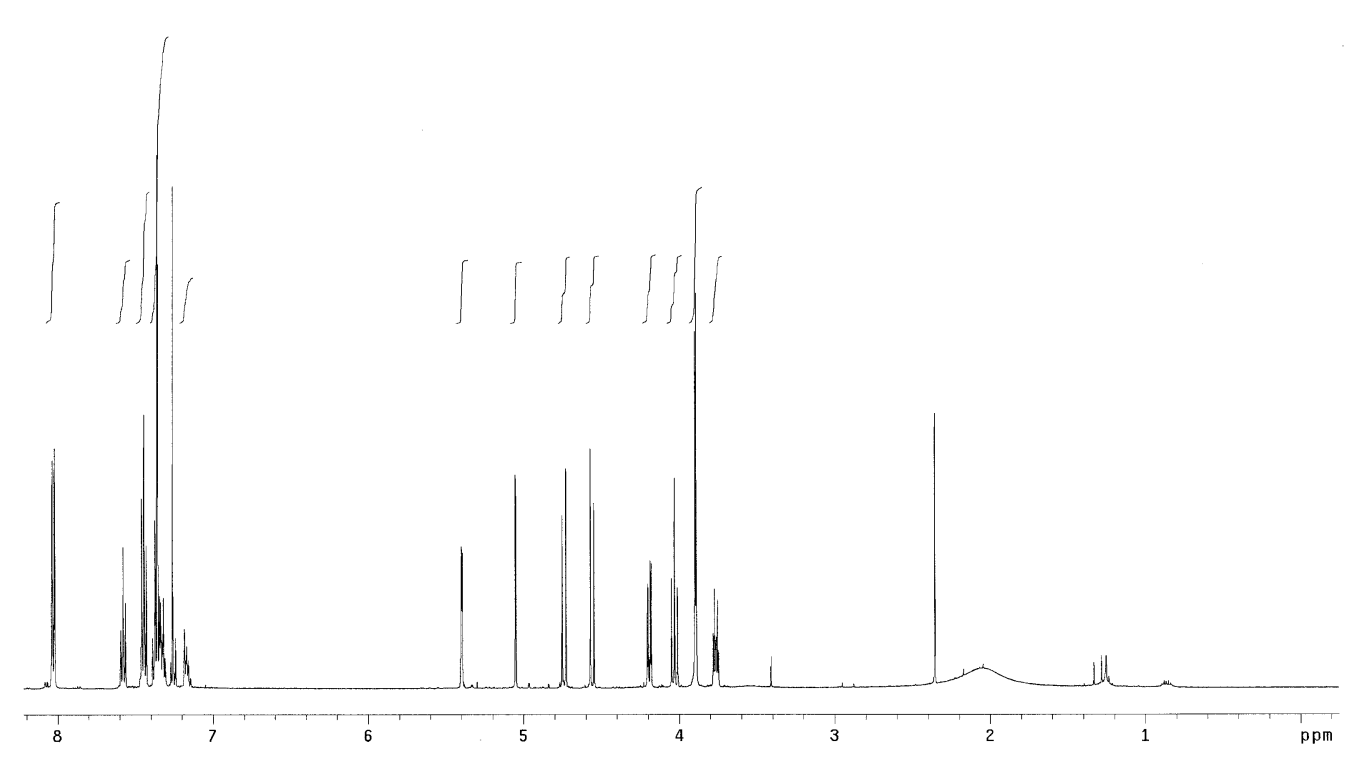

${ }^{1} \mathrm{H}$ NMR

$\mathrm{CDCl}_{3}, 500 \mathrm{MHz}$

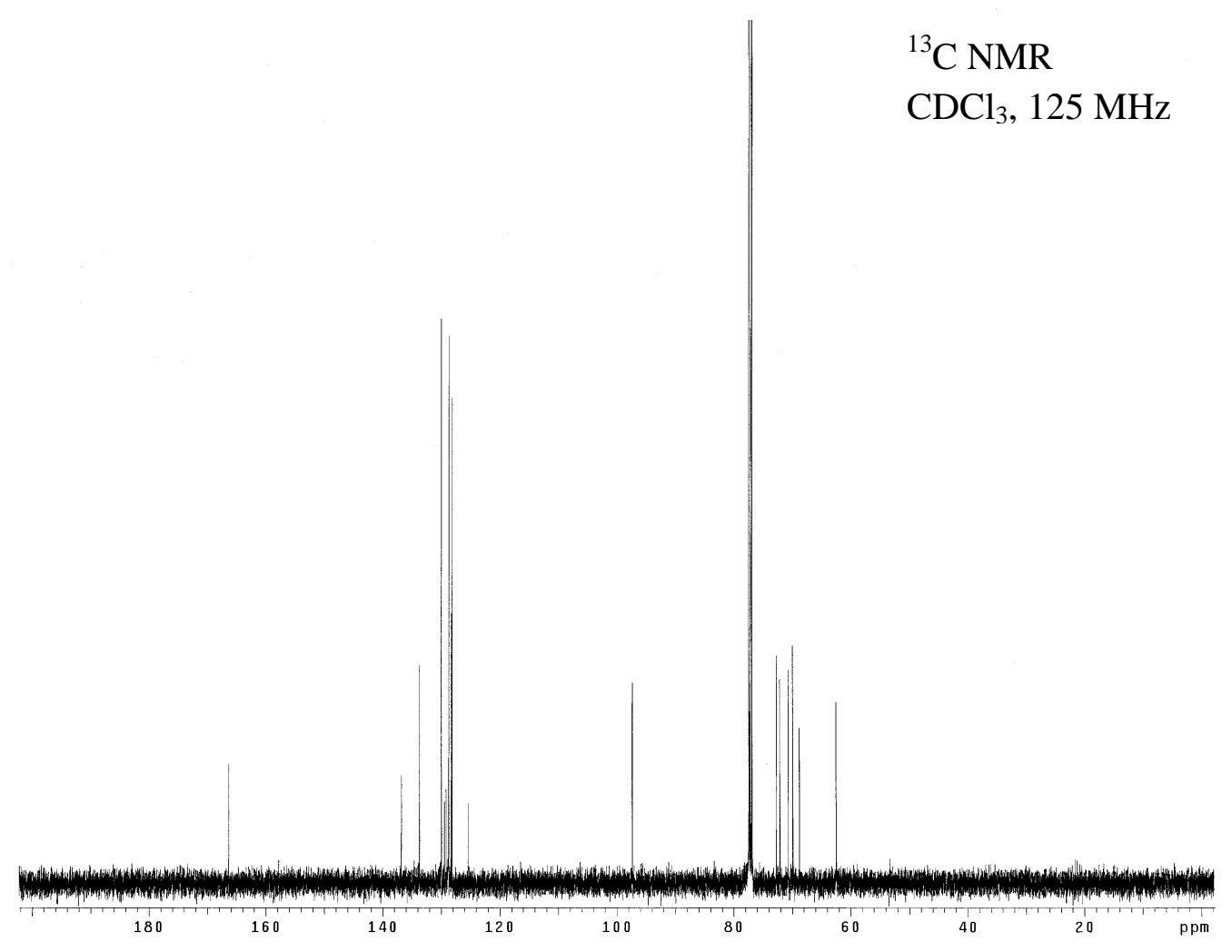



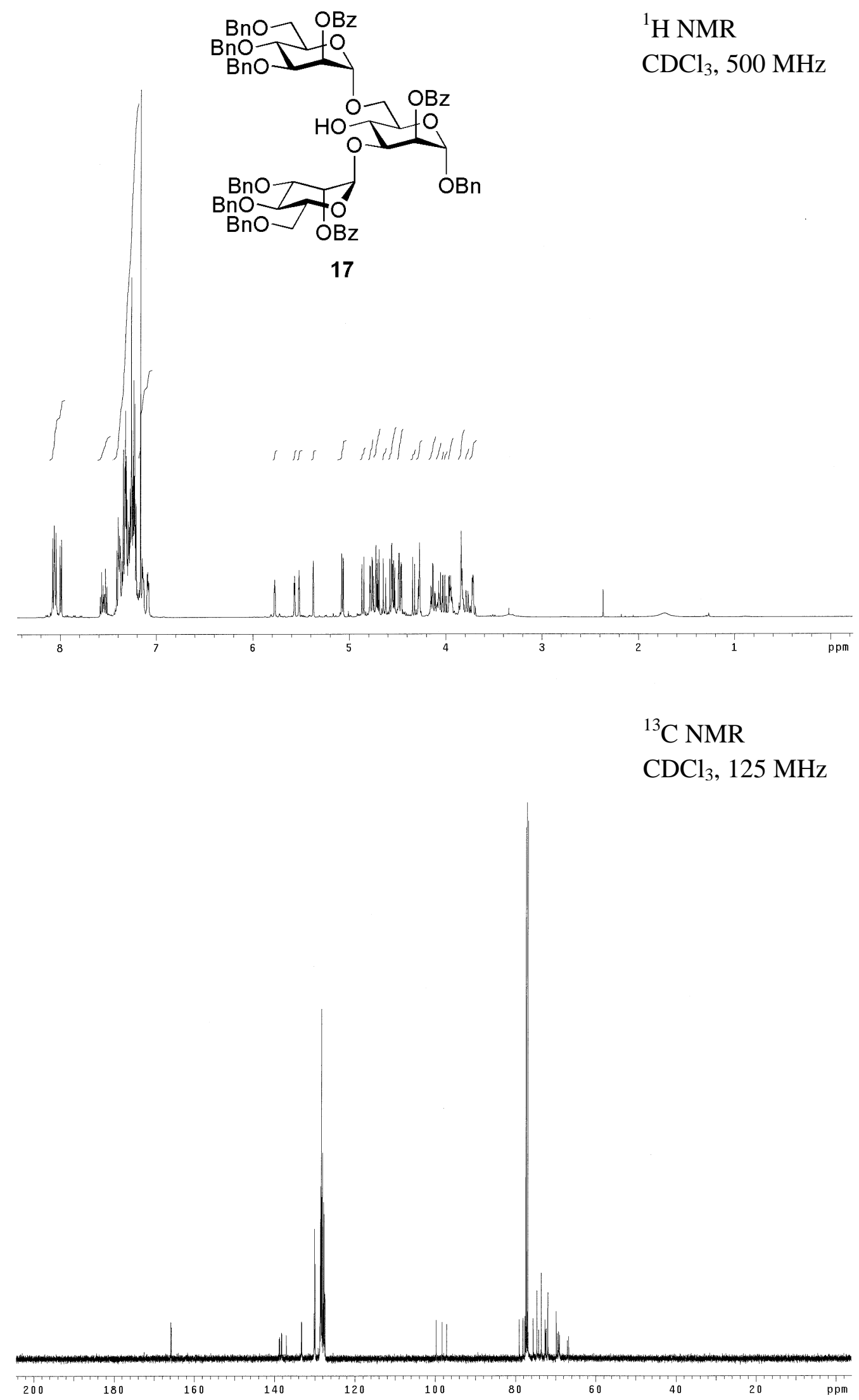


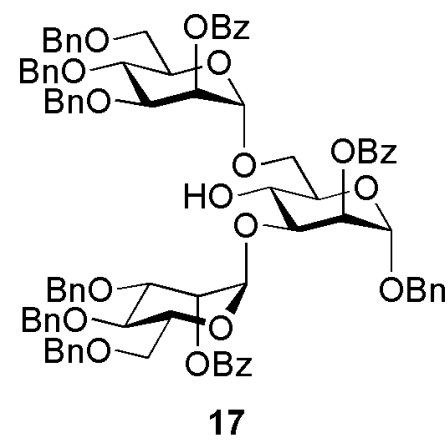

HMBC NMR

$\mathrm{CDCl}_{3}$

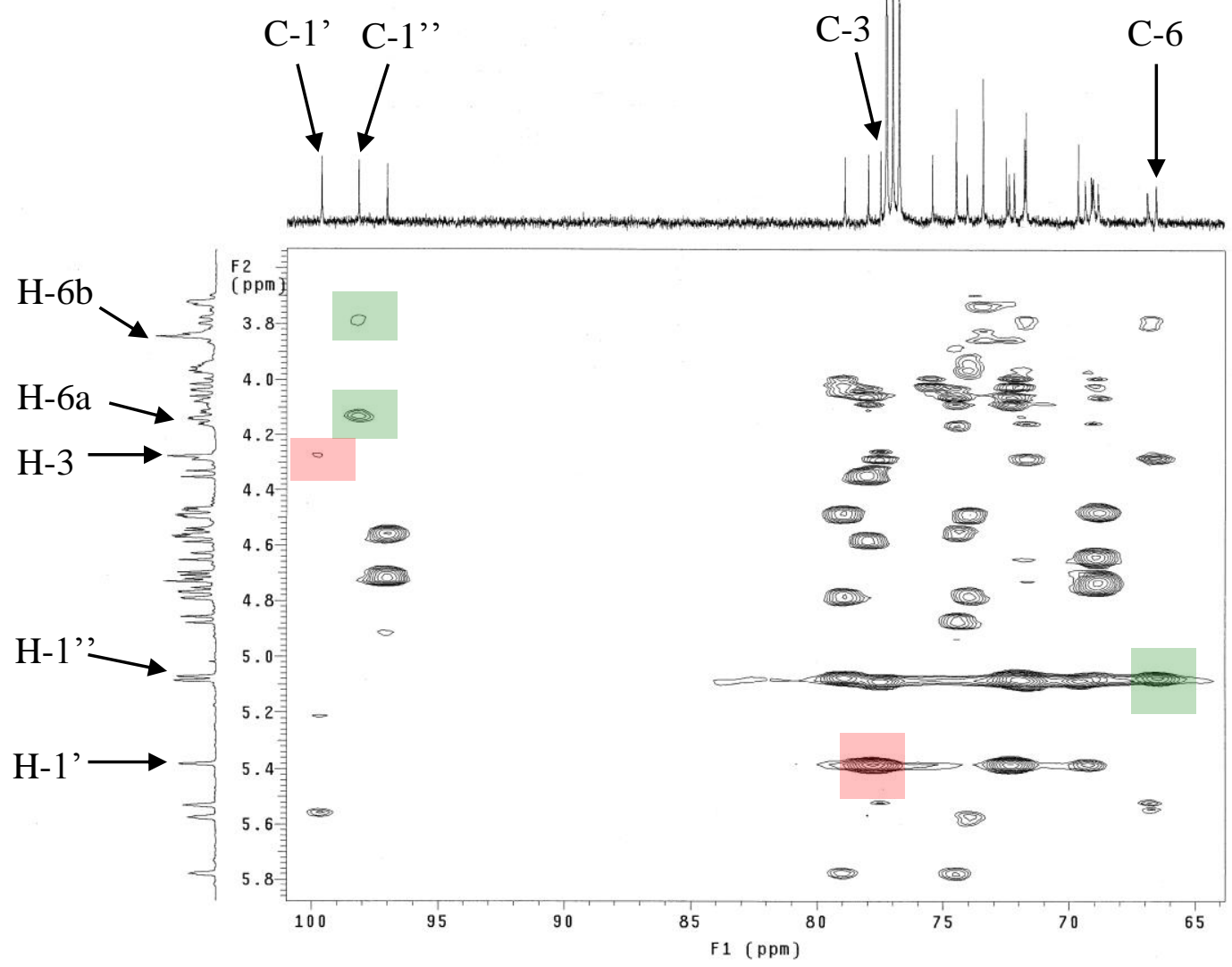



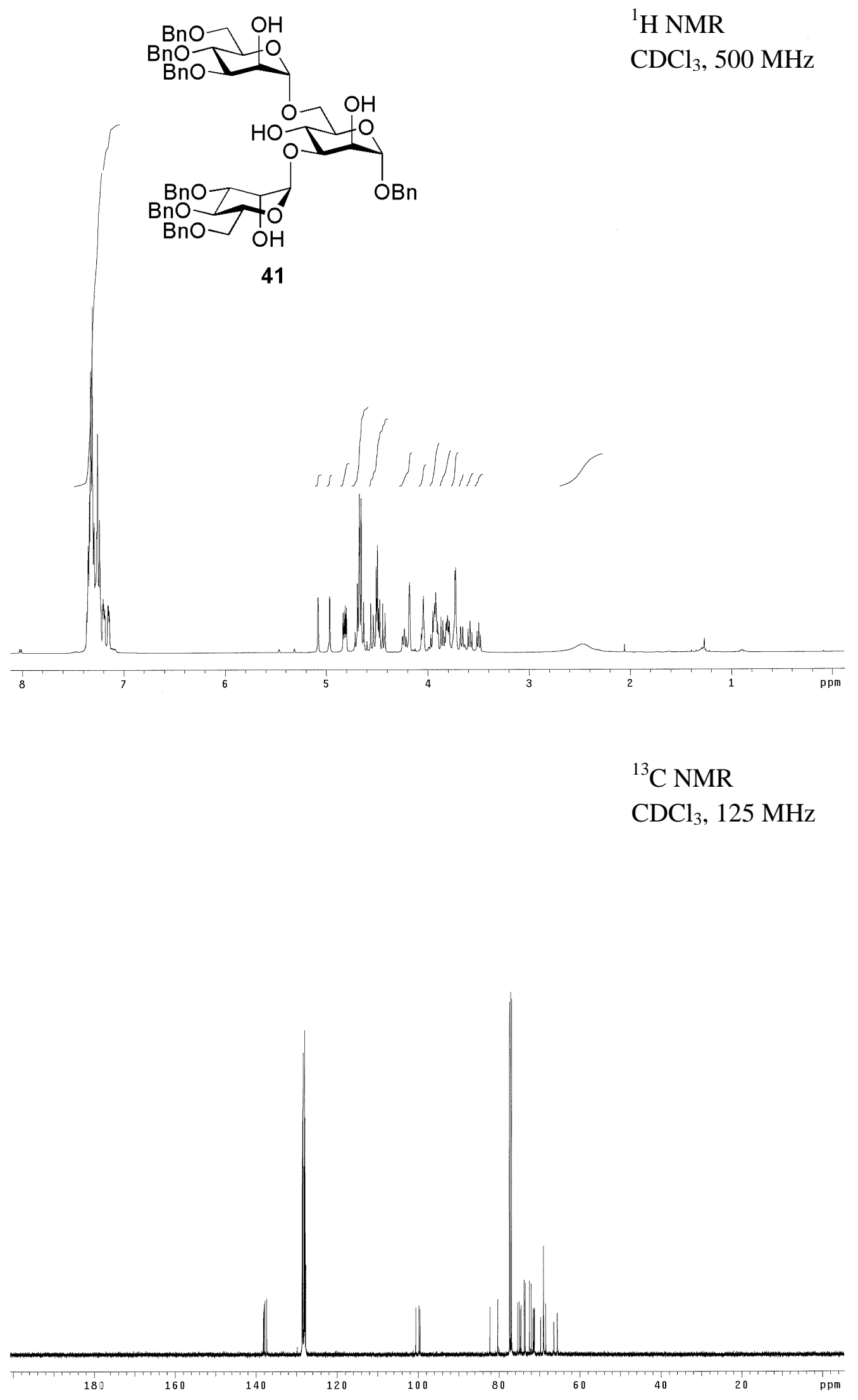


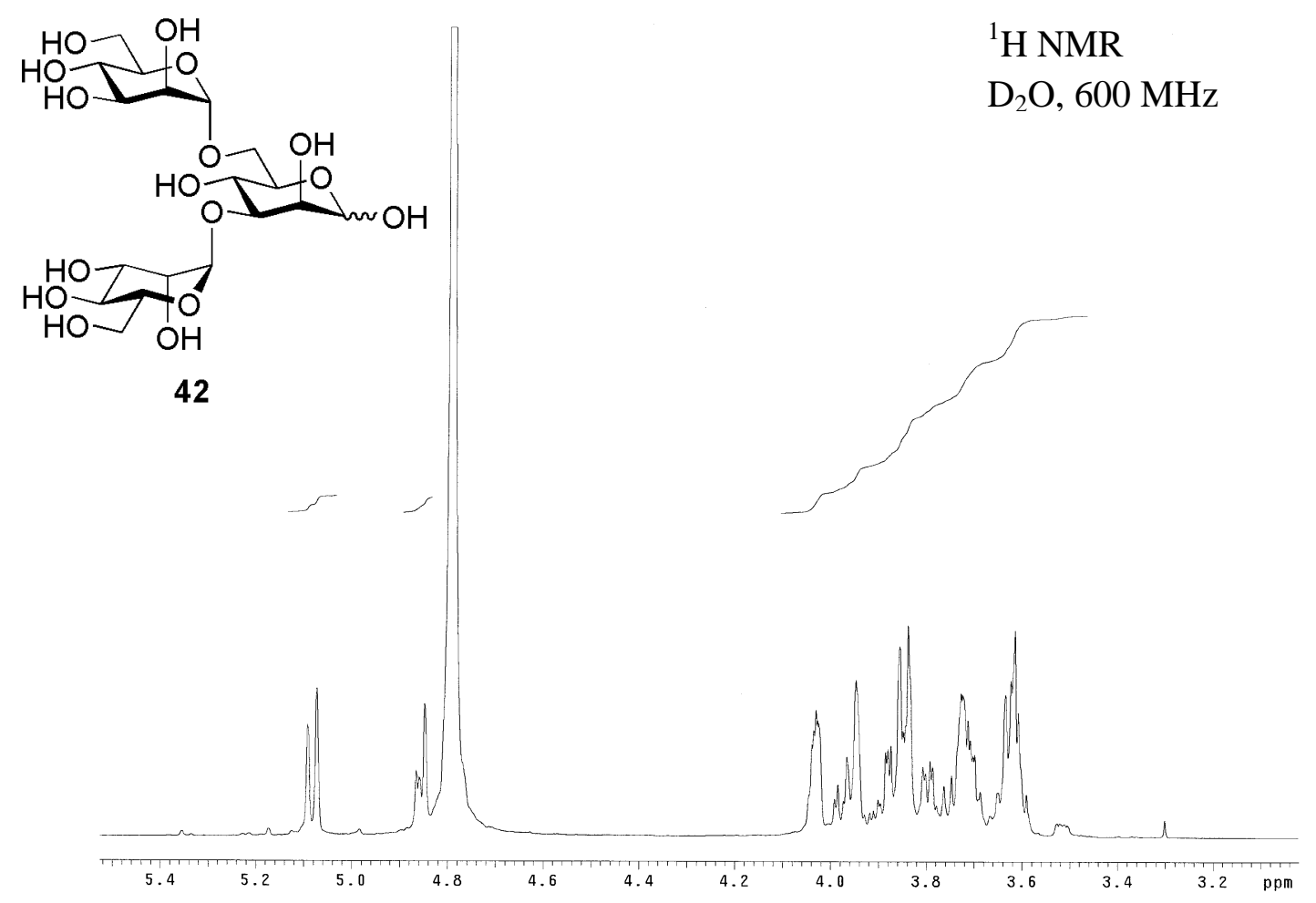

${ }^{13} \mathrm{C}$ NMR

$\mathrm{D}_{2} \mathrm{O}, 150 \mathrm{MHz}$

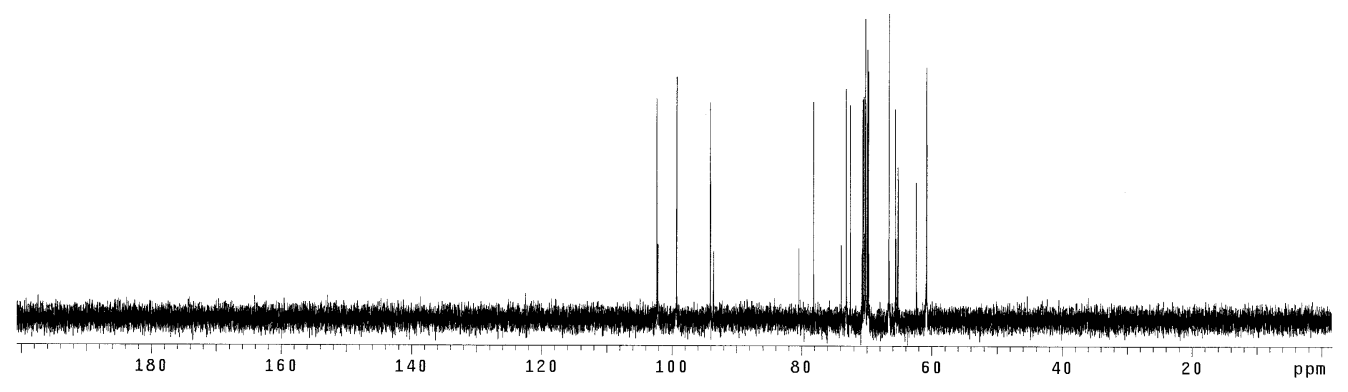




\section{$\widehat{C}_{A C O}^{O A C} \mathcal{Z}_{O A C}$}

46
${ }^{1} \mathrm{H}$ NMR

$\mathrm{CDCl}_{3}, 500 \mathrm{MHz}$

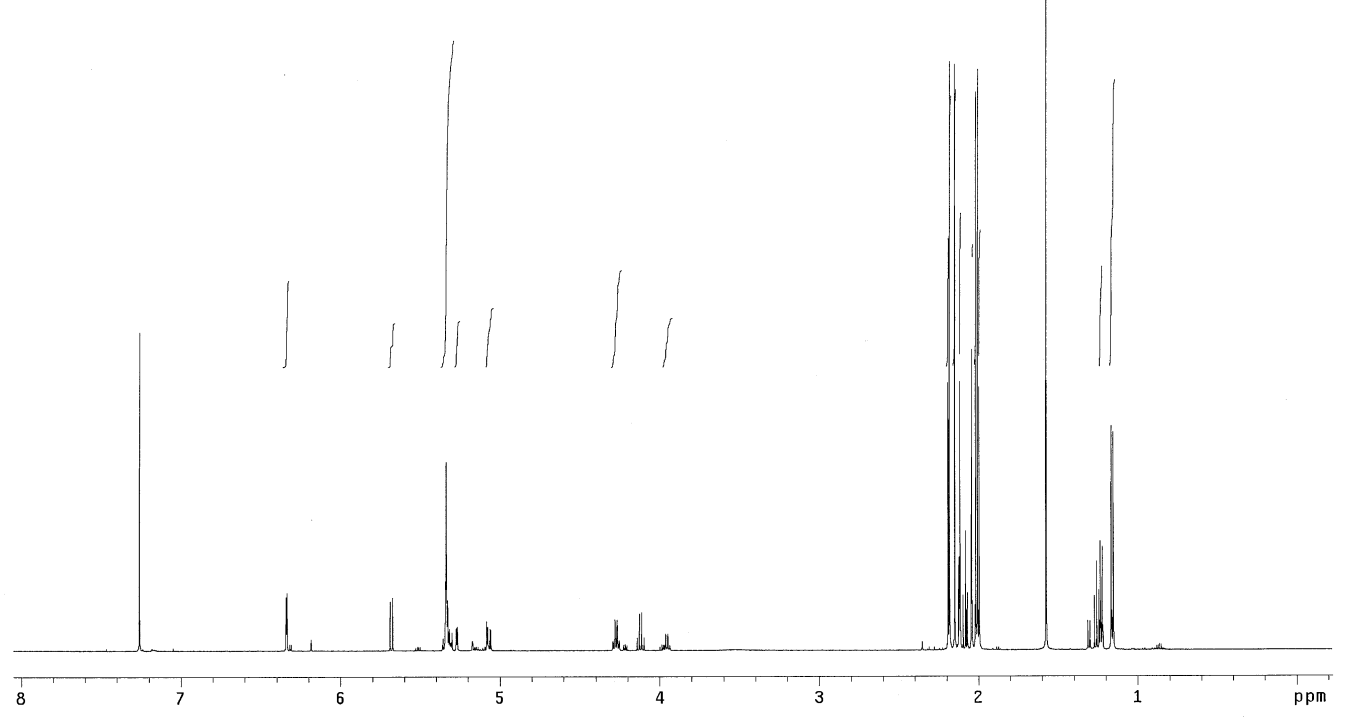


$\sum_{A 7}^{\mathrm{Br}}$
${ }^{1} \mathrm{H}$ NMR

$\mathrm{CDCl}_{3}, 500 \mathrm{MHz}$
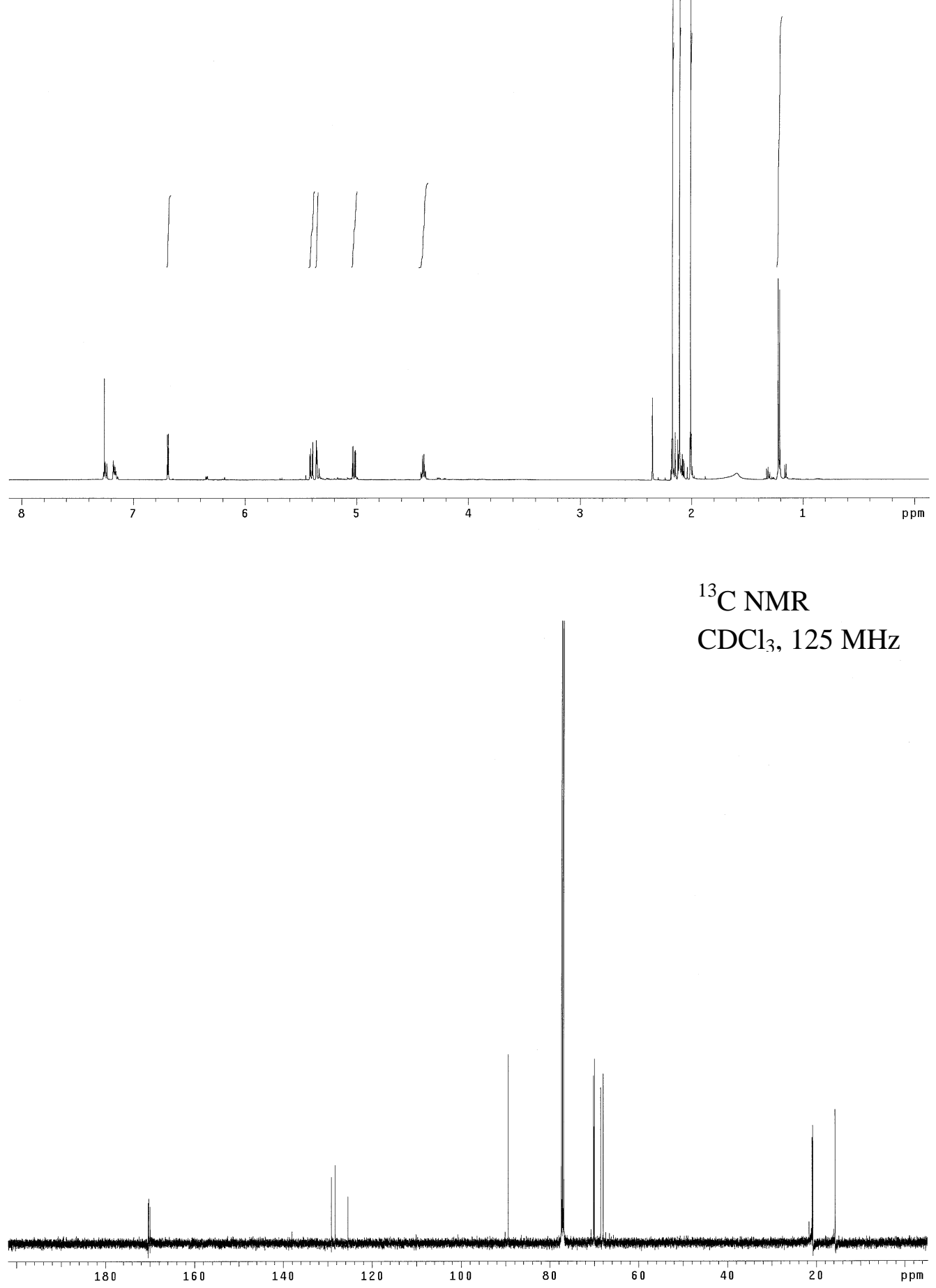


\section{$\mathrm{FO}_{\mathrm{OH}}^{\mathrm{OH}} \mathrm{SEt}$}

48
${ }^{1} \mathrm{H}$ NMR

$\mathrm{CDCl}_{3}, 500 \mathrm{MHz}$
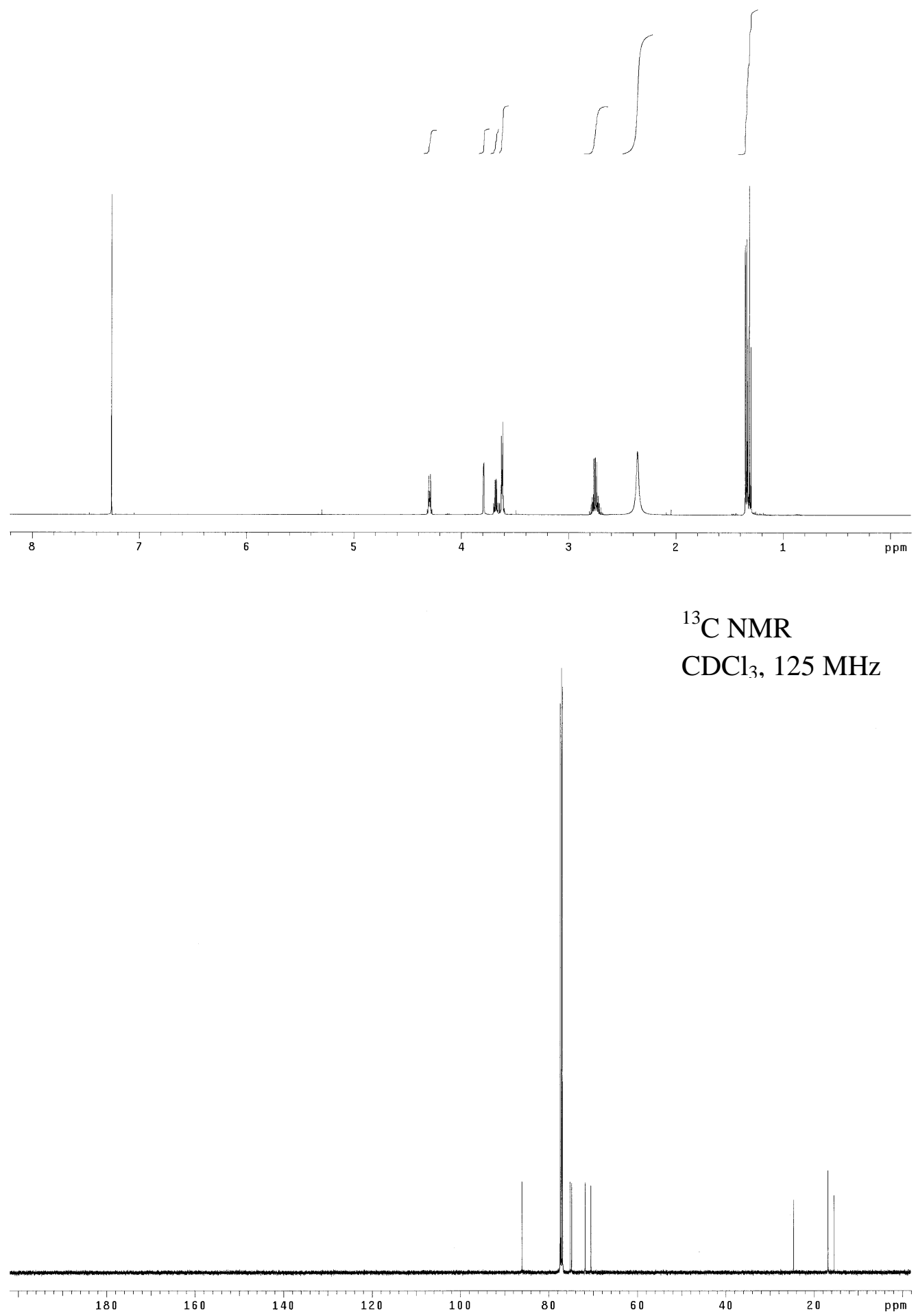

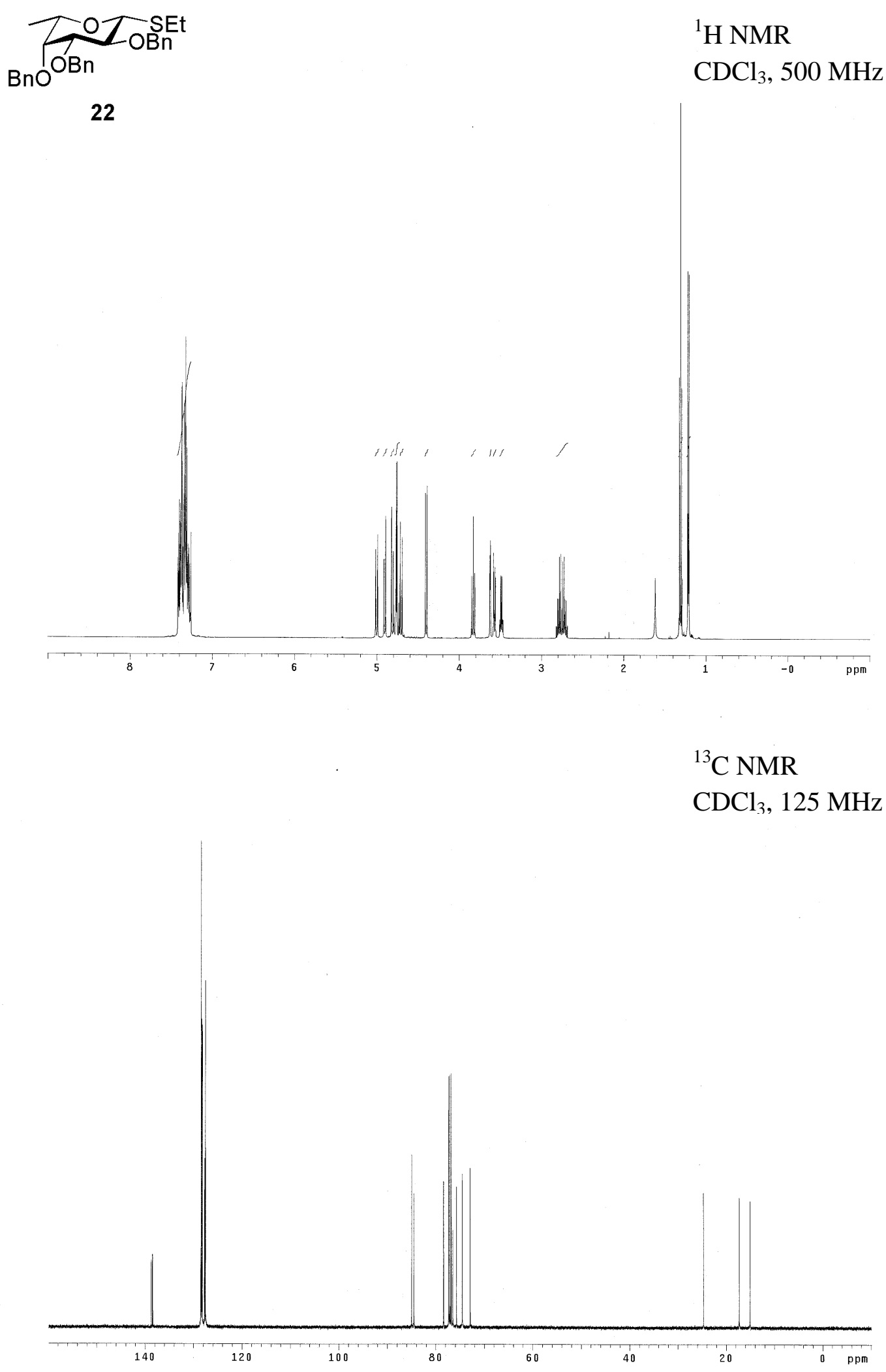

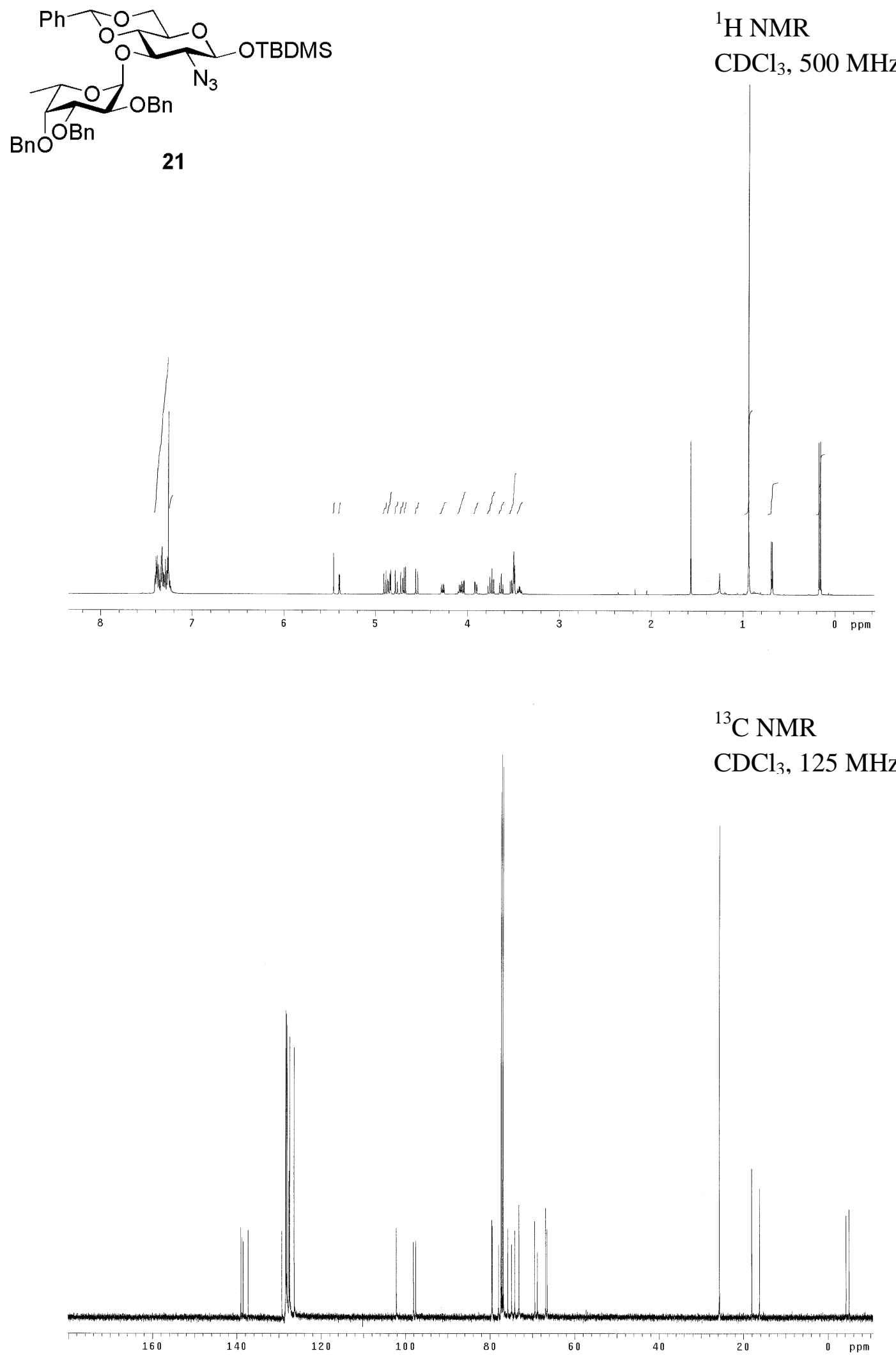


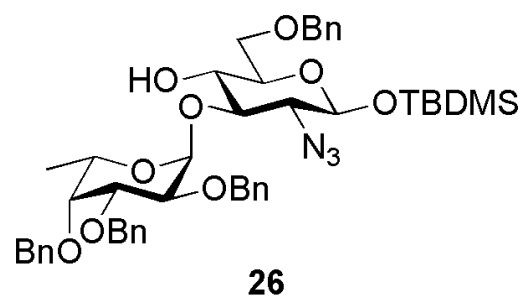

${ }^{1} \mathrm{H}$ NMR

$\mathrm{CDCl}_{3}, 500 \mathrm{MHz}$

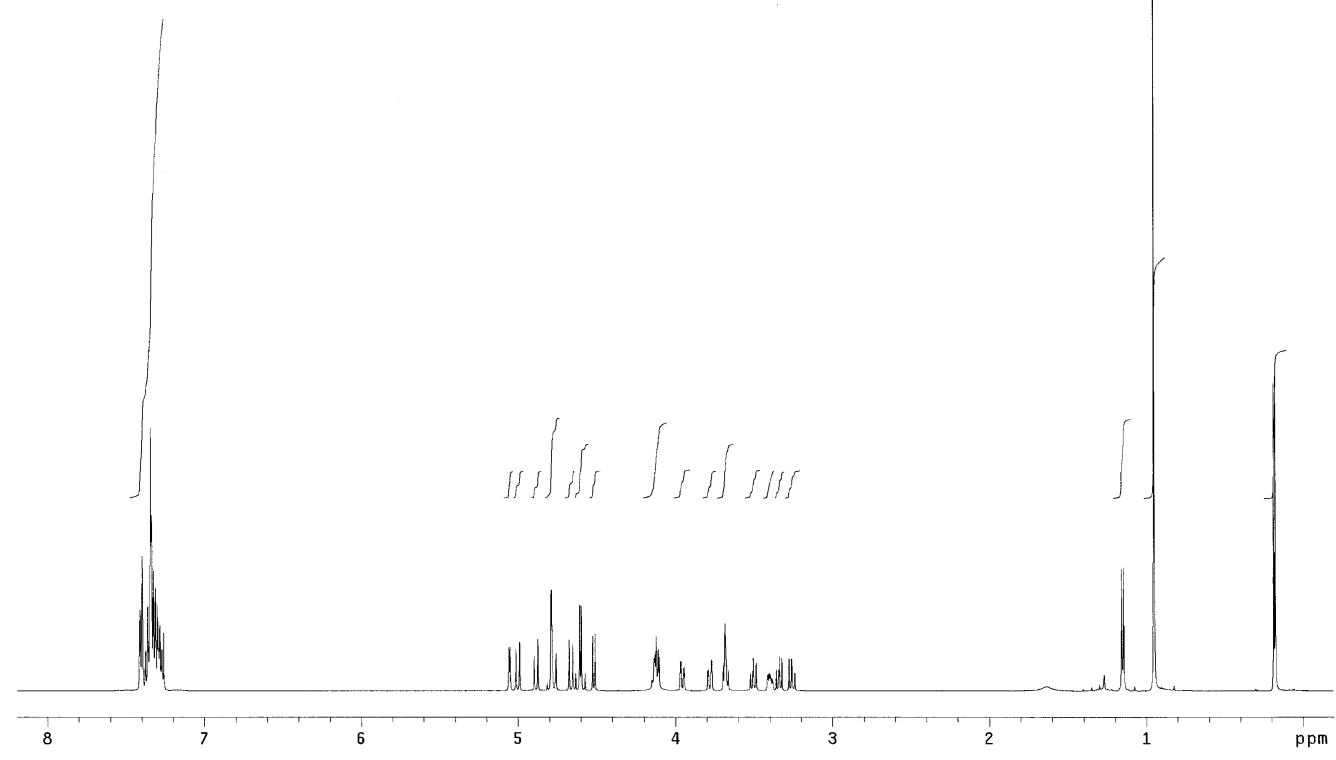

${ }^{13} \mathrm{C}$ NMR

$\mathrm{CDCl}_{3}, 125 \mathrm{MHz}$

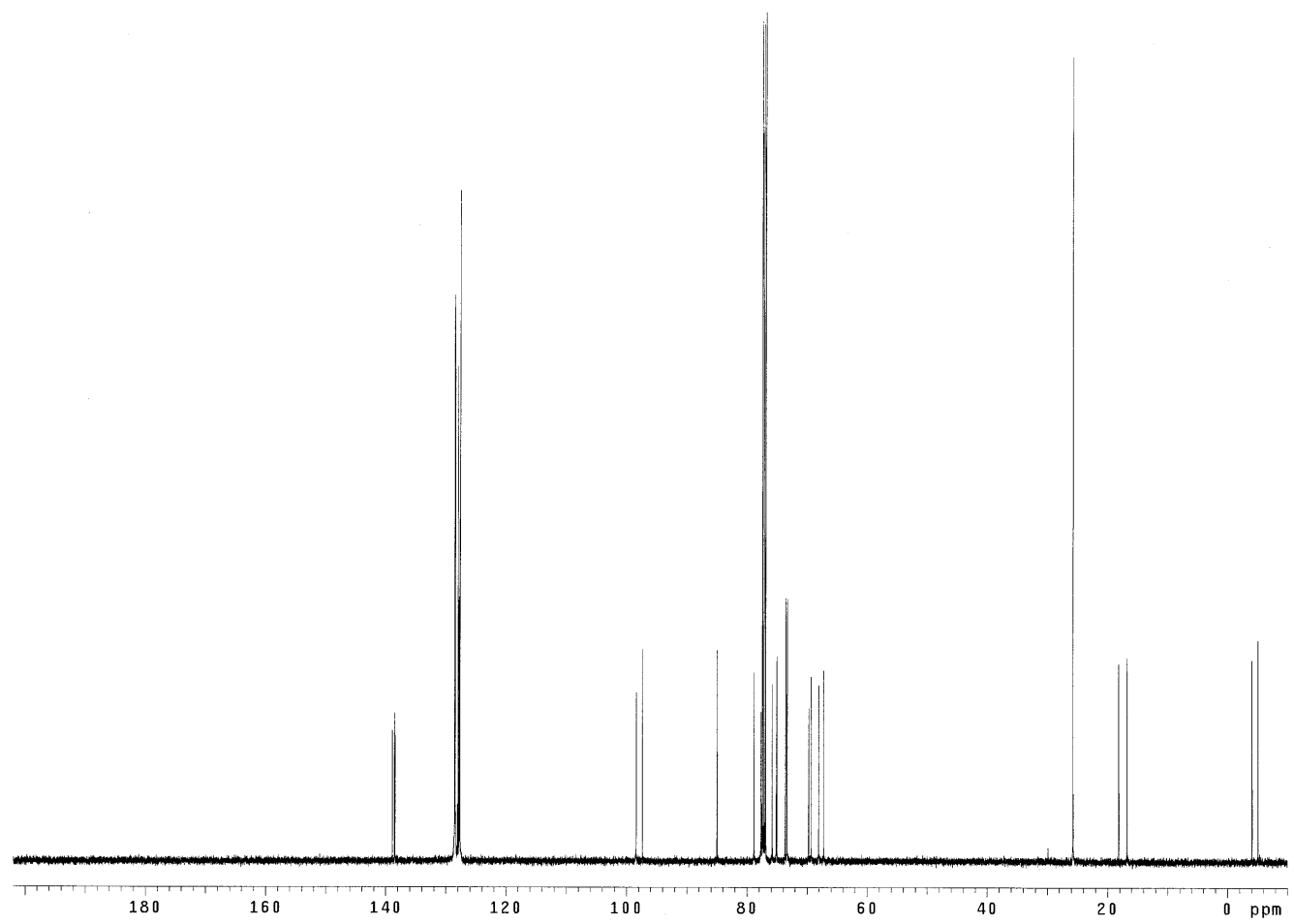



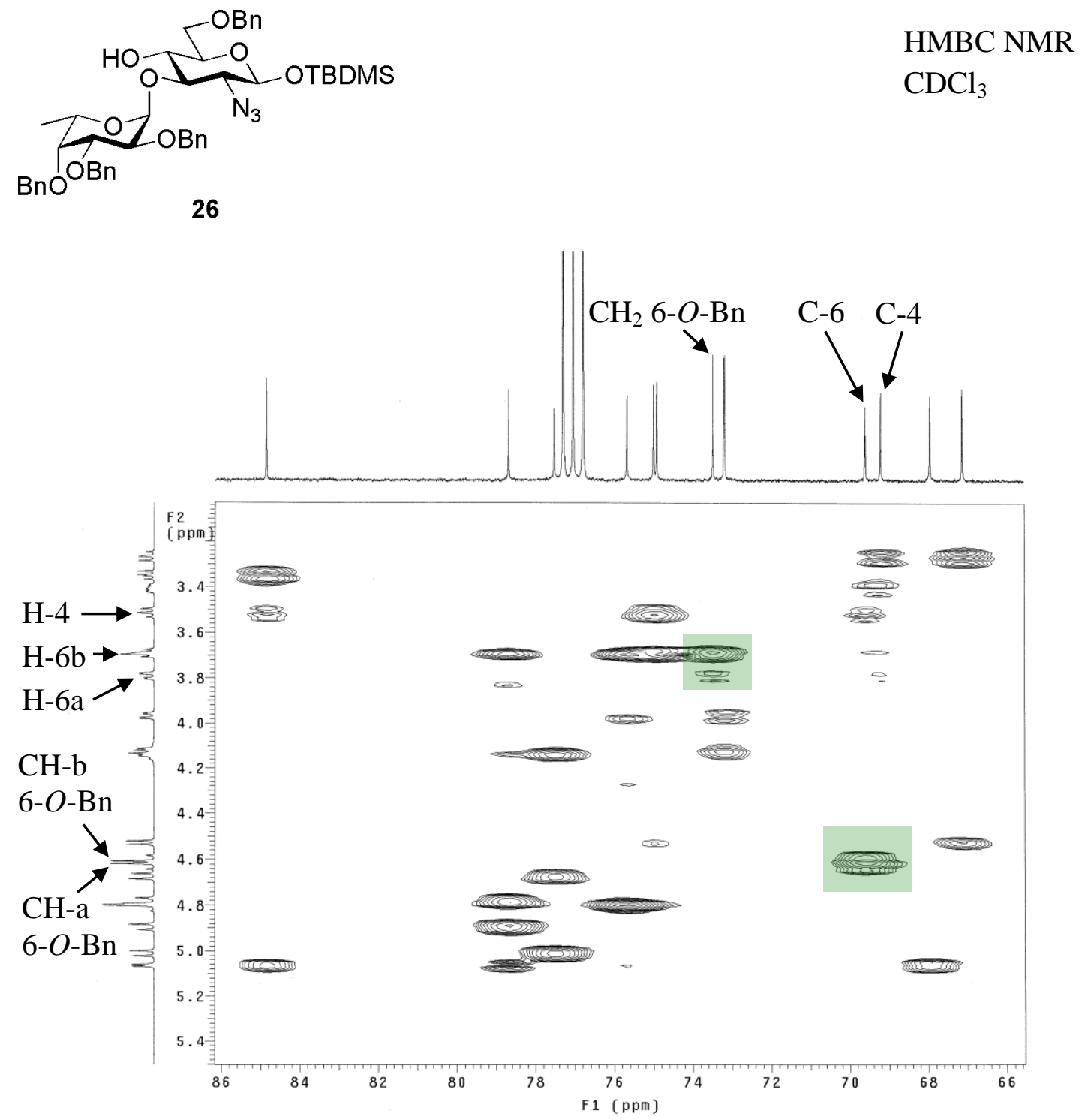


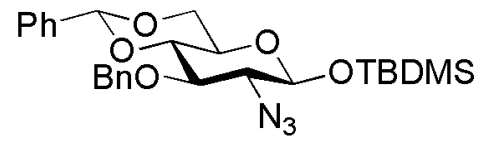

49
${ }^{1} \mathrm{H}$ NMR

$\mathrm{CDCl}_{3}, 500 \mathrm{MHz}$
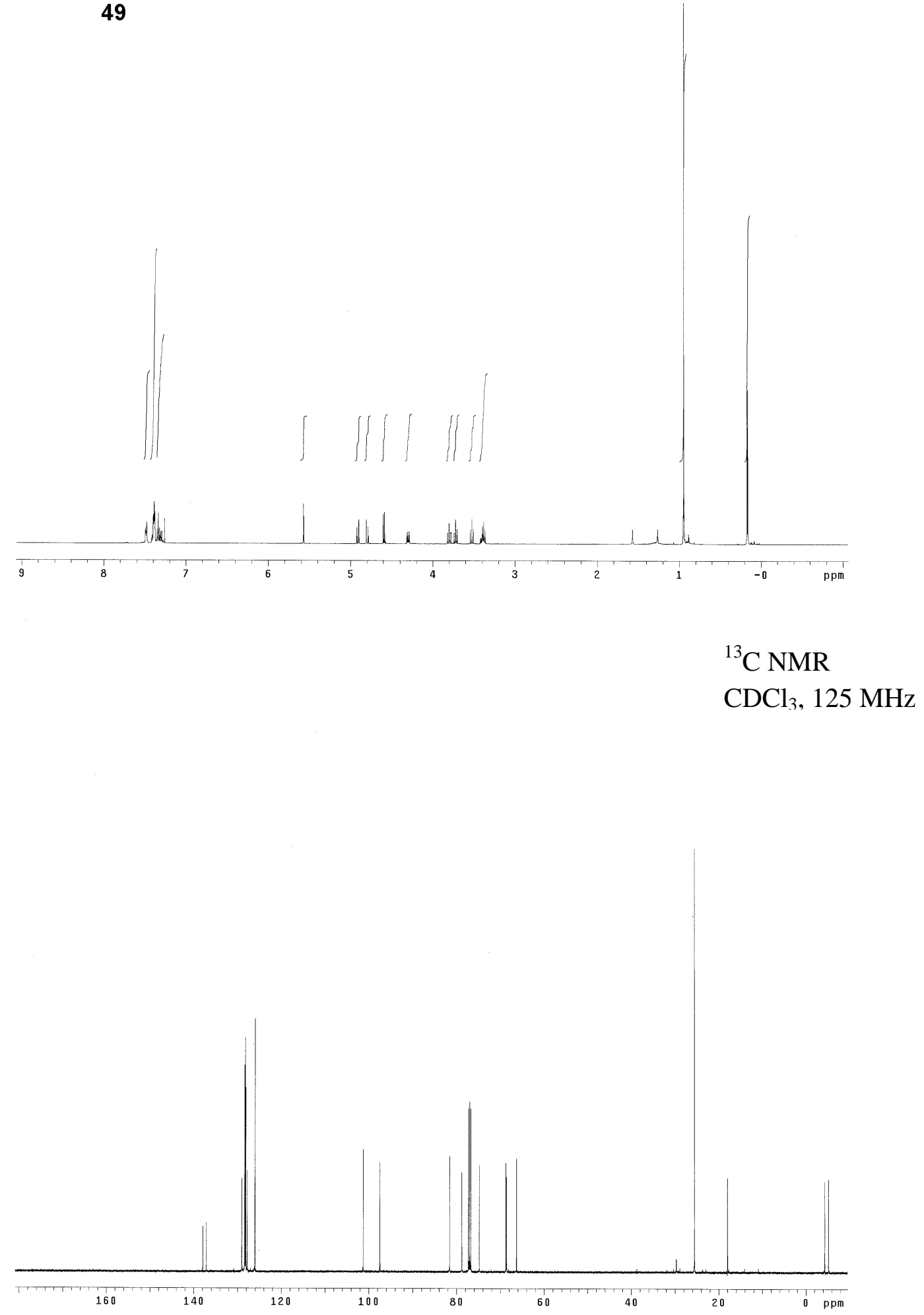

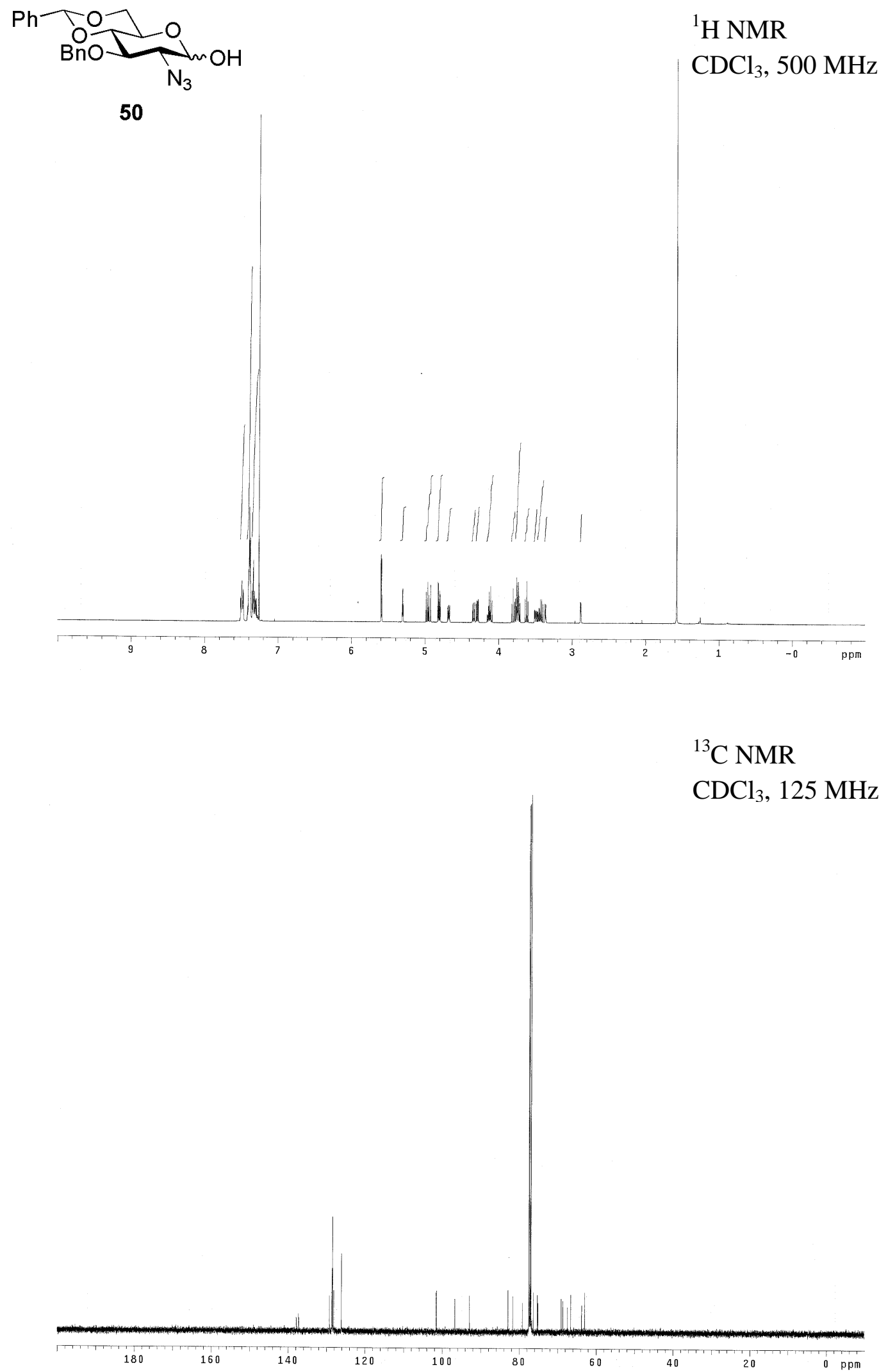

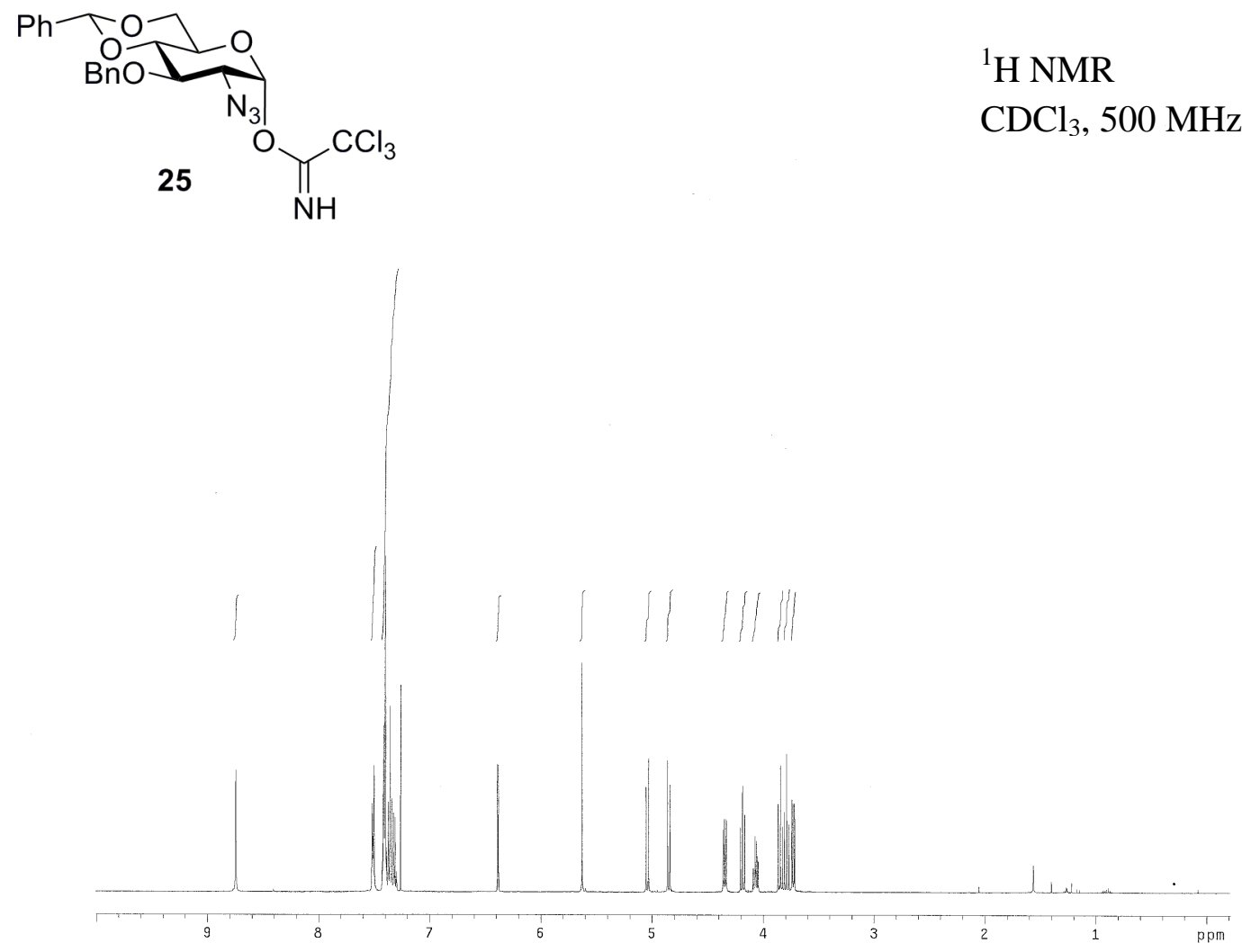

${ }^{13} \mathrm{C}$ NMR

$\mathrm{CDCl}_{3}, 125 \mathrm{MHz}$

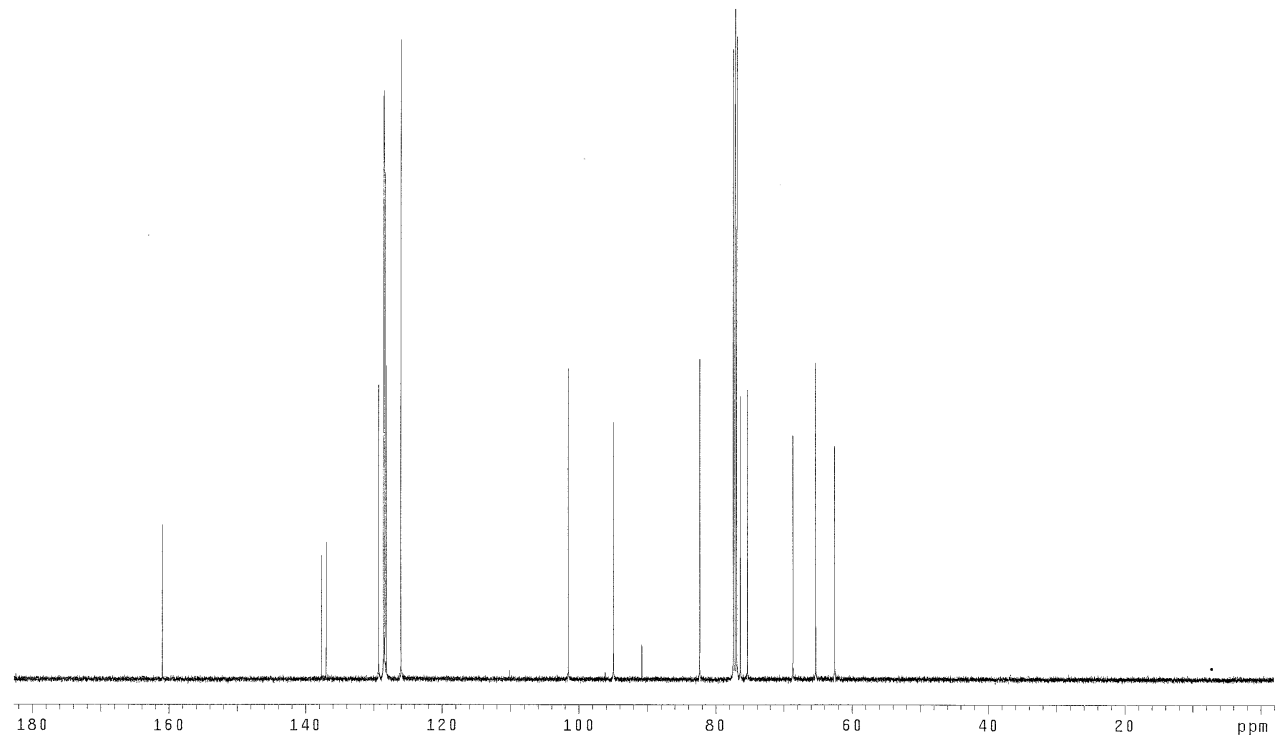




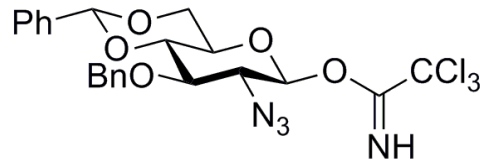

25

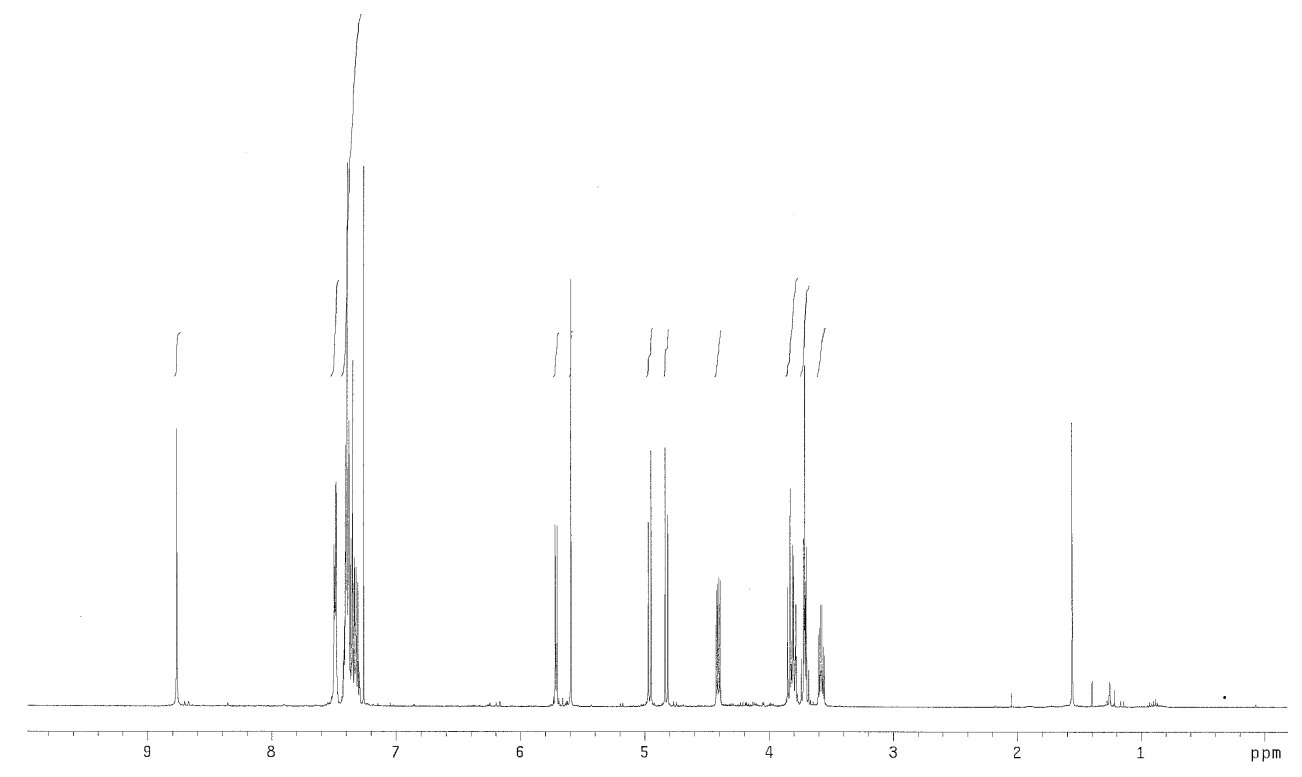

${ }^{13} \mathrm{C}$ NMR

$\mathrm{CDCl}_{3}, 125 \mathrm{MHz}$

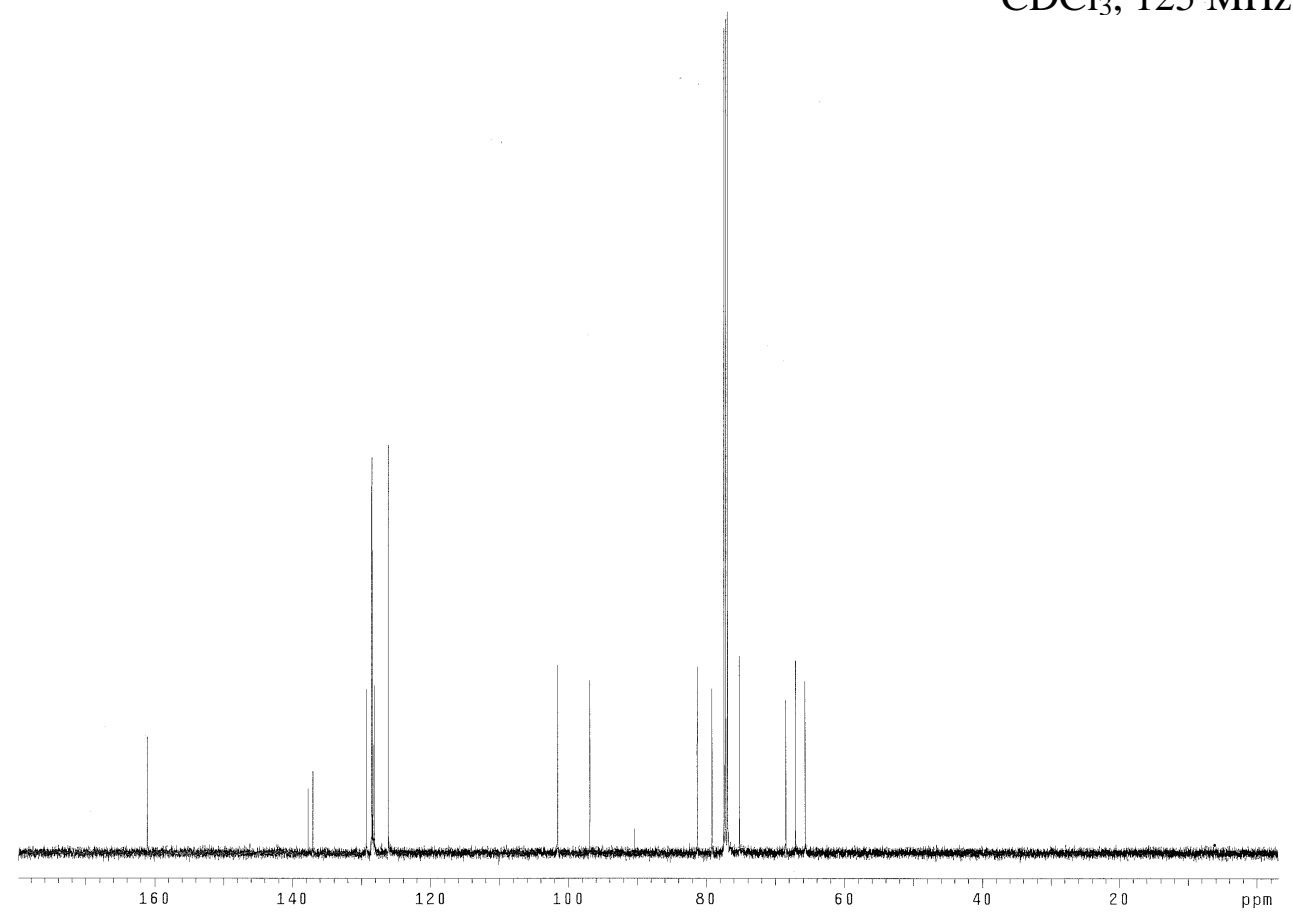



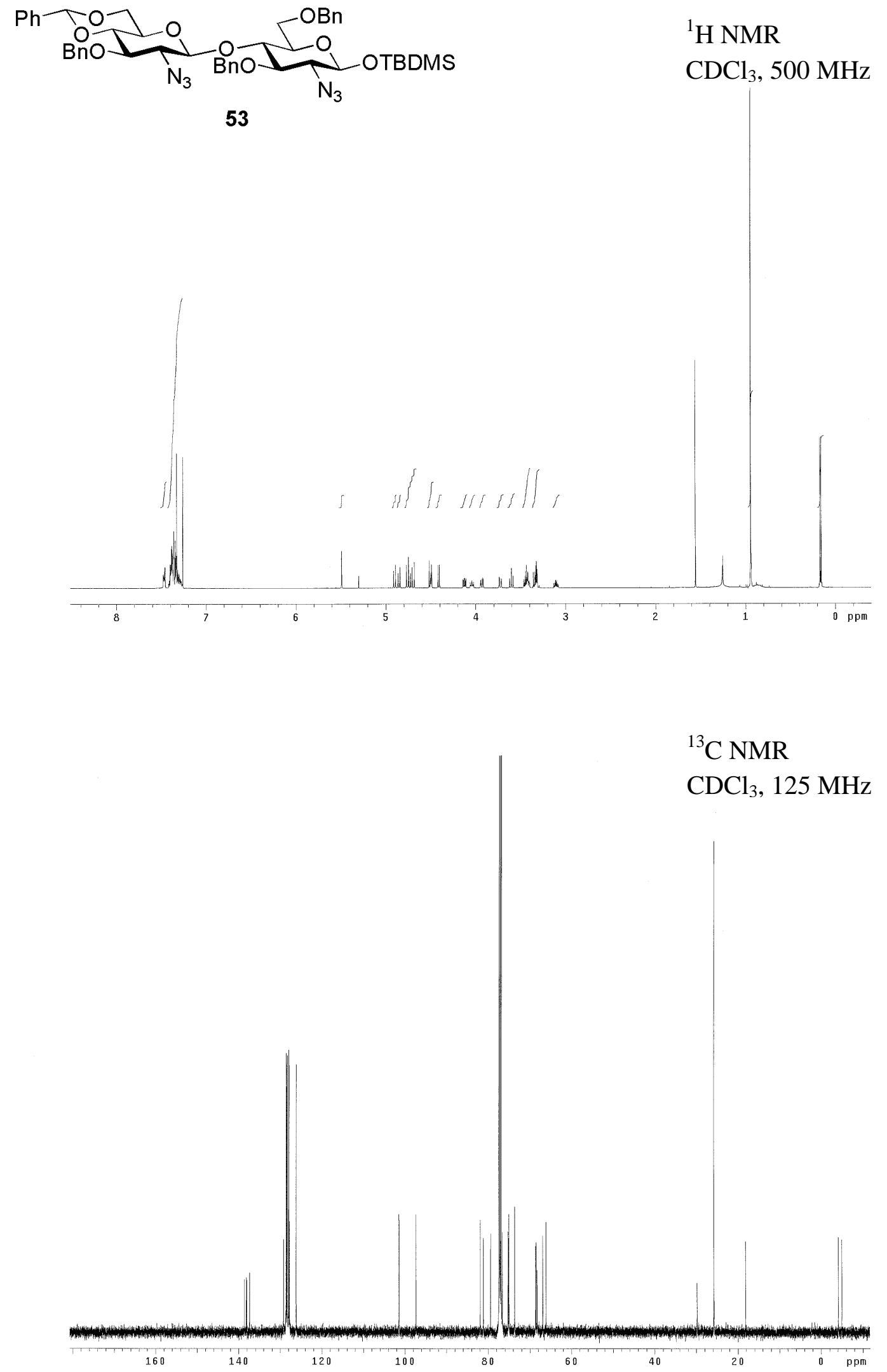


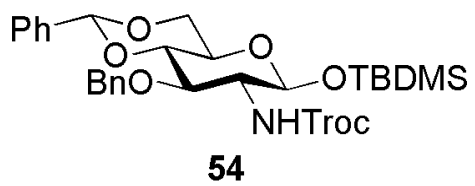

54
${ }^{1} \mathrm{H}$ NMR

$\mathrm{CDCl}_{3}, 500 \mathrm{MHz}$

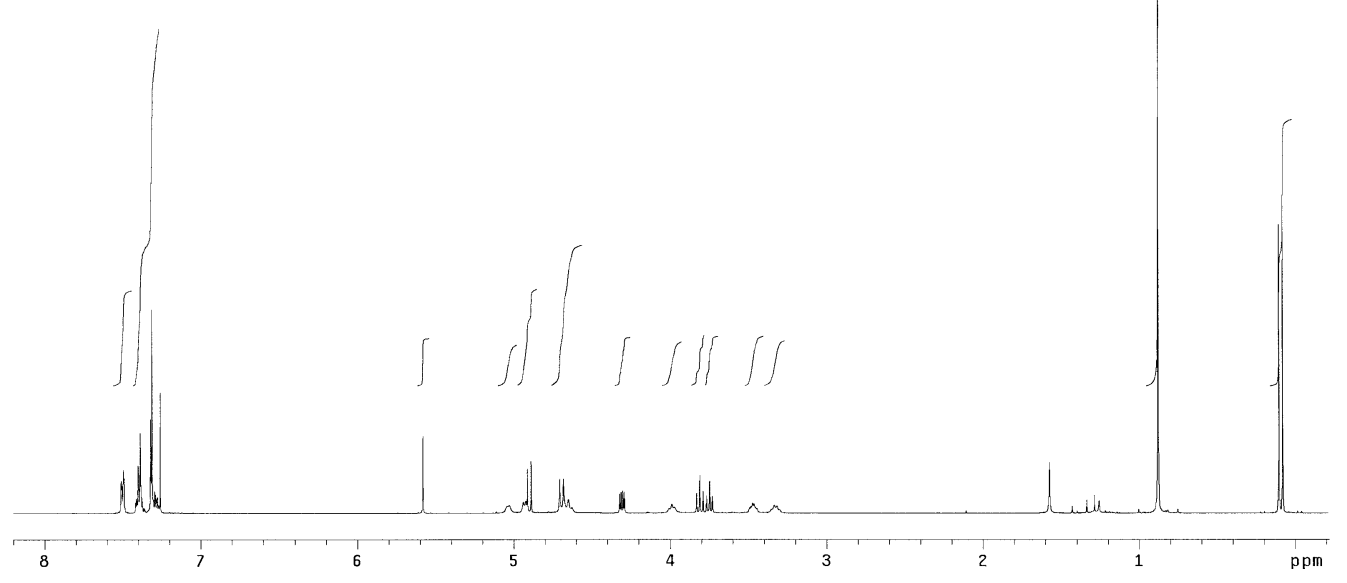

${ }^{13} \mathrm{C}$ NMR

$\mathrm{CDCl}_{3}, 125 \mathrm{MHz}$

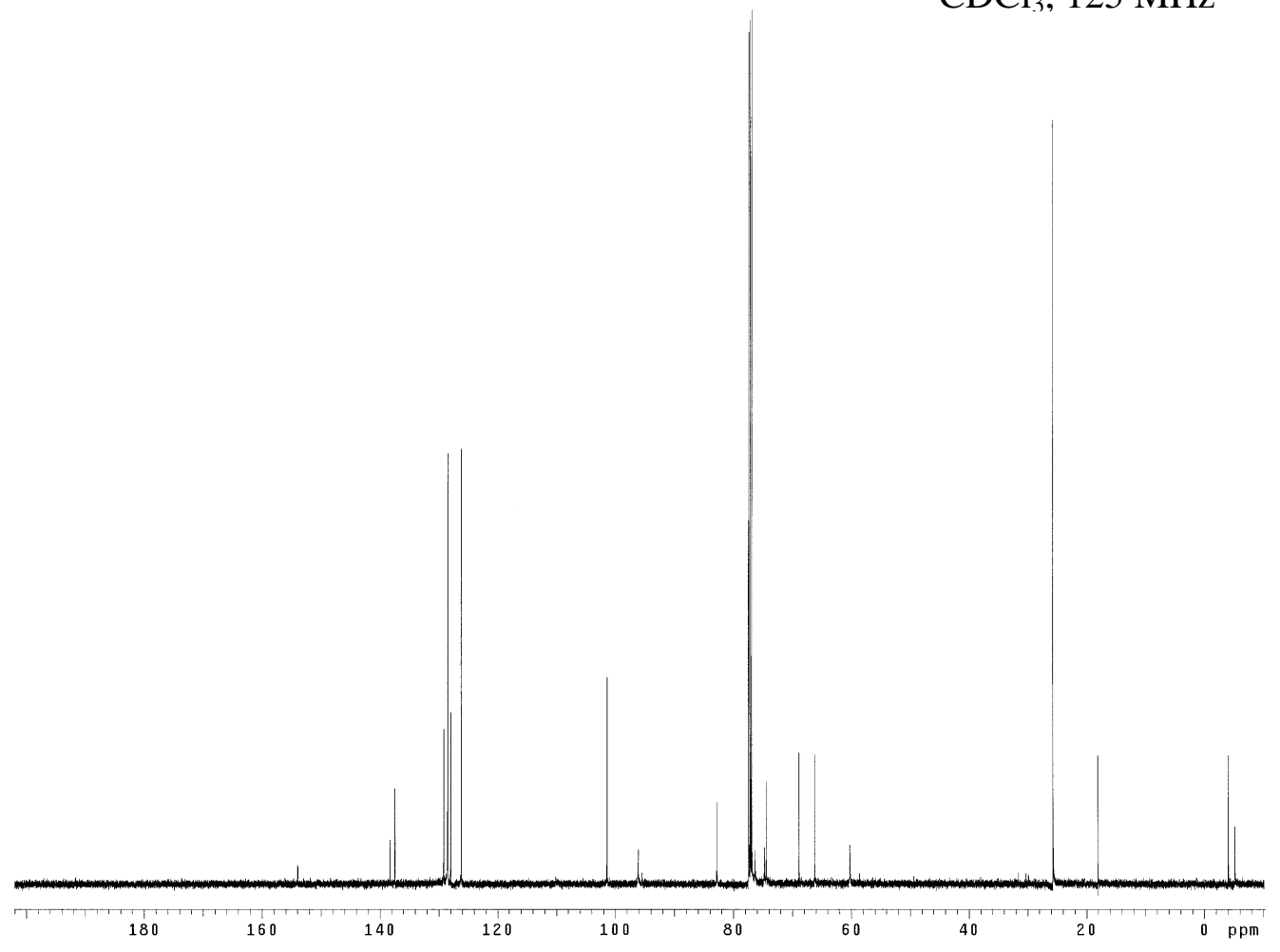




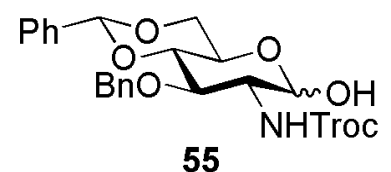

${ }^{1} \mathrm{H}$ NMR

55

$\mathrm{CDCl}_{3}, 500 \mathrm{MHz}$

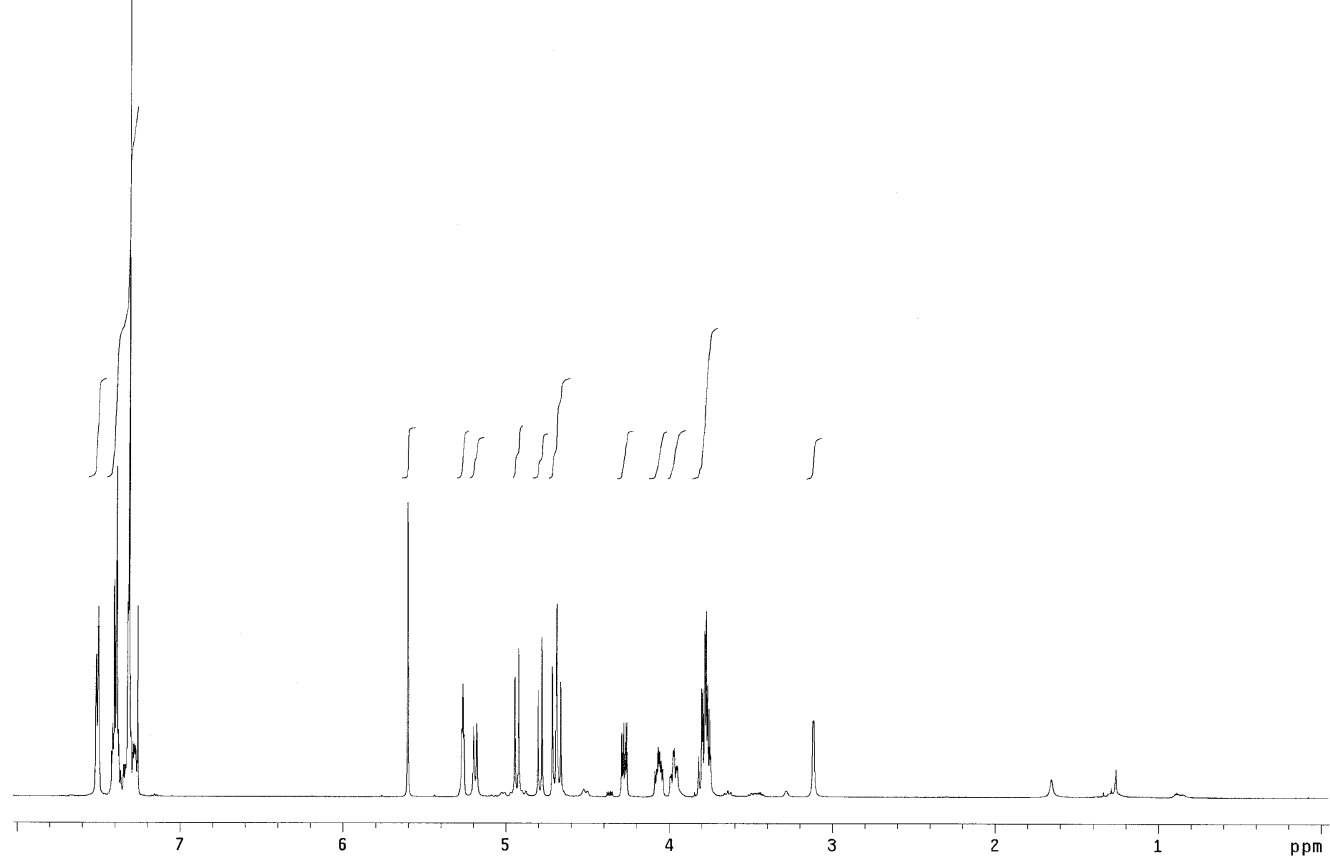

${ }^{13} \mathrm{C}$ NMR

$\mathrm{CDCl}_{3}, 125 \mathrm{MHz}$

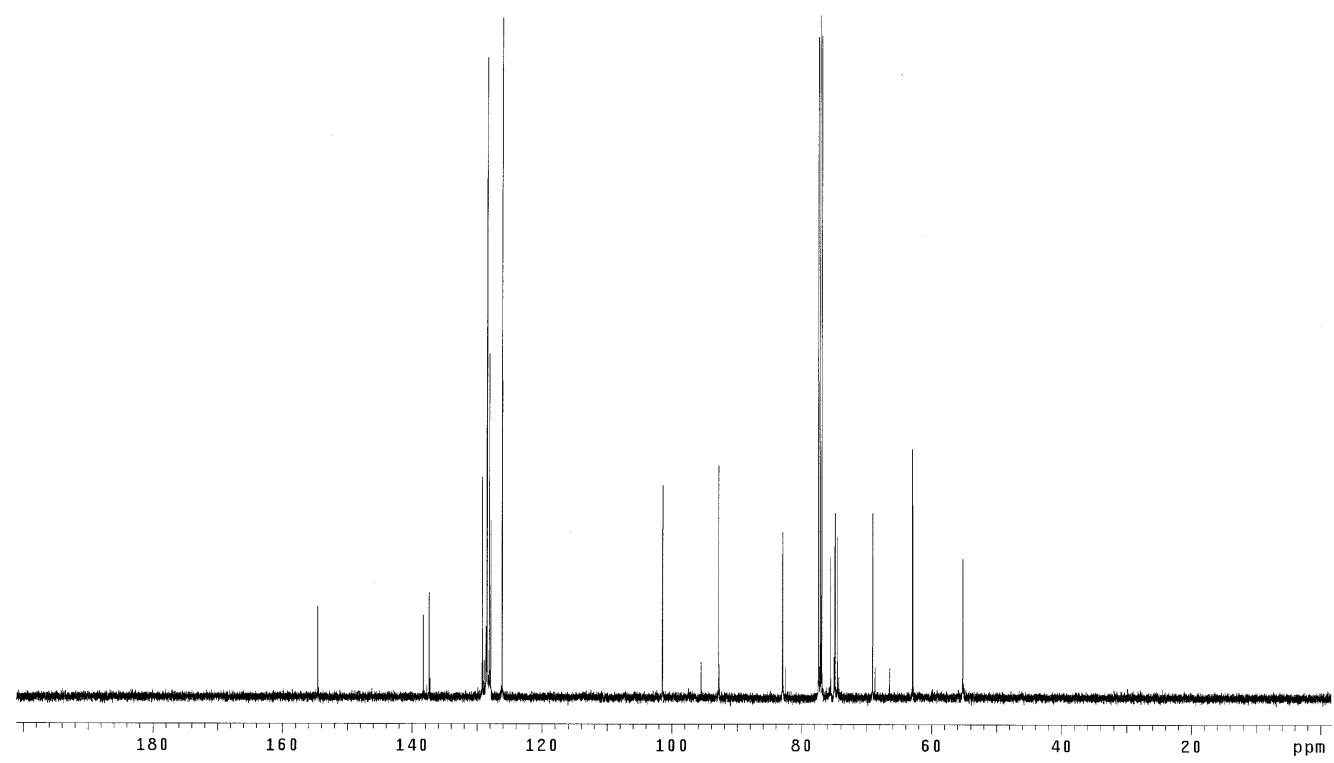




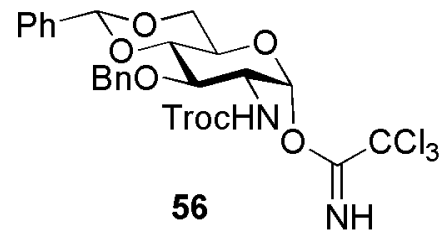

${ }^{1} \mathrm{H}$ NMR

$\mathrm{CDCl}_{3}, 500 \mathrm{MHz}$

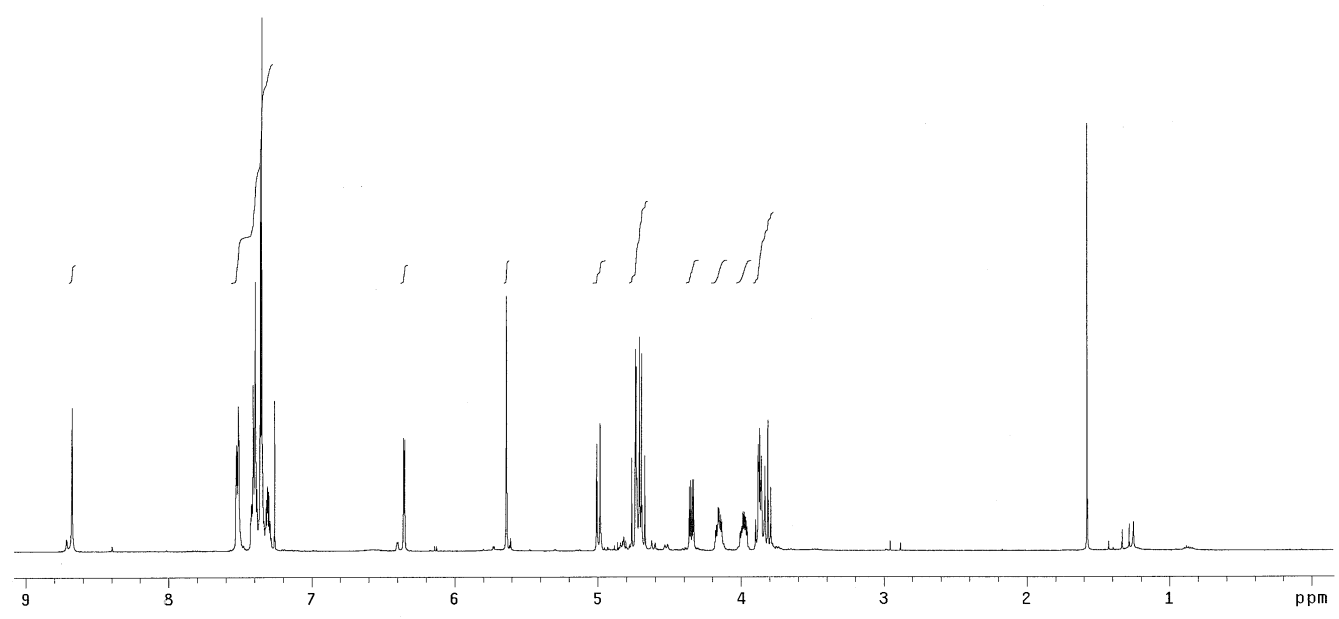

${ }^{13} \mathrm{C}$ NMR

$\mathrm{CDCl}_{3}, 125 \mathrm{MHz}$

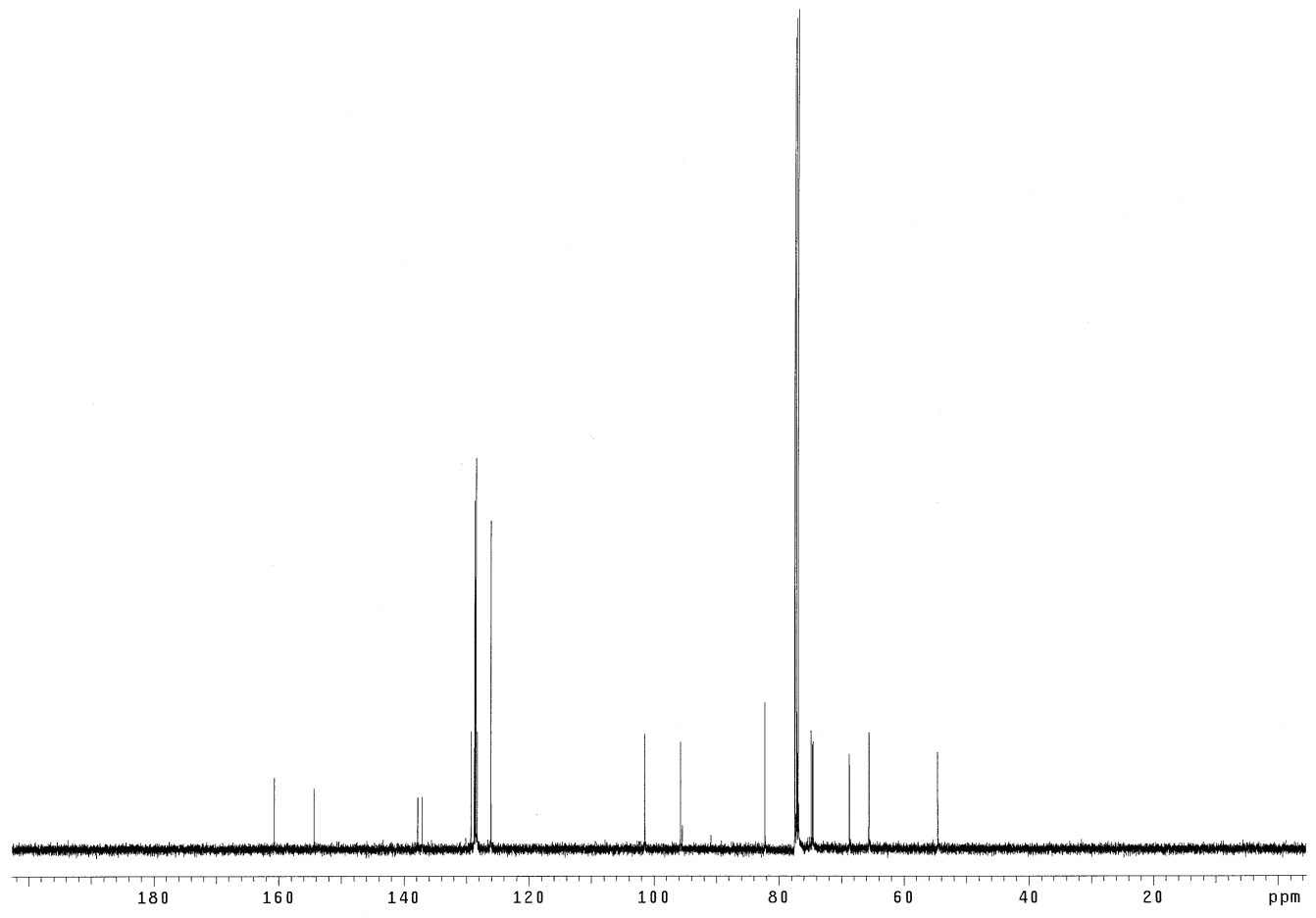




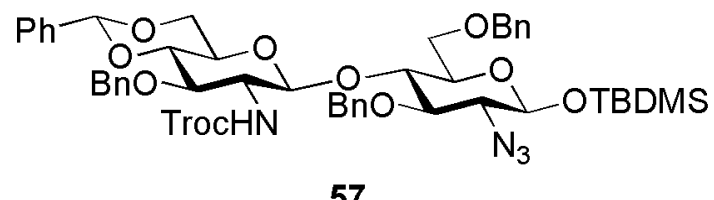

57

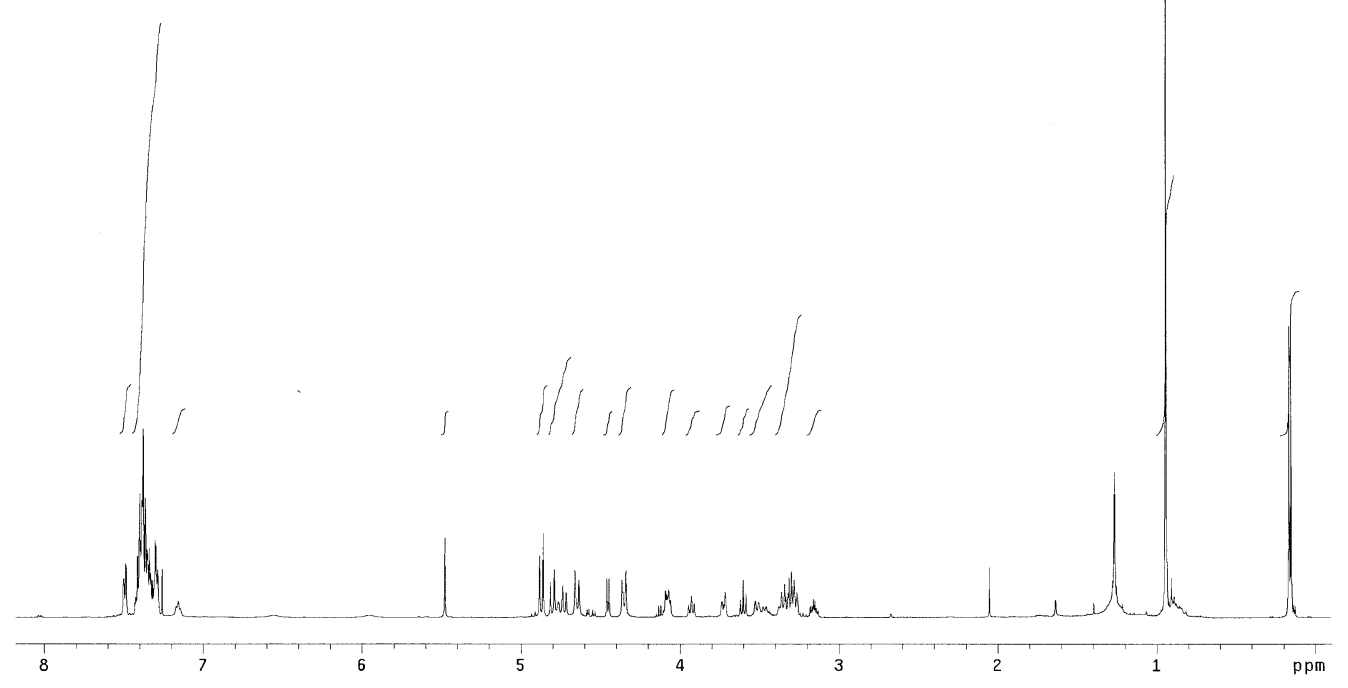

${ }^{13} \mathrm{C}$ NMR

$\mathrm{CDCl}_{3}, 125 \mathrm{MHz}$

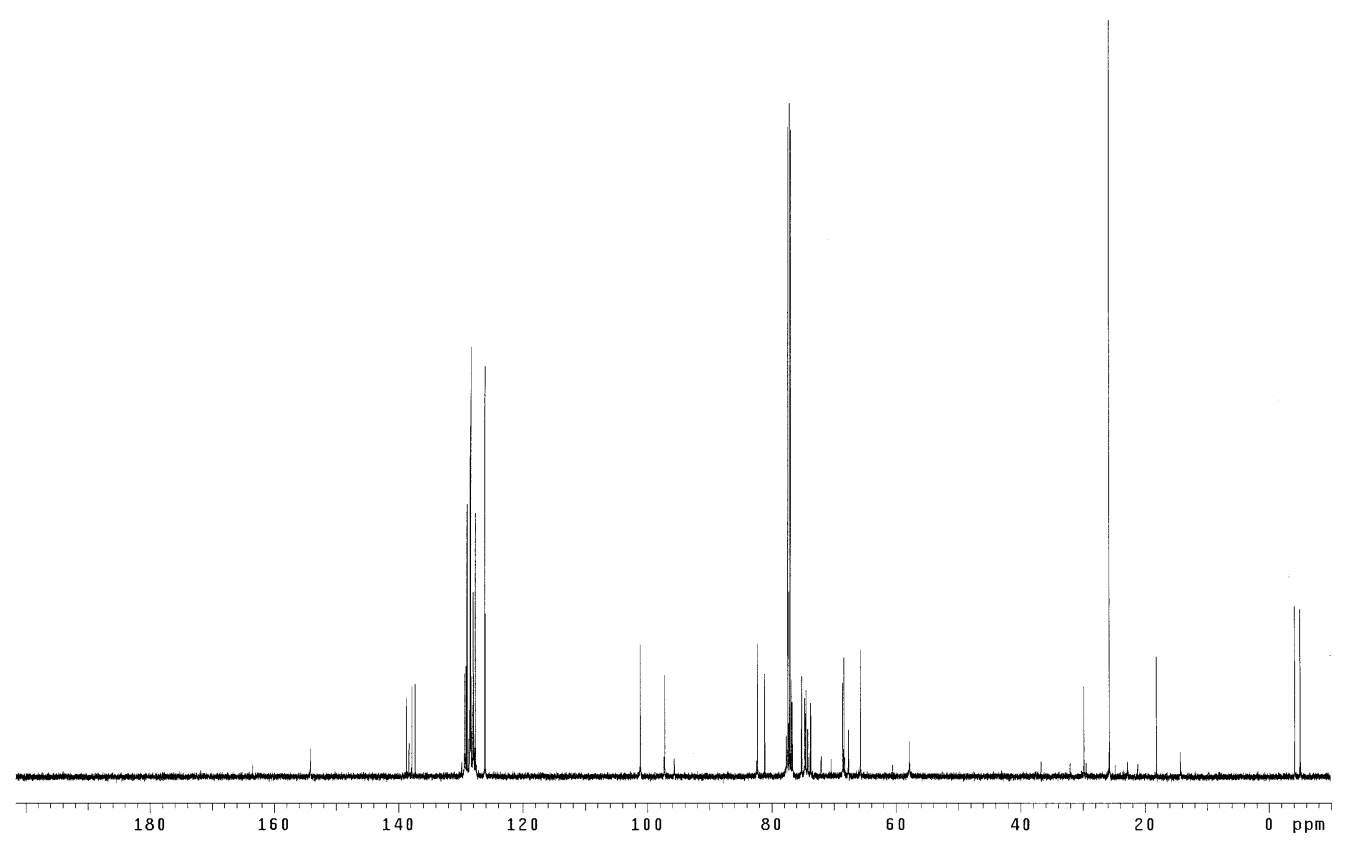




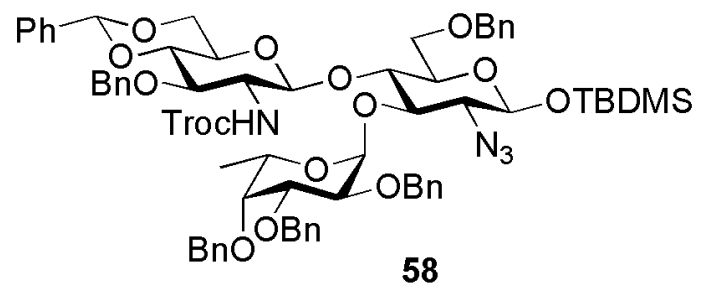

${ }^{1} \mathrm{H}$ NMR

$\mathrm{CDCl}_{3}, 500 \mathrm{MHz}$

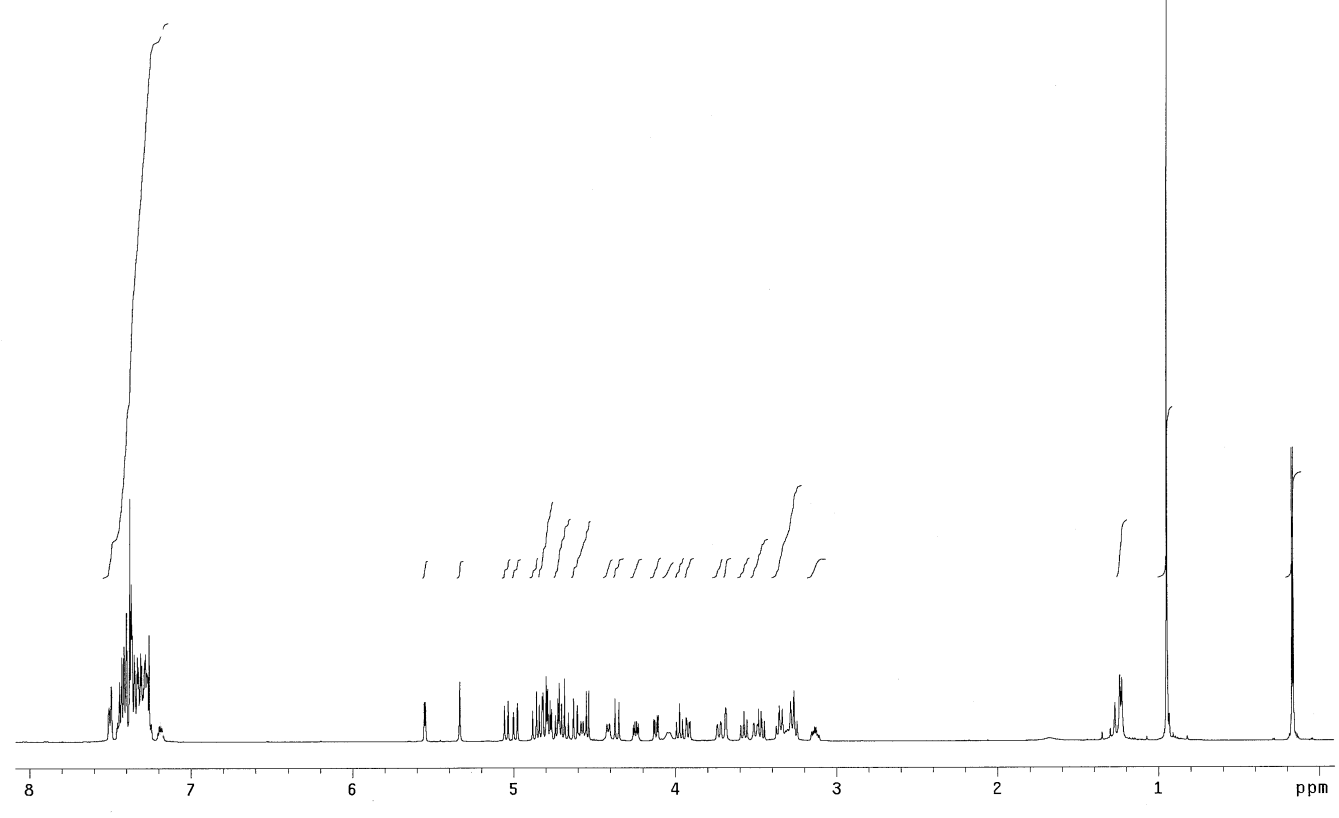

${ }^{13} \mathrm{C}$ NMR

$\mathrm{CDCl}_{3}, 125 \mathrm{MHz}$

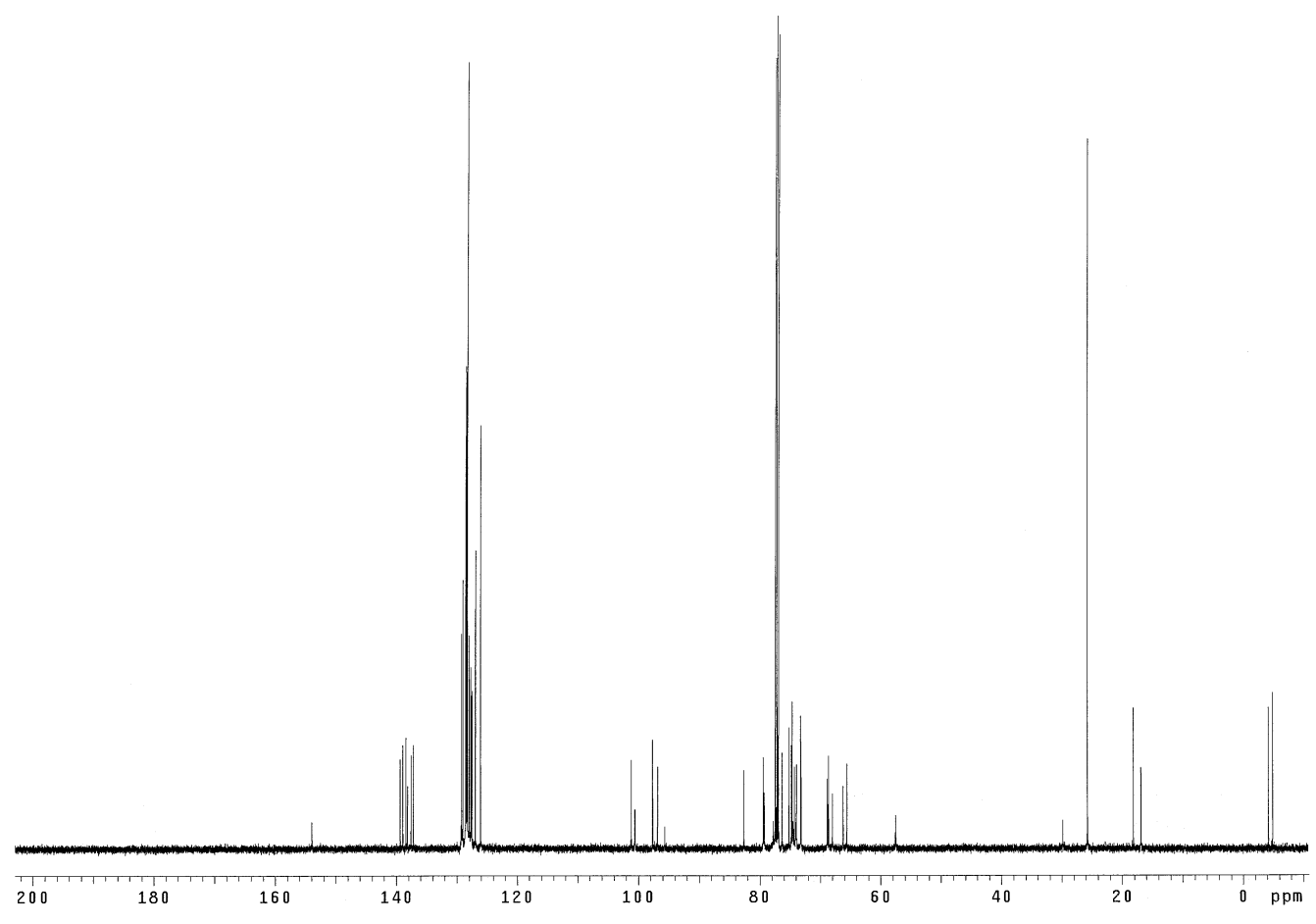




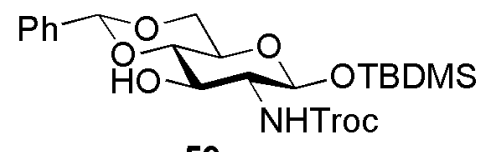

59
${ }^{1} \mathrm{H}$ NMR

$\mathrm{CDCl}_{3}, 500 \mathrm{MHz}$
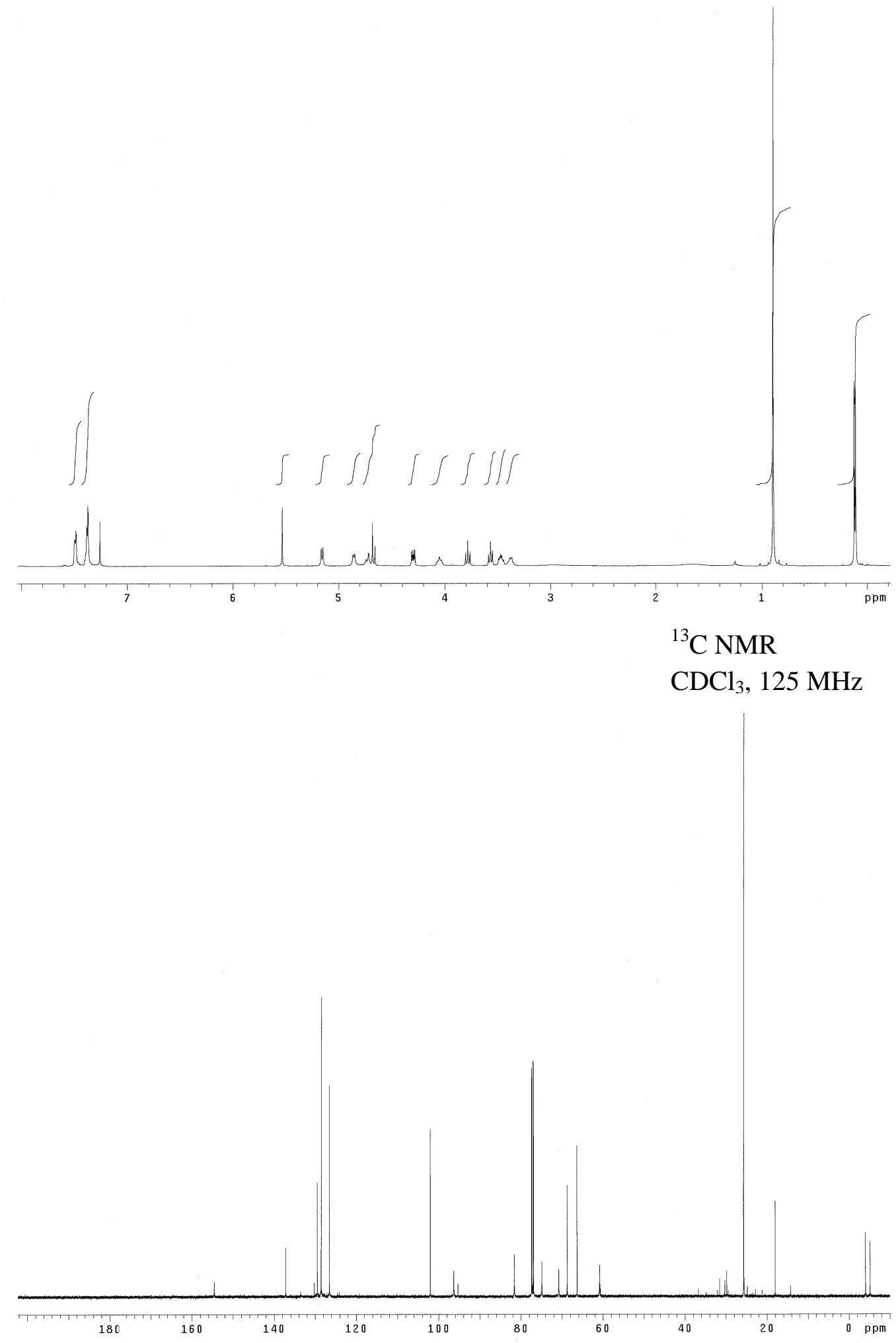


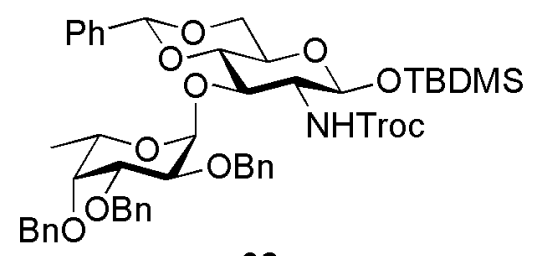

62

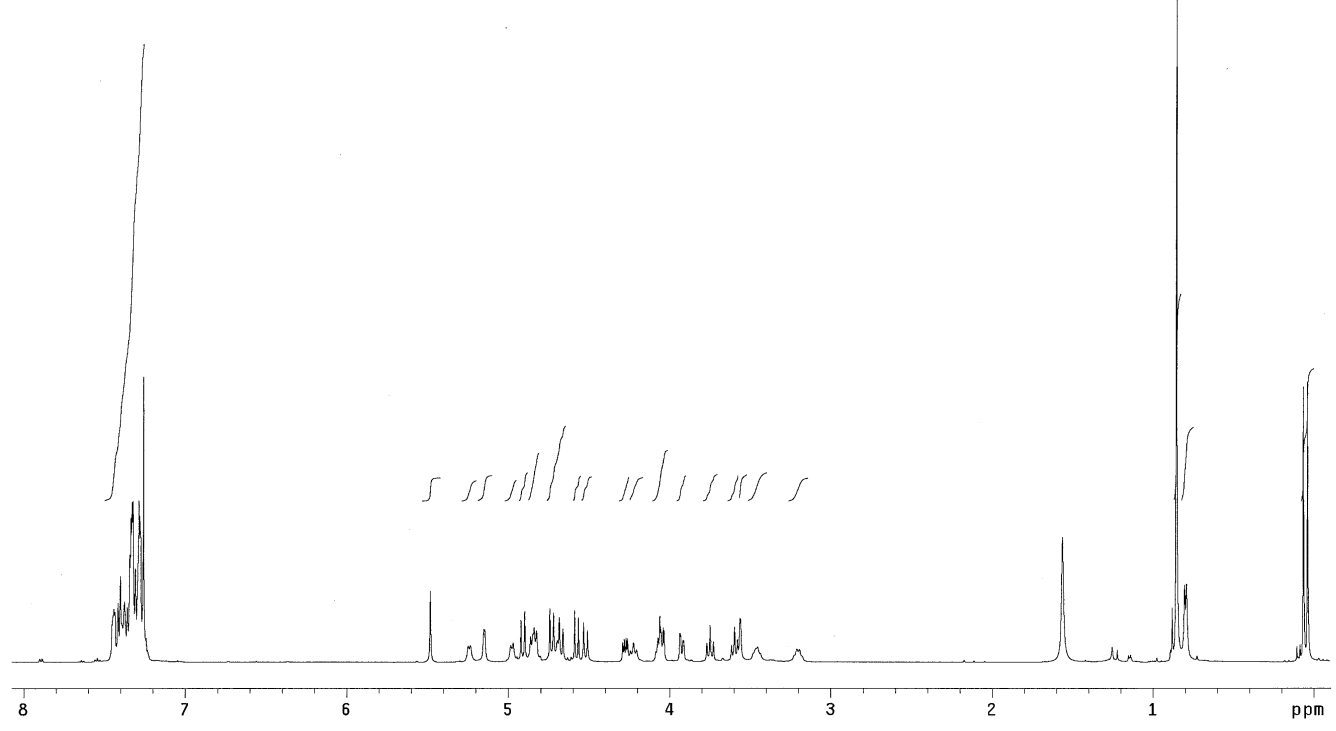

${ }^{13} \mathrm{C}$ NMR

$\mathrm{CDCl}_{3}, 125 \mathrm{MHz}$

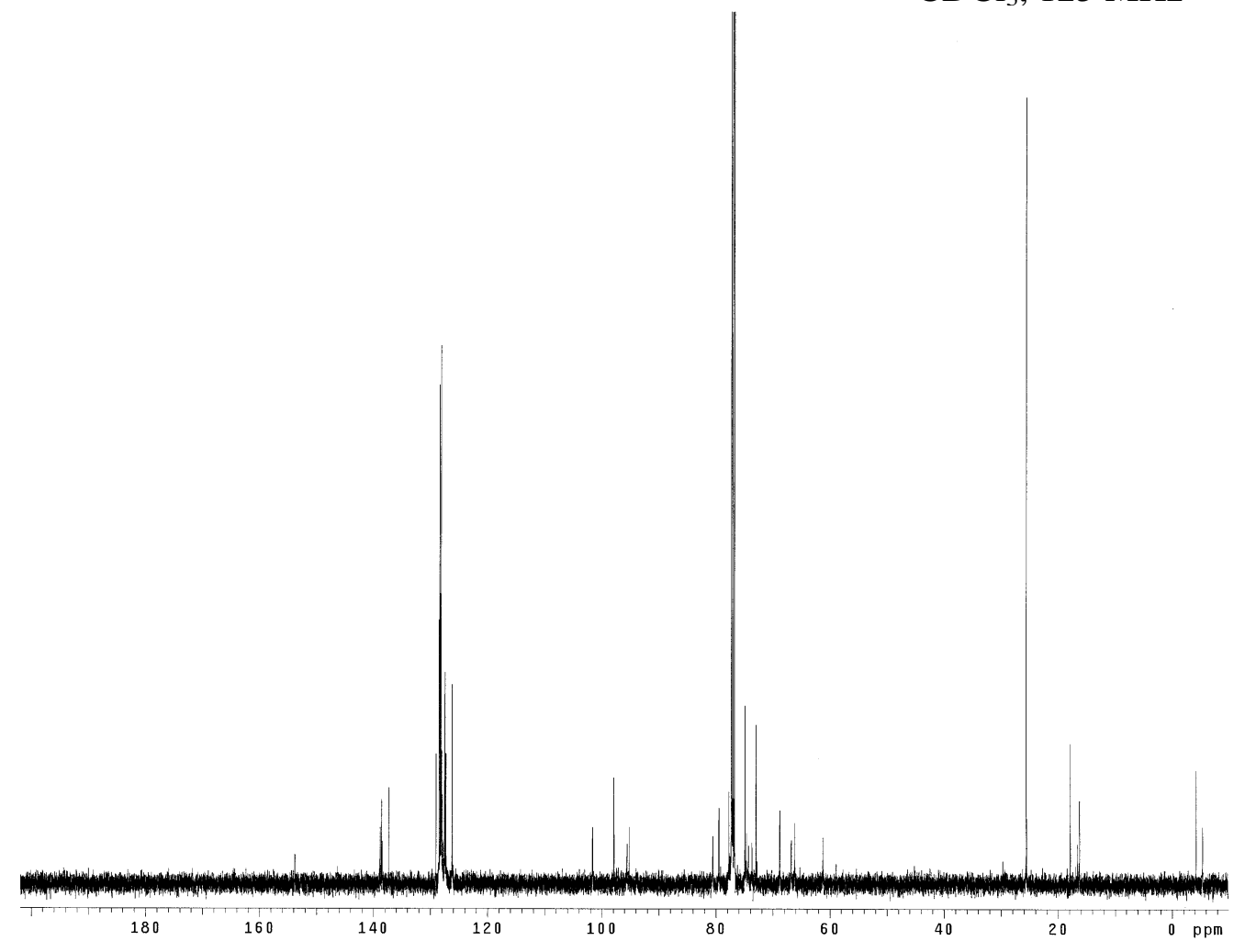




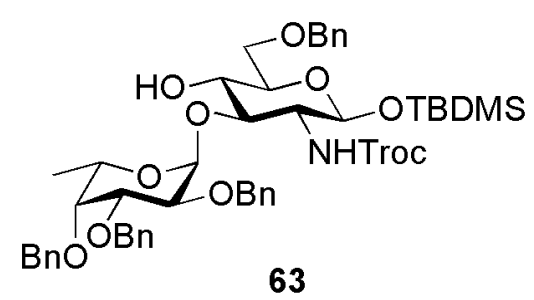

${ }^{1} \mathrm{H}$ NMR

$\mathrm{CDCl}_{3}, 500 \mathrm{MHz}$

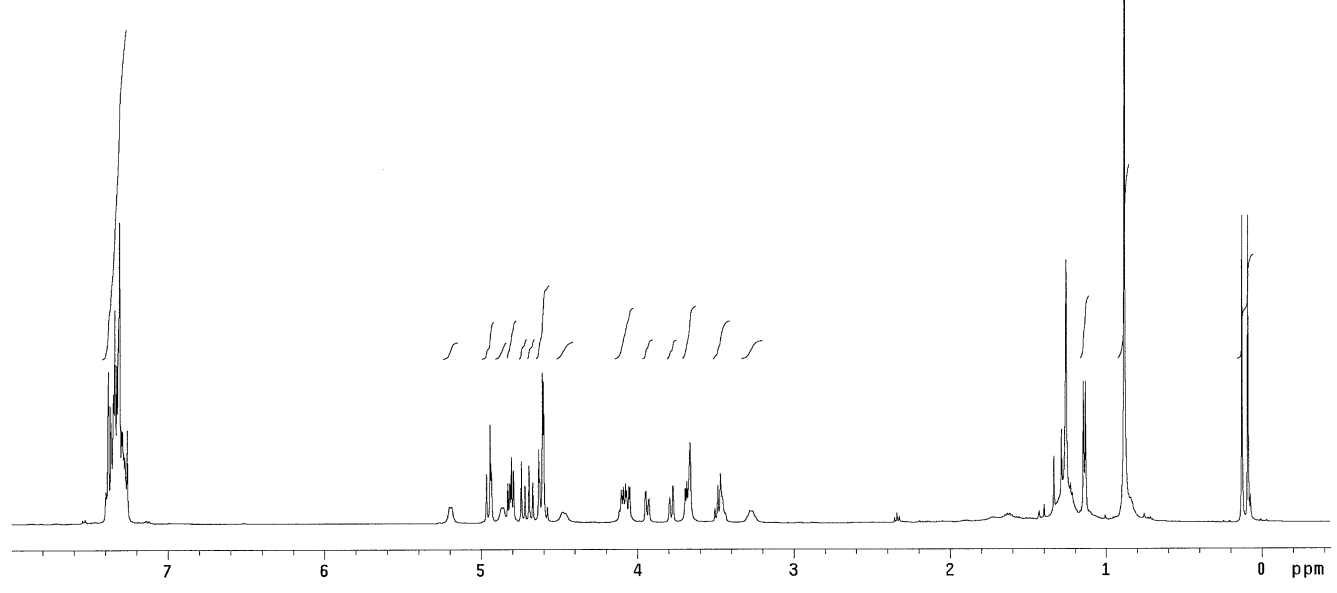

${ }^{13} \mathrm{C}$ NMR

$\mathrm{CDCl}_{3}, 125 \mathrm{MHz}$

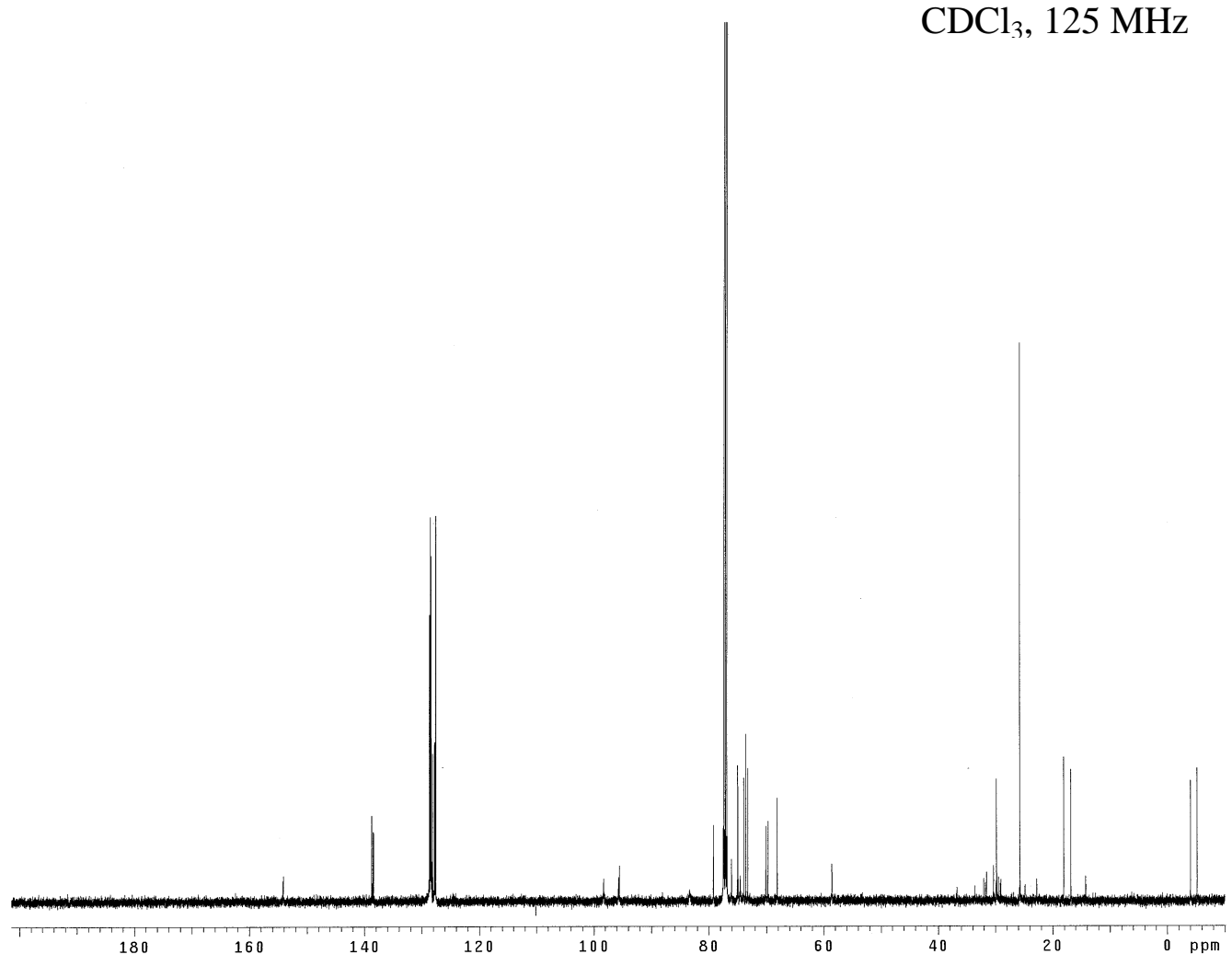




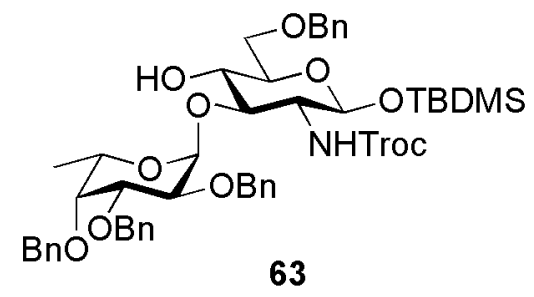

HMBC NMR

$\mathrm{CDCl}_{3}$

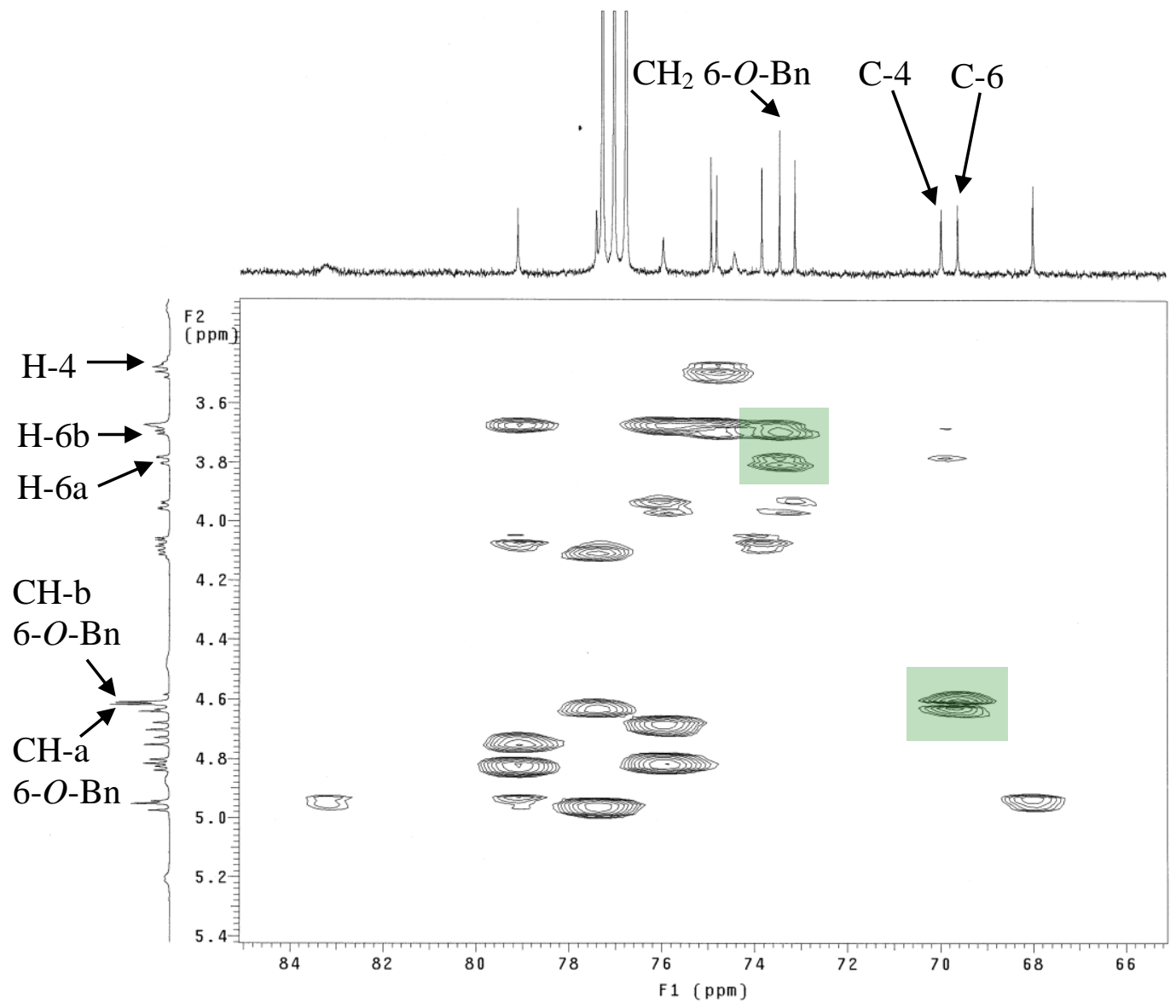




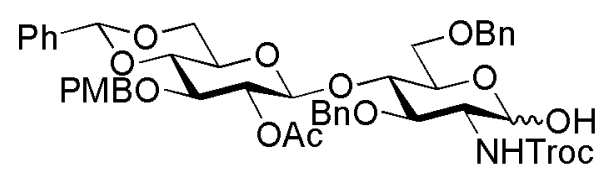

${ }^{1} \mathrm{H}$ NMR

$\mathrm{CDCl}_{3}, 500 \mathrm{MHz}$

68

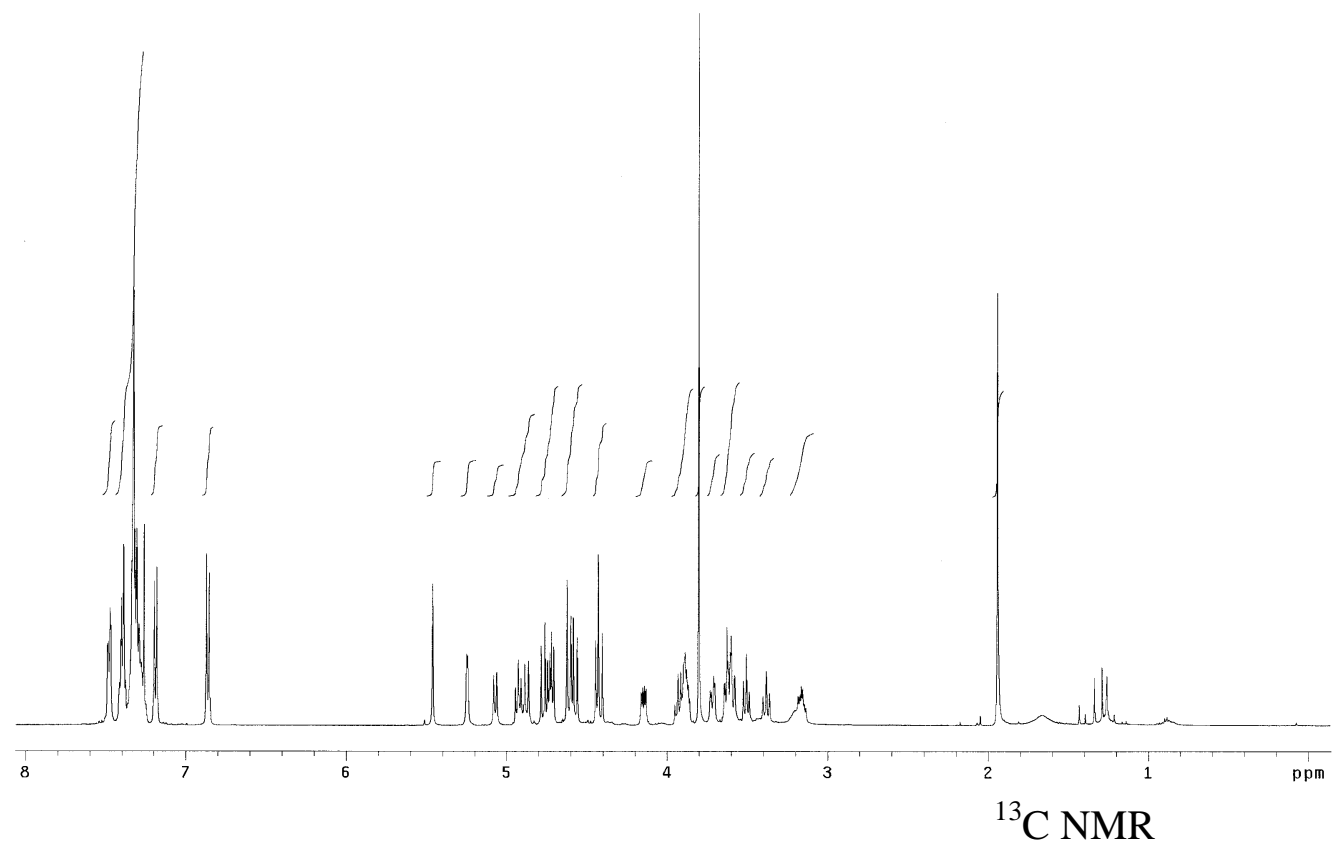

$\mathrm{CDCl}_{3}, 125 \mathrm{MHz}$

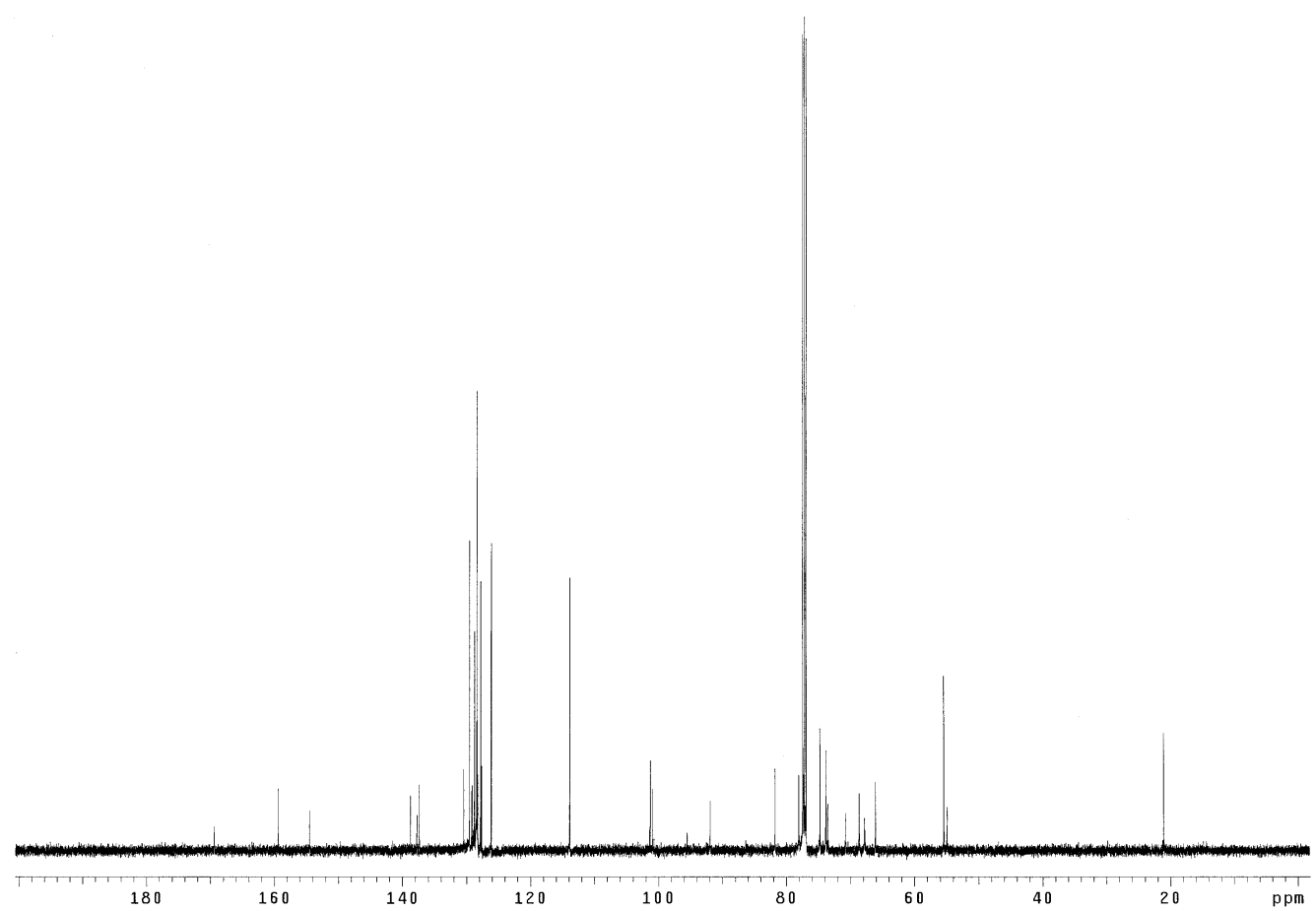



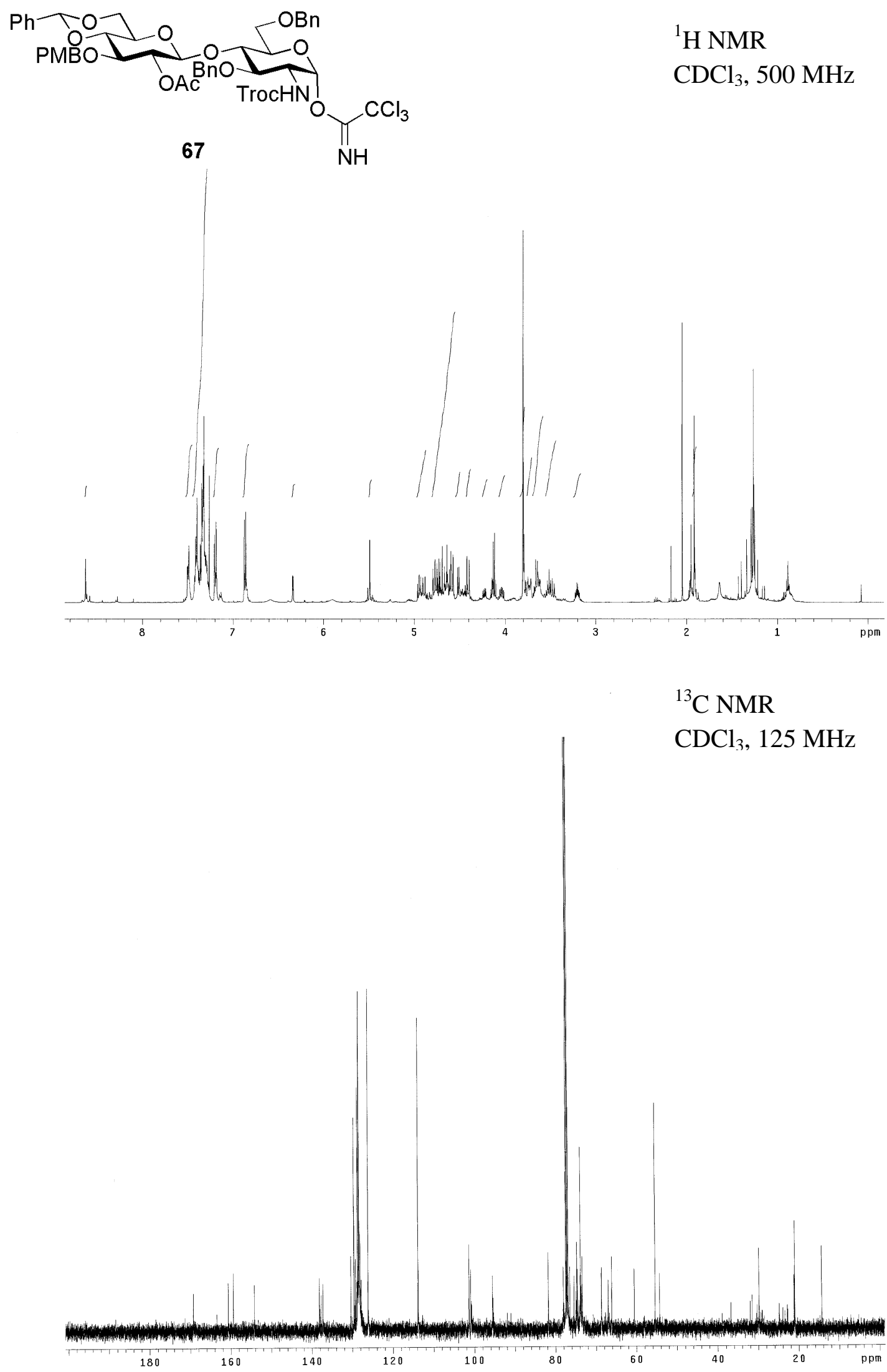


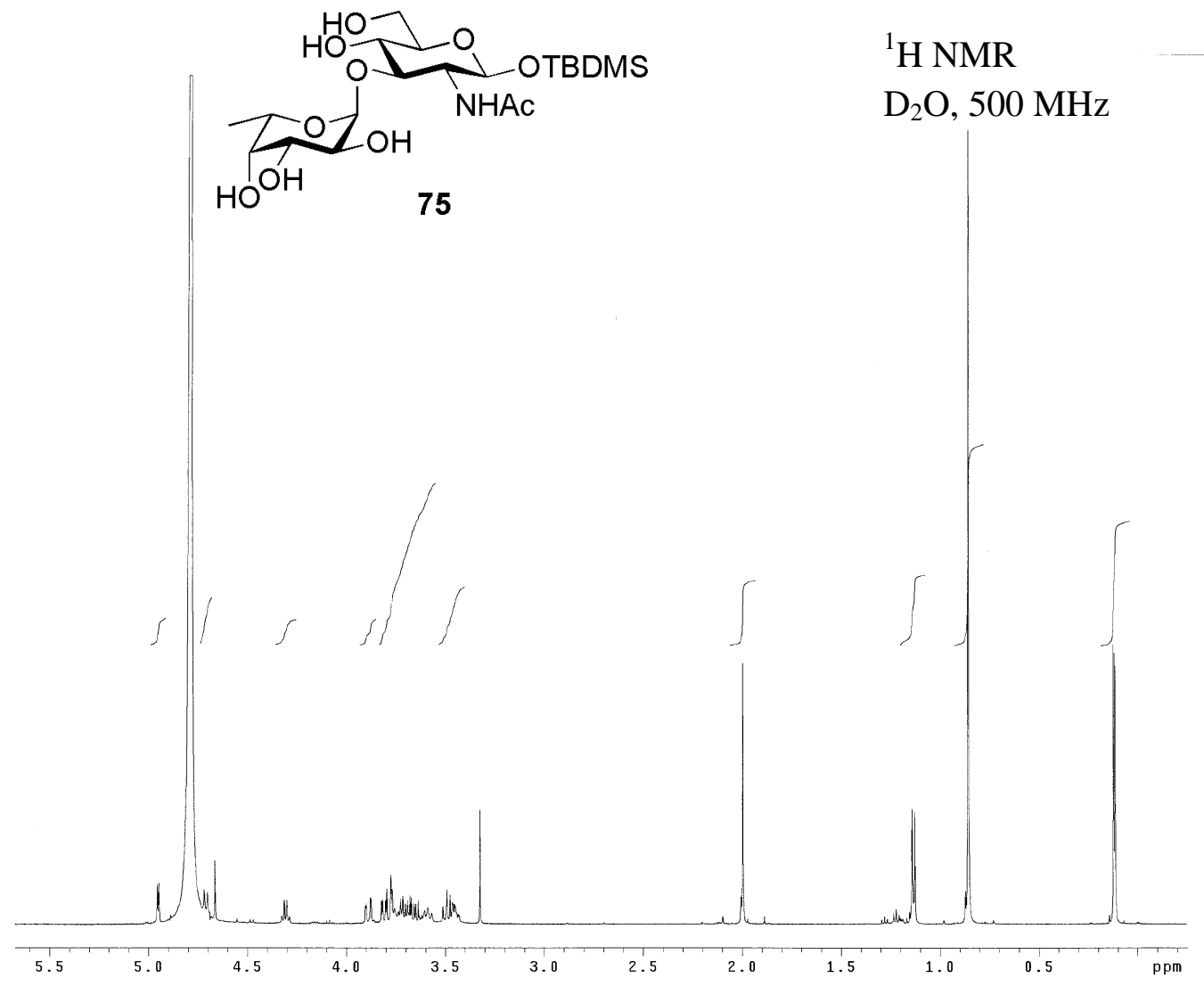




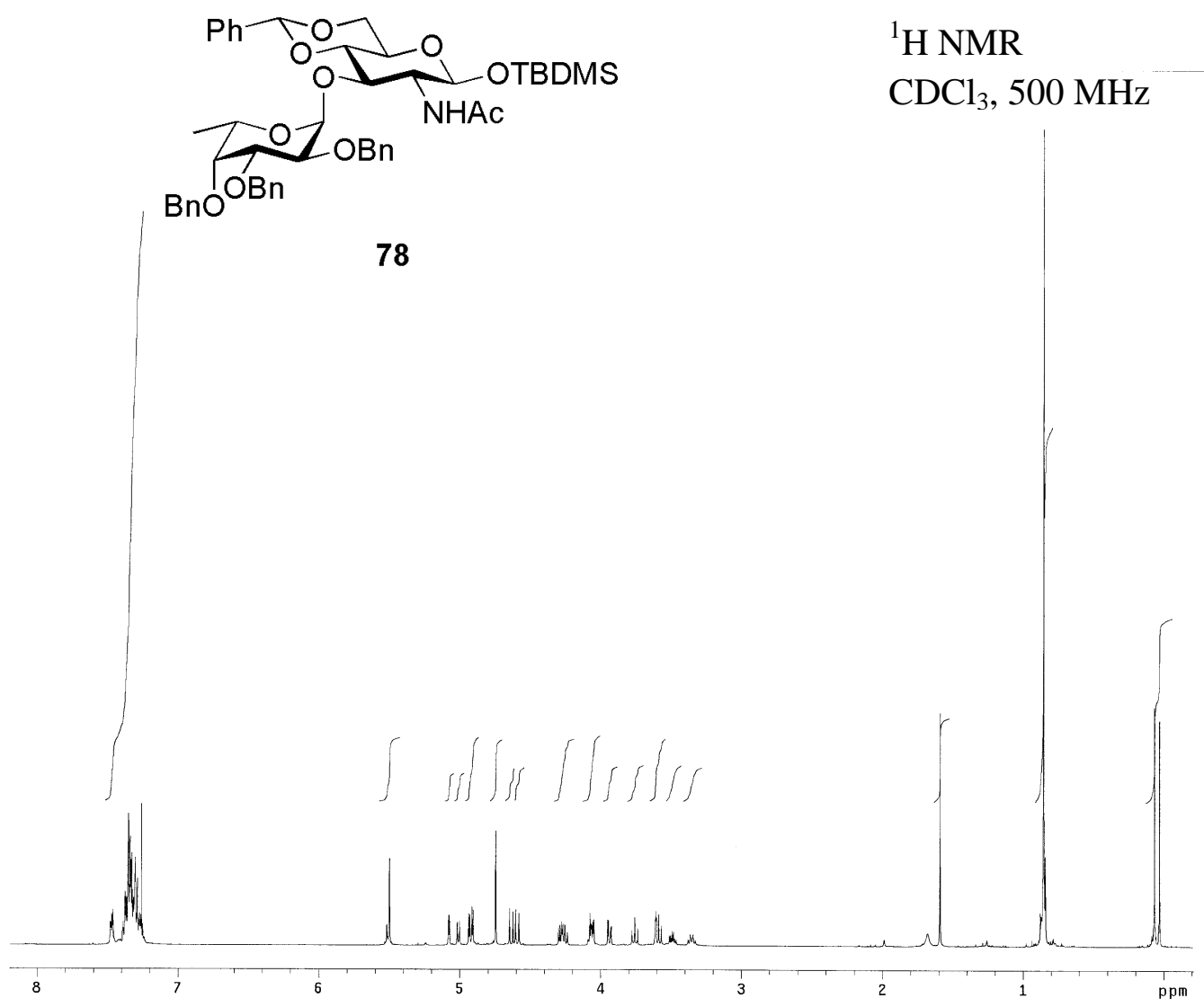

${ }^{13} \mathrm{C}$ NMR

$\mathrm{CDCl}_{3}, 125 \mathrm{MHz}$

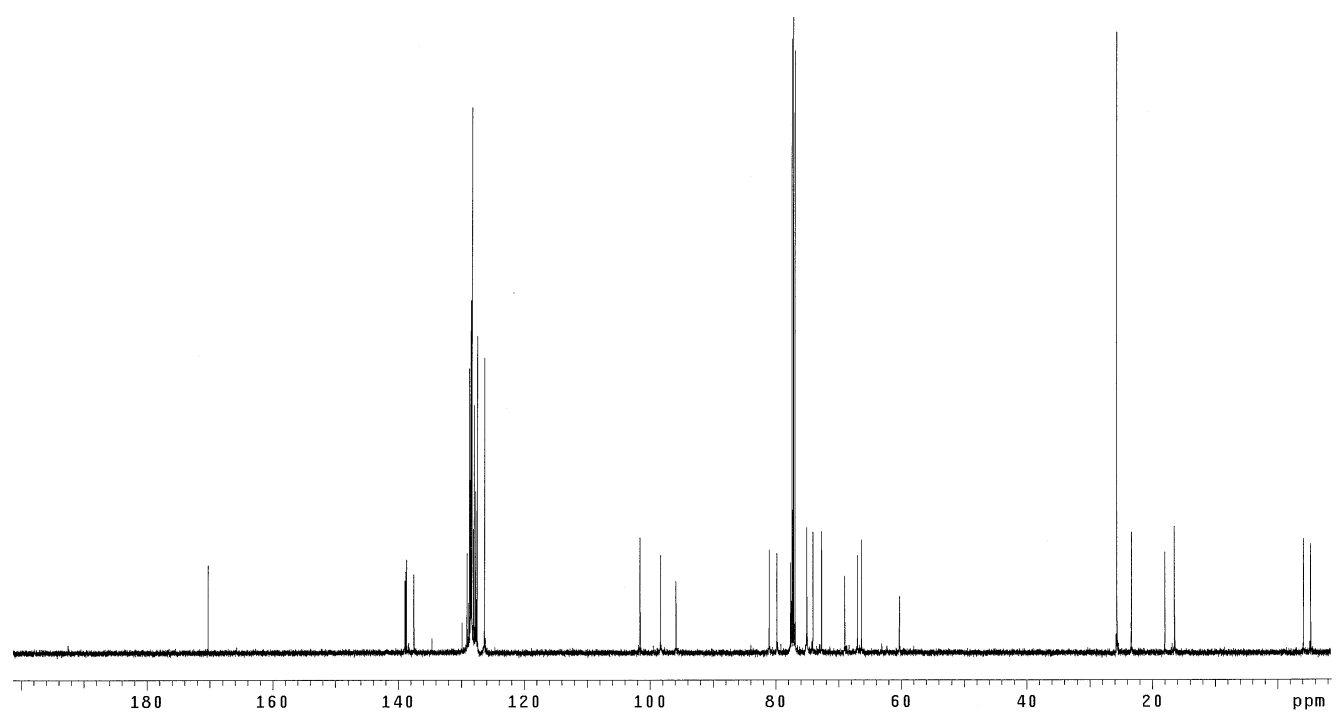



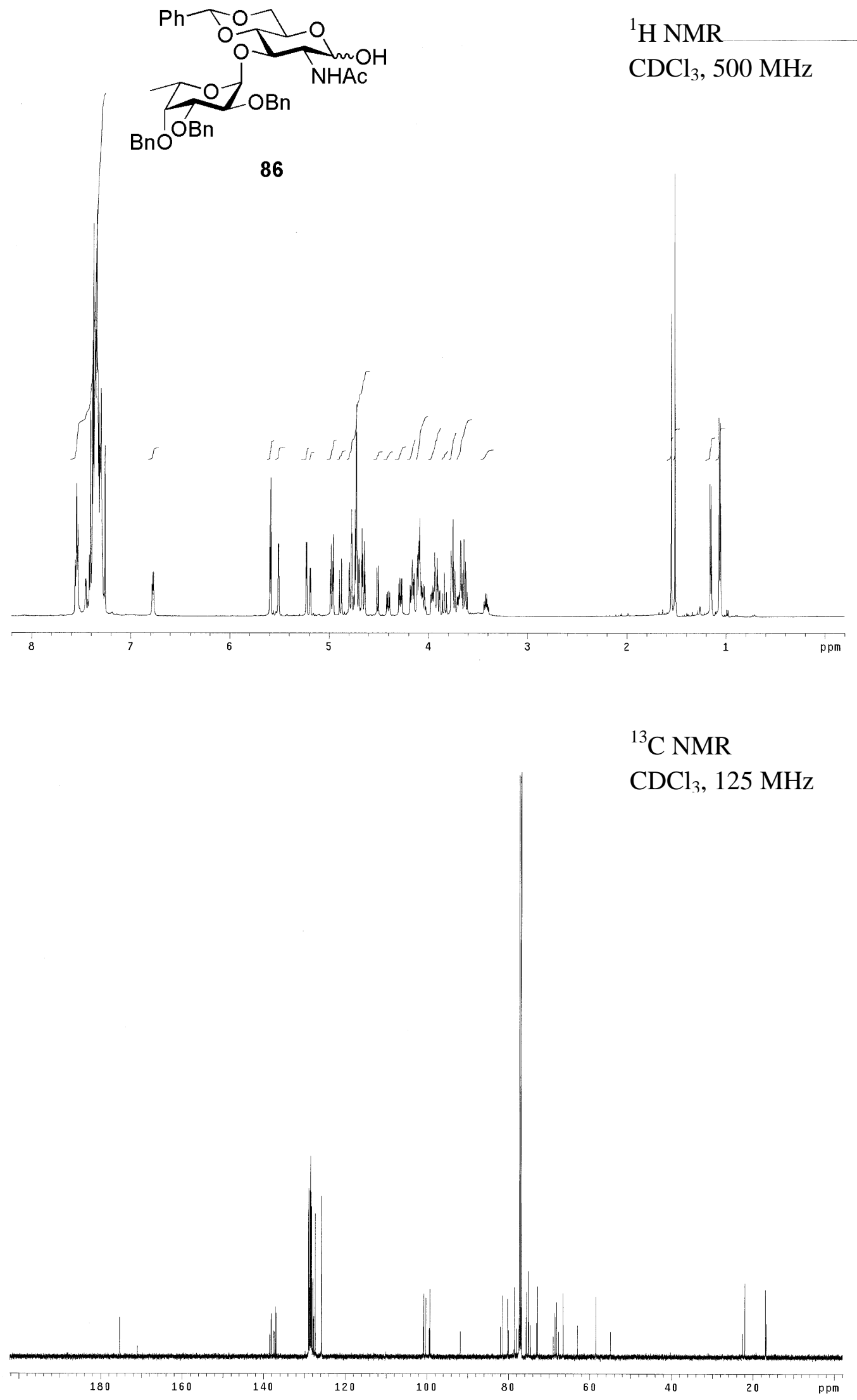


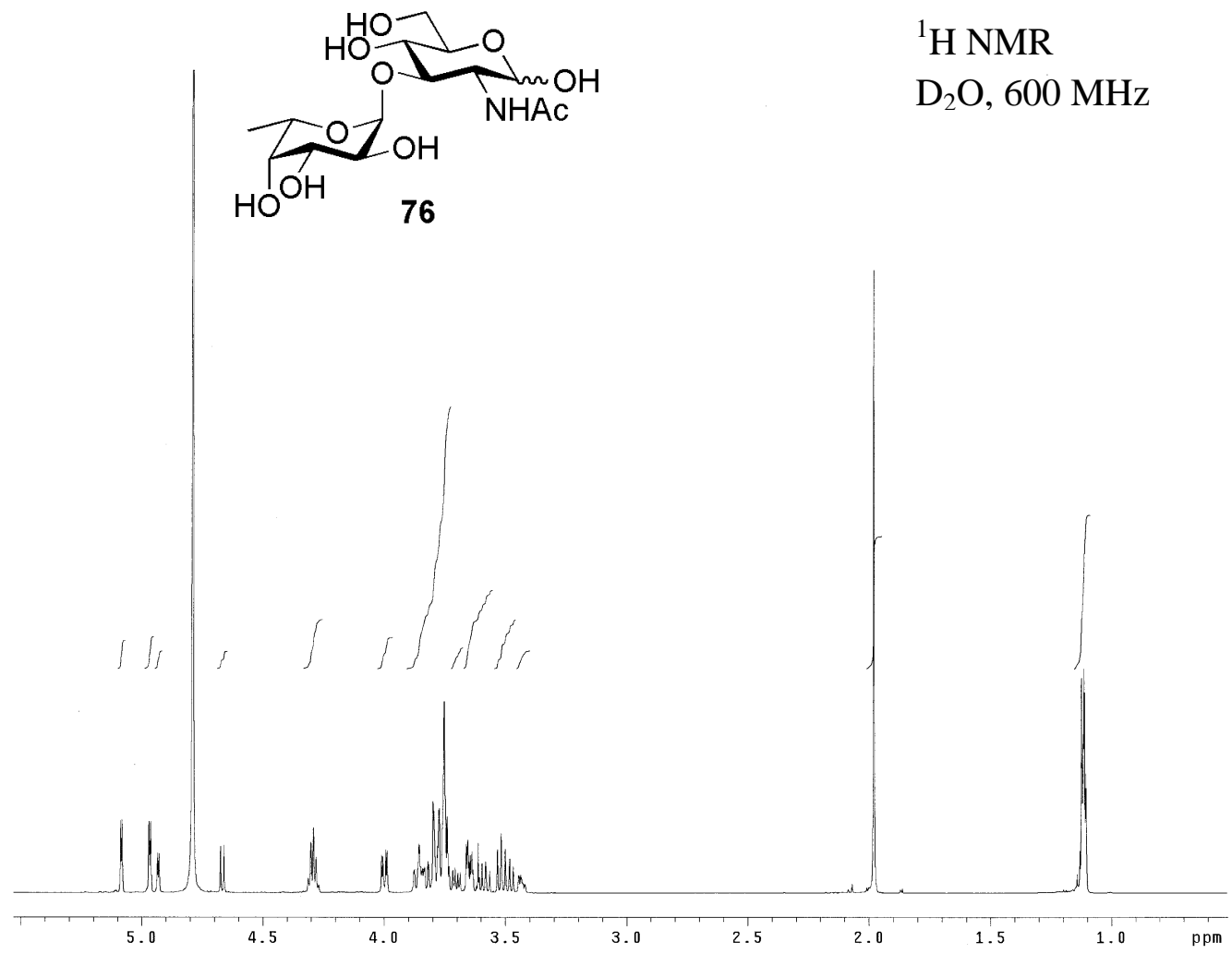

${ }^{13} \mathrm{C}$ NMR

$\mathrm{D}_{2} \mathrm{O}, 150 \mathrm{MHz}$

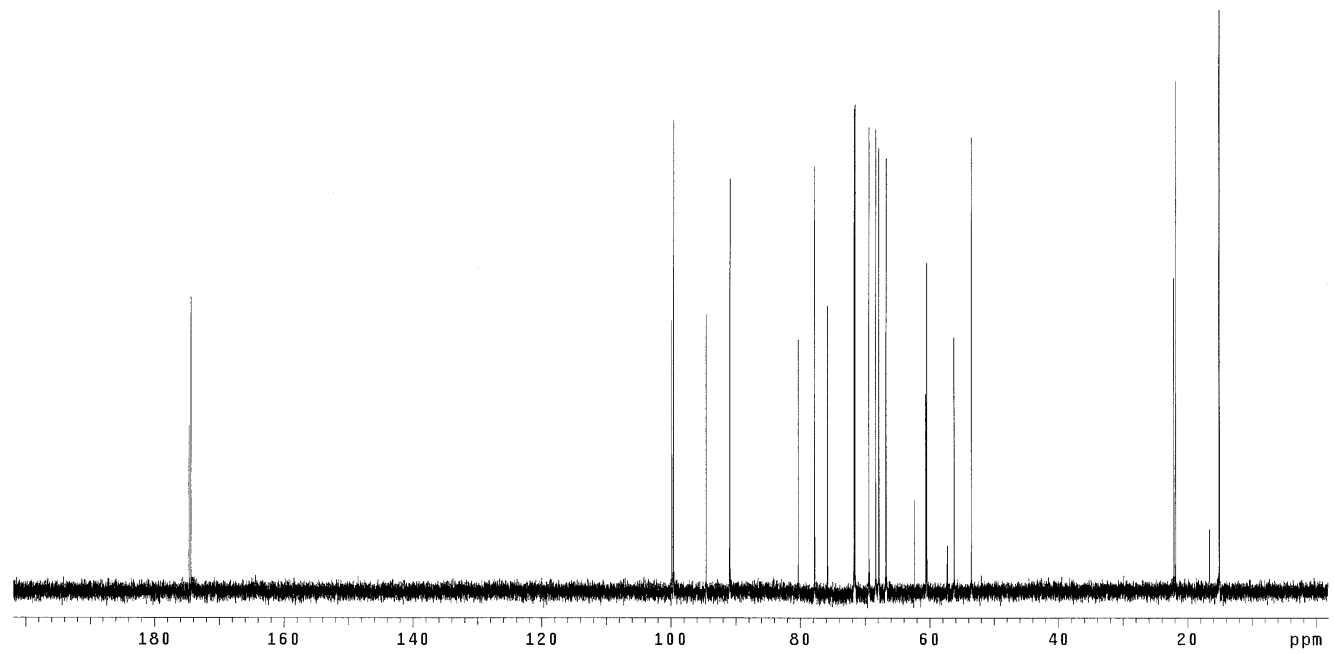




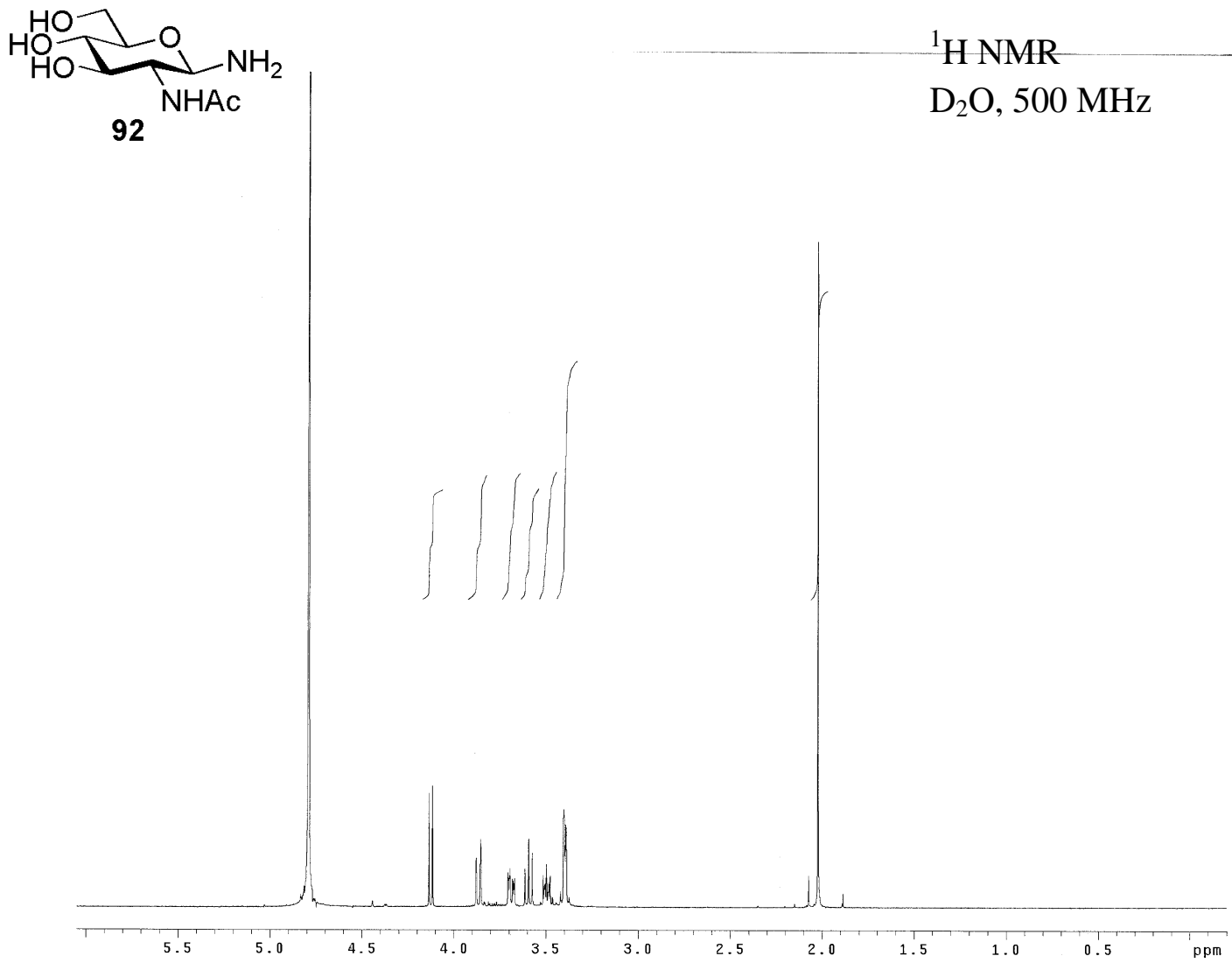

${ }^{13} \mathrm{C}$ NMR

$\mathrm{D}_{2} \mathrm{O}, 125 \mathrm{MHz}$

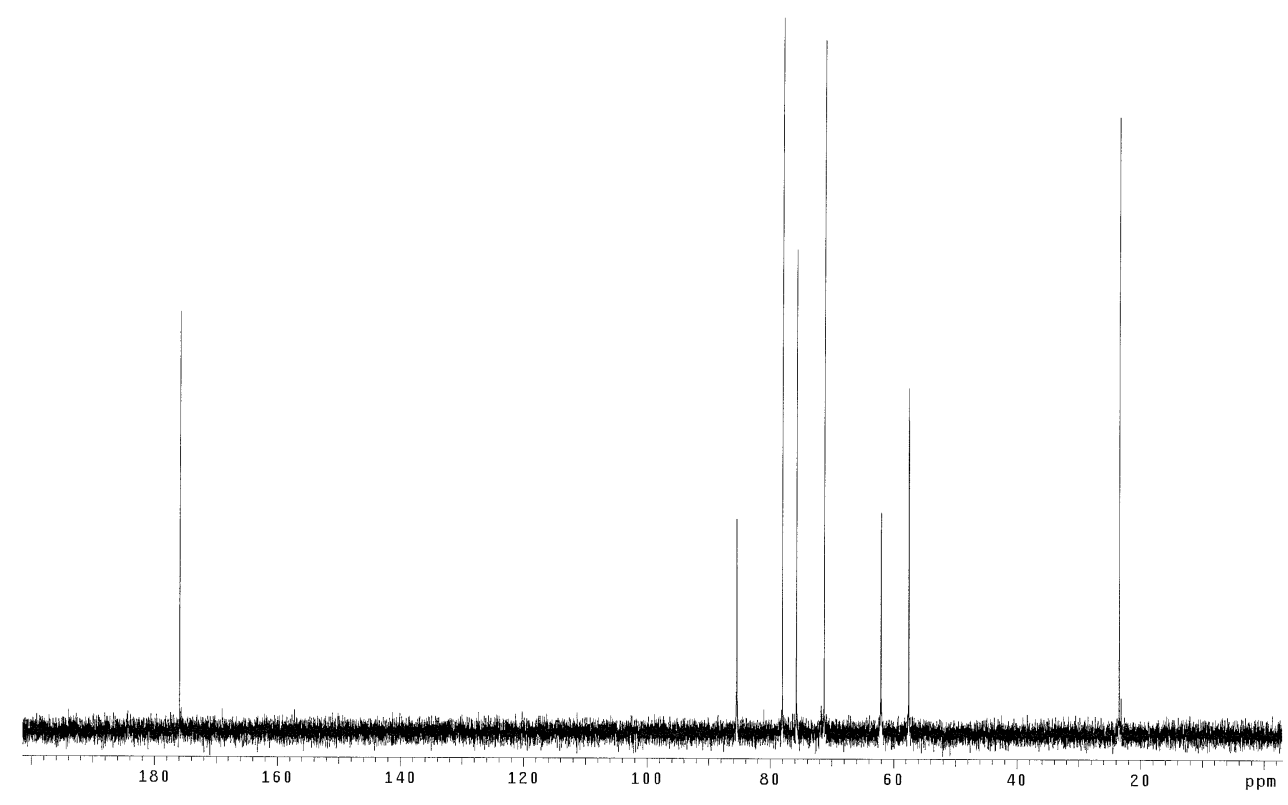

